\title{
Does the Financial Reporting Transparency of Securitization Affect Bank Lending Decisions?
}

\author{
by \\ Kaleab Yesuneh Mamo
}

\author{
A thesis \\ presented to the University of Waterloo \\ in fulfillment of the \\ thesis requirement for the degree of \\ Doctor of Philosophy \\ in \\ Accounting
}

Waterloo, Ontario, Canada, 2018

(C) Kaleab Yesuneh Mamo 2018 


\section{Examining Committee Membership}

The following served on the Examining Committee for this thesis. The decision of the Examining Committee is by majority vote.

$\begin{array}{lll}\text { External Examiner } & \begin{array}{l}\text { NAME } \\ \text { Title }\end{array} & \begin{array}{l}\text { Stephen G. Ryan } \\ \text { Professor of Accounting }\end{array} \\ \text { Nupervisor } & \begin{array}{l}\text { NAME } \\ \text { Title }\end{array} & \begin{array}{l}\text { Patricia O'Brien } \\ \text { Professor of Accounting }\end{array} \\ \text { NAME } & \begin{array}{l}\text { Christine Wiedman } \\ \text { Professor of Accounting }\end{array} \\ \text { Title } & \text { NAME } & \begin{array}{l}\text { James R. Thompson } \\ \text { Associate Professor of Finance }\end{array} \\ \text { Tnternal Member } & \text { Title } & \text { Matthew Doyle } \\ \text { Internal-external Member } & \text { NAME } & \text { Associate Professor of Economics } \\ & \text { Title } & \end{array}$




\section{Author's Declaration}

I hereby declare that I am the sole author of this thesis. This is a true copy of the thesis, including any required final revisions, as accepted by my examiners.

I understand that my thesis may be made electronically available to the public. 



\begin{abstract}
This thesis examines the effect of financial reporting transparency for securitization on banks' mortgage lending decisions. Prior research (e.g., Mian \& Sufi 2009, Keys, Mukherjee, Seru \& Vig 2010) shows that securitization reduces banks' incentives to screen and monitor borrowers. I posit that transparency plays a significant role by affecting bank stakeholders' ability to monitor and discipline bank lending decisions. I identify three specific channels for monitoring and discipline, namely corporate governance, regulatory oversight, and market discipline by uninsured depositors. I hypothesize that transparency affects bank risk-taking in mortgage lending, and that monitoring and discipline from external stakeholders moderates this effect.

I test my hypotheses using difference-in-differences tests around five FASB pronouncements relating to securitization, issued since 1996, of which one decreases and the others increase transparency. I obtain loan-level data to construct new measures of bank risktaking in mortgage lending based on the borrower income, loan amount and property location. I validate the proposed measures using bank-level future mortgage delinquencies and charge-offs.

The main results generally do not support my hypotheses. I find that, in most cases, the effect of transparency on risk-taking is either insignificant or in the opposite direction of the prediction. These findings are robust to multiple sensitivity tests. However, I find some evidence supporting my hypotheses when comparing bank lending decisions during the least transparent period to those during the most transparent period within my sample. As a whole, my findings support the null hypothesis that transparency does not affect banks' risk-taking in their mortgage lending decisions. This conclusion is counter-intuitive and contrary to the commonly held view that transparency promotes better stakeholder monitoring of bank risk-taking. I identify alternative explanations for the null results, including: (i) whether the accounting pronouncements affect transparency as expected, (ii) the complexity of the setting, and (iii) potential noise in the data sources and the development of my measures.

This thesis contributes to the literature in multiple ways. The proposed risk-measures might prove useful to future researchers examining risk-taking in mortgage lending. My findings are also relevant to the branches of literature examining the effect of securitization on bank lending decisions, the effect of transparency on bank risk-taking, and the real effects of accounting standards. This thesis might also be useful to standard setters and regulators in their attempt to improve financial reporting quality and to promote better decision making.
\end{abstract}





\section{Acknowledgements}

First and foremost, I would like to extend my deepest gratitude to my advisor Prof. Patricia O'Brien for her invaluable guidance, support, and mentorship throughout my PhD. From the first year of my doctoral study, Pat has made herself generously available to read

my work and to meet with me. Her penetrating questions and thoughtful feedback are irreplaceable. I have learned a great deal from her about research, teaching, and academic life in general. Thank you Pat! It has been a great honor and privilege to be your $\mathrm{PhD}$ student.

Besides my advisor, I would like to thank the other members of my thesis committee: Prof. Matthew Doyle, Prof. James Thompson, and Prof. Christine Wiedman, for their insightful and timely feedback that helped me improve my thesis. Their comments and encouragements were crucial in completing this thesis.

My sincere thanks also goes to Prof. Changling Chen for her encouragement, Prof. Sally Gunz for her help in understanding the institutional background for my research, Prof. Jeong-Bon Kim for his comments during the early stages of my thesis, Prof. Ken Klassen for his valuable comments on my thesis and my presentation skills, and Prof. Tony Wirjanto for his helpful comments about the research design.

I thank all faculty members and PhD students of the School of Accounting and Finance at the University of Waterloo for their helpful comments and encouragement during my PhD. I am particularly grateful to Prof. Alan Webb for his outstanding class on research methods.

This thesis has benefited from workshop presentation at Wilfrid Laurier University, conference presentation at the 2017 annual meeting of the Canadian Academic Accounting Association, and positive feedback from an anonymous reviewer for the 2017 annual meeting of the American Accounting Association. 



\section{Table of Contents}

List of Tables $\quad$ xiii

List of Figures $\quad$ XV

Abbreviations $\quad$ xvii

1 Introduction $\quad 1$

2 Background and Hypothesis Development $\quad 9$

2.1 Introduction . . . . . . . . . . . . . . . . . . 9

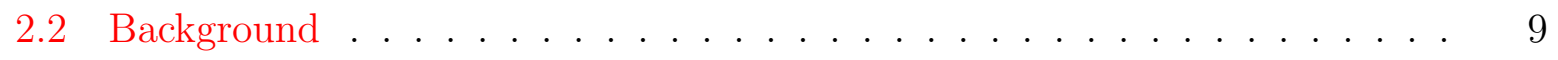

2.2.1 Securitization . . . . . . . . . . . . . . . . 9

2.2.2 Financial Reporting Transparency . . . . . . . . . . . . . . . 13

2.2.3 The Financial Reporting of Securitization . . . . . . . . . . . . . 14

2.3 Related Literature . . . . . . . . . . . . . . . . . . . . 23

2.3.1 Transparency and Bank Operating Decisions . . . . . . . . . . . 24

2.3.2 Securitization and Lending Decisions . . . . . . . . . . . . . . . 27

2.4 Hypotheses Development . . . . . . . . . . . . . . . . 27

2.4.1 Transparency and Securitization-driven Bank Risk-taking . . . . . 28

2.4.2 Hypotheses . . . . . . . . . . . . . . . . . . . . . . 32 
3 Research Design and Sample $\quad 35$

3.1 Introduction . . . . . . . . . . . . . . . . . . . 35

3.2 Difference-in-Differences Design . . . . . . . . . . . . . . 35

3.2.1 Securitization Indicator . . . . . . . . . . . . . . . 38

3.3 Data Sources . . . . . . . . . . . . . . . . . 38

3.3.1 The Home Mortgage Disclosure Act Database . . . . . . . . . . . 38

3.3.2 FR Y-9C Database . . . . . . . . . . . . . . . . 39

3.3.3 Other Data Sources . . . . . . . . . . . . . . . . . 40

3.4 Sample Selection Procedure . . . . . . . . . . . . . . . . . . . . 41

4 Mortgage Lending Risk Measures $\quad 47$

4.1 Introduction . . . . . . . . . . . . . . . . . 47

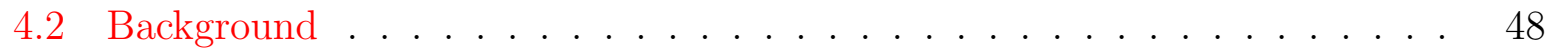

4.3 Constructing Mortgage Lending Risk Measures . . . . . . . . . . . . . 50

4.3.1 Individual Mortgage Risk Characteristics . . . . . . . . . 51

4.3.2 Composite Risk Measures . . . . . . . . . . . . . . 56

4.4 Descriptive Statistics . . . . . . . . . . . . . . . . . . . . 57

4.5 Validation Tests . . . . . . . . . . . . . . . . 58

4.5.1 Individual Characteristics . . . . . . . . . . . 61

4.5.2 BHC-level Measures . . . . . . . . . . . . . . . . . . 66

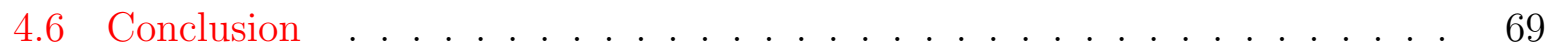

$5 \quad$ Empirical Analyses $\quad 73$

5.1 Introduction . . . . . . . . . . . . . . . . . 73

5.2 Descriptive Statistics . . . . . . . . . . . . . . . 73

5.3 The Effect of Transparency on Bank Lending Decisions . . . . . . . . . . . 75

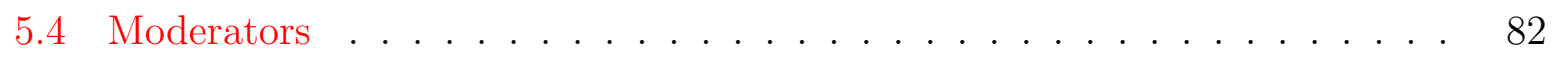

5.4.1 Corporate Governance . . . . . . . . . . . . . . . . . . 82 
5.4 .2 Regulatory Oversight . . . . . . . . . . . . . . . . . 89

5.4 .3 Market Discipline . . . . . . . . . . . . . . . . . 93

5.5 Additional Analyses . . . . . . . . . . . . . . . . . . . . 97

5.5 .1 Alternative Test Windows . . . . . . . . . . . . . . . . 97

5.5.2 Alternative Propensity Score Model Assumptions . . . . . . . . . . 99

5.5.3 Alternative Definition of Composite Mortgage Risk Score . . . . . . 102

5.5.4 Alternative Matching Method . . . . . . . . . . . . . . . 102

5.5 .5 Alternative Research Designs _. . . . . . . . . . . 106

5.5.6 Least-transparent Versus Most-transparent Periods . . . . . . . . . 115

5.6 Conclusion . . . . . . . . . . . . . . . . . . . . . . 117

6 Large Securitizing BHCs 119

6.1 Introduction . . . . . . . . . . . . . . . . . . . . . . . . . . 119

6.2 Background and Literature . . . . . . . . . . . . . . . 120

6.3 Analyses of Large BHCs . . . . . . . . . . . . . . . . . . . . . . . 124

6.3 .1 Descriptive Statistics . . . . . . . . . . . . . . . . . . . . 124

6.3.2 Mortgage Lending Around Standard Changes . . . . . . . . . 128

6.4 Conclusion . . . . . . . . . . . . . . . . . . . . . 135

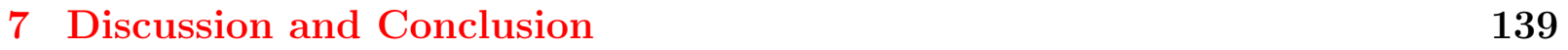

$\begin{array}{ll}\text { References } & 145\end{array}$

$\begin{array}{lr}\text { APPENDICES } & 155\end{array}$

$\begin{array}{ll}\text { A Variable Descriptions } & 157\end{array}$

A.1 Mortgage Lending Risk Measures . . . . . . . . . . . . . . . 157

A.2 Loan Portfolio Performance Measures and Other Variables . . . . . . . 160

B Matching FR Y-9C and HMDA Datasets 161 
C Propensity Score Matching

D Determinants of Mortgage Risk: Literature Summary 


\section{List of Tables}

3.1 Summary of Sampling Procedure . . . . . . . . . . . . . . . . . . 44

3.2 Sample Composition . . . . . . . . . . . . . . . . . . 45

4.1 Descriptive Statistics . . . . . . . . . . . . . . . . . . . . . . . . 59

4.2 Individual Mortgage Characteristics and On-Balance-Sheet Mortgage Portfolio Performance . . . . . . . . . . . . . . . . . . 63

4.3 Individual Mortgage Characteristics and Mortgage Yield . . . . . . . . 67

4.4 Mortgage Lending Risk Measures and Mortgage Portfolio Performance Whole Sample . . . . . . . . . . . . . . . . . . . . . 70

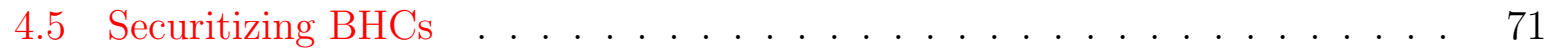

4.6 Non-Securitizing BHCs . . . . . . . . . . . . . . . . . . . 72

5.1 Descriptive Statistics . . . . . . . . . . . . . . . . . . . . . 74

5.2 The Effect of Transparency on Bank Lending Decisions . . . . . . . . . . 78

5.3 Descriptive Statistics for Moderating Variables . . . . . . . . . . . . 83

5.4 The Moderating Role of Manager-shareholder Alignment . . . . . . . . . 85

5.5 The Moderating Role of Regularity Oversight . . . . . . . . . . . . . 91

5.6 The Moderating Role of Market Discipline . . . . . . . . . . . . . . . . . . 95

5.7 Alternative Test Windows ． . . . . . . . . . . . . . . . . . 98

5.8 Alternative Propensity Score Matching Assumptions . . . . . . . . . . 101

5.9 Alternative Definition of Composite Mortgage Risk Score . . . . . . . 103

5.10 Alternative Matching Strategy _. . . . . . . . . . . . . . . 105 
5.11 Alternative Research Design . . . . . . . . . . . . . . . . . . . . 108

5.12 Least v. Most Transparent Periods . . . . . . . . . . . . . . . . . 116

6.1 Descriptive Statistics . . . . . . . . . . . . . . . . . . . 126

6.2 Transparency and Risk-taking by Top-five BHCs . . . . . . . . . . . . 133

6.3 Transparency and Risk-taking by BHCs in the Top Securitization Decile . 136

C.1 Covariates Description . . . . . . . . . . . . . . . 166

C.2 Propensity Score Model . . . . . . . . . . . . . . . . . . . . . 168

C.3 Covariate Balance . . . . . . . . . . . . . . . . . . . 170 


\section{List of Figures}

1.1 Major Loan Types on U.S. Banks' Balance Sheet . . . . . . . . . . . . . . 3

1.2 Total Outstanding U.S. Single Family Mortgages . . . . . . . . . . . . . . . 4

1.3 Mortgage Securitization vs Total Securitization by BHCs . . . . . . . . 5

2.1 Classical Banking Model . . . . . . . . . . . . . . . . . . . 11

2.2 Banking with Securitization . . . . . . . . . . . . . 13

2.3 Timeline of GAAP and Regulatory Changes . . . . . . . . . . . . . . . 17

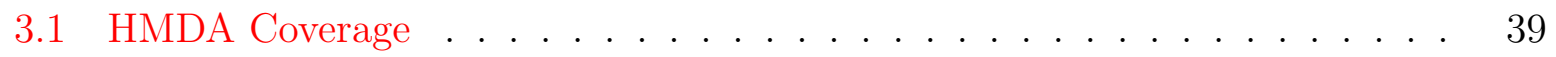

6.1 Outstanding Securitized Mortgages . . . . . . . . . . . . . . . . 121

6.2 The time series of mortgage lending risk . . . . . . . . . . . . . . . . 129

C.1 Covariate Balance Before and After Matching . . . . . . . . . . . . . 172 



\title{
List of Abbreviations
}

\author{
ABCP Asset-Backed Commercial Paper \\ ABS Asset-Backed Securities \\ BEA Bureau of Economic Analysis \\ BHC Bank Holding Company \\ BLS Bureau of Labor Statistics \\ BS Balance Sheet \\ CEO Chief Executive Officer \\ CRA Community Reinvestment Act \\ CRSP Center for Research in Security Prices \\ DELR Delay in Expected Loss Recognition \\ DiD Difference-In-Differences \\ ECB European Central Bank \\ EU European Union \\ FAS Financial Accounting Standard \\ FASB Financial Accounting Standards Board \\ FFIEC Federal Financial Institutions Examination Council \\ FHA Federal Housing Association \\ FHFA Federal Housing Finance Agency \\ FIN FASB Interpretation Number \\ FRT Financial Reporting Transparency \\ FSA Farm Service Agency \\ GAAP Generally Accepted Accounting Principles \\ GDP Gross Domestic Product \\ HMDA Home Mortgage Disclosure Act \\ HUD Housing and Urban Development \\ HPI House Price Index \\ IBES Institutional Brokers' Estimate System \\ LTV Loan-to-Value Ratio
}




$\begin{array}{ll}\text { MLRM } & \text { Mortgage Lending Risk Measure } \\ \text { MSA } & \text { Metropolitan Statistical Area } \\ \text { NPL } & \text { Non-Performing Loans } \\ \text { NPV } & \text { Net Present Value } \\ \text { QDiD } & \text { Quasi Difference-In-Differences } \\ \text { QSPE } & \text { Qualified Special-Purpose Entity } \\ \text { RHS } & \text { Rural Housing Service } \\ \text { SME } & \text { Small and Medium Enterprises } \\ \text { SFAS } & \text { Statement of Financial Accounting Standard } \\ \text { VA } & \text { Veterans Association } \\ \text { VIE } & \text { Variable Interest Entity }\end{array}$




\section{Chapter 1}

\section{Introduction}

The financial crisis of late 2000s has motivated an ongoing discussion about the effect of financial reporting transparency (FRT) on banks' real operating and financing decisions, and on systemic stability. Morgan (2002), Nier \& Baumann (2006), and Acharya \& Ryan (2016) argue that opacity can allow excessive bank risk-taking to go undetected, and that transparency can expose bank risk-taking to discipline from external parties. ${ }^{1}$ Prior literature (e.g., Bushman \& Williams 2012, 2015) examines the effect of FRT on overall bank risk exposure, using market-based risk measures, which aggregate risk-taking from all operating activities together with leverage, and other stock market and macroeconomic factors that may affect these market-based measures. However, these studies do not examine the effect of FRT on banks' risk-taking in specific operating decisions, such as mortgage lending, which is the focus of this thesis. Dou, Ryan \& Xie (2018) examine mortgage lending decision around FAS 166 \& 167, and they find that banks that recognize more securitized assets following FAS 166 \& 167 exhibit larger decreases in mortgage approval rates and larger increases in mortgage sale rates. Unlike Dou et al. (2018), I examine the risk profile of mortgages originated or purchased by banks.

The role of securitization in the financial crisis is a significant part of the discussion about transparency and bank risk-taking. Prior literature (e.g., Pennacchi 1988, Gorton \& Pennacchi 1995, Loutskina \& Strahan 2009) argues that securitization can reduce banks' incentives to screen and monitor borrowers by enabling them to transfer loans to investors thereby reducing their exposure to the risk of these loans they originate. Consistent with this theory, Mian \& Sufi (2009), Keys et al. (2010), and Wang \& Xia (2014) find that,

\footnotetext{
${ }^{1}$ See Beatty \& Liao (2014) and Acharya \& Ryan (2016) for more discussion about the role of transparency in the banking sector.
} 
in the pre-crisis period, banks decreased their lending standards more for loans that were easier to securitize. This literature, however, focuses on the general association between securitization and bank lending decisions, taking the FRT of securitization as a given. Despite the widely held view that opacity was to blame for the role of securitization in the crisis (e.g., Kiff, Jobst, Scarlata \& Kisser 2009), prior literature does not directly examine the role of transparency in this setting.

This thesis explores the role of securitization transparency, as opposed to the securitization activity, on banks' risk-taking in their mortgage lending decisions. I investigate whether and how FRT for securitization (hereafter, transparency) affects securitizing banks' risk-taking in their residential mortgage lending decisions (hereafter, risk-taking). I examine residential mortgage securitizations because: (i) residential mortgages make up a large portion of bank loans throughout my sample period (see Figure 1.1), (ii) residential mortgages are a significant component of the overall U.S. economy (see Figure 1.2), and (iii) residential mortgage securitizations make up a large portion of banks' securitization activity (see Figure 1.3). Moreover, I can identify the origination year for residential mortgages, which is crucial to my research design that depends on measuring risk in terms of lending decisions before and after transparency shocks. 


\section{Figure 1.1: Major Loan Types on U.S. Banks' Balance Sheet}

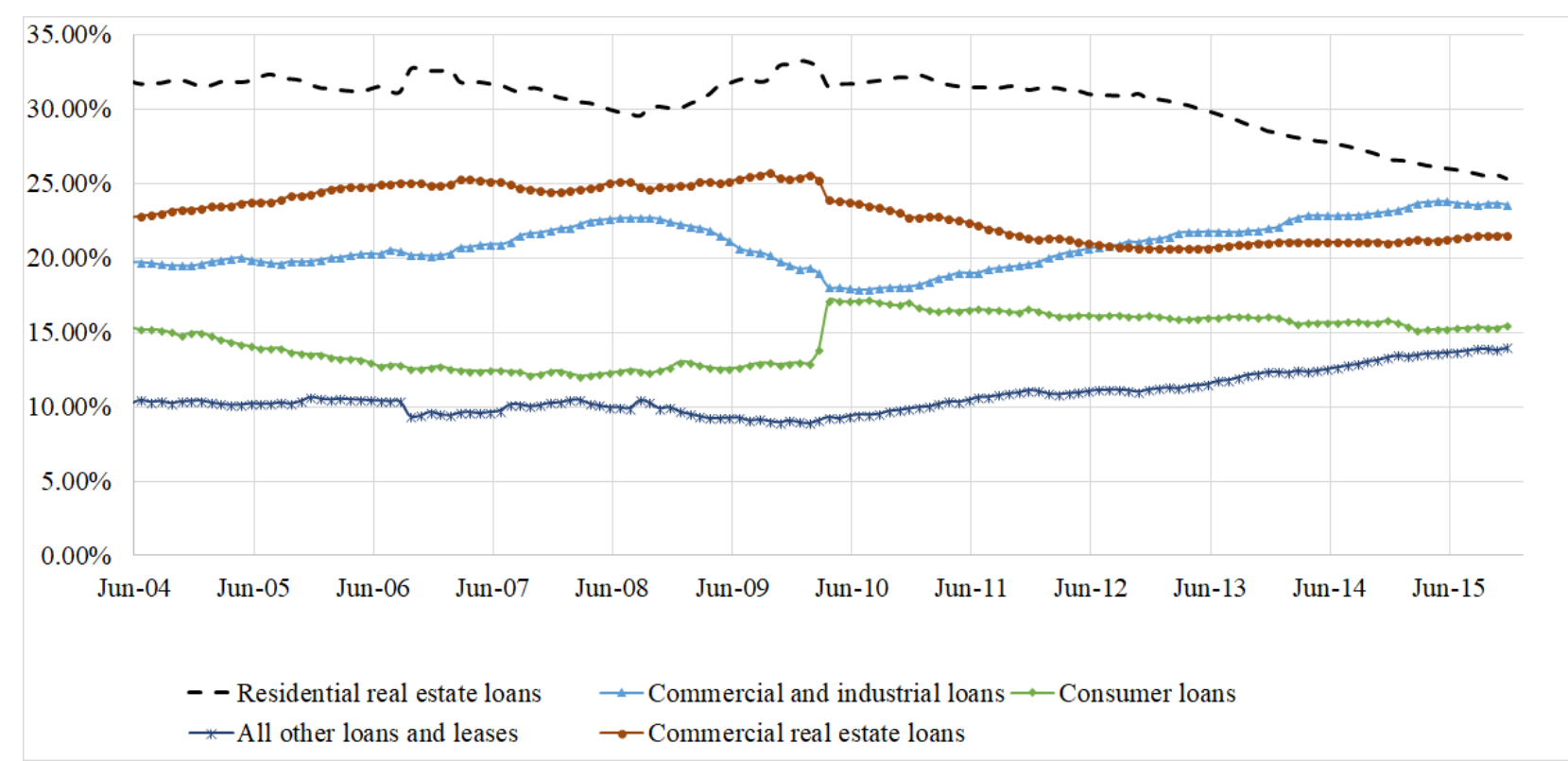

This figure presents different types of loans on U.S. commercial banks' balance sheet as a percentage of total loans for the period 2004-2012. The black broken line shows the percentage of residential mortgages, which is the largest loan group on banks' balance sheet. The other lines represent commercial real estate loans, commercial loans, consumer loans, and other loans and leases. The data are from the Federal Reserve website (https://www.federalreserve.gov/datadownload/Choose. aspx?rel=H8). 
Figure 1.2: Total Outstanding U.S. Single Family Mortgages

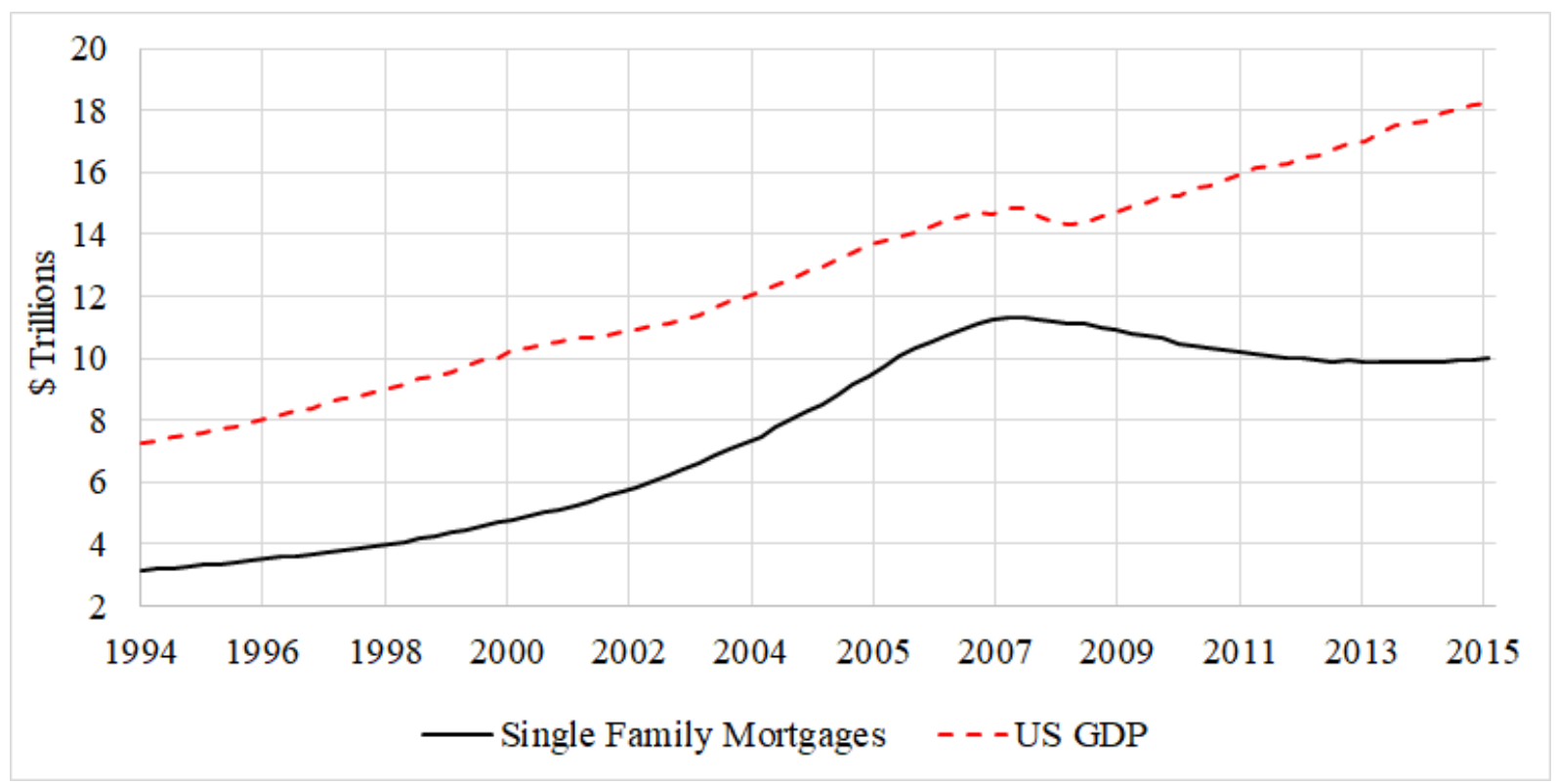

This figure shows the outstanding US residential mortgages backed by single-family property (black solid line) and US GDP (red dashed line) for the period 1994-2015.

Following Barth \& Schipper (2008), I define transparency as the extent to which financial reports reveal the underlying economics of securitization in an understandable way. By revealing the underlying economics of securitization, transparency allows bank stakeholders to observe assets the securitizing bank controls, liabilities it has incurred, and risks it faces due to retained interests in the securitization. ${ }^{2}$ This allows stakeholders to monitor banks' exposure to the risk of securitized loans, and to discipline risk-taking that is not aligned with their preferences. I hypothesize that greater transparency affects risktaking through three channels for monitoring and discipline, namely market discipline by uninsured creditors, regulatory oversight, and corporate governance (i.e., shareholder discipline). Transparency may fail to affect risk-taking if securitization transfers substantially all the risks to investors. Accounting standards that attempt to improve transparency may fail to do so, if banks restructure securitization transactions to subvert new reporting requirements, as Bens \& Monahan (2008) document for asset-backed commercial paper. To test the above-hypothesized channels, I investigate whether transparency has a larger

\footnotetext{
${ }^{2}$ Bank stakeholders include directors, shareholders, investors, creditors, and regulators.
} 
effect for banks with weak corporate governance, banks with low regulatory capital ratios, and banks with more uninsured depositors.

Figure 1.3: Mortgage Securitization vs Total Securitization by BHCs

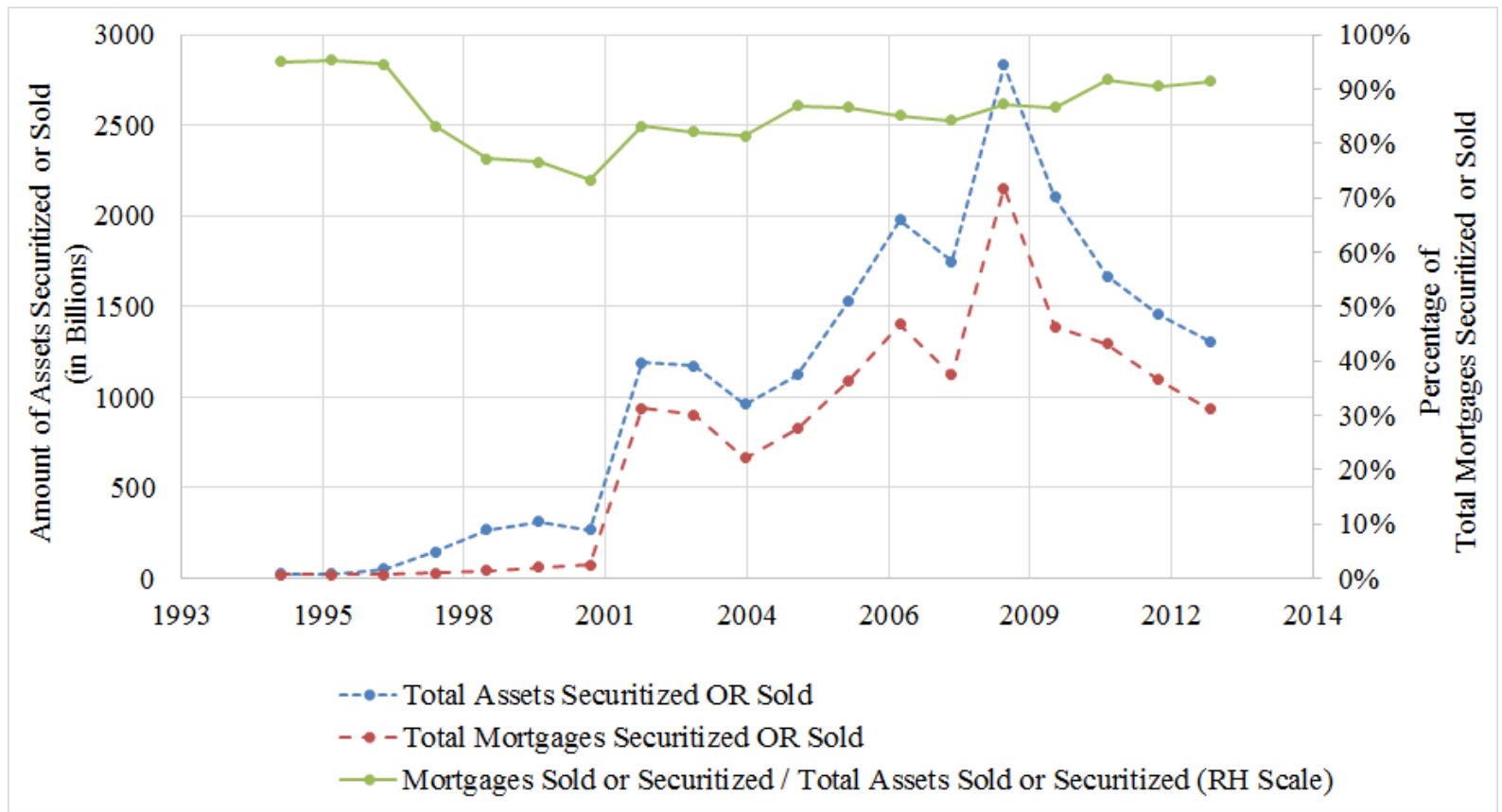

This figure presents the amounts of BHCs mortgage securitizations relative to their total securitizations. The dollar amounts of "total assets securitized or sold" and "total mortgages securitized or sold" are presented on the left-hand side scale. The scale on the right-hand side corresponds to the percentage of "total mortgages securitized or sold" relative to "total assets securitized or sold".

I obtain a sample of securitizing bank holding companies (BHCs) from the Federal Reserve's FR Y-9C database for the period 1996-2015. I focus on BHCs because consolidation at this level ensures proper aggregation of all securitization and mortgage-banking activities, which are often conducted by different subsidiaries. I propose four new mortgage lending risk measures (MLRMs) at the BHC-year level, which I develop based on mortgage-level and local area characteristics for mortgages approved by the BHCs in a given year.

I obtain mortgage application-level data from the Home Mortgage Disclosure Act (HMDA) database, and combine it with location-specific socioeconomic information from 
a variety of other U.S. government sources to create a mortgage-level risk score. ${ }^{3}$ I identify 24 different characteristics, such as borrower income, the ratio of borrower income to the amount of the loan, and the local area unemployment rate, that can reflect the riskiness of individual mortgages. I add them to create a composite risk score (MRSCORE) for each mortgage.

I validate the mortgage lending risk measures including all the 24 individual components, using BHC-level mortgage portfolio outcome measures such as delinquencies and charge-offs. I also show that most of the 24 individual component characteristics used to create the composite measures are positively associated with mortgage delinquencies and charge-offs in future years, and that they are associated positively with mortgage yield.

I then examine changes in lending decisions by securitizing BHCs around significant transparency shocks caused by five securitization accounting pronouncements (hereafter, the pronouncements or the standards). ${ }^{4}$ I argue that the first pronouncement decreases transparency and the other four increase transparency. The pronouncements affect transparency because they determine: (i) accounting policies such as the sales treatment of securitization and the measurement of retained interests, or (ii) disclosure requirements related to securitization activity. The use of five accounting standard changes issued at four different times mitigates the concern that factors other than the transparency shocks drive the results, and allows me to provide more comprehensive evidence. I identify securitizing BHCs as those with outstanding amounts of assets securitized or sold with recourse. ${ }^{5}$ I use a propensity-score matched sample of non-securitizing BHCs to control for size and other factors (e.g., industry and macroeconomic) that can affect lending decisions. The matching alleviates concerns that endogenous factors that affect the decision to securitize drive the risk-taking differences between treatment and control BHCs. I also perform additional analyses using coarsened exact matching based on the three most important covariates in the propensity score model, to ensure that my results are not driven by a specific matching method.

The results generally do not support my hypothesis that transparency affects bank risk-taking in mortgage lending. Except in a few cases, all the estimated effects are either

\footnotetext{
${ }^{3}$ Census data are available at the census tract level. The U.S. Census Bureau defines census tracts as "small, relatively permanent statistical subdivisions of a county", with "an optimum size of 4,000 people". More information can be found at https://www. census.gov/geo/reference/gtc/gtc_ct.html Personal income and unemployment data are available from the Bureau of Economic Analysis and the Bureau of Labor statistics at the county level, respectively. House price indexes are available from the Federal Housing Finance Agency at the metropolitan statistical area-level.

${ }^{4}$ FAS 125 (1996), FAS 140 (2000), FIN 46(R) (2003), FAS 166 (2009), and FAS 167 (2009)

${ }^{5}$ Prior to 2001Q2, FR Y-9C filings did not distinguish between securitized assets and assets sold with recourse. They simply reported the combined outstanding amount.
} 
indistinguishable from zero or go in the opposite direction of the predictions. This finding, which is robust to various sensitivity tests discussed in detail in chapter 5, suggests that transparency as defined in this thesis does not affect bank lending decisions in the predicted manner. However, it is also possible that the null results are driven by measurement error in the proposed mortgage lending risk measures, or weakness in the research design's ability to identify the hypothesized relationships. I discuss potential ways to address these issues in chapters 5 and 7.

The remainder of this thesis is organized as follows. Chapter 2 discusses the institutional background, reviews related literature, and develops the hypotheses. Chapter 3 describes the data sources, sampling procedure, and the research design. Chapter 4 develops and validates the proposed mortgage lending risk measures. Chapter 5 presents the empirical results. Chapter 6 discusses five large securitizing BHCs excluded from the main sample. Chapter 7 concludes the thesis. 



\section{Chapter 2}

\section{Background and Hypothesis Development}

\section{$2.1 \quad$ Introduction}

This chapter provides a discussion of the institutional and financial reporting environment of securitization, a review of related literature, and the hypotheses development. The first part of section 2.2 discusses the structure of securitization, comparing the classical banking model (Diamond 1984) and banking with securitization. The second part of section 2.2 formally defines financial reporting transparency of securitization. The last part of section 2.2 discusses the financial reporting of securitization per GAAP and regulatory reporting requirements. I present the evolution of GAAP and regulatory reporting since the early 1990's. Section 2.3 presents a review the related literature. Finally, section 2.4 presents the hypotheses development.

\subsection{Background}

\subsubsection{Securitization}

\subsubsection{Classical Banking}

In the classical banking model without securitization, illustrated in Figure 2.1, banks act as financial intermediaries between many dispersed lenders (primarily depositors) and bor- 
rowers. These parties cannot interact directly because of transaction costs and information asymmetries (Diamond 1984, Boyd \& Prescott 1986). ${ }^{1}$ Information asymmetries between lenders and borrowers can arise both before the origination of loans (i.e., adverse selection) and after the origination of loans (i.e., moral hazard). Diamond (1984) shows that uncoordinated screening and monitoring by a large group of individual lenders can be costly due to duplication of efforts. It can also result in a free rider problem where no individual lender screens and monitors borrowers because their share of the benefits is too small.

Banks can solve the information asymmetry and coordination problems by screening and monitoring borrowers on lenders' behalf. However, Leland \& Pyle (1977) argue that banks cannot simply act as information intermediaries that sell information about borrower creditworthiness, because users who cannot distinguish between good and bad information would not buy. Thus, banks act as financial intermediaries that collect deposits (i.e., borrow from depositors) and lend to borrowers, creating and holding illiquid loans. In this case, banks are exposed to the risks in the loans that they originate, and thus have an incentive to avoid excessive risk by screening and monitoring borrowers.

Bank stakeholders monitor banks' overall loan performance instead of the individual borrowers. Shareholders can align bank risk-taking behavior with their risk preferences through corporate governance. Uninsured creditors, who wish to protect their investment in banks' liabilities, can "'punish' banks for greater risk-taking by demanding higher yields on those liabilities" (Nier \& Baumann 2006, p. 333), or in the case of uninsured depositors, by withdrawing or withholding their deposits. ${ }^{2}$ Regulators can use bank inspections and regulatory constraints to minimize the likelihood of both individual bank and systemic failures.

\footnotetext{
${ }^{1}$ I focus on the information asymmetry problem because it is more relevant to this thesis.

${ }^{2}$ Prior research Merton (1977), Holod \& Peek (2007) shows that deposit insurance significantly reduces insured depositors' incentive to monitor banks.
} 
Figure 2.1: Classical Banking Model

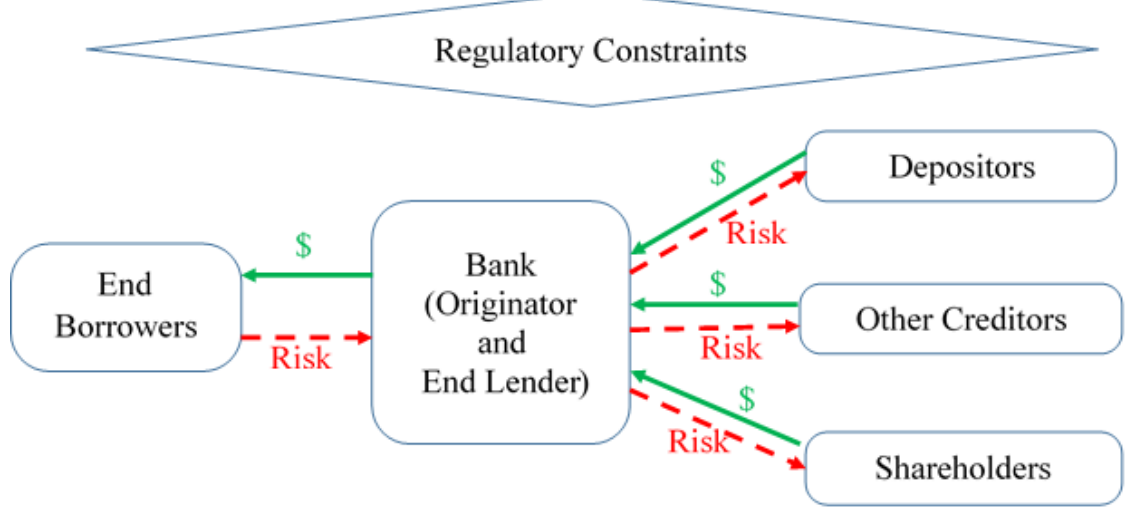

This figure presents a graphical depiction of the classical banking model (Diamond 1984). In this model, banks acts as a financial intermediary between depositors and borrowers by financing loans through deposits. In this process, banks are typically the end lenders and they hold the loans they originate until maturity. Other Bank stakeholders include shareholders, other creditors (e.g., bondholders) and bank regulators.

\subsubsection{Banking with Securitization}

Securitization changes the traditional banking model by providing banks with an additional avenue for financing their lending activities. While there are many types of securitization structures with varying degrees of complexity, I focus on a basic form of securitization to emphasize the major differences with the classical banking model. A typical securitization allows banks to convert less liquid loans into more liquid asset-backed securities (ABS) that can more easily be sold to investors. As shown in figure 2.2, a bank transfers a pool of loans to a securitization entity, which issues securities backed by the loans received from the bank. The proceeds from ABS sales are then transferred to the originating bank.

In principle, securitization allows banks to transfer risk to investors, who would become the effective end lenders that collectively hold the loans on their balance sheet. ${ }^{3}$ Prior literature Greenbaum \& Thakor (1987), Pennacchi (1988), Barth, Ormazabal \& Taylor (2012) suggests that risk transfer is among the primary motivations for securitization. In this case, banks have less incentive to screen and monitor borrowers because they no

\footnotetext{
${ }^{3}$ In some cases, banks securitize loans and hold all or a significant portion of the resulting ABS on their balance sheet under assets held for sale, thus swapping loans for ABS on their balance sheets. This practice can provide banks with more financial flexibility as ABS are easier to sell than the underlying loans.
} 
longer hold the risk of the loans they originate. Cortes \& Thakor (2015) argue that securitizations that transfer risk to outsiders reduce the benefits to banks of borrower screening and monitoring, without reducing the costs. For similar reasons, stakeholders' incentives to monitor and discipline bank lending decisions decreases when they believe that banks transfer risk through securitization.

However, securitizations are complex and opaque transactions that do not necessarily transfer all risks and rewards to ABS investors. Securitizing banks often retain significant interests in securitized loans. Common types of retained interests include servicing rights, recourse obligations, and liquidity and credit guarantees for securitization entities. Transparency can increase stakeholders' ability to observe the extent of risk transferred through securitization (i.e., where the underlying risk of securitized loans lies, within the gray shaded area in figure 2.2). If the risk transfer is not observable, stakeholders cannot effectively monitor and discipline bank risk-taking, which in turn affects banks' risk-taking incentives in securitizable loans. 


\section{Figure 2.2: Banking with Securitization}

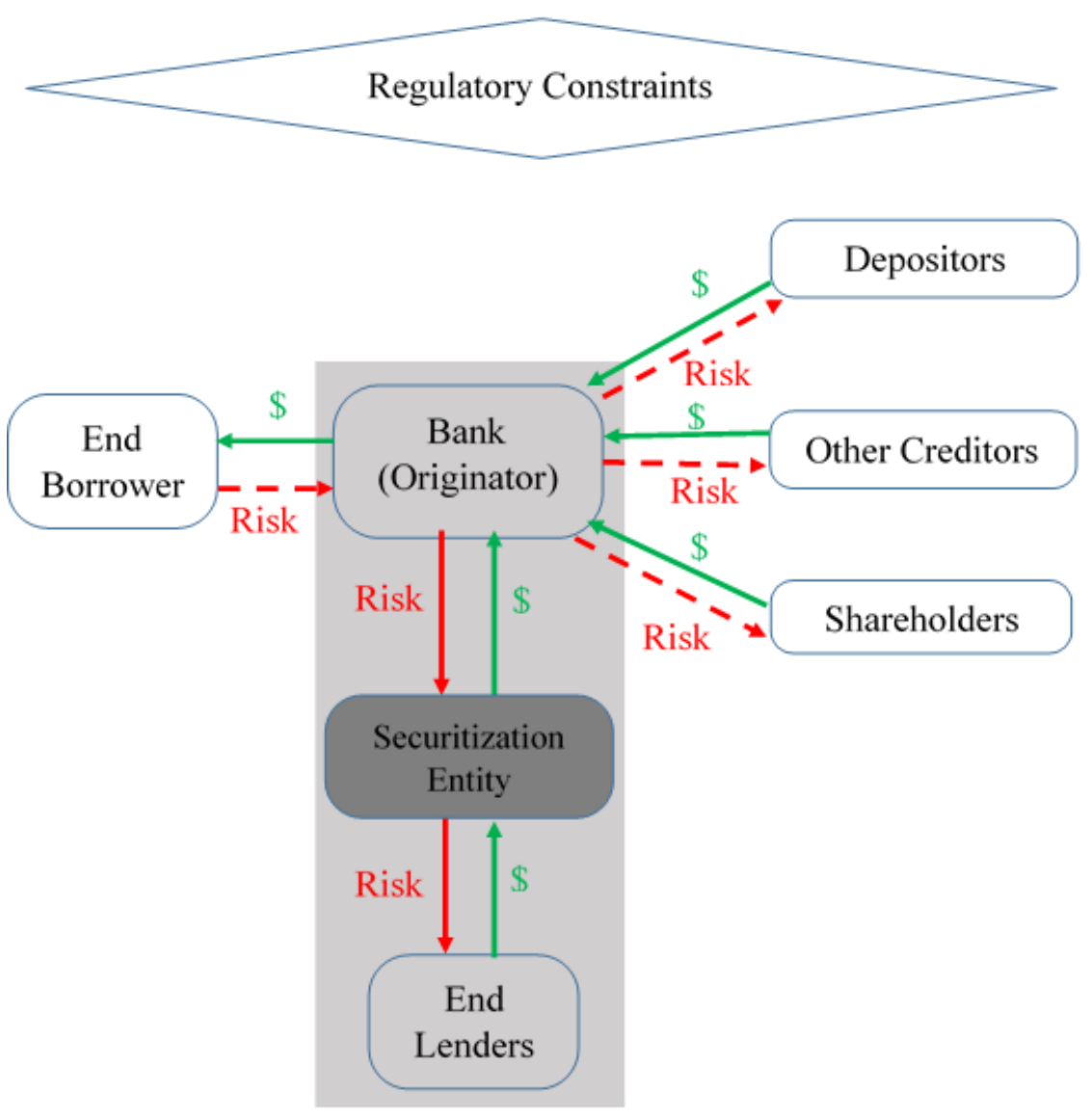

This figure presents a graphical depiction of banking with securitization. Securitization provides banks with an alternative way to fund loans, represented by the shaded area. Banks can transfer the loans they originate to third parties by selling or securitizing. Banks are no longer the end lenders if they transfer the loans to outsiders without recourse.

\subsubsection{Financial Reporting Transparency}

Accounting policy choices, measurement principles, and additional disclosures are among the primary determinants of transparency. For instance, accounting policies that allow derecognition of securitized assets while the transferor retains significant interest in the assets, or prohibit derecognition when the assets are transferred, reduce financial reports' 
ability to reveal underlying economics. ${ }^{4}$ Securitized assets are derecognized and securitization income is recognized, if the transaction qualifies for sales treatment and the utility is not consolidated. ${ }^{5}$ If the transaction does not qualify for sales treatment or the utility is consolidated, the securitized assets remain on the balance sheet and the proceeds from the transaction are recognized as a liability.

Measurement principles can affect transparency because they determine the accuracy of reported values. For instance, measurement of retained interests affects the allocation of carrying value between the transferred and retained part of the securitized pool, and therefore can affect securitization gain or loss. Additional disclosures about specific accounting policies, assumptions, and estimates used in accounting for securitization can affect both revelation of underlying economics, and understandability.

Financial reports without adequate supplemental disclosure, even when they apply appropriate accounting policies and measurement methods, cannot communicate the underlying economics in an understandable way.

\subsubsection{The Financial Reporting of Securitization}

Accounting standards and regulatory disclosure requirements shape accounting policies, measurement principles, and disclosure by financial institutions. Generally Accepted Accounting Principles (GAAP) and regulatory disclosure for securitization have evolved significantly over the last couple of decades. Figure 2.3 presents the timeline of GAAP and regulatory accounting changes for securitizations considered in this thesis.

Over the last 25 years, the Financial Accounting Standards Board (FASB) issued five major pronouncements relating to securitization, namely SFAS No, 125 (1996), SFAS No. 140 (2000), FIN 46 (R) (2003), SFAS No. 166 (2009), and SFAS No. 167 (2009). FASB issued the accounting pronouncements to enhance transparency through their effect on accounting policies, measurement principles, and disclosure. For instance, in the statements of the standards, FASB emphasizes its aim to ensure that each party to the transaction recognizes assets it controls and liabilities it has incurred, and derecognizes assets only when control has been surrendered and liabilities only when they have been extinguished. ${ }^{6}$

The standards can also influence transparency through their impacts on regulatory reports (e.g., FR Y-9C) and on regulatory capital ratios such as Tier 1 leverage, Tier 1

\footnotetext{
${ }^{4}$ Schipper \& Yohn (2007) identify the derecognition of securitized assets as the primary securitization accounting policy issue.

${ }^{5}$ FAS 125, FAS 140, and FAS 166 describe the criteria for sales treatment of securitization transactions. ${ }^{6}$ SFAS No. 125 (1996, par.6), SFAS No. 140 (2000, par.5), and SFAS No. 166 (2009, par.5)
} 
capital, and total risk capital ratios. ${ }^{7}$ Regulatory accounting and disclosure requirements for securitization also changed significantly over the same period, with major expansions in disclosure requirements in 2001 and 2010. These expansions in regulatory disclosure mirror expansions in GAAP disclosure requirements, generally with lag. While regulatory filings contain more standardized (and more disaggregated prior to FAS 166 \& 167) financial information than GAAP reports, they are typically prepared per GAAP. ${ }^{8}$ For instance, off-balance-sheet treatment for securitizations and recognition of securitization income in regulatory filings typically follow GAAP. Recognizing securitization income in Tier 1 capital increases the numerator of Tier 1 leverage, Tier 1 capital, and total risk capital ratios. Increasing regulatory capital ratios, when banks retain significant interest in securitized assets, fails to reveal the underlying economics. Off-balance sheet treatment can increase Tier 1 capital and total risk capital ratios because the risk-weighted total amount of the offbalance-sheet assets can be lower than the risk-weighted total amount the underlying loans had they not been securitized, decreasing the denominator. ${ }^{9}$ Off-balance sheet treatment also increases the Tier 1 leverage ratio because off-balance-sheet assets are not included in the denominator (average total assets).

In addition to containing more disaggregated information than GAAP reports, regulatory reports provide information that is not required by GAAP. In the 1990s, Y-9C filings contained the outstanding amount of assets sold with recourse, which includes securitized assets that are treated as sales per GAAP. Regulatory reports also contain the maximum contractual value of recourse, which is used instead of fair values in calculating risk-weighted assets.

This thesis focuses on FASB pronouncements that affect BHC-level financial reports, i.e., the bank's (originator's) financial reports in 2.2. I do not examine the effect of information environment in ABS markets, i.e., the transparency of securitization utilities to investors (the end lenders in figure 2.2) on bank lending decisions as I believe this is a

\footnotetext{
${ }^{7}$ See appendix A.2 for definitions of regulatory capital ratios.

${ }^{8}$ Acharya \& Ryan (2016) state that "Although banks appear to respond more to regulatory capital requirements than to financial reporting standards, regulatory reporting and thus capital requirements often are based on financial reporting standards." (p.322)

${ }^{9}$ The Risk-based Capital Guidelines published on November 29, 2001 state that "Highly rated investment-grade positions in securitizations receive a favorable (less than 100 percent) risk-weight. Belowinvestment-grade or unrated positions in securitizations would receive a less favorable risk-weight (generally greater than 100 percent risk-weight). A residual interest retained by a banking organization in an asset securitization (other than a credit-enhancing I/O strip) would be subject to this capital framework. Therefore, if the external rating provided to such a residual interest is investment grade or no more than one category below investment grade, the final rule affords that residual interest more favorable capital treatment than the dollar-for-dollar capital requirement otherwise required for residuals." (p.59619)
} 
closely related but separate research question. Regulation AB, which was effective in 2006, enhances transparency in ABS markets by requiring periodic pool-level performance disclosures by SEC-registered ABS. I do not expect Reg AB to confound my analyses because it does not fall in any of the test periods around the standards.

The remainder of this subsection discusses the major securitization accounting standards, their effect on transparency, and instances where GAAP and regulatory accounting differ. In the discussion below, I focus on reporting standards that apply to securitization of residential mortgages. 


\section{Figure 2.3: Timeline of GAAP and Regulatory Changes}

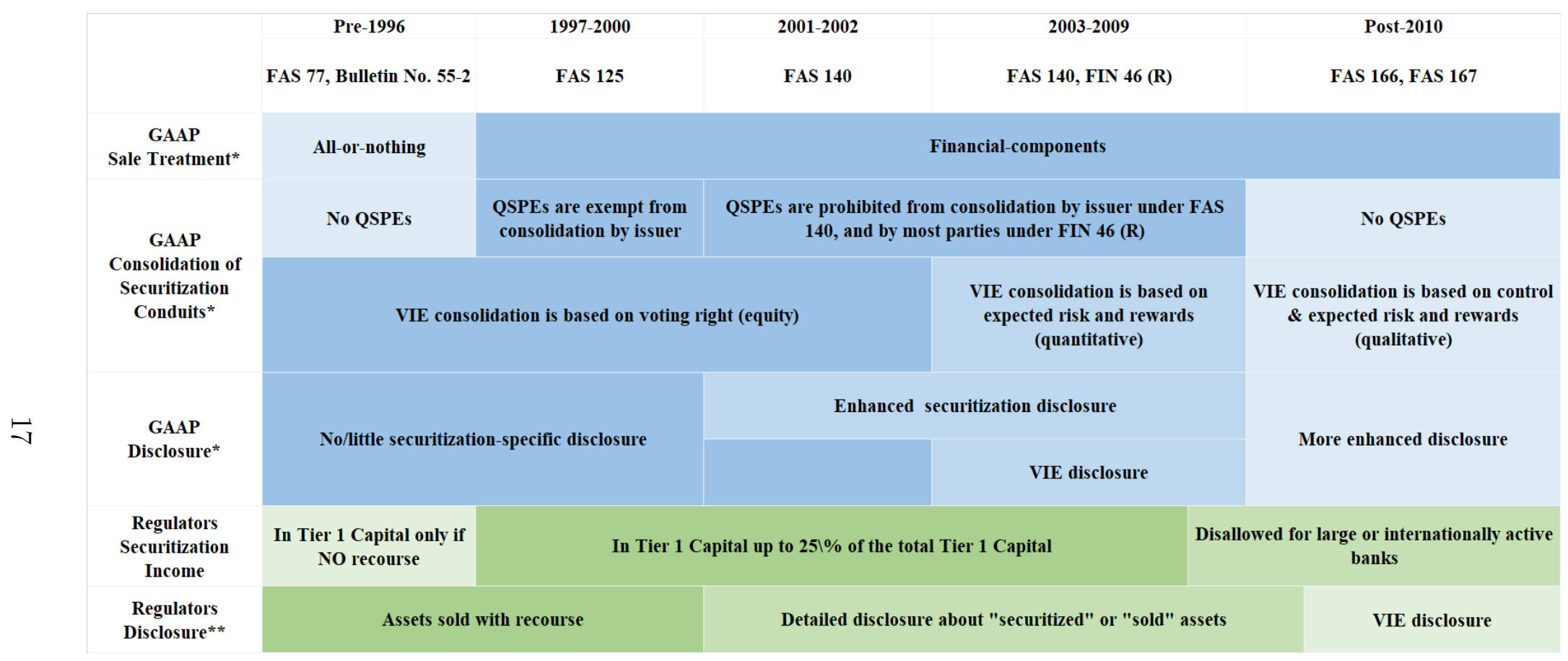

This figure presents a simplified timeline of U.S. GAAP and regulatory accounting changes relating to securitization over the period 1994-2012. Lighter shades represent more transparency.

* While I focus on the elements of the standards that apply to securitization of residential mortgages, the standards apply for all types of transfers of financial assets.

** Regulatory disclosures increase in various ways after the crisis. Most of these changes, mandated by the Dodd-Frank Act, did not become effective in my test window around FAS 166 \& 167. 


\subsubsection{Pre-FAS 125}

Accounting standards prior to FAS 125 in 1996 followed an all-or-nothing approach to securitization accounting. This approach treated financial assets as indivisible units, and it relied on the legal form and predominant characteristics of the transaction to determine sales treatment for securitizations. FAS 125, in its description of pre-FAS 125 practice, states that "For example, whether a transfer "purported to be a sale" was sufficient to determine whether the transfer was accounted for and reported as a sale of receivables under one accounting standard or as a secured borrowing under another." (FAS 125 par.5). If the transaction purports to be a sale, the securitization is treated as a sale if it meets the conditions in FAS 77. ${ }^{10}$ FAS 77 addressed neither the consolidation of securitization entities nor retained interests other than recourse obligations and servicing rights. ${ }^{11}$ A securitization is treated as a secured loan if the transaction does not meet FAS 77 requirements, or if it purports to be a loan, in which case Bulletin No. 85-2 applies. ${ }^{12}$

When a securitization is treated as a sale and the securitization entity is not consolidated, the associated gain or loss is recognized in net income. Kane (1995) reports that regulatory accounting diverged from GAAP by allowing securitization income in Tier 1 capital only for securitizations with no recourse. Kane $(1995,1997)$ argues that the all-ornothing approach can lead to opacity because: (i) banks can easily manipulate the legal form of securitization to fit the desired accounting, and (ii) because they are not required to recognize all assets and liabilities created as a result of securitization. To justify FAS 125, FASB states that previous approaches were difficult to apply and produced inconsistent and arbitrary results (FAS 125, par.7) and do not provide an appropriate basis for developing consistent and operational standards (FAS 125, par.8).

\subsubsection{FAS 125}

FASB issued FAS 125 in 1996 to improve the accounting for transfer of financial assets by eliminating inconsistencies and confusions that resulted from previous standards and accounting practice (FAS 125 par.97). In FAS 125, FASB concluded that an objective of

\footnotetext{
${ }^{10}$ FAS 77 deals with transferors' accounting for transfers of receivables with recourse. A transfer is treated as a sale if (i) the transferor surrenders control of the assets (i.e., no option to repurchase), (ii) the recourse to the transferor can be reasonably estimated, and (iii) the transferee cannot require the transferor to repurchase the assets except through recourse provisions (FAS 77, par.5).

${ }^{11}$ The consolidation of securitization entities was covered by existing standards for consolidated financial statements, ARB No. 51 (1959) as amended by FAS 94 (1987).

${ }^{12}$ Bulletin 85-2 deals with accounting for collateralized mortgage obligations.
} 
securitization accounting is for each party to the transaction "to recognize only assets it controls and liabilities it has incurred, to derecognize assets only when control has been surrendered, and to derecognize liabilities only when they have been extinguished." (FAS 125 par.5). This is consistent with enhancing transparency by revealing the underlying economics of the securitization transactions.

The following are the main elements of FAS 125. First, it introduced the financialcomponents approach in which the transferor decomposes securitized assets into multiple asset and liability components (e.g., interest-only strips, servicing rights, and letters of credit), and accounts separately for each component. Second, it provided control-based qualification criteria for sales treatment of securitization transactions. Sales treatment applies per FAS 125 if the transferor surrenders control over the securitized assets. ${ }^{13}$ Third, FAS 125 created a special class of securitization entities, qualifying special purpose entities (QSPEs) that are exempt from consolidation. QSPEs are passive entities that are demonstrably distinct from the transferor and that can only engage in a predetermined set of activities. While FAS 125 is generally silent about the consolidation of securitization entities, the Emerging Issues Task Force (EITF) reached a consensus that FAS 125's definition of control should be applied in assessing consolidation of QSPEs, allowing transferors to avoid consolidation of QSPE. ${ }^{14}$

When a securitization is treated as a sale and the conduit is not consolidated, the original assets are derecognized, and all assets obtained and liabilities incurred in association with the securitization are recognized. The carrying amount of the original assets is allocated between the sold and retained components based on their fair value proportions, and the difference between the proceeds and the carrying amount allocated to the sold part is recognized as a gain or loss on the income statement. The retained components are initially recognized at their fair value, if a reasonable measurement is possible. If it is not practicable to estimate the fair values of retained assets and liabilities, the assets are recorded at zero, and the liabilities at the greater of (i) the net fair value of other assets obtained and liabilities incurred less the carrying amount of the transferred assets, and (ii) the amount that would be recognized per FAS 5 "Accounting for Contingencies" as interpreted by FIN 14 "Reasonable Estimation of the Amount of Loss". FAS 5 requires recognition of estimated loss from loss contingencies when it is probable that an asset had been impaired or a liability had been incurred and the loss can be reasonably estimated.

${ }^{13}$ The transferor surrenders control if (i) the assets are isolated from the transferor even in bankruptcy, (ii) the transferee has the right to pledge or exchange the assets, and (iii) the transferor does not maintain effective control over the securitized assets through arrangements other than cleanup calls.

${ }^{14}$ EITF Issue No. 96-20 "Impact of FASB Statement No. 125 on Consolidation of Special-Purpose Entities." was issued only three months after FAS 125. 
FIN 14 deals with cases where only a range of loss can be reasonably estimated. In this case, "When some amount within the range appears at the time to be a better estimate than any other amount within the range, that amount shall be accrued. When no amount within the range is a better estimate than any other amount, however, the minimum amount in the range shall be accrued." (FIN 14, par. 3)

In contrast to the pre-FAS 125 era, beginning with the adoption of FAS 125, regulators included securitization income in Tier 1 capital regardless of recourse to the transferor. Regulators discontinued this practice later and prohibited large or internationally active BHCs (i.e., those following the Basel II Advanced Capital Adequacy Framework) from including non-cash securitization gains in Tier 1 capital in 2008, and all other BHCs with at least $\$ 500$ million in total assets in $2014 .^{15}$

In principle, FAS 125 can enhance transparency by allowing securitizing entities to recognize only assets they control and liabilities they have incurred and not extinguished. Securitizations are typically complex transactions that do not fit the all-or-nothing approach, as a portion of the risk in the underlying loans is transferred while the rest is retained by the transferor. The financial-components approach would ideally allow the transferor to account separately for the transferred and retained parts, derecognizing the transferred assets, retaining on its balance sheet only the assets it still controls, and recognizing only the liabilities it has incurred. However, due to the complexity of securitizations, it can be difficult to reliably measure the distinct components, and to provide sufficient disclosure that enables external stakeholder to understand and value the components.

FAS 125 and the financial-components approach can increase opacity for several reasons. First, as O'Brien (2011) argues, the underlying risk in securitized assets (e.g., mortgages) is not separable, so creating synthetic components that are accounted for separately obscures the underlying economics. Second, measurement errors or biases in fair-valuing retained interests can obscure the transferor's true exposure to the securitized assets and misrepresent the securitization gain. This approach is susceptible to measurement errors and biases because retained interests are not tradable (O'Brien 2011), which necessitates reliance on discretionary non-market inputs. Last, while purporting to be a sale is no longer sufficient,

\footnotetext{
${ }^{15}$ The "Risk-Based Capital Standards: Advanced Capital Adequacy FrameworkBasel II; Final Rule" published in 2007 and effective in April 2008 states that "Under the proposed rule, a bank would deduct from tier 1 capital any after-tax gain-on-sale. Gain-on-sale was defined as an increase in a bank's equity capital that resulted from a securitization, other than an increase in equity capital that resulted from the bank's receipt of cash in connection with the securitization." The "Regulatory Capital Rules: Regulatory Capital, Implementation of Basel III, Capital Adequacy, Transition Provisions, Prompt Corrective Action, Standardized Approach for Risk-weighted Assets, Market Discipline and Disclosure Requirements, Advanced Approaches Risk-Based Capital Rule, and Market Risk Capital Rule" published in 2013 contains a similar provision.
} 
legal form remains a key element in determining sales treatment. For example, QSPEs are immune from consolidation. Banks can manipulate the legal form and structure of securitization transactions to fit their desired accounting outcome, while maintaining significant interest that exposes them to significant risk if the QSPE is in trouble. As discussed in the previous paragraph, the financial-components approach can, in ideal cases, lead to greater transparency than the all-or-nothing approach. However, I argue that the accounting and disclosure practice established by FAS 125 were less than ideal. ${ }^{16}$

While no prior research systematically examines the transparency effects of FAS 125, a stream of literature provides evidence that suggests the major elements of FAS 125 reduce transparency. Niu \& Richardson (2006), Landsman, Peasnell \& Shakespeare (2008), Barth et al. (2012), and Dou, Liu, Richardson \& Vyas (2014) show that equity and bond markets on average treat securitizations as if they were secured loans, suggesting that investors believe the sales treatment is not consistent with the underlying economics. ${ }^{17}$ Hence, standards that allow sales treatment of securitization instead of secured loan treatment may reduce transparency. Karaoglu (2005), Dechow \& Shakespeare (2009), Dechow, Myers \& Shakespeare (2010), and Acharya, Schnabl \& Suarez (2013) show that banks use securitizations to manipulate earnings and regulatory capital, again suggesting that the accounting does not mirror the underlying economics.

\subsubsection{FAS 140}

FAS 140, issued in 2000, carries forward most elements of FAS 125 with the following exceptions. First, FAS 140 strengthened qualification requirements for QSPEs by restricting the activities they conduct, financial assets they hold, and the type and timing of asset sales. Second, FAS 140 prohibited the consolidation of QSPEs. Third, FAS 140 required more disclosure including: (i) the characteristics of securitizations, (ii) accounting policies and key assumptions in measuring retained interests, (iii) sensitivity analyses for fair values of retained interests, (iv) cash flows between the conduit and the transferor, and (v) total principal amounts, delinquencies, and credit losses for outstanding securitized assets. This expansion in disclosure requirements was followed by a similar increase in regulatory disclosure requirements with a one quarter lag.

\footnotetext{
${ }^{16} \mathrm{I}$ leave for future researchers the question of whether the financial components approach dominates the all-or-nothing approach under an ideal disclosure regime for both approaches.

${ }^{17}$ Chen, Liu \& Ryan (2008) find that the relation between securitizing banks' equity risk and their securitized assets depends on the type of securitization. For example, the relation is strong when the securitized loans have higher or less externally verifiable credit risk.
} 
FAS 140 can enhance transparency because it requires extensive disclosure, and because it tightens the qualification criteria for QSPEs, which can reduce their use for purely accounting purposes. However, FAS 140 carries over the financial-components approach and the QSPE concept from FAS 125, and it prohibits consolidation of QSPEs. Thus, FAS 140 's overall effect on transparency depends on the extent to which the expanded disclosures and tightening of QSPE qualification, in practice, offset the transparency-decreasing effects of the financial-components approach and non-consolidation of QSPEs.

\subsubsection{FIN $46(\mathrm{R})$}

Prior to FIN 46 (R) in 2003, variable interest entities (VIEs) were effectively consolidated by the entity that held the majority of voting rights. ${ }^{18}$ Under FIN 46 (R), a VIE is consolidated by the primary beneficiary, the entity holding the majority of the VIE's expected losses or rewards. FIN $46(\mathrm{R})$ expanded disclosure requirements for parties involved in a VIE. It required the primary beneficiary of a VIE to disclose: (i) the nature, size, purpose, and activities of the VIE, (ii) the carrying amount and classification of consolidated assets used as collateral for the VIE's obligations, and (iii) lack of recourse if the primary beneficiary has no recourse obligations to other parties in association with the VIE. ${ }^{19}$ FIN 46 (R) also required a party that holds a significant interest in a VIE but is not the primary beneficiary to disclose item (i) above, the nature and timing of its involvement in the VIE, and the maximum exposure to the loss of the VIE.

FIN $46(\mathrm{R})$ can enhance transparency if the expected risk and rewards approach to VIE consolidation better reflects underlying economics than the voting rights approach. For example, consolidation of a VIE based on voting rights would not reveal the underlying economics if the voting and cash flow rights are separate, or if the VIE has no voting class. Consolidation of VIEs per FIN 46 (R) can also affect transparency through regulatory capital because it increases the risk-weighted capital base of the entity exposed to the majority of the expected risks. The enhanced VIE disclosures would improve transparency by providing more information about the extent of risk exposure by the parties with significant involvement in a VIE.

However, FIN 46 (R) may fail to enhance transparency. Bens \& Monahan (2008) show that some U.S. banks, especially those with binding regulatory constraints, structured transactions to avoid consolidation of asset-backed commercial paper (ABCP) conduits per FIN 46 (R). Bank regulators exempted consolidated ABCP conduits from inclusion in

\footnotetext{
${ }^{18}$ FIN 46 (R) section "Reasons for Issuing This Interpretation', p.3, par.1.

${ }^{19} \mathrm{FIN} 46(\mathrm{R})$ par.23
} 
the risk-weighted asset base (ABCP exclusion) seven months after FIN 46 (R) was effective. Banks retaining substantial risks in ABCP conduits continued to avoid consolidation of these conduits and to exclude the conduits from risk-based capital ratios, so the accounting did not reflect the underlying economics. Hence, the ultimate effect of FIN $46(\mathrm{R})$ on transparency is uncertain. On balance, I conjecture that FIN 46 (R) enhances transparency for mortgage-related securitizations because: (i) the evidence suggests that transaction restructuring was concentrated among banks with binding regulatory constraints, (ii) the regulatory exception is only for ABCP conduits, not for all securitization entities, and (iii) the regulatory exception did not allow exclusion of ABCP conduits from the Tier 1 leverage ratio.

\subsubsection{FAS 166 and FAS 167}

FAS 166 and FAS 167, issued in 2009, represent the most extensive changes to securitization accounting. These standards eliminate the QSPE concept, thereby require existing QSPEs be considered for consolidation, tighten the criteria for determining the primary beneficiary of a VIE, and enhance required disclosures regarding securitization activities. Under FAS 166 \& 167, the primary beneficiary of a VIE is the entity with (i) the power to direct the VIE's activities that most significantly impact the VIE's economic performance, and (ii) the obligation to absorb significant losses of the VIE or the right to receive significant benefits from the VIE. Unlike FIN $46(\mathrm{R})$, there is no requirement to hold the majority of expected risks and rewards of the VIE.

FAS 166 \& 167 can enhance transparency by tightening the criteria for off-balance-sheet treatment of securitizations and by requiring additional disclosures. Moreover, similar

disclosure requirements in regulatory filings followed within a year. Following FAS 166 \& 167, regulators also eliminated the ABCP exclusion established in response to FIN 46 (R), limiting banks' ability to bolster their regulatory capital ratios through securitization. Supporting the claim that FAS 166 \& 167 enhance transparency, Oz (2016) shows that information asymmetry, as measured by bid-ask spread, declines more for securitizing banks than non-securitizing banks after the adoption of FAS 166 \& 167.

\section{$2.3 \quad$ Related Literature}

This section discusses two streams of literature related to my thesis. The first stream examines the effects of accounting standards and transparency on banks' operating decisions, 
and the second stream deals with the effects of securitization on banks' lending decisions. I discuss the contribution of my thesis relative to these two streams of literature.

\subsubsection{Transparency and Bank Operating Decisions}

My thesis is closely related to the growing stream of literature examining the real effects of accounting policies and disclosure on banks' operating decisions (e.g., Bushman \& Williams 2012, 2015, Xie 2016, Dou 2017, Ertan, Loumioti \& WITTENBERG-MOERMAN 2017, Dou et al. 2018, Neilson, Ryan, Wang \& Xie 2018, Schmidt \& Zhang 2018). Of these studies, Ertan et al.'s (2017) study examining the effect transparency on loan quality is the most closely related to my thesis. Ertan et al. (2017) exploit new reporting standards introduced by the European Central Bank (ECB) in 2013. Under the new reporting regime, banks that use ABS as collateral to borrow from the ECB are required: (i) to disclose the structure of ABS used as collateral, and (ii) to collect and disclose detailed loan- and borrower-specific information for loans backing the ABS. Ertan et al. (2017) use loan-level data on securitized loans to SMEs (small and medium-sized enterprises) that are reported under the new ECB requirement and find that greater loan-level disclosure increases loan quality.

This thesis differs from Ertan et al. (2017) in the following ways. First, my thesis examines a related but distinct type of transparency. In contrast to ECB's loan-by-loan disclosures examined in Ertan et al. (2017), I focus on the transparency of BHC-level financial reports (i.e., financial statements and supplemental disclosures) filed with the SEC and banks regulators. While the ECB disclosures about a specific securitization provide information about the risk profile of the underlying loans, it does not reveal whether and how much risk is transferred through the securitization- a central focus of this thesis. Referring to figure 2.2, the ECB disclosure reveals the riskiness of the loan pool in the securitization entity, and financial reporting transparency reveals whether and how much of this risk is transferred to external parties. As a result, my study answers a different question than Ertan et al. (2017). Their study answers the question of whether banks would improve their lending decisions when they are required to disclose detailed information about individual loans. In contrast, my thesis addresses whether banks would improve their lending decision when they are required to provide more transparent financial reports that summarize their operating activities.

Second, my thesis examines different mechanisms through which transparency affects lending decisions than Ertan et al. (2017). As discussed in section 2.4, financial reporting transparency affects bank lending decision through its effect on bank stakeholders' ability 
to observe bank risk exposures. I specifically identify three distinct types of stakeholders, namely shareholders, uninsured creditors, and regulators, and examine how transparency affects their ability to monitor bank lending decisions. In contrast, Ertan et al. (2017) examine the effect of the ECB's ABS reporting standard on bank lending decisions through its effect on banks' information collection process and on ABS investors' ability to observe the underlying loans.

Last, in addition to the primary differences discussed above, I examine my research question in a different setting than that of Ertan et al. (2017). I use a U.S. residential mortgage setting as opposed to the European SME loan setting in Ertan et al. (2017). Accounting, regulatory, and other institutional differences between the European Union and the United States may result in differential responses by EU and U.S. banks to changes in transparency. Moreover, banks may have different lending models for SMEs and residential mortgage borrowers because of differences in their underlying economics. Hence, results in one of these settings may not generalize to the other.

Schmidt \& Zhang (2018) and Neilson et al. (2018) examine the effect of Regulation AB (2006) and Regulation AB II (2016) on ABS markets, respectively. These regulations require issuers of SEC-registered structured instruments to provide periodic pool-level (Reg AB) and asset-level (Reg AB II) disclosure about the performance of the underlying assets starting in 2006 and in 2016, respectively. ${ }^{20}$ Schmidt \& Zhang (2018) document an increase in trading activity and liquidity in the ABS market around the filing dates of Reg AB disclosures (form 10-D). Neilson et al. (2018) find that asset-level disclosures after Reg AB II improve investors' valuations of ABS, and improve credit rating agencies' evaluation of ABS. This thesis differs from these studies because it examines financial reporting transparency of BHCs, as opposed to disclosures by securitization utilities that are not included in the BHCs' financial reports, and because it examines lenders' decision-making, as opposed to that of ABS investors and credit rating agencies. My thesis examines a dimension of the securitization market and associated disclosures not explored in these studies (Schmidt \& Zhang 2018, Neilson et al. 2018), and hence it complements them. Schmidt \& Zhang (2018) and Neilson et al. (2018) focus on disclosures by securitization entities and their effects on ABS investors and credit rating agencies. In contrast, I examine BHC-level transparency and its effect on BHCs' lending decisions.

Xie (2016), Dou (2017), and Dou et al. (2018) examine the effect of specific accounting policies on bank operating decision. Xie (2016) finds no evidence that fair value accounting has procyclical effects on banks' supply of credit to residential borrowers. Dou (2017) and

\footnotetext{
${ }^{20}$ Reg $\mathrm{AB}$ does not fall in any of the test periods around the pronouncements, and Reg AB II was not in effect during my sample period.
} 
Dou et al. (2018) show that consolidation of VIEs per FAS 166 \& 167 leads to lower supply of credit to residential mortgage borrowers and small business, respectively. My thesis differs from these studies because I examine financial reporting transparency across several accounting standard changes as opposed to a single such event, and because I examine the riskiness (or quality) of bank lending decisions instead of the quantity of credit supply (e.g., mortgage approval rate). While the quantity of credit supply is an important lending decision, it does not completely capture banks' risk-taking in their lending decision. For instance, an increase in the proportion of applications for high-quality mortgages can lead to higher approval rates, without necessarily increasing risk.

Bushman \& Williams (2012) and Bushman \& Williams (2015) examine the relation between the transparency of loan loss provisioning and bank risk. Bushman \& Williams (2012) use a sample of banks from 27 countries to examine whether the transparency of loan loss provisioning affects external monitoring of bank risk-taking. They find that forwardlooking discretionary provisioning designed to smooth earnings (smoothing) dampens external discipline of bank risk-taking and that forward-looking discretionary provisioning reflecting timely recognition of expected loan losses (forward- $N P L$ ) enhances external discipline of bank risk-taking. ${ }^{21}$ Bushman \& Williams (2015) examine a sample of U.S. banks over the 1993-2009 period and find that greater delay in loan loss recognition $(D E L R)$ is associated with greater stock market illiquidity risk and stock market down side risk. ${ }^{22}$ My thesis differs from these studies because I focus on bank risk-taking in a specific operating activity, namely residential mortgage lending decisions, as opposed to bank-level risk, which allows me to better identify the effect of transparency. Bank-level risk measures used in prior literature are not limited to risk-taking in operating activities, as they capture only the aggregate effect of all types risk the bank takes, including leverage.

${ }^{21}$ They estimate smoothing as $\gamma_{1}$ and forward-NPL as $\gamma_{2}$ from the following regression.

$$
\begin{aligned}
L L P_{i t j}=\gamma_{0}+\gamma_{1} \text { Ebllp }_{i t j}+\gamma_{2} \Delta N L P_{i t+1 j}+ & \gamma_{3} \Delta N L P_{i t j}+\gamma_{4} \Delta N L P_{i t-1 j}+\gamma_{5} \Delta N L P_{i t-2 j}+ \\
& \gamma_{6} C A P_{i t-1 j}+\gamma_{7} S I Z E_{i t-1 j}+\gamma_{8} \Delta G D P_{i j}+\epsilon_{i t j}
\end{aligned}
$$

where $L L P$ stands for loan loan provisions, $N P L$ stands for non-performing loans, Ebllp stands for earnings before loan loss provisions and taxes, $C A P$ is equity capital to total assets, and $S I Z E$ is the the natural logarithm of total assets.

${ }^{22}$ Bushman \& Williams (2015) use two measures of down-side risk, namely the value-at-risk and conditional value-at-risk of stock returns 


\subsubsection{Securitization and Lending Decisions}

This thesis is also related to prior studies that examine the effect of securitization on bank lending decisions (e.g., Mian \& Sufi 2009, Keys et al. 2010, Agarwal, Chang \& Yavas 2012, Jiang, Nelson \& Vytlacil 2014b). This stream of literature documents that securitization leads to banks reducing their screening and monitoring of borrowers, which results in greater bank risk-taking. The literature identifies risk transfer through securitization as the primary mechanism for this effect. I extend this literature by examining the effect of transparency on risk-taking. By comparing securitizing banks' lending decisions before and after a transparency shock, I can disentangle the effect of the securitization activity from the effect of transparency.

\subsection{Hypotheses Development}

Securitization can affect bank lending decisions through three non-mutually exclusive channels. First, as discussed in section 2.2.1.2, securitization can enable banks to transfer the risk of the underlying loans they originate to ABS investors. Regardless of transparency, true risk transfer leads to lower borrower screening and monitoring incentives because it reduces banks' exposure to the loans they originate, assuming reputation alone is not sufficient to motivate banks to screen and monitor borrowers.

Second, securitizations, when treated as sales, enable banks to record gains upon securitization in lieu of periodic income over the life of the securitized assets. Securitization gains immediately increase GAAP earnings and Tier 1 capital throughout my sample period, except for large and internationally active banks that were required to exclude certain types of securitization gains from their Tier 1 capital beginning in 2008. Securitizations can also enable banks to reduce their risk-weighted asset base because off-balance-sheet securitized assets often receive lower risk-weights. All else equal, lowering risk-weighted assets decreases the amount of capital required to meet the minimum regulatory capital and leverage ratios. Karaoglu (2005), Dechow \& Shakespeare (2009), and Dechow et al. (2010) provide evidence of earnings and regulatory capital management through securitization income. Acharya et al. (2013) document that banks used ABCP conduits to lower their risk-weighted asset base. These accounting and regulatory advantages can change banks' focus from quality to quantity of loan origination to increase securitization volume, if banks and their stakeholders believe that securitization transfers risk to investors (Acharya \& Ryan 2016).

The magnitude of securitization gain, the difference between the consideration received 
and the carrying amount of the sold components, is in principle a function of the risk transferred through securitizations. Higher fair valuation of the retained components, ceteris paribus, leads to higher securitization gain. The bank allocates the carrying value of securitized loans between sold and retained components based on their proportional fair values. Given fixed proceeds for the sold components, higher fair valuation of the retained components leads to lower carrying value allocation to the sold components, and to higher securitization gain. All else equal, higher fair valuation of the retained components indicates lower retained risk. Higher valuation arises from either higher cash flow forecasts for a given discount rate or a lower discount rate for a given cash flow forecasts. Off-balancesheet securitized assets receive lower risk weights, because regulators believe that banks transfer risk through securitization. Thus, the extent of perceived risk transfer affects the extent to which securitization enables banks to manage earnings and regulatory ratios, and securitization accounting can influence stakeholders' perception of the risk transferred.

Last, Pennacchi (1988), Schipper \& Yohn (2007), Loutskina \& Strahan (2009), and Nadauld \& Sherlund (2013) show that securitization can reduce banks' cost of funding securitizable assets. The Federal Reserve's BHC Supervision Manual (2016, sec. 2128.02) states that "securitized issues often carry a higher credit rating than that which the banking organization itself could normally obtain and, consequently, may provide a cheaper form of funding". Thus, securitization can transform relatively high-risk loans with negative net present value (NPV) under traditional funding methods into positive NPV loans. All else equal, this leads to an increase in the riskiness of banks' loan originations. The cost of raising funds through securitization depends on securitization investors' risk preference and the extent of risk transferred to these investors. Thus, for a given level of investor risk preference, banks' ability to lower funding cost through securitization depends on investors' perception of risk transfer through securitization.

\subsubsection{Transparency and Securitization-driven Bank Risk-taking}

Bank transparency can affect bank risk-taking if it enhances stakeholders' ability to monitor banks' risk exposure. The Bank for International Settlements (2012) and Plosser (2014) suggest that greater transparency increases stakeholders' ability to discipline banks by making the inherent risks more visible. ${ }^{23}$ The Federal Reserve's Commercial Bank Examination Manual (2016, sec.4030.1) states that "well informed investors, depositors, creditors, and other counterparties can provide a BO [banking organization] with strong incentives for maintaining sound risk management systems and internal controls."

\footnotetext{
${ }^{23}$ Charles I. Plosser was the President and CEO of the Federal Reserve Bank of Philadelphia from 2006-2015.
} 
Securitization can affect banks' risk-taking incentives when originating securitizable assets. For all the three channels identified above, the effect of securitization on risktaking is a function of the extent of risk transfer, and transparency affects the accuracy of observed risk transfer. In figure 2.2, transparency sheds light on the gray shaded area, allowing bank stakeholders to observe how much risk remains with the bank. The specific effect of transparency on bank risk-taking depends on managers' and stakeholders' relative risk preferences, as stakeholders only discipline risk-taking that is not aligned with their preferences. Based on potential conflicts of interest among managers and stakeholders, I explore three channels through which transparency can affect bank risk-taking.

\subsubsection{Manager-Shareholder Alignment}

Transparency can affect bank risk-taking through corporate governance when bank managers and shareholders have conflicting risk preferences, and if transparency helps to align their preferences. Following Stulz (2014), I assume that the primary goal of bank governance is to maximize shareholder value subject to regulatory constraints, and that good governance strives to align managers' risk preferences with those of shareholders. Based on these assumptions and prior evidence (Laeven \& Levine 2009), I characterize bank risktaking as a function of the relative powers of managers and shareholders within the corporate governance structure, and focus my discussion on manager-shareholder alignment. Greater transparency can affect the power balance between managers and shareholders in the governance structure in favor of shareholders, if observability of banks' activities affects shareholders' ability to align managers' actions with their preferences. (Bushman 2014, p. 387) argues that "transparency plays a fundamental corporate governance role in all industries" by supporting monitoring by directors and by enhancing protection of investor rights.

The direction of the effect of transparency on risk-taking through this channel depends on managers' and shareholders' relative risk preferences. Greater transparency leads to lower risk-taking if shareholders prefer less risk than managers do, and to higher risktaking if shareholders prefer more risk than do managers. Prior research provides evidence that the average bank shareholder prefers more risk than do managers. Saunders, Strock \& Travlos (1990) and Laeven \& Levine (2009) show that shareholder-controlled banks, as measured by managerial ownership or ownership concentration, take more risk than manager-controlled banks. Fahlenbrach \& Stulz (2011) show that banks with better manager-shareholder alignment, as measured by managerial ownership and CEOs' equity portfolio sensitivity to stock price changes, performed worse during the financial crisis than banks with poor manager-shareholder alignment, suggesting that banks with better align- 
ment took more risk prior to the crisis. John, Litov \& Yeung (2008) examine the effect of corporate governance, as measured by investor protection, on corporate risk-taking using an international sample of non-financial firms, and find that the quality of investor protection is positively associated with corporate risk-taking.

The literature identifies several reasons for bank managers to prefer lower risk than do shareholders. First, Saunders et al. (1990), Laeven \& Levine (2009), and Stulz (2014) argue that managers' wealth is less diversifiable than that of shareholders because it mostly depends on bank- or industry-specific human capital. Thus, managers exhibit more riskaverse behavior than their diversified do shareholders. Second, Saunders et al. (1990), Laeven \& Levine (2009), Bebchuk \& Spamann (2010), and Stulz (2014) argue that bank shareholders, with limited liability, have an incentive to increase bank risk because the value of their call-option-like equity claims increases with the volatility of bank assets. Moreover, Bebchuk \& Spamann (2010) argue that limited liability implies bank shareholders have no incentive to minimize the magnitude of loss given default. These moral hazard problems, which also exist in non-bank firms, are stronger for banks because deposit insurance and explicit or implicit government guarantees reduce depositors' and other bank creditors' monitoring incentives (Saunders et al. 1990, Bebchuk \& Spamann 2010), and because small and dispersed bank creditors lack resources to monitor banks (Bebchuk \& Spamann 2010). Lastly, Demsetz \& Lehn (1985), John et al. (2008), and Laeven \& Levine (2009) suggest that risk-taking is negatively related with managers' expected private benefits of control. John et al. (2008) argue that private benefits that arise from diverting cash and other corporate resources for personal benefit, prior to settling the cash flow claims, may be easier to detect during periods of poor firm performance and make managers behave like senior debtholders.

While the literature discussed above provides theory and evidence suggesting bank shareholders prefer more risk than managers, it does not rule out cases where managers may prefer more risk than their shareholders. For instance, option-based compensation, intended to align managers' incentives with those of shareholders, can lead managers to prefer higher risk than shareholders (Bebchuk \& Spamann 2010). In this case, transparency could curtail managers' risk-taking. However, even in this case, Bebchuk \& Spamann (2010) argue that it is unlikely that risk-taking decreases to the "social optimal" level because shareholders generally prefer more risk than is socially optimal.

\subsubsection{Market Discipline}

Market discipline refers to the use of available information by market participants to monitor and discipline banks' risk-taking behavior (Bushman \& Williams 2012, 2015). Prior 
literature shows that market discipline provides banks with ex ante incentives to avoid excessive risk-taking and that the effectiveness of market discipline relies on transparency. Goldberg \& Hudgins (2002) and Nier \& Baumann (2006) show that uninsured creditors shy away from failing banks, which forces banks to raise funds in more expensive equity markets. Bushman \& Williams $(2012,2015)$ argue that investors will demand higher expected returns from banks with excessive risk. Plosser (2014) argues that transparency enhances the availability of useful information that allows markets to better price banks' inherent risks. I study how transparency, by allowing stakeholders to observe the risky activity, affects bank risk-taking.

Transparency can also assist market discipline by increasing the likelihood and extent of regulatory actions. Bushman \& Williams (2012, 2015) argue that non-regulator outsiders' ability to observe bank risk-taking can affect regulator's willingness and ability to withhold regulatory actions on risky and poorly performing banks. Gallemore (2013) shows that bank opacity, measured by delays in loan loss provisioning, enables bank regulators to forbear on systemically important banks to prevent contagion without attracting nonregulator outsiders' attention.

\subsubsection{Regulatory Oversight}

Bank regulators and supervisors oversee banks' activities to ensure the safety and soundness of individual banks and the banking system. ${ }^{24}$ Greater transparency can reduce bank risktaking if it improves bank regulators' and supervisors' ability to observe the risk profile of individual banks. Bank regulators develop and implement regulations, such as those requiring periodic reporting and the maintenance of regulatory capital ratios. As discussed in section 2.2.3, GAAP accounting policies influence regulatory accounting and disclosure rules. Therefore, greater transparency in banks' financial reporting can help regulators in developing and implementing bank safety and soundness regulations. For example, to the extent that GAAP securitization gains are included in Tier 1 capital and those gains do not accurately capture the economics of the transaction, transparency can affect regulators' ability to ensure banks maintain adequate regulatory ratios.

Bank supervisors evaluate the safety and soundness of individual banks by performing on-site examinations and off-site monitoring. ${ }^{25}$ Transparency can influence supervisors'

\footnotetext{
${ }^{24}$ https://www.federalreserve.gov/econresdata/bsrstaff.htm and http://www.frbsf.org/ education/teacher-resources/what-is-the-fed/supervision-regulation/\#Supervision (accessed on August 16, 2016).

${ }^{25} \mathrm{http}$ ://www.frbsf .org/education/teacher-resources/what-is-the-fed/ supervision-regulation/\#Supervision (accessed on August 16, 2016).
} 
ability to observe and evaluate banks' securitization activities. For example, the Federal Reserve's BHC Supervision Manual (2016, sec.1000.0) indicates that supervisors use SEC filings such as quarterly and annual reports in their preliminary risk assessments. The Federal Reserve's Commercial Bank Examination Manual (2016, sec.4030.2) states that supervisors are responsible for ensuring banks' activities are properly accounted for on banks' books and are correctly reported on regulatory filings. As part of this responsibility, they verify models, assumptions, and estimates used in accounting (GAAP) for retained interests in securitizations. The supervision manuals advise bank examiners to pay attention to the fact that current regulatory rules may not fully incorporate the economic substance of banks' securitization-related risk exposure, and encourage the supervisors to examine closely the economic substance of securitizations (Commercial Bank Examination Manual, 2016, sec.4030.1). These examples demonstrate that transparency can improve regulators' and supervisors' ability to ensure the safety and soundness of individual banks and the banking system. ${ }^{26}$

\subsubsection{Hypotheses}

Section 2.4.1 argues that transparency can reduce bank risk-taking by: (i) allowing uninsured creditors to discern banks' risk exposure and discipline their suboptimal risk-taking, (ii) improving bank regulators' and supervisors' information set, and (iii) decreasing the likelihood and extent of regulatory forbearance. On the other hand, if shareholders prefer more risk than managers and other non-shareholder outsiders do, transparency can increase bank risk-taking by increasing existing shareholders' ability to observe and align bank risk-taking with their risk preference. However, if managers prefer more risk than shareholders do, transparency reduces risk-taking by allowing shareholder to mitigate the mis-alignment. Since the regulatory oversight and the market discipline channels predict a negative relation between transparency, and the manager-shareholder alignment channel could go either way, I expect that the average effect of transparency is to reduce bank risk-taking. Transparency may fail to affect bank risk-taking in their mortgage lending if securitizing banks can truly transfer the underlying risk to ABS investors, which can happen for two reasons. First, ABS investors with high risk-appetite (e.g., hedge funds) may knowingly take the underlying risk and encourage greater risk-taking in the origination of mortgages. Second, transparency, as defined in this thesis, may not sufficiently reveal the riskiness of the securitized mortgages. In this case, banks can transfer the risk to unsuspecting ABS investors. Disclosure of the securitization structure and loan- and

\footnotetext{
${ }^{26}$ Similar to Plosser's (2014) argument for market signals and supervisory assessments, my argument is not that GAAP reports are superior to regulatory reports, but that they complement each other.
} 
borrower specific information (e.g., current delinquency status) for the securitized loans, such as the disclosure requirements for sec-registered ABS per Reg AB and Reg AB II and the ECB reporting requirement that is examined in Ertan et al. (2017), can address the second issue. Based on this discussion, I hypothesize that securitizing banks' risk-taking varies inversely with transparency.

Hypothesis 1 (H1). As transparency increases, securitizing banks decrease their risktaking in mortgage lending more than non-securitizing banks.

As discussed in section 2.4.1, manager-shareholder alignment is more likely to moderate the relation between transparency and bank risk-taking incentives when managers and shareholders have conflicting risk preferences. Transparency enhances shareholders' ability to align managers' risk-taking incentives with their preferences by increasing the observability of bank risk-taking. Transparency would not play a significant role for banks with strong manager-shareholder alignment because managers' and shareholders' risk-taking incentives are already aligned. However, transparency can significantly affect banks with weak alignment by tipping the power balance in favor of shareholders. Based on theory and past empirical evidence discussed in section 2.4.1.1, I assume that shareholders prefer higher risk than managers do.

Hypothesis 2 (H2). As transparency increases, securitizing banks with low managershareholder alignment increase their risk-taking more than securitizing banks with high manager-shareholder alignment.

Section 2.4.1.3 argues that transparency affects bank risk-taking through the regulatory channel if it affects regulators' ability to observe risk-taking behavior, or if it reduces regulators' flexibility to refrain from taking regulatory action on banks with high risk exposure. In both cases, the effect of transparency on risk-taking should be greater for banks that are more likely to face regulatory action. However, transparency may not reduce risk through this channel if regulators believe transparency improves the efficiency of ABS markets, and the underlying risk is revealed and priced properly, which leads to better risk-sharing among banks and investors. In this case, regulators may be comfortable with greater risk-taking because it might not increase systemic risk.

Hypothesis 3 (H3). As transparency increases, securitizing banks with low regulatory ratios decrease their risk-taking more than securitizing banks with high regulatory ratios.

Section 2.4.1.2 argues that transparency affects bank risk-taking through the market discipline channel if it enables investors and creditors to observe bank risk-taking and 
penalize banks that take greater risk. Since such market discipline works through the cost of raising additional funds or capital, its effect is more significant for banks that rely on uninsured deposits or corporate bonds to a greater extent, or that need to raise additional capital from equity markets.

Hypothesis 4 (H4). As transparency increases, securitizing banks that face stronger market discipline decrease their risk-taking more than securitizing banks that face weaker market discipline. 


\section{Chapter 3}

\section{Research Design and Sample}

\subsection{Introduction}

This chapter discusses the research design and sample. Section 3.2 presents the differencein-differences design used to test the effect of transparency around the four securitization accounting pronouncement events. Section 3.3 introduces the primary data sources, including the Home Mortgage Disclosure Act (HMDA) database that contains loan-level residential mortgage information and the FR Y-9C database that contains BHC-level financial information. Section 3.4 presents the sampling procedure.

\subsection{Difference-in-Differences Design}

I use a difference-in-differences $(D i D)$ research design, comparing securitizing BHCs with a matched sample of non-securitizing BHCs, pre- and post- the adoption of each of the five securitization accounting pronouncements discussed in section 2.2.3. A key feature of this design is that it exploits five accounting pronouncements that form four distinct transparency treatments, of which one decreases transparency and the others increase transparency. ${ }^{1}$ This feature increases confidence in transparency as the causal influence.

I use three alternative test windows for each pronouncement. The first test window spans two years where the post-period is the first calendar year for which the pronouncement is effective, and the pre-period is the calendar year prior to post-period. For example,

\footnotetext{
${ }^{1}$ FAS 166 and FAS 167 provide only one treatment because they have the same effective date.
} 
for FAS 125 the pre-period is the calendar year 1996 and the post-period is the calendar year 1997. FAS 125 was issued in June 1996 and was effective for securitizations occurring after December 31, 1996. This narrow test window mitigates the possibility that changes in lending behavior are driven by factors other than the effective change in transparency. In the second test window, I use the calendar year prior to the adoption year as the preperiod because BHCs may change their lending behavior in response to the adoption of a pronouncement when it is issued and before the effective date. Continuing the above example for FAS 125, the post-period remains the calendar year 1997 while the pre-period is now the calendar year 1995. The third test window spans four years with the first two calendar years for which the pronouncement is effective forming the post-period (e.g., 1997 \& 1998 for FAS 125) and the two calendar years immediately preceding the post period forming the pre-period (e.g., 1995 \& 1996 for FAS 125).

Section 2.2.3 presents the case for why FAS 125 decreases transparency, and why the other pronouncements increase transparency. This section provides several reasons to support my claim that the adoptions of the first three of the pronouncements are plausibly exogenous to my research question. First, suboptimal risk-taking in primary mortgage markets was not a major concern in the pre-crisis period. In the pre-crisis period, many commentators (e.g., Laderman 2001, Gramlich 2004) focused on the benefits of securitization in promoting competition in the sub-prime markets and in increasing the flow of funds to borrowers in this market. Second, FASB provides no indication in its discussions that it issued these pronouncements because previous standards failed to reveal bank risktaking, which it does for FAS 166. This is in line with FASB's intent to write standards that neutrally reflect underlying economics, without attempting to directly influence the economic activity. Last, even FIN 46 (R), which was issued in response to Enron's highprofile accounting scandal, did not directly target bank lending decisions. However, there is likely endogeneity around the adoption of FAS $166 \& 167$. The role of sub-prime mortgage securitizations in the financial crisis plausibly motivated these pronouncements.

While the first three pronouncements were not issued as a direct response to bank risk-taking, it is possible that other economic events that preceded or occurred contemporaneously with these pronouncements can affect bank risk-taking. For example, FAS 125 was issued during the early stages of the securitization market, when it was growing rapidly. FAS 140 was preceded by the 1998 Russian debt and hedge fund crisis. Many subprime mortgage lenders either failed or were acquired by larger banks, and subprime mortgage securitization volume declined following the 1998 Russian debt/hedge fund crisis (Chomsisengphet \& Pennington-Cross 2006). As discussed in the previous paragraph, FIN 46(R) was issued as a response to the Enron scandal. It is possible that these events affect bank risk-taking, and do so more than transparency affects bank risk-taking, making the 
effect of transparency a second order effect and difficult to disentangle from the effect of these economic events. However, to the extent that these events affect both securitizing and non-securitizing banks, my DiD design with non-securitizing banks as a control group should isolate securitization-related transparency as the treatment.

I use non-securitizing BHCs, which are not affected by securitization accounting pronouncements, as a control group to account for changes in bank risk-taking driven by other factors, such as changes in economic and market conditions, government policy, industry practice, and regulatory policy in the same period. To alleviate selection problems that arise if the factors that cause BHCs to securitize also drive their differential risk-taking relative to non-securitizing BHCs, I form a propensity score-matched control group. ${ }^{2}$ I form a distinct test sample of matched treatment-control pairs for each transparency event.

I employ the following procedure to create a matched pair of treatment and control BHCs. I first estimate a logistic propensity score model of the probability of securitization, conditional on characteristics observable in the year immediately prior to the treatment, separately for private and publicly traded BHCs. ${ }^{3}$ I then match each public (private) securitizing $\mathrm{BHC}$ to the public (private) non-securitizing $\mathrm{BHC}$ with the closest propensity score. I perform the matching with replacement and imposing a $10 \%$ caliper. While it is common in the accounting literature (e.g., Casu, Clare, Sarkisyan \& Thomas 2013, Lawrence, Minutti-Meza \& Zhang 2011, Oz 2016) to use a caliper width $<5 \%$ to reduce the likelihood of matched pairs with drastically different propensity scores, I choose a relatively wider caliper to reduce the number of observations lost in the matching process. ${ }^{4}$ King \& Nielsen (2016) show that pruning more observations can result in greater biases and model dependence.

The primary dependent variable is bank risk-taking in mortgage lending as reflected by the risk profiles of mortgages originated or purchased by each BHC. All else equal, more aggressive risk-taking corresponds to looser lending standards and origination or purchase of riskier mortgages. Chapter 4 discusses validation of the specific measures of risk-taking used in this thesis.

\footnotetext{
${ }^{2}$ To reduce the likelihood that my results are driven by this particular matching method, I test the robustness of my findings to using other matching techniques in section 5.5.

${ }^{3}$ Appendix $\mathrm{C}$ discusses the propensity score matching in greater detail, including a description of the ex ante observable covariates, which I selected based on prior literature (e.g., Minton, Sanders, Strahan et al. 2004, Uzun \& Webb 2007, Affinito \& Tagliaferri 2010, Cardone-Riportella, Samaniego-Medina \& Trujillo-Ponce 2010) that examines determinants of securitization, and Oz (2016) who performs a similar propensity score matching of securitizing and non-securitizing BHCs around FAS 166 \& 167.

${ }^{4}$ I test the sensitivity of my results to using other caliper width. See appendix C for more details.
} 


\subsubsection{Securitization Indicator}

I define a given BHC-year as securitizing if the BHC has a stock of outstanding securitized mortgages in the three-year period ending in the current year. I use a three-year period to identify securitizing banks because some BHCs securitize sporadically. I define mortgages as securitized if they are: (i) "sold with recourse" for the 1993-2000 period, and (ii) "sold and securitized" or "sold with recourse but not securitized" for the 2001-2015 period. ${ }^{5}$ While mortgages "sold with recourse but not securitized" are not directly securitized by the reporting BHC, they likely represent participations in securitizations by other entities such as Fannie Mae, Freddie Mac, and unaffiliated private securitization conduits. Moreover, these types of financial asset transfers are within the scopes of all the accounting pronouncements explored in this study.

\subsection{Data Sources}

\subsubsection{The Home Mortgage Disclosure Act Database}

I obtain data about individual mortgage applications from the Home Mortgage Disclosure Act (HMDA) database, which covers most mortgage lending institutions in the United States, beginning 1993. HMDA requires covered institutions to file loan-level information about the loan, borrower, and property characteristics annually for all new residential mortgage loans and applications (hereafter, loans). Figure 3.1 shows HMDA coverage over the 1990-2012 period. The number of institutions varies between 7,652 in 2001 and 9,880 in 1994. The total number of loans and applications varies from 11.2 million in 1995 to 41.6 million in 2003. I supplement the mortgage-level information from the HMDA database with census, demographic, income, house price, mortgage term, and other economic data from other sources, as discussed in section 3.3.3. This combined dataset allows me to construct mortgage lending risk measures, discussed in chapter 4, at the BHC level.

\footnotetext{
${ }^{5}$ The information about securitized mortgages is from the FR Y-9C data base discussed in detail in section 3.3.2. That section also explains why it is necessary to define securitized assets differently before and after 2000.
} 


\section{Figure 3.1: HMDA Coverage}

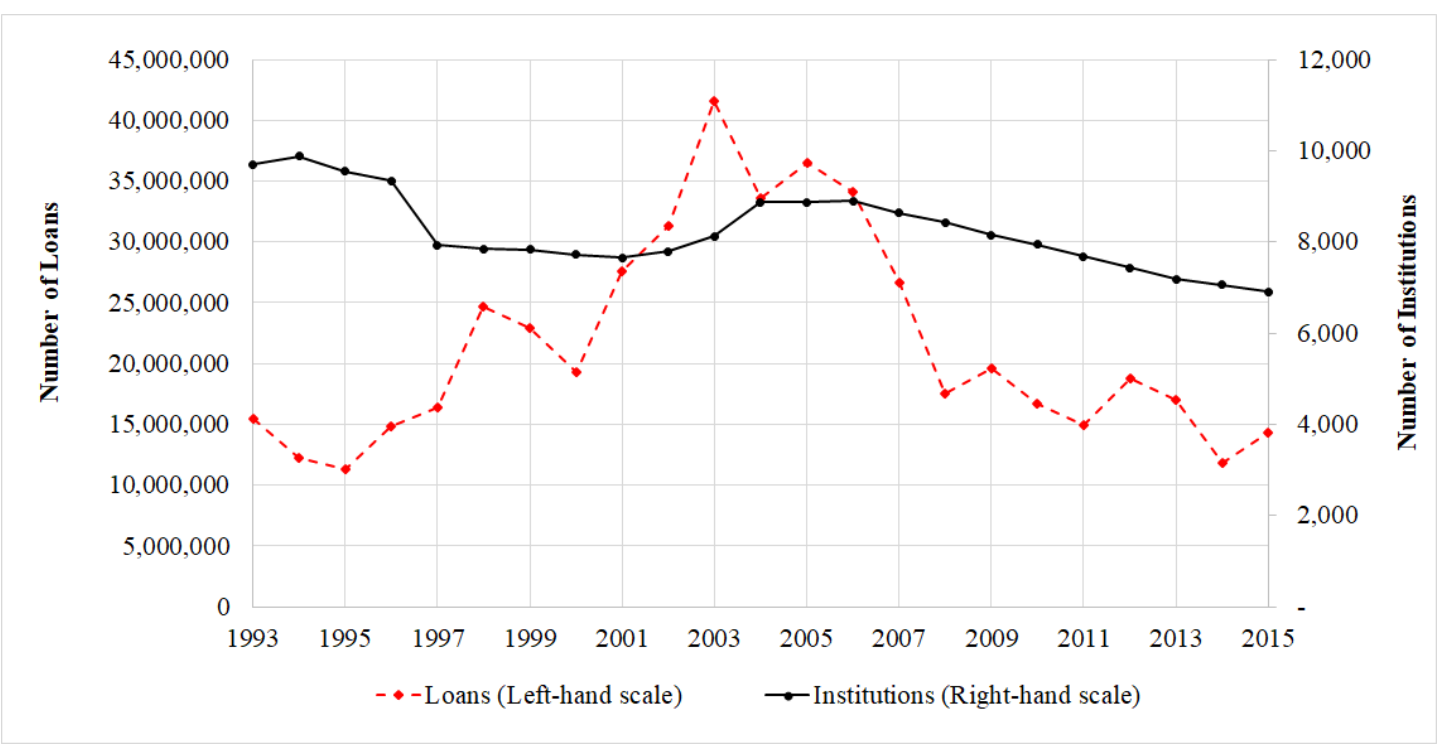

This graph presents the HMDA coverage for the 1993-2015 period. The dashed red line represents the total number of mortgage loan applications in each year. The solid dark line represents the number of lending institutions in the HMDA database in each year. Both the number of institutions and the number of loans are for the entire HMDA sample, before I applied any of the filters in the sampling procedure.

\subsubsection{FR Y-9C Database}

I obtain all financial data for BHCs from the FR Y-9C dataset, available from the Federal Reserve Bank of Chicago. The Federal Reserve uses form FR Y-9C to collect detailed financial information on a quarterly basis from all large BHCs and all multibank holding companies that engage in non-banking activities or that have outstanding public debt. Form FR Y-9C contains a consolidated balance sheet and income statement along with additional disaggregated disclosure about on- and off-balance-sheet activities including securitization. These data allow me to identify securitizing BHCs, to create loan portfolio performance measures such as delinquencies and net charge-offs, and to create the covariates for the propensity score model.

Prior to 2001Q2, the Federal Reserve required BHCs to disclose their outstanding assets sold with recourse, disaggregated by three asset classes: residential mortgages, small business obligations, and other assets. Assets "sold with recourse" include assets securitized by the reporting entity and assets sold with recourse to third parties including securitization 
conduits sponsored by other entities. Beginning 2001Q2, the Federal Reserve requires more detailed information about securitized assets. The new disclosure requirement splits assets from the "sold with recourse" category into "assets sold and securitized" and "assets sold with recourse but not securitized" categories. For both categories, BHCs disclose detailed information about the outstanding transferred assets, disaggregated by seven asset classes. For each category and asset class, they disclose the outstanding amounts of assets sold or securitized and the maximum contractual credit exposure, unused liquidity commitments, past due amount, charge-offs and recoveries in relations to these activities.

\subsubsection{Other Data Sources}

The Federal Financial Institutions Examination Council (FFIEC) provides the HMDA/Community Reinvestment Act (CRA) census data at the Metropolitan Statistical Area (MSA) and Census tract levels for use with the HMDA and CRA databases. This census database contains select demographic, income, population, and housing data. While most of the data are from the preceding decennial census, the FFIEC updates the HMDA/CRA census database annually to reflect estimated changes to MSA boundaries, income estimates developed by the Department of Housing and Urban Development (HUD), and to include CRA distressed/underserved tracts as announced by the federal bank regulatory agencies. The HMDA/CRA census and BEA (described below) databases contain multiple local area income characteristics. The HMDA/CRA census database contains median household and family income at the census tract level and median family income at the MSA level. ${ }^{6}$

As an alternative to the HMDA/CRA census database, which can become less accurate overtime, I obtain additional local economic data from the Bureau of Economic Analysis (BEA) annual regional GDP and personal income database and local area unemployment data from the Bureau of Labor Statistics (BLS). The BEA database contains information about the per capita personal income, the proportion of the population employed, and the average earnings per job at the county level. Furthermore, the database provides per capita personal income disaggregated by the source of income such as wages, dividends, interest, and government benefit. Combining the BEA and BLS databases with HMDA mortgage data allows me to identify whether a given mortgage is in high-risk county or whether the borrower income is lower than the local area average personal income. I define a high-risk

\footnotetext{
${ }^{6}$ The U.S. Census Bureau defines a household as a group of people occupying a single housing unit and a family as a household of individuals related by birth, marriage, or adoption. See https://www.census.gov/programs-surveys/cps/technical-documentation/ subject-definitions.html (accessed on May 4, 2017).
} 
county as one with low per capita personal income, high unemployment rate, or high per capita government assistance.

I obtain house price indexes from the Federal Housing Finance Agency (FHFA) House Price Index (HPI) database. ${ }^{7}$ The HPI database provides MSA-level house price indexes that reflect average price changes based on repeat sales or refinancings on the same properties. The house price indexes allow me to estimate the local area median house value, which is useful in estimating the loan-to-value ratio for a given mortgage, one of the mortgage lending risk measures discussed in chapter 4.

For the publicly traded BHCs, I obtain stock market data from the Center for Research in Security Prices (CRSP) and analyst following data from Institutional Brokers' Estimate System (IBES). The CRSP and IBES variables are used in the propensity score matching model. I use the linking table from the Federal Reserve Bank of New York to match the Federal Reserve identification number (RSSD ID) used in the FR Y-9C database to CRSP identifier (PERMCO). ${ }^{8}$

\subsection{Sample Selection Procedure}

Table 3.1 presents a summary of the sampling procedure. I start with 23,123 financial institutions with over 499 million residential mortgage loans in the HMDA database and 4,021 large BHCs with 33,141 BHC-year observations in the FR Y-9C database, both over the period 1993-2015. I focus on large BHCs because regulators require them to file detailed financial information in form FR Y-9C (see section 3.3.2), which allow me to construct variables relevant to my tests. In comparison, the regulatory filing requirement for small BHCs are less detailed. ${ }^{9}$ I apply the following screens to obtain the final sample.

First, I restrict the mortgage sample to single-family (1-4 family) home purchase loans to have a more economically homogeneous sample of mortgages. Mortgages secured by multifamily properties ( 5 or more families) are economically different from those secured by single-family properties. Multifamily properties ( 5 or more families) such as apartment buildings are more likely to be investment properties than single-family properties. Borrowers of multifamily mortgages are more likely to be companies than those of single-family

\footnotetext{
${ }^{7}$ Available at https://www.fhfa.gov/DataTools/Downloads (accessed on March 29, 2017).

8 https://www.newyorkfed.org/research/banking_research/datasets.html (accessed on November 27,2015.)

${ }^{9}$ Large BHCs are those with total assets of $\$ 150$ million or more for the period prior to $2006, \$ 500$ million or more for the period 2006-2014, and $\$ 1$ billion or more for the period after 2014.
} 
mortgages. Unlike single-family mortgages, HMDA does not require the borrower income to be reported for multi-family mortgages. Home purchase loans are also economically different from home improvement loans, mortgage refinancing, and home equity loans. This filter results in approximately 194 million observations for 22,631 distinct institutions. The large drop in the number of loans is due to the exclusion of refinancing loans, which make up $53 \%$ of the mortgages in the HMDA database.

Second, I restrict the mortgage sample to conventional home purchase loans because BHCs have minimal risk exposure to non-conventional mortgages, which are insured or guaranteed by U.S. government agencies such as the FHA, VA, FSA, and RHS. ${ }^{10}$ The resulting sample contains 151 million observations for 22,514 distinct institutions.

Third, I restrict the mortgage sample to observations with valid location ID, valid loan amount, and non-missing values for variables used to construct the mortgage lending risk measures discussed in chapter 4, resulting in 118 million observations for 22,095 distinct institutions.

Fourth, I restrict the BHC sample to only top-tier BHCs, resulting in 30,506 BHC-year observations for 3,725 distinct BHCs. I identify top-tier BHCs using the Regulatory High Holder ID in the FR Y-9C dataset. This variable contains the RSSD ID of the highest holding company in a tiered BHC structure, and is set to zero if the BHC is the toptier BHC. Analysis at the top-tier BHC-level is appropriate because consolidation at this level ensures proper matching of all related securitization and mortgage-banking activities, which can be performed by different subsidiaries, and avoids double-counting.

Fifth, I further restrict the BHC sample to observations with non-missing loan performance measures, which are used to validate the mortgage lending risk measures in chapter 4. This screen results in 30,502 BHC-year observations for 3,723 unique BHCs.

Sixth, I combine the two samples to form a sample of 24,999 BHC-year observations for 3,106 unique top-tier BHCs with 52 million mortgage loans or applications in the HMDA dataset, filed by 7,128 distinct branches or subsidiaries. HMDA filings are at the subsidiary or branch level, and they do not identify the top-tier BHC. I describe the procedure for identifying branches and subsidiaries of the BHCs, and the procedure for matching the FR Y-9C and HMDA databases in Appendix B. This filter results in a large drop in the number of loans/applications, and in the number institutions with HMDA filings. I believe that this drop is primarily driven by small BHCs and independent (i.e., non-BHC) mortgage lenders, both of which are not included in my sample. As I explained at the beginning of

\footnotetext{
${ }^{10} \mathrm{FHA}=$ Federal Housing Association, VA = Veterans Association, FSA = Farm Service Agency, and RHS $=$ Rural Housing Service.
} 
this section, small BHCs are not included in my sample because they are not required to file FR Y-9C. As a result, the loans/application in HMDA associated with their branches and subsidiaries are dropped at this stage in the sampling process. Similarly, independent mortgage lenders such as mortgage brokers and their loans/applications are not included in my sample because they are not required to file FR Y-9C.

While I exclude small BHCs and independent mortgage lenders, I acknowledge that this filter biases my sample to large financial institutions. I do not assume that risktaking by small BHCs and independent institutions is irrelevant. Rather, I exclude these institutions because of limited data availability, and because I focus on loan origination and securitization within the same organization. I expect the effect of the bias to be limited because most active securitizers tend to be large BHCs.

Finally, I exclude the top five securitizing BHCs (Bank of America, Citigroup, Countrywide, JP Morgan, and Wells Fargo) because they are unique in terms of their size, complexity, and extent of securitization activity. I dedicate chapter 6 to detailed analyses of these banks because of their apparent economic significance. The final sample contains 24,902 BHC-year observations for 3,100 unique top-tier BHCs with 28,463,187 conventional residential mortgage loans or application for home purchase. As evidenced by the change in the number of loans, the top six BHCs are responsible for $45 \%$ of the loans.

Table 3.2 presents the composition of the final sample. The sample contains 1,064 (8,751 BHC-years) publicly traded BHCs and 2,242 (16,151 BHC-years) privately held BHCs, of which 393 (2,495 BHC-years) and 446 (2,493 BHC-years) are securitizing, respectively. About $25 \%$ of the private BHCs are registered with the SEC. Private BHCs can be registered with the SEC, for example, if they have outstanding public debt. Overall, there are 2,833 securitizing BHCs (19,914 BHC-years) and 806 non-securitizing BHCs (4,988 BHC-years). 
Table 3.1: Summary of Sampling Procedure

\begin{tabular}{|c|c|c|c|c|}
\hline \multirow[b]{2}{*}{ Selection Criteria } & \multicolumn{4}{|c|}{ Number of } \\
\hline & $\begin{array}{l}\text { Bank Holding } \\
\text { Companies } \\
(\mathrm{BHCs})^{*}\end{array}$ & $\begin{array}{c}\text { BHC-year } \\
\text { Observations }\end{array}$ & $\begin{array}{c}\text { Loans or } \\
\text { Applications }\end{array}$ & $\begin{array}{l}\text { Institutions } \\
\text { with HMDA } \\
\text { filing* }\end{array}$ \\
\hline \multicolumn{5}{|l|}{ Mortgage Sample } \\
\hline Initial HMDA sample for the period 1993-2015 & & & $499,374,046$ & 23,123 \\
\hline \multicolumn{5}{|l|}{ Restrict to: } \\
\hline Single-family home purchase mortgages & & & $193,972,086$ & 22,631 \\
\hline Conventional home purchase mortgages & & & $151,273,950$ & 22,514 \\
\hline \multicolumn{5}{|l|}{ Observations with: } \\
\hline Valid location IDs & & & $122,190,765$ & 22,384 \\
\hline Valid loan amount & & & $122,190,741$ & 22,384 \\
\hline $\begin{array}{l}\text { Non-missing value for variables used } \\
\text { to construct mortgage lending } \\
\text { risk measures }\end{array}$ & & & $118,249,671$ & 22,095 \\
\hline \multicolumn{5}{|l|}{ Bank Holding Company Sample } \\
\hline Initial BHC sample for the period 1993-2015 & 4,021 & 33,141 & & \\
\hline \multicolumn{5}{|l|}{ Restrict to: } \\
\hline Top-tier BHCs & 3,725 & 30,506 & & \\
\hline \multicolumn{5}{|l|}{ Observations with non-missing values for } \\
\hline loan portfolio performance measures & 3,723 & 30,502 & & \\
\hline \multicolumn{5}{|l|}{ Combined Sample } \\
\hline Top-tier BHCs with HMDA data & 3,106 & 24,999 & $51,622,995$ & 7,128 \\
\hline Remove the five largest securitizing BHCs & 3,100 & 24,902 & $28,463,187$ & 6,532 \\
\hline
\end{tabular}

* The number of BHCs and lending institution in HMDA in these tables are the unique number of BHCs and lenders available for at least one year during the period 1993-2015. 
Table 3.2: Sample Composition

\begin{tabular}{|c|c|c|c|c|c|c|}
\hline & (1) & $(2)$ & $(3)$ & $(4)$ & (7) & (8) \\
\hline & \multicolumn{2}{|c|}{ Public BHCs } & \multicolumn{2}{|c|}{ Private BHCs } & \multicolumn{2}{|c|}{ Total } \\
\hline & $\begin{array}{c}\text { BHC-year } \\
\text { Obs }\end{array}$ & $\begin{array}{l}\text { Unique } \\
\text { BHCs }\end{array}$ & $\begin{array}{c}\text { BHC-year } \\
\text { Obs }\end{array}$ & $\begin{array}{l}\text { Unique } \\
\text { BHCs }\end{array}$ & $\begin{array}{c}\text { BHC-year } \\
\text { Obs }\end{array}$ & $\begin{array}{l}\text { Unique } \\
\text { BHCs }\end{array}$ \\
\hline Securitizing BHCs & 2,495 & 393 & 2,493 & 446 & 4,988 & 806 \\
\hline Non-securitizing BHCs & 6,256 & 892 & 13,658 & 2113 & 19,914 & 2,833 \\
\hline Total & 8,751 & 1,064 & 16,151 & 2242 & 24,902 & 3,100 \\
\hline
\end{tabular}





\section{Chapter 4}

\section{Mortgage Lending Risk Measures}

\subsection{Introduction}

In this chapter, I propose and validate measures of bank risk-taking in residential mortgage lending in the United States (hereafter, mortgage lending risk measures, or MLRMs). To construct the measures, I first review prior research and identify individual mortgage characteristics that are associated with the underlying risk of the mortgages. ${ }^{1,2}$ Because I am interested in the original lending decisions, I require that a characteristic be observable by lenders at mortgage origination. To make my data analysis possible, I also require that it be available publicly. I then create a mortgage-level high-risk indicator based on each characteristic. I add the individual high-risk indicators to obtain a mortgagelevel composite risk score. Finally, I aggregate the mortgage-level composite scores across mortgages to the BHC level to obtain the proposed BHC-level MLRMs.

\footnotetext{
${ }^{1}$ The phrases "mortgage risk" and "mortgage lending risk" have a closely related but distinct meaning. Mortgage risk refers to the underlying risk of an individual mortgage such as default risk or prepayment risk. Mortgage lending risk refers to the riskiness of a bank's mortgage lending decisions such as increasing the approval rate for mortgages with high default risk. For a given lender, mortgage lending risk increases with more originations of riskier mortgages (i.e., mortgages with greater "mortgage risk").

${ }^{2}$ The literature examines different sample periods, geographic areas, and types of mortgages. For example, earlier studies (e.g., Morton 1975, Sandor \& Sosin 1975, Vandell \& Thibodeau 1985) use mortgages from the 1960-1980 period, whereas others (e.g., Elul, Souleles, Chomsisengphet, Glennon, Hunt et al. 2010, Demyanyk, Koijen, Van Hemert et al. 2010, Jagtiani \& Lang 2011, Chan, Gedal, Been \& Haughwout 2013) study mortgages originated in the 2000s. These studies also differ in terms of how many factors they consider and the measurement timeline of the factors relative to mortgage origination. These contextual differences could affect the generalizability of their results to the context I examine.
} 
The remainder of the chapter is organized as follows. Section 4.2 discusses the background of mortgage risk, focusing on the types of mortgage risks and their primary determinants. Section 4.3 identifies specific mortgage characteristics associated with underlying risk and constructs the proposed measures. Section 4.5 presents the validation tests. Section 4.6 concludes the chapter.

\subsection{Background}

Residential mortgage lenders face two major types of mortgage risk, namely interest rate risk and mortgage termination risk. Interest rate risk refers to the uncertainty in the fair value of lenders' mortgage portfolios due to interest rate fluctuations. ${ }^{3}$ When interest rates rise, the fair value of fixed-rate mortgages declines, which in turn results in loss from the opportunity cost of having funds tied up in low interest mortgages. When interest rates decline, borrowers can reduce their periodic mortgage payments by refinancing their mortgages. I do not explore interest rate risk in this thesis because it is a macroeconomic factor that does not vary across banks or borrowers. Moreover, banks' exposure to interest rate risk is not limited to residential mortgages, as banks engage in overall interest rate risk management, making it impossible to isolate their exposure to interest rate risk due to residential mortgages alone.

Mortgage termination risk arises from the uncertainty that borrowers may prematurely terminate mortgages through default or prepayment. ${ }^{4}$ In mortgage defaults, lenders lose all or part of principal and future interest on foreclosed mortgages, and incur the additional costs associated with the foreclosure process. Mortgage termination via prepayment, a full payment of the principal before the term ends, reduces lenders' mortgage portfolio yield because of the loss of future interest. Prior literature (e.g., Jackson \& Kaserman 1980, Campbell \& Dietrich 1983, Deng, Quigley \& Order 2000, Elul et al. 2010) documents that a combination of factors such as negative home equity, borrowers' inability to make payments (illiquidity), declining interest rates, and borrower mobility determine whether and how borrowers terminate their mortgages.

Prior research (e.g., Jackson \& Kaserman 1980, Campbell \& Dietrich 1983, Vandell \& Thibodeau 1985, Elul et al. 2010, Campbell \& Cocco 2015) examines the competing effects

\footnotetext{
${ }^{3}$ Interest rate fluctuations can also affect the demand for mortgages. For instance, high periodic mortgage payments due to high interest rates can lead to lower demand for mortgages. Conversely, low periodic payments when interest rates are low can fuel mortgage demand. This study focuses on banks' risk-taking in mortgage lending, given aggregate mortgage demand.

${ }^{4}$ LaCour-Little (2008) provides a detailed review of the literature examining mortgage termination risk.
} 
of negative home equity and borrower illiquidity on default. The illiquidity hypothesis predicts that borrowers default on mortgages when they can no longer make scheduled payments. In contrast, the negative equity hypothesis predicts that borrowers default only if they have negative home equity. Under the latter hypothesis, illiquid borrowers with positive home equity would not default on their mortgages. They would rather terminate their mortgage by selling the house and prepaying the remaining balance. Borrowers with negative equity would default regardless of their illiquidity.

While earlier studies (e.g., Jackson \& Kaserman 1980, Campbell \& Dietrich 1983) find evidence consistent only with the negative equity hypothesis, recent studies provide empirical (e.g., Elul et al. 2010) and theoretical (e.g., Campbell \& Cocco 2015) evidence that supports both the equity and illiquidity hypotheses. One explanation for the mixed findings is that these studies cover different types of mortgages from different time periods and geographic areas, with different economic and institutional conditions. Jackson \& Kaserman (1980) use a 5\% random sample of FHA-insured loans originated in 1969, Campbell \& Dietrich (1983) use a sample of mortgages insured by the Mortgage Guarantee Insurance Corporation between 1960 and 1980, and Elul et al. (2010) use a sample of fixed-rate, owner-occupied, single-family mortgages originated in 2005 and 2006. Another explanation is that the earlier studies do not control for many of the other factors that influence mortgage default decisions. For example, Jackson \& Kaserman's (1980) regression model contains only three independent variables whereas Elul et al.'s (2010) regression model contains over 30 independent variables. Both home equity and borrower illiquidity are relevant in my setting because (i) Elul et al.'s (2010) empirical findings are based on relatively similar sample of mortgages as this thesis, and (ii) predictions from Campbell \& Cocco's (2015) equilibrium model are consistent with these empirical findings.

Deng et al. (2000) examine default and prepayment decisions simultaneously and provide theoretical and empirical evidence that mortgage terminations due to negative home equity tend to be defaults, while terminations due to declining interest rates tend to be prepayments. As discussed above, I do not explore prepayment risk due to declining interest rates because interest rate conditions do not vary in my cross-sectional comparisons. Besides declining interest rates, prior literature (e.g., Mattey \& Wallace 2001) documents that borrower mobility can also lead to mortgage prepayments. A borrower moving to a new home may sell the previous home and terminate the mortgage. Changes in household income or size can influence mobility within an area (e.g. city). Career factors and local economic conditions can affect borrower mobility outside the local area. For example, borrowers may move away from high unemployment areas to find better job opportunities.

In summary, mortgage lenders are exposed to risks that arise from fluctuations in borrower income, home equity, market interest rates, and borrower mobility. I focus on 
risk factors that vary across individual mortgages or across individual banks at a point in time to develop the proposed MLRMs. I exclude macroeconomic factors such as market interest rates from the development of the proposed measures because they do not reflect cross-sectional differences.

\subsection{Constructing Mortgage Lending Risk Measures}

This section develops the proposed BHC-level residential mortgage lending risk measures using the following procedure. First, I review prior literature on the determinants of mortgage termination and expected loss given termination to identify factors associated with the underlying risk in individual mortgages. I categorize these factors into four groups as borrower, loan, property, and local area characteristics, though some of them (e.g. loan-to-value or mortgage payment-to-income) combine categories. ${ }^{5}$ I focus on the characteristics that are observable by lenders at origination and that are available in the public databases. I define each characteristic to be increasing in risk. I measure dollarvalued characteristics relative to MSA medians to ensure comparability of mortgages across areas with varying socio-economic conditions. For example, the amount of borrower income required to afford a property can be significantly different across geographic areas due to significant differences in house prices. ${ }^{6}$ Second, for each characteristic, I create a high-risk indicator variable that equals one for mortgages that are riskier than the median mortgage at the MSA-year level. For binary characteristics (e.g., existence of a coborrower), the high-risk indicator variable equals one when the mortgage exhibits the riskier of the two possible values of that characteristic (e.g., mortgages with no coborrower). I use $I$. at the beginning of variable names to indicate that the variable is an indicator variable based on the underlying characteristics. For example, I.NOCOBORR is an indicator for mortgages with no coborrower and I.INCOME is an indicator for mortgages with borrower income below the MSA median, i.e., the high-risk indicator based on borrower income. Third, I add all the high-risk indicators to create a mortgage-level composite risk score. To the extent that each individual high-risk indicator reflects the underlying risk arising from the corresponding characteristic, I expect the composite score to reflect the overall risk

\footnotetext{
${ }^{5}$ Appendix D presents a more comprehensive summary of the determinants of mortgage risk, including those not used in constructing my measures.

${ }^{6}$ While I use MSA as the definition of a local area, it is also possible define a local area more narrowly as a county or a census tract. I prefer the MSA as the local are definition because some data (e.g. house price index) are available only at the MSA level.
} 
underlying individual mortgages. ${ }^{7}$ Last, I use the mortgage-level composite score to create the proposed $\mathrm{BHC}$-level measures that reflect the riskiness of $\mathrm{BHCs}$ ' mortgage lending activity in a given year.

\subsubsection{Individual Mortgage Risk Characteristics}

\subsubsection{Borrower-specific Characteristics}

Borrower illiquidity, which arises from shocks to or fluctuations of borrowers' residual income, is a primary borrower-specific factor affecting mortgage termination. Borrowers can become illiquid if their income decreases (e.g., due to unemployment) or if their non-housing non-discretionary expenses (e.g., medical expenses) increase, resulting in insufficient residual income to cover mortgage payment. Income volatility from seasonal employment can increase the risk of borrower illiquidity off-season.

Prior literature (e.g., Morton 1975, Sandor \& Sosin 1975, Vandell \& Thibodeau 1985, Elul et al. 2010, Demyanyk et al. 2010, Jagtiani \& Lang 2011, Chan et al. 2013) examines multiple characteristics that reflect borrower income (or illiquidity) risk. Some examples include current income, employment status, employment history, length of employment in current job, occupation, number of dependents, marital status, non-housing wealth, and government assistance. The first four characteristics capture the level and stability of borrowers' income in the past, which can predict future income level and stability. The other characteristics reflect non-housing non-discretionary expenses, which predict borrowers' ability to withstand negative income shocks. Of these borrower illiquidity factors, I can observe only borrower income at origination. I define INCOME as the ratio of the median borrower income at the MSA-year level to the individual borrower income. Borrower income is in the denominator to ensure that it is increasing in risk. Illiquidity risk increases as borrower income decreases relative to the MSA median income. ${ }^{8}$

Borrowers' debt burden can affect their ability to pay back their mortgages. Everything else equal, borrowers with greater debt burden are more likely to default on their mortgage than borrowers with lower debt burden because they are more likely to become illiquid over the mortgage term. Prior research (e.g., Elul et al. 2010, Demyanyk et al. 2010, Chan

\footnotetext{
${ }^{7}$ This aggregation assumes that all individual components are equally important, which can reduce the quality of the composite risk score if some components are more important than others.

${ }^{8}$ In 5.5, I test the sensitivity of my results to defining INCOME relative to other local area income benchmarks such as MSA median household income from the Census database and MSA personal income per capita from the BEA database.
} 
et al. 2013) documents that indicators of borrower debt burden such as debt payment-toincome, debt-to-income, credit card utilization, and existence of a second mortgage predict mortgage defaults. Since I do not have access to information about non-mortgage debt, I use the mortgage loan-to-income ratio, in lieu of debt-to-income ratio, as a proxy for debt burden. I argue that this ratio captures overall debt burden to a reasonable degree because a mortgage is typically the largest household debt. I define the mortgage loan-to-income ratio $(L T I)$ as the MSA median mortgage loan-to-income ratio divided by the borrower mortgage loan-to-income ratio, where the MSA median mortgage loan-to-income is the median loan-to-income for all mortgage applications in the MSA during the same year.

Other borrower characteristics associated with mortgage default include credit score, age, existence of coborrower, and race, of which I can observe the last two. Households with two earners are less likely to become illiquid if one earner experiences income shocks. Consistent with this, Chan et al. (2013) find that loans with a coborrower are less likely to default. I create an indicator variable I.NOCOBORR that equals one when a mortgage has no coborrower, and zero otherwise.

Prior research (e.g., Berkovec, Canner, Gabriel \& Hannan 1994, Firestone, Van Order \& Zorn 2007, Chan et al. 2013, Jiang, Nelson \& Vytlacil 2014a) provides evidence of higher likelihood of default for Black and Hispanic borrowers. Berkovec et al. (1994) use a sample of FHA-insured mortgages originated over the period 1987-1989 and find that minority borrowers are more likely to default, after controlling for other determinants of default. Firestone et al. (2007) examine 3-year fixed-rate mortgages originated over the period 19931997 and purchased by Freddie Mac, and they find that minority borrowers default at a higher rate, even after controlling for other factors. Chan et al. (2013) document a similar relation between race and mortgage default using a sample of first-lien adjustable-rate and 30-year fixed-rate mortgages originated in New York City between 2004 and 2007. Jiang et al. (2014a) also find similar association between borrower race and default using loanlevel data for a sample of mortgages originated by a major national mortgage bank during the 2004-2008 period. $^{9}$ I create two indicator variables I.BLACK and I.HISPANIC for borrowers' race and ethnicity, respectively.

\subsubsection{Loan-specific Characteristics}

Prior research (e.g., Sandor \& Sosin 1975, Morton 1975, Campbell \& Dietrich 1983, Deng et al. 2000, Elul et al. 2010, Jagtiani \& Lang 2011, Chan et al. 2013, Elul 2016) documents

\footnotetext{
${ }^{9}$ None of these studies claim a causal link between borrower race and defaults, and Chan et al. (2013) argue that the association between race and default may be driven by differential treatment of minority borrowers by the mortgage industry or other unobservable factors correlated to race.
} 
an association between the likelihood of mortgage termination and loan characteristics such as loan-to-value, mortgage payment-to-income, loan amount, the lack of proper documentation (e.g., missing borrower income), mortgage age, and term-to-maturity. Of these characteristics, I can observe the loan amount, missing borrower income, and mortgage age. In addition, I can construct a proxy for loan-to-value ratio. I do not use mortgage age in my thesis because it is equal to zero for all mortgages at origination.

The size of the loan can affect the likelihood of mortgage termination because it affects borrower's home equity and periodic payments. Elul et al. (2010) and Elul (2016) find that borrowers with larger loans are more likely to default than those with smaller loans, and Jagtiani \& Lang (2011) find that jumbo loans are more likely to be foreclosed. I define $L O A N$ as the ratio of the dollar amount of the mortgage loan to the MSA median mortgage amount.

Lack of proper documentation can reflect lenders' poor borrower screening that may result in approval of riskier mortgages. Low documentation mortgages can be riskier if the lack of documentation allows high-risk borrowers to obtain mortgages at more favorable terms when they would otherwise not qualify for these mortgages. Consistently, Elul et al. (2010) show that low documentation mortgages have greater default risk. I define an indicator variable I.NOINCOME, which equals one if borrower income is missing, as a proxy for loans with low documentation. ${ }^{10}$

The loan-to-value ratio (LTV), the ratio of the amount borrowed to the value of the property, reflects home equity and the amount the lender can recover in case of default. ${ }^{11}$ An LTV greater than 100 percent (i.e., negative home equity) can trigger strategic defaults by borrowers who do not want to pay loans that are worth more than the collateral. A large literature (e.g., Sandor \& Sosin 1975, Morton 1975, Campbell \& Dietrich 1983, Deng et al. 2000, Elul et al. 2010, Jagtiani \& Lang 2011) documents a positive association between LTV and the likelihood of mortgage default. I use the loan-to-estimated median value ratio ( $L T M E D V$ ), defined as the ratio of the loan amount to an estimated census tract median house value, as a proxy for LTV. I adjust the census tract median value of owner-occupied units from the decennial Census data using the changes in MSA-level house price indexes from FHFA to obtain estimated median house values at the census tract level.

\footnotetext{
${ }^{10}$ Note that I.INCOME does not capture all possible types of low documentation mortgages such as those without employment verification.

${ }^{11} \mathrm{LTV}$ is one of the primary risk indicators used in practice. For example, borrowers are required to make a minimum 20 percent down payment, which is equivalent to maximum of 80 percent LTV, to qualify for uninsured conventional mortgages.
} 


\subsubsection{Property-specific Characteristics}

Property characteristics such as current and expected value, current condition, and whether it is owner-occupied can affect mortgage termination risk, of which I can observe only the last one. Chan et al. (2013) find that mortgages secured by an owner-occupied property are more likely to default than mortgages secured by properties not occupied by the owner, which include investment properties. A potential explanation for this finding is that mortgages secured by investment properties, unlike those secured by owner-occupied properties, are less sensitive to income shocks because the property itself can generate rent income to cover mortgage payments. Another explanation is that borrowers who buy investment properties or second homes (e.g., vacation homes) are high-income borrowers unlikely to default on their mortgage. However, in my validation tests (section 4.5), I find evidence of the opposite relation between owner-occupancy and mortgage risk. I specifically find that BHCs with more mortgages secured by owner-occupied properties have lower mortgage delinquencies and charge-offs and that owner-occupied mortgages are more likely to have high interest rates. As a result, I reverse-coded the high-risk indicator variable for owner-occupancy and creates the indicator variable I.NOTOW NOCC which equals one if the property is not owner-occupied, and zero otherwise.

\subsubsection{Geographic-specific Characteristics}

Prior research (e.g., Sandor \& Sosin 1975, Vandell \& Thibodeau 1985, Elul et al. 2010, Ghent \& Kudlyak 2011, Chan et al. 2013, Anacker 2015) documents that mortgage termination risk is associated with local area characteristics such as current and expected housing market conditions, median house value, home ownership rate, percentage of vacant units, median house age, neighborhood life cycle, local area unemployment rate, median income, minority percentage, and neighborhood desirability rating. I can observe all these characteristic except for neighborhood desirability rating, which is a function of the other geographic characteristics.

Local area housing market conditions affect property values, which in turn affect the likelihood of negative home equity. Using census-tract-level data about foreclosure starts during the period January 2007 to June 2008, Anacker (2015) documents that mortgages in areas with low median house value are more likely to be foreclosed than those in areas with high median house value. Anacker (2015) also finds that home ownership rate, vacancy rate, and median house age are positively associated with foreclosure rates, and that census tracts in central cities and mature suburbs have greater default rate than those in developing suburbs. 
I create the following variables to capture local area housing market condition. $M E D V A L U E$ is the average value of owner-occupied units, averaged to the MSA level, divided by the median value of owner-occupied units in the census tract. ${ }^{12}$ I use the change in MSA-level house price indexes over the previous one-year and five-year periods ( $\triangle H P I 1$ and $\triangle H P I 5$, respectively) as proxies for the local area housing market condition. I create an indicator variable I.LIFECYCLE that equals one if a census tract is a central tract or is in a mature suburb, and zero otherwise. A central census tract is one in the central areas of a city, which are more mature than the peripheral and suburban areas. A mature suburb is a suburban area with a median house age of 30 years or more. I group central cities and mature suburbs together because Anacker (2015) finds that tracts in central cities and mature suburbs exhibit similar mortgage foreclosure rate, which is higher than for tracts in developing suburbs. Other proxies for local area housing market conditions include the proportion of owner-occupied properties (OWNRATE) and the proportion of vacant properties (VACRATE).

Local area unemployment rate and economic condition can be associated with mortgage risk if they reflect current and expected borrower illiquidity or housing market condition. Elul et al. (2010) document that an increase in county unemployment rate is positively associated with mortgage default. Chan et al. (2013) find that neighborhoods with lower median income exhibit more defaults than those with higher median income.

I use the following variables to measure local area unemployment rate and economic conditions. UNEMPRATE is the county unemployment rate from the BLS database, and $\triangle U N E M P R A T E$ is the annual change in UNEMPRATE. I use the personal income data from BEA to create four county-level local area income measures, namely $P E R I N C$, EARPERJOB, NONHOUSWLTH, and GOVASSIST. I use local area income data from the BEA database instead of the HMDA/CRA census database because the BEA database is updated annually and contains more up to date information. PERINC is the MSA personal income per capita divided by the county personal income per capita. Similarly, EARPERJOB is the MSA average earnings per job divided by the county average earnings per job. NONHOUSWLTH is the MSA non-housing wealth per capita divided by the county non-housing wealth per capita. GOVASSIST is the county government assistance per capita divided by the MSA government assistance per capita.

Chan et al. (2013) find that mortgage default rate increases with the percentage of Black population in the neighborhood, after controlling for other default risk indicators.

\footnotetext{
${ }^{12}$ The MSA average value of owner-occupied is the census tract-level median value of owner-occupied units averaged over all census tracts in the MSA, used as a proxy for the MSA median value of owneroccupied units.
} 
They argue that this association "likely indicates the differential treatment of Black neighborhoods by the mortgage industry" (Chan et al. 2013, p.100). To reflect the local area minority percentage, I use the percentage of Black population (BLACKPERC) and Hispanic population (HISPANICPERC) in the census tract. The corresponding high-risk indicators I.BLACKPERC and I.HISPANICPERC are equal to one if the census tract has a majority of Black and Hispanic population, respectively.

Sandor \& Sosin (1975) and Vandell \& Thibodeau (1985) show that neighborhood desirability rating is negatively associated with mortgage risk premium. While I do not have access to such desirability ratings, I argue that the other geographic factors discussed above proxy for neighborhood desirability. For example, current and expected housing market conditions, unemployment rates, median income, minority percentage, and median house value can all influence the desirability rating of a neighborhood. Krysan, Couper, Farley \& Forman (2009) show that a neighborhood's social class and racial composition affect its desirability, providing evidence supporting the claim that the above socio-economic factors affect neighborhood desirability.

\subsubsection{Composite Risk Measures}

I create a mortgage-level composite risk score $(M R S C O R E)$ by adding all the 24 individual high-risk indicators from the previous subsection. I use all the characteristics as components in MRSCORE, despite some failing one of the validity test presented in section 4.5. None of the characteristics fails both validity tests, except owner-occupancy, which I reverse coded, and neither validation test is superior to the other. ${ }^{13} M R S C O R E$ is increasing in mortgage risk because each component is defined to reflect high-risk mortgages based on the underlying characteristic. I then aggregate MRSCORE across mortgages within a BHC-year to obtain the BHC-level MLRMs.

I propose four alternative MLRMs designed to capture different types of bank risktaking in mortgage lending. BHCs can increase their risk-taking in mortgage lending either by approving a higher proportion of risky mortgages from the pool of applications they receive, or by actively seeking to attract risky applications, for example, through branch locations or advertisements. In either case, the underlying risk of the portfolio of approved mortgages increases. To the extent that MRSCORE reflects the underlying risk of individual mortgages, greater risk-taking leads to more approved mortgaged with

\footnotetext{
${ }^{13}$ In section 5.5, I perform sensitivity analysis using alternative MLRMs constructed only from those mortgage characteristics that passed both validity tests.
} 
high $M R S C O R E$. This suggests the average $M R S C O R E$ for all mortgages approved by a BHC in a given year ( $A V G M R S C O R E)$ as the first BHC-level MLRM.

$A V G M R S C O R E$ reflects the overall risk profile of approved mortgages without considering the risk profile of the mortgage application pool. However, the risk profile of mortgage application pools can vary significantly across BHCs because of exogenous factors such as local area economic downturn which can lead to deteriorations in their mortgage application pool. A BHC operating in areas experiencing difficult economic conditions is more likely to receive and approve more high-risk applications than a BHC operating in areas with better economic conditions. As a result, comparing any two BHCs' mortgage approval without considering their applicant pool can be misleading. To control for such demand effect, I create $S A V G M R S C O R E$ as the average $M R S C O R E$ for all mortgages approved by a $\mathrm{BHC}$ in a given year divided by the average $M R S C R E$ for all applications (including those denied, closed, etc.) for the same BHC-year.

$S A V G M R S C O R E$ does not capture a risky lending behavior that begins with deliberately targeting high-risk borrowers. This kind of lending behavior results in a high-risk application pool and a high-risk portfolio of approved loans. In this case, SAVGMRSCORE does not reflect the risky lending decisions because the high-risk loans approved appear normal relative to the high-risk application pool, which the BHC deliberately targeted.

I propose two other measures (NHIGHRISK and $\$ H I G H R I S K$ ) that can reflect risky lending decisions both through targeting potential high-risk borrowers and through approving loans to more risky borrowers from a given applicant pool. These measures focus on the risk profile of mortgages approved by a BHC relative to the risk profile of all applicants in the MSA, which allows them to capture risk-taking both by actively targeting high-risk borrowers in a given MSA or by approving riskier mortgages out of their application pool. To create NHIGHRISK and $\$ H I G H R I S K$, I first partition all loans and applications in a given MSA into high- and low-MRSCORE groups based on the MSA median MRSCORE. I then define NHIGHRISK as the number of high-MRSCORE mortgages approved by a $\mathrm{BHC}$ in a given year, divided by the total number of mortgages approved for the same BHC-year. Similarly, $\$ H I G H R I S K$ is the total dollar value of high-MRSCORE mortgages approved by a $\mathrm{BHC}$ in a given year, divided by the total dollar value of all approved mortgages for the same BHC-year.

\subsection{Descriptive Statistics}

Table 4.1 presents the descriptive statistics for the individual mortgage risk characteristics, the BHC-level composite MLRMs, and the BHC-level mortgage portfolio performance 
measures used in validating the risk measures.

Panel A contains the statistics for the whole sample. The mean (median) value of 8.731 (8.593) for $A V G M R S C O R E$ show that the average mortgage application approved by the average $\mathrm{BHC}$ exhibits approximately 9 out of the 24 individual risk characteristics that make up the composite score. The value of $A V G M R S C O R E$ ranges from 3 to 18, which shows that there is a considerable variation in the risk profile of mortgages approved by different BHCs. The mean (median) value of 0.998 (0.999) for the scaled version ( $S A V G M R S C O R E$ ) suggest that, on average, the risk profile of the portfolio of mortgages approved by BHCs is comparable to that of their application pool. However, $S A V G M R S C O R E$ ranges from 0.5-1.731, showing that BHCs vary in this dimension as well. The mean and median values of NHIGHRISK are 0.439 and 0.405 , respectively. Approximately $40 \%$ of the mortgages approved by the average BHC are high-risk mortgages relative to all mortgage applications in their MSA. NHIGHRISK ranges from 0 to 1 , suggesting that some BHCs approve only low-risk mortgages while other approve only high-risk mortgages within an MSA. The observations for $\$ H I G H R I S K$ are similar to that of NHIGHRISK.

Another observation from panel $\mathrm{A}$ is that there are apparent outliers for INCOME, $L T I, L O A N$, and $L T M E D V$ on the right-hand tails of their distributions. These outliers do not affect the composite risk measures because their construction is based on median splits of the individual risk characteristics and not their actual values.

Panel B shows the statistics separately for the securitizing and non-securitizing subsamples. For all variables except for $A V G M R S C O R E$, at least one of the mean or median differ significantly across the two subsamples. In many cases, both the mean and median are significantly different across the two subsamples. Comparing the BHC-level composite measures across the two subsamples reveals that non-securitizing BHCs take more risk than securitizing BHCs. However, the magnitude of these differences is relatively small. For example, the mean difference for NHIGHRISK is only $10 \%$ of the standard deviation of NHIGHRISK for the combined sample.

\subsection{Validation Tests}

In this section, I assess the validity of the proposed measures for bank risk-taking in residential mortgage lending. I specifically test whether the proposed MLRMs reflect the riskiness of BHCs' mortgage lending decisions in a given year. Since the composite measures are only as good as the components they are made of, I first test the validity of the 
Table 4.1: Descriptive Statistics

Panel A: Whole Sample

\begin{tabular}{|c|c|c|c|c|c|c|c|c|}
\hline & $\mathbf{N}$ & Mean & St. Dev. & Min & P25 & Median & P75 & $\operatorname{Max}$ \\
\hline \multicolumn{9}{|l|}{ BHC-level MLRMs } \\
\hline$A V G M R S C O R E$ & 24809 & 8.731 & 1.535 & 3 & 7.677 & 8.593 & 9.656 & 18.000 \\
\hline$S A V G M R S C O R E$ & 24809 & 0.998 & 0.027 & 0.500 & 0.991 & 0.999 & 1.004 & 1.731 \\
\hline NHIGHRISK & 24809 & 0.439 & 0.216 & 0 & 0.295 & 0.405 & 0.560 & 1.000 \\
\hline$\$ H I G H R I S K$ & 24809 & 0.403 & 0.227 & 0 & 0.249 & 0.356 & 0.526 & 1.000 \\
\hline \multicolumn{9}{|c|}{ Individual Risk Characteristics } \\
\hline I.BLACK & 24809 & 0.029 & 0.070 & 0 & 0 & 0.009 & 0.031 & 1.000 \\
\hline I.HISPANIC & 24809 & 0.036 & 0.086 & 0 & 0 & 0.010 & 0.035 & 1.000 \\
\hline I.NOCOBORR & 24809 & 0.431 & 0.172 & 0.000 & 0.325 & 0.419 & 0.516 & 1.000 \\
\hline I.NOINCOME & 24809 & 0.102 & 0.173 & 0 & 0.000 & 0.034 & 0.115 & 1.000 \\
\hline I.NOTOWNOCC & 24809 & 0.282 & 0.234 & 0.000 & 0.111 & 0.216 & 0.392 & 1.000 \\
\hline I.LIFECYCLE & 24809 & 0.581 & 0.253 & 0 & 0.411 & 0.600 & 0.773 & 1.000 \\
\hline$B L A C K P E R C$ & 24809 & 0.077 & 0.089 & 0 & 0.021 & 0.049 & 0.098 & 0.984 \\
\hline HISPANICPERC & 24809 & 0.062 & 0.092 & 0 & 0.014 & 0.030 & 0.070 & 0.944 \\
\hline$M E D V A L U E$ & 24809 & 1.085 & 0.232 & 0.225 & 0.967 & 1.051 & 1.164 & 6.257 \\
\hline OWNRATE & 24809 & 0.601 & 0.108 & 0 & 0.536 & 0.613 & 0.679 & 0.960 \\
\hline POVERTY & 24809 & 9.661 & 4.331 & 0 & 6.74 & 8.947 & 11.659 & 56.365 \\
\hline$V A C R A T E$ & 24809 & 0.083 & 0.049 & 0.000 & 0.055 & 0.072 & 0.096 & 0.827 \\
\hline INCOME & 24618 & 1.093 & 0.479 & 0.011 & 0.917 & 1.068 & 1.216 & 24.316 \\
\hline$L T I$ & 24618 & 2.399 & 3.091 & 0.104 & 1.478 & 1.911 & 2.640 & 167.685 \\
\hline$L O A N$ & 24809 & 1.312 & 1.021 & 0.036 & 0.990 & 1.196 & 1.435 & 99.312 \\
\hline$L T M E D V$ & 24809 & 0.955 & 0.893 & 0.043 & 0.764 & 0.904 & 1.045 & 115.666 \\
\hline$\triangle H P I 1$ & 24809 & -0.040 & 0.055 & -0.411 & -0.061 & -0.040 & -0.013 & 0.371 \\
\hline$\triangle H P I 5$ & 24809 & -0.209 & 0.230 & -1.440 & -0.295 & -0.206 & -0.072 & 0.597 \\
\hline PERINC & 24809 & 1.032 & 0.103 & 0.354 & 0.996 & 1.006 & 1.045 & 1.885 \\
\hline NONHOUSWLTH & 24809 & 1.122 & 0.250 & 0.210 & 1.000 & 1.039 & 1.158 & 3.713 \\
\hline GOVASSIST & 24809 & 0.929 & 0.146 & 0.168 & 0.887 & 0.966 & 1.000 & 2.682 \\
\hline EARNPERJOB & 24809 & 1.088 & 0.138 & 0.618 & 1.004 & 1.041 & 1.110 & 2.101 \\
\hline UNEMPRATE & 24902 & 5.487 & 1.984 & 1.100 & 4.144 & 5.117 & 6.410 & 20.600 \\
\hline$\triangle U N E M P R A T E$ & 24902 & 0.009 & 0.186 & -0.487 & -0.107 & -0.044 & 0.067 & 1.330 \\
\hline \multicolumn{9}{|c|}{ Mortgage Portfolio Performance Measures } \\
\hline$B S M O R T P D U E<90$ & 15047 & 0.014 & 0.017 & 0 & 0.004 & 0.009 & 0.018 & 0.352 \\
\hline$B S M O R T P D U E \geq 90$ & 24801 & 0.003 & 0.011 & 0 & 0 & 0.000 & 0.002 & 0.464 \\
\hline$B S M O R T N A C C$ & 24816 & 0.011 & 0.023 & 0 & 0.001 & 0.004 & 0.012 & 0.678 \\
\hline BSMORTCHOFF & 24723 & 0.003 & 0.025 & -0.104 & 0 & 0.000 & 0.002 & 3.766 \\
\hline
\end{tabular}


Panel B: Securitizing vs. Non-securitizing BHCs

\begin{tabular}{|c|c|c|c|c|c|c|c|c|}
\hline & \multicolumn{4}{|c|}{ Non-securitizing BHCs } & \multicolumn{4}{|c|}{ Securitizing BHCs } \\
\hline & $\mathbf{N}$ & Mean & St. Dev. & Median & $\mathbf{N}$ & Mean & St. Dev. & Median \\
\hline \multicolumn{9}{|l|}{ BHC-level MLRMs } \\
\hline$A V G M R S C O R E$ & 19826 & 8.736 & 1.579 & 8.600 & 4983 & 8.713 & 1.349 & 8.574 \\
\hline$S A V G M R S C O R E$ & 19826 & 0.998 & 0.029 & 0.999 & 4983 & 0.997 & 0.018 & 0.997 \\
\hline NHIGHRISK & 19826 & 0.443 & 0.226 & 0.411 & 4983 & 0.421 & 0.169 & 0.392 \\
\hline$\$ H I G H R I S K$ & 19826 & 0.409 & 0.237 & 0.362 & 4983 & 0.381 & 0.177 & 0.343 \\
\hline \multicolumn{9}{|c|}{ Individual Risk Characteristics } \\
\hline I.BLACK & 19826 & 0.028 & 0.070 & 0.006 & 4983 & 0.029 & 0.068 & 0.014 \\
\hline I.HISPANIC & 19826 & 0.035 & 0.089 & 0.008 & 4983 & 0.038 & 0.075 & 0.017 \\
\hline I.NOCOBORR & 19826 & 0.429 & 0.181 & 0.413 & 4983 & 0.437 & 0.132 & 0.435 \\
\hline I.NOINCOME & 19826 & 0.101 & 0.178 & 0.030 & 4983 & 0.102 & 0.148 & 0.048 \\
\hline I.NOTOWNOCC & 19826 & 0.297 & 0.245 & 0.231 & 4983 & 0.222 & 0.174 & 0.175 \\
\hline I.LIFECYCLE & 19826 & 0.575 & 0.263 & 0.596 & 4983 & 0.604 & 0.204 & 0.608 \\
\hline$B L A C K P E R C$ & 19826 & 0.078 & 0.092 & 0.047 & 4983 & 0.070 & 0.077 & 0.053 \\
\hline HISPANICPERC & 19826 & 0.062 & 0.096 & 0.029 & 4983 & 0.061 & 0.076 & 0.037 \\
\hline$M E D V A L U E$ & 19826 & 1.091 & 0.244 & 1.056 & 4983 & 1.064 & 0.173 & 1.036 \\
\hline OWNRATE & 19826 & 0.599 & 0.111 & 0.611 & 4983 & 0.611 & 0.092 & 0.620 \\
\hline POVERTY & 19826 & 9.873 & 4.559 & 9.177 & 4983 & 8.816 & 3.131 & 8.377 \\
\hline$V A C R A T E$ & 19826 & 0.084 & 0.052 & 0.072 & 4983 & 0.079 & 0.037 & 0.072 \\
\hline$I N C O M E$ & 19648 & 1.087 & 0.497 & 1.058 & 4970 & 1.117 & 0.399 & 1.094 \\
\hline$L T I$ & 19648 & 2.491 & 3.404 & 1.960 & 4970 & 2.036 & 1.156 & 1.791 \\
\hline$L O A N$ & 19826 & 1.320 & 1.113 & 1.187 & 4983 & 1.280 & 0.506 & 1.221 \\
\hline$L T M E D V$ & 19826 & 0.959 & 0.990 & 0.900 & 4983 & 0.937 & 0.277 & 0.918 \\
\hline$\triangle H P I 1$ & 19826 & -0.041 & 0.056 & -0.040 & 4983 & -0.033 & 0.052 & -0.035 \\
\hline$\triangle H P I 5$ & 19826 & -0.219 & 0.230 & -0.212 & 4983 & -0.172 & 0.230 & -0.167 \\
\hline PERINC & 19826 & 1.034 & 0.107 & 1.005 & 4983 & 1.025 & 0.086 & 1.009 \\
\hline NONHOUSWLTH & 19826 & 1.125 & 0.256 & 1.034 & 4983 & 1.112 & 0.227 & 1.057 \\
\hline GOVASSIST & 19826 & 0.929 & 0.154 & 0.971 & 4983 & 0.928 & 0.110 & 0.949 \\
\hline EARNPERJOB & 19826 & 1.090 & 0.143 & 1.036 & 4983 & 1.081 & 0.110 & 1.052 \\
\hline$U N E M P R A T E$ & 19914 & 5.462 & 2.012 & 5.098 & 4988 & 5.587 & 1.865 & 5.213 \\
\hline$\triangle U N E M P R A T E$ & 19914 & 0.011 & 0.185 & -0.040 & 4988 & 0.003 & 0.190 & -0.056 \\
\hline \multicolumn{9}{|c|}{ Mortgage Portfolio Performance Measures } \\
\hline$B S M O R T P D U E<90$ & 11493 & 0.014 & 0.017 & 0.009 & 3554 & 0.014 & 0.014 & 0.010 \\
\hline$B S M O R T P D U E \geq 90$ & 19821 & 0.002 & 0.009 & 0.000 & 4980 & 0.004 & 0.016 & 0.000 \\
\hline$B S M O R T N A C C$ & 19831 & 0.011 & 0.024 & 0.004 & 4985 & 0.013 & 0.021 & 0.007 \\
\hline BSMORTCHOFF & 19747 & 0.002 & 0.008 & 0.000 & 4976 & 0.004 & 0.054 & 0.001 \\
\hline
\end{tabular}

This table presents the descriptive statistics for the proposed BHC-level MLRMs, the individual risk characteristics used in constructing these measures, and balance sheet mortgage portfolio performance measures. Panel A presents the statistics for the whole sample of BHCs over the period 1993-2015, and panel B presents the statistics separately for securitizing and non-securitizing BHCs over the same period. Bold font indicates no significant difference across groups. All variables are as defined in appendix A. 
component characteristics. I perform the validity tests using the full sample of all BHCs over the period 1993-2015. In contrast, the hypotheses test samples consist of matched pairs of securitizing and non-securitizing BHCs over restricted test periods around the effective dates of the accounting pronouncements. The broader validation sample allows me to test the validity of my measures more generally, and on subsamples that are not used to test the main hypotheses.

\subsubsection{Individual Characteristics}

I perform two tests to assess the validity of the individual characteristics. First, I test the ability of the characteristics to predict mortgage portfolio performance over the following four years. If the characteristics reflect underlying risk, I expect to find an association between each characteristic and future mortgage delinquency or default. Second, I test whether these characteristics are associated with the likelihood that a mortgage is a highyield mortgage with annual interest rate at least $3 \%$ greater than the yield on the treasury security with a comparable maturity. I expect that each characteristic is positively associated with the likelihood that a mortgage is high-yield mortgage if the characteristic reflects underlying risk and mortgage interest rates reflect lenders' assessment of the underling risk.

\subsubsection{Predicting Mortgage Portfolio Performance}

To assess the ability of each component characteristic to predict subsequent mortgage portfolio performance, I test the correlation between each trait and future on-balancesheet (BS) mortgage portfolio outcomes such as delinquencies and charge-offs. I focus on BS mortgages because performance data for off-balance-sheet mortgages is not available prior to 2001, and because it is sparsely populated when available in the post-2001 period. I would ideally use the subsequent mortgage performance of on- and off-balance-sheet mortgages because the combined pool better matches with mortgage originations, some of which are kept on the balance sheet while other are securitized or sold. My validity test will be weakened to the extent that on-balance-sheet mortgages performance measures capture only part of the risk associated with mortgage origination. Assuming that the proposed measures capture the risk in banks' lending decisions, my on-balance-sheet mortgaged performance based tests might understate the validity of my measures, if banks securitize the riskiest loans. In contrast, these tests might overstate the validity of my measures, if banks securitize the least risky loans. I perform these tests using BHC-level aggregations because I cannot observe individual mortgage performance. For example, I assess the 
validity of INCOME by testing the correlation between the average INCOME and future BS mortgage portfolio performance at the BHC-year level.

I measure mortgage performance using the amount of BS mortgages past due between 30 and 89 days $(B S M O R T P D U E<90)$, the amount of BS mortgages past due for 90 or more days and still accruing $(B S M O R T P D U E>=90)$, the amount of non-accrual mortgages on the balance sheet $(B S M O R T N A C C)$, and the amount of BS mortgage net charge-off ( $B S M O R T C H O F F)$. I scale all these variables by the total amount of BS mortgages. Appendix A.2 presents the description all loan portfolio performance measures.

I estimate the pairwise correlations between each component characteristic in year $t$ and BS mortgage performance in years $t, t+1, t+2, t+3$, and $t+4$. I choose a four-year horizon based on prior literature. Elul et al. (2006) show that default rates increase in the first several years, and Elul (2016) finds that mortgage default hazard increases over the first two or three years and declines thereafter.

Table 4.2 presents a summary of the results from the pairwise correlation tests. Most characteristics are positively associated with future BS mortgage delinquency and chargeoff, consistent with my expectation that the individual characteristics reflect mortgage risk. I.LIFECYCLE and OWNRATE are negatively associated with subsequent mortgage portfolio performance, contrary to my expectation that mortgages in mature neighborhoods and in neighborhoods with high home ownership rate are riskier than those in developing neighborhoods and in neighborhoods with low ownership rate, respectively. Recall that Anacker (2015) finds that mortgages in mature census tracts and mortgages in census tracts with high home ownership rate are riskier than mortgages in developing census tracts and mortgages in census tracts with low home ownership rate. I conjecture that the conflicting findings from my tests arise because I use a different setting than Anacker (2015). For example, Anacker (2015) focuses on individual mortgage foreclosures during 2007-2008 in the top 100 MSA, whereas I examine BS mortgage delinquencies and charge-offs during the period 1993-2015.

Table 4.2 also shows that the correlations between the characteristics and $B S M O R T P D U E>90$ are weak relative to the other mortgage performance measures. This finding is consistent with the FR Y-9C reporting requirement that mortgages that are past due for more than 90 days be classified as non-accrual mortgages unless the collateral is well-secured and the lender is in the process of collection. Consistently, I find that the correlations are strong for BSMORTNACC.

Overall, table 4.2 shows that the individual risk characteristics have some ability to predict future BHC mortgage portfolio outcomes, which supports their use as components in constructing mortgage lending risk measures. In untabulated analyses, I estimate multi- 
variate regressions with each loan portfolio performance measure as dependent variable and all component characteristics as independent variables, and arrive at a similar conclusion.

\section{Table 4.2: Individual Mortgage Characteristics and On-Balance-Sheet Mortgage Portfolio Performance}

\begin{tabular}{|c|c|c|c|c|c|c|c|c|c|c|}
\hline & \multicolumn{5}{|c|}{$B S M P D U E<90$} & \multicolumn{5}{|c|}{$B S M P D U E \geq 90$} \\
\hline & $\mathrm{i}=0$ & $\mathrm{i}=1$ & $\mathrm{i}=2$ & $\mathrm{i}=3$ & $\mathrm{i}=4$ & $\mathrm{i}=0$ & $\mathrm{i}=1$ & $\mathrm{i}=2$ & $\mathrm{i}=3$ & $\mathrm{i}=4$ \\
\hline I.BLACK & $* * *$ & $* * *$ & $* * *$ & $* * *$ & $* * *$ & $* * *$ & $* * *$ & $* * *$ & $* *$ & $* * *$ \\
\hline I.HISPANIC & $* * *$ & $* * *$ & $* * *$ & $* * *$ & $* * *$ & & & & & \\
\hline I.NOCOBORR & $* * *$ & $* * *$ & $* * *$ & $* * *$ & $* * *$ & $* *$ & $* * *$ & & $* * *$ & $* * *$ \\
\hline I.NOINCOME & & & $* * *$ & $* * *$ & $* * *$ & & & & & \\
\hline I.NOTOWNOCC & $* * *$ & $* * *$ & $* * *$ & $* * *$ & $* * *$ & & & & & \\
\hline I.LIFECYCLE & $(* * *)$ & $(* * *)$ & $(* * *)$ & $(* * *)$ & $(* * *)$ & & & & & \\
\hline$B L A C K P E R C$ & $* * *$ & $* * *$ & $* * *$ & $* * *$ & $* * *$ & $* * *$ & $* * *$ & $* * *$ & $* * *$ & $* * *$ \\
\hline HISPANICPERC & & & & & & & & & & \\
\hline$M E D V A L U E$ & $* * *$ & $* * *$ & $* * *$ & $* * *$ & $* * *$ & & & & & $* * *$ \\
\hline OWNRATE & $(* * *)$ & $(* * *)$ & $(* * *)$ & $(* * *)$ & $(* * *)$ & & & $(* * *)$ & $(* * *)$ & \\
\hline POVERTY & $* * *$ & $* * *$ & $* * *$ & $* * *$ & $* * *$ & $* *$ & $* * *$ & $* *$ & & $* *$ \\
\hline$V A C R A T E$ & $* * *$ & $* * *$ & $* * *$ & $* * *$ & $* * *$ & & & & & \\
\hline$I N C O M E$ & $* * *$ & $* * *$ & $* * *$ & $* * *$ & $* * *$ & & $* * *$ & & $* * *$ & $* *$ \\
\hline$L T I$ & & & & & & & & & & \\
\hline$L O A N$ & $(* * *)$ & $(* * *)$ & $(* * *)$ & & $(* *)$ & & & $* *$ & & \\
\hline$L T M E D V$ & & & & & & & & $* * *$ & $*$ & \\
\hline$\triangle H P I 1$ & $* * *$ & $* * *$ & $* * *$ & & $(* * *)$ & $* * *$ & $* * *$ & $*$ & & \\
\hline$\triangle H P I 5$ & $* * *$ & $* * *$ & & $(* * *)$ & $(* * *)$ & $* * *$ & $* * *$ & $*$ & & \\
\hline$P E R I N C$ & $* * *$ & $* * *$ & $* * *$ & $* * *$ & $* * *$ & & & & & \\
\hline NONHOUSWLTH & $* * *$ & $* * *$ & $* * *$ & $* * *$ & $* * *$ & & & & & \\
\hline$G O V A S S I S T$ & $* * *$ & $* * *$ & $* *$ & $* * *$ & $* *$ & & & & & \\
\hline EARN PERJOB & $* * *$ & $* * *$ & $* * *$ & $* * *$ & $* * *$ & $*$ & $* *$ & & & \\
\hline UNEMPRATE & $* * *$ & $* * *$ & & & & $* * *$ & $* * *$ & $* * *$ & & \\
\hline$\triangle U N E M P R A T E$ & $* * *$ & $* * *$ & $* * *$ & & $(* * *)$ & & & & & \\
\hline
\end{tabular}

\section{Continued on next page-}


- continued from previous page

\begin{tabular}{|c|c|c|c|c|c|c|c|c|c|c|}
\hline & \multicolumn{5}{|c|}{$B S M N A C C$} & \multicolumn{5}{|c|}{$B S M C H O F F$} \\
\hline & $\mathrm{i}=0$ & $\mathrm{i}=1$ & $\mathrm{i}=2$ & $\mathrm{i}=3$ & $\mathrm{i}=4$ & $\mathrm{i}=0$ & $\mathrm{i}=1$ & $\mathrm{i}=2$ & $\mathrm{i}=3$ & $\mathrm{i}=4$ \\
\hline I.BLACK & $* * *$ & $* * *$ & $* * *$ & $* * *$ & $* * *$ & & & & & \\
\hline I.HISPANIC & $* * *$ & $* *$ & $* * *$ & $* * *$ & $* * *$ & & & & & \\
\hline I.NOCOBORR & $* * *$ & $* * *$ & $* * *$ & $* * *$ & $* * *$ & $* * *$ & $* * *$ & $* * *$ & $* * *$ & $* * *$ \\
\hline$I . N O I N C O M E$ & $* * *$ & $* * *$ & $* * *$ & $* * *$ & $* * *$ & $* * *$ & $* * *$ & $* * *$ & $* * *$ & $* * *$ \\
\hline I.NOTOWNOCC & $* * *$ & $* * *$ & $* * *$ & $* * *$ & $* * *$ & $* * *$ & $* * *$ & $* * *$ & $* * *$ & $* * *$ \\
\hline \multicolumn{11}{|l|}{ I.LIFECYCLE } \\
\hline$B L A C K P E R C$ & $* * *$ & $* * *$ & $* * *$ & $* * *$ & $* * *$ & $* * *$ & $* * *$ & $* * *$ & $* * *$ & $* * *$ \\
\hline HISPANICPERC & $* * *$ & $* * *$ & $* * *$ & $* * *$ & $* * *$ & $* * *$ & $* * *$ & $* * *$ & $* * *$ & $* * *$ \\
\hline$M E D V A L U E$ & & $* * *$ & $* * *$ & $* * *$ & $* * *$ & & & $* * *$ & $* * *$ & $* * *$ \\
\hline$O W N R A T E$ & $(* * *)$ & $(* * *)$ & $(* * *)$ & $(* * *)$ & $(* * *)$ & $(* * *)$ & $(* * *)$ & $(* * *)$ & $(* * *)$ & $(* * *)$ \\
\hline POVERTY & $*$ & $* *$ & $* * *$ & $* * *$ & $* * *$ & & & & & \\
\hline$V A C R A T E$ & $* * *$ & $* *$ & & & & & & & & \\
\hline$I N C O M E$ & $* * *$ & $* * *$ & $* * *$ & $* * *$ & $* * *$ & $* *$ & & & & \\
\hline$L T I$ & & & & $* * *$ & & & & & & \\
\hline$L O A N$ & & & & & $*$ & & & $* * *$ & & $* * *$ \\
\hline$L T M E D V$ & $* * *$ & $* * *$ & $* * *$ & $* * *$ & $* * *$ & $* * *$ & $* * *$ & $* * *$ & $* * *$ & $* * *$ \\
\hline$\triangle H P I 1$ & $* * *$ & $* * *$ & $* * *$ & $* * *$ & $* * *$ & $* * *$ & $* * *$ & $* * *$ & $* * *$ & \\
\hline$\triangle H P I 5$ & $* * *$ & $* * *$ & $* * *$ & & $(* * *)$ & $* * *$ & $* * *$ & $* * *$ & $(* * *)$ & $(* * *)$ \\
\hline$P E R I N C$ & & & & & & & & & $*$ & $*$ \\
\hline NON HOUSWLTH & & & $* *$ & $* *$ & $* * *$ & & $* *$ & $* *$ & $* * *$ & $* * *$ \\
\hline$G O V A S S I S T$ & $* * *$ & $* * *$ & $* * *$ & $* * *$ & $* * *$ & $* * *$ & $* * *$ & $* * *$ & $* * *$ & \\
\hline EARNPERJOB & & & & & & & & & & \\
\hline$U N E M P R A T E$ & $* * *$ & $* * *$ & $* * *$ & $* * *$ & $* * *$ & $* * *$ & $* * *$ & $* * *$ & $* * *$ & \\
\hline$\triangle U N E M P R A T E$ & $* * *$ & $* * *$ & $* * *$ & $* * *$ & $* * *$ & $* * *$ & $* * *$ & $* * *$ & $* * *$ & \\
\hline
\end{tabular}

Continued on next page- 


\section{- continued from previous page}

This table presents summary of the association tests between the individual characteristics (e.g., borrower income) of mortgages approved by BHCs' and on-balance-sheet mortgage portfolio performance (e.g., proportion delinquent). I estimate the pair-wise correlation between each mortgage characteristic observed in year $t$ and each mortgage portfolio performance measure observed in year $t+i$ where $i \in\{0,1,2,3,4\}$. Since the mortgage portfolio performance measures are observable at the BHC-level, I aggregate the mortgage characteristics to the BHC-level. I specifically use the average value of the characteristics for all approved mortgages. I then report in this table the sign and significance of the pairwise correlations. $* * *, * *$, and $*$ represent significance at $1 \%, 5 \%$, and $10 \%$ levels, respectively, with Bonferroni adjustment. The asterisks in parenthesis indicate negative correlation. For example, the $* * *$ in the first column and first row indicates that the proportion of approved mortgages to Black borrowers is positively correlated with the contemporaneous proportion of mortgages that are delinquent between 30 and 89 days, and that this correlation is significant at the $1 \%$ level. Similarly, the $(* * *)$ in the first column and sixth row indicates that the proportion of approved mortgages in mature neighborhoods is negatively correlated with the contemporaneous proportion of mortgages that are delinquent between 30 and 89 days and that this correlation is significant at the $1 \%$ level. All variables are defined in appendix A.

\subsubsection{Association with Mortgage Interest Rates}

I create a mortgage-level indicator variable I.HIGHY IELD that equals one if the mortgage is a high-yield mortgage with an annual interest rate at least $3 \%$ more than that of the comparable treasury security, and zero otherwise. I then perform a $2 \times 2$ contingency test of the association between I.HIGHY IELD and each individual characteristic as well as the mortgage-level composite risk score $M R S C O R E$.

Table 4.3 presents a summary of the results. Column (1) presents the contingency coefficient, column (2) contains the odds ratio, and column (3) contains the p-values from the $\chi^{2}$ test. The contingency coefficient is a scaled version of the $\chi^{2}$ statistic and reflects the strength of the association being tested with $0 \%$ for no association and $100 \%$ for perfect association.

The first observation from table 4.3 is that all the characteristics and MRSCORE are significantly associated with I.HIGHYIELD. The second observation is that the contingency coefficients range from $0.63 \%$ for I.NOTOWNOCC to $11.68 \%$ for I.HISPANIC, which indicates that the associations between the individual characteristics and mortgage yield are weak to moderate. The last observation is that most of the odds ratios are greater 
than one, while some are below one. The odds ratios that are greater than one are consistent with my expectation because they suggest that mortgages with those specific traits are more likely to be high-yield than those without the traits. For instance, the odds ratio of 1.4 for I.MRSCORE indicates that mortgages with composite risk score above MSA median are 1.4 times more likely to be high-yield mortgages than those with composite risk score below MSA median. Conversely, the odds ratios that are below one are contrary to my expectation as they indicate a negative association between those characteristics and I.HIGHY IELD. For example, the odds ratio of 0.36 for I.NOINCOME suggests that the likelihood that a mortgage with no reported borrower is a high-yield mortgage is only 0.36 times that of a mortgage with reported income.

One explanation for these negative associations between I.HIGHYIELD and the characteristics is that those characteristics do not reflect mortgage risk as perceived by lenders. For example, lenders may not report borrower income in their HMDA filings if income was not part of the consideration in the approval process, for instance, because the borrower is wealthy. In this case, the mortgage is less likely to be a high-yield mortgage. Another explanation is that lenders approve mortgages with those characteristics only when they believe that the loan is otherwise secured, for instance, by the rising value of the collateral, as was the case prior to the 2007-2008 mortgage crisis. Stiglitz (2010) states that the assumption that house values will keep rising led lenders to originate mortgages that were equal to or more that $100 \%$ of the value of the house.

Overall, most individual characteristics are positively associated with mortgage yield, suggesting that those characteristics reflect mortgage risk as assessed by lenders. The negative association for 7 (out of 24) characteristics indicates either that lenders do not believe these characteristics reflect mortgage risk, or that lenders take active measures to reduce their exposure to these risk characteristics. In either case, the negative associations with mortgage yield cast a doubt about the validity of these characteristics as input to a mortgage lending risk measure. However, in section 4.5.1.1, none of the characteristics with odds ratios below one exhibit a consistent negative association with subsequent BS mortgage performance, suggesting these characteristics may reflect mortgage risk that lenders did not account for.

\subsubsection{BHC-level Measures}

This section presents the validity tests for the proposed BHC-level MLRMs (i.e., AVGMRSCORE, SAVGMRSCORE, NHIGHRISK, and $\$ H I G H R I S K)$. Similar to section 4.5.1.1, I rely on the BHC-level MLRMs' ability to predict subsequent BHC mortgage portfolio performances to assess whether these reflect the riskiness of BHCs' lending 


\section{Table 4.3: Individual Mortgage Characteristics and Mortgage Yield}

\begin{tabular}{|c|c|c|c|}
\hline & $\begin{array}{c}(1) \\
\text { Contingency } \\
\text { Coefficient }\end{array}$ & $\begin{array}{c}(2) \\
\text { Odds } \\
\text { Ratio }\end{array}$ & $\begin{array}{c}(3) \\
\text { P-value for } \\
\text { Pearson's } \chi^{2} \text { Test }\end{array}$ \\
\hline I.MRSCORE & $4.71 \%$ & 1.4 & $<0.0001$ \\
\hline I.BLACK & $11.03 \%$ & 2.957 & $<0.0001$ \\
\hline I.HISPANIC & $11.68 \%$ & 2.731 & $<0.0001$ \\
\hline I.NOCOBORR & $11.36 \%$ & 2.382 & $<0.0001$ \\
\hline I.NOINCOME & $6.92 \%$ & 0.36 & $<0.0001$ \\
\hline I.NOTOWNOCC & $0.64 \%$ & 1.064 & $<0.0001$ \\
\hline I.LIFECYCLE & $1.02 \%$ & 1.077 & $<0.0001$ \\
\hline I.BLACKPERC & $6.76 \%$ & 2.241 & $<0.0001$ \\
\hline I.HISPANICPERC & $4.73 \%$ & 1.796 & $<0.0001$ \\
\hline I.MEDV ALUE & $10.2 \%$ & 2.219 & $<0.0001$ \\
\hline I.OWNRATE & $4.38 \%$ & 1.708 & $<0.0001$ \\
\hline I.POVERTY & $0.79 \%$ & 1.695 & $<0.0001$ \\
\hline I.V ACRATE & $1.24 \%$ & 1.099 & $<0.0001$ \\
\hline I.INCOME & $2.53 \%$ & 1.201 & $<0.0001$ \\
\hline I.LTI & $4.03 \%$ & 1.343 & $<0.0001$ \\
\hline I.LOAN & $13.85 \%$ & 0.367 & $<0.0001$ \\
\hline I.LTMEDV & $5.49 \%$ & 0.675 & $<0.0001$ \\
\hline I. $\triangle H P I 1$ & $6.63 \%$ & 0.511 & $<0.0001$ \\
\hline I. $\triangle H P I 5$ & $9.32 \%$ & 0.213 & $<0.0001$ \\
\hline I.PERINC & $2.23 \%$ & 1.171 & $<0.0001$ \\
\hline I.NONHOUSWLTH & $1.06 \%$ & 1.078 & $<0.0001$ \\
\hline I.GOV ASSIST & $2.45 \%$ & 0.637 & $<0.0001$ \\
\hline I.EARNPERJOB & $1.16 \%$ & 0.914 & $<0.0001$ \\
\hline I.UNEMPRATE & $3.23 \%$ & 1.258 & $<0.0001$ \\
\hline I. $\triangle U N E M P R A T E$ & $3.88 \%$ & 0.656 & $<0.0001$ \\
\hline
\end{tabular}

This table presents a summary of the results from the 2 contingency tests of the association between the high-risk indicator variables based on individual characteristics (e.g., I.INCOME) and the high-yield indicator I.HIGHYIELD. The first column contains the contingency coefficient, which is a scaled version of the $\chi^{2}$ statistic and reflects the strength of the association being tested with $0 \%$ for no association and $100 \%$ for perfect association. The second column presents the odds ratio, which reflects the odds that a mortgage is a high-yield mortgage (i.e., I.HIGHYIELD = 1) given that it exhibits the high-risk characteristics (e.g., borrower income below MSA median or I.INCOME $=1$. Column (3) contains the p-values from the $\chi^{2}$ test. 
decisions. I use the mortgage portfolio performance measures described in section 4.5.1.1. Similar to the component characteristics, I expect each of these composite measures to be associated with subsequent mortgage portfolio delinquencies and charge-offs.

Table 4.4 presents the results for the full sample of all BHCs over the period 1993-2015. AVGMRSCORE, NHIGHRISK, and $\$ H I G H R I S K$ are all significantly positively associated with subsequent mortgage portfolio delinquency and charge-offs for all years up to four years ahead. These findings suggest that the measures reflect the risk underlying the BHCs mortgage portfolio. However, except for a few cases, the scaled version of the average risk score $S A V G M R S C O R E$ is not associated with future mortgage portfolio performance. This finding suggests that $S A V G M R S C O R E$ does not reflect BHCs risk-taking in their mortgage lending, which is consistent with the argument in section 4.3.2 that $S A V G M R S C O R E$ cannot reflect banks' risk-taking through targeting risky borrowers.

Tables 4.5 and 4.6 present the results of similar tests using the securitizing and nonsecuritizing subsamples for the period 1993-2015, respectively. In both cases, the inferences about the validity of the proposed measures are similar to those above for the whole sample. In untabulated analyses, I find similar results for the private- and public-BHC subsamples over the period 1993-2015.

I also perform similar tests using three different sub-periods, namely 1993-1995, 20052009, and 2012-2015. The 1993-1995 and 2012-2015 periods do not overlap with the hypotheses test periods, and provide an opportunity to assess the validity of my measures in periods that are not directly related to my hypotheses. I use the 2005-2009 period to test the validity of my measures around the 2007-2008 mortgage crisis. For the 2005-2009 and 2012-2015 periods, I find results that are similar to those in table 4.4 for the full sample and support the validity of the MLRMs. Specifically, the results for the 2005-2009 period suggest that the measures reflect BHCs' risky lending decisions in the period immediately prior to the crises. The result for the 2012-2015 period indicate that the validity of the results holds outside my main test periods and in the post-crisis period.

I find that the associations between my measures and subsequent BHC mortgage portfolio performance are weak for the 1993-1995 period. SAVGMRSCORE, NHIGHRISK, and $\$ H I G H R I S K$ are mostly unrelated to the mortgage performance measures, while $A V G M R S C O R E$ is significantly associated with non-accrual mortgages $(B S M O R T N A C C)$ for up to three years ahead and with mortgage charge-offs (BSMORTCHOFF) for up to two years ahead.

Overall, three of the proposed measures exhibit a reasonable ability to predict future mortgage portfolio performance. I use $A V G M R S C O R E$ as the primary MLRM because 
it predicts mortgages performance in all the sub-sample tests, unlike NHIGHRISK and \$HIGHRISK that fail to do so in the 1993-1995 period.

\subsection{Conclusion}

This chapter proposes and validates measures of risk-taking in residential mortgage lending at the BHC level. I rely on prior literature to identify 24 individual factors associated with mortgage risk. I combine these factors to obtain a mortgage-level composite risk score, which I then aggregate to the BHC level to obtain the proposed measures. To ensure that the measures allow comparison of BHCs that operating in different areas, I measure the individual characteristics relative to local area averages. The validity tests generally support the hypothesis that the individual characteristics and the composite measures reflect mortgage risk. However, some individual characteristics fail one of the two validity tests. In chapter 5, I test the sensitivity of my finding to excluding these characteristics from the composite scores.

To the best of my knowledge, I am the first to propose comprehensive BHC-level mortgage lending risk measures based on mortgage-level data. Prior studies of bank mortgage lending decisions focus on specific characteristics such as borrower credit score (Keys et al. 2010, Keys, Seru \& Vig 2012) or on mortgage approval rates (Xie 2016, Dou et al. 2018). In contrast, I consider multiple risk characteristics, enabling me to capture mortgage risk that is not reflected in single characteristics such as borrower credit score or approval rates. My measures, which are observable at origination, are also different from the outcome variables such as mortgage delinquencies and defaults subsequent to origination that are used as bank risk-taking measures in prior research (Keys et al. 2010, 2012, Ertan et al. 2017). Ertan et al. (2017) also explore the intensity of loan-level information collection by banks at origination as a measure of loan quality. Measures that are observable at origination allow researchers and regulators to assess bank risk-taking at the time of the lending decision. 


\section{Table 4.4: Mortgage Lending Risk Measures and Mortgage Portfolio Performance - Whole Sample}

\begin{tabular}{|c|c|c|c|c|c|}
\hline Panel A: AVGMRSCORE & $i=0$ & $i=1$ & $i=2$ & $i=3$ & $i=4$ \\
\hline$B S M P D U E<90$ & $0.157^{* * *}$ & $0.154^{* * *}$ & $0.139^{* * *}$ & $0.109^{* * *}$ & $0.064^{* * *}$ \\
\hline$B S M P D U E \geq 90$ & $0.024^{* *}$ & $0.045^{* * *}$ & $0.046^{* * *}$ & $0.030^{* *}$ & $0.032^{* *}$ \\
\hline$B S M N A C C$ & $0.236^{* * *}$ & $0.264^{* * *}$ & $0.278^{* * *}$ & $0.253^{* * *}$ & $0.211^{* * *}$ \\
\hline$B S M C H O F F$ & $0.217^{* * *}$ & $0.231^{* * *}$ & $0.223^{* * *}$ & $0.201^{* * *}$ & $0.145^{* * *}$ \\
\hline \multicolumn{6}{|l|}{ Panel B: $S A V G M R S C O R E$} \\
\hline & $i=0$ & $i=1$ & $i=2$ & $i=3$ & $i=4$ \\
\hline$B S M P D U E<90$ & -0.001 & -0.001 & 0.007 & 0.020 & 0.014 \\
\hline$B S M P D U E \geq 90$ & -0.004 & -0.006 & -0.007 & -0.005 & 0.022 \\
\hline$B S M N A C C$ & -0.001 & -0.019 & 0.009 & 0.010 & $0.028^{* *}$ \\
\hline$B S M C H O F F$ & 0.012 & 0.010 & $0.026^{* *}$ & $0.036^{* * *}$ & 0.025 \\
\hline
\end{tabular}

Panel C: NHIGHRISK

\begin{tabular}{lccccc} 
& $\boldsymbol{i}=\mathbf{0}$ & $\boldsymbol{i}=\mathbf{1}$ & $\boldsymbol{i}=\mathbf{2}$ & $\boldsymbol{i}=\mathbf{3}$ & $\boldsymbol{i}=\mathbf{4}$ \\
\hline BSMPDUE $<90$ & $0.121^{* * *}$ & $0.120^{* * *}$ & $0.134^{* * *}$ & $0.137^{* * *}$ & $0.107^{* * *}$ \\
BSMPDUE $\geq 90$ & 0.018 & $0.044^{* * *}$ & $0.036^{* * *}$ & $0.030^{* *}$ & $0.028^{* *}$ \\
BSMNACC & $0.058^{* * *}$ & $0.076^{* * *}$ & $0.096^{* * *}$ & $0.095^{* * *}$ & $0.090^{* * *}$ \\
BSMCHOFF & $0.064^{* * *}$ & $0.064^{* * *}$ & $0.081^{* * *}$ & $0.091^{* * *}$ & $0.070^{* * *}$ \\
\hline
\end{tabular}

\section{Panel D: \$HIGHRISK}

\begin{tabular}{lccccc} 
& $\boldsymbol{i}=\mathbf{0}$ & $\boldsymbol{i}=\mathbf{1}$ & $\boldsymbol{i}=\mathbf{2}$ & $\boldsymbol{i}=\mathbf{3}$ & $\boldsymbol{i}=\mathbf{4}$ \\
\hline BSMPDUE $<90$ & $0.113^{* * *}$ & $0.108^{* * *}$ & $0.135^{* * *}$ & $0.137^{* * *}$ & $0.118^{* * *}$ \\
BSMPDUE $\geq 90$ & $0.019^{*}$ & $0.044^{* * *}$ & $0.039^{* * *}$ & $0.032^{* * *}$ & $0.030^{* *}$ \\
BSM NACC & $0.061^{* * *}$ & $0.078^{* * *}$ & $0.102^{* * *}$ & $0.109^{* * *}$ & $0.102^{* * *}$ \\
BSMCHOFF & $0.065^{* * *}$ & $0.061^{* * *}$ & $0.090^{* * *}$ & $0.105^{* * *}$ & $0.095^{* * *}$ \\
\hline
\end{tabular}

This table presents the univariate correlations between the proposed BHC-level MLRMs and the contemporaneous and subsequent performance of BHCs' on-balance-sheet mortgages, up to four years ahead, for the whole sample of BHCs over the period 1993-2015.***,**, and $*$ represent significance at $1 \%, 5 \%$, and $10 \%$ levels, respectively, with Bonferroni adjustment. 
Table 4.5: Securitizing BHCs

\begin{tabular}{lccccc}
\hline Panel A: $\boldsymbol{A}$ VGM RSCORE & & & & \\
& $\boldsymbol{i}=\mathbf{0}$ & $\boldsymbol{i}=\mathbf{1}$ & $\boldsymbol{i}=\mathbf{2}$ & $\boldsymbol{i}=\mathbf{3}$ & $\boldsymbol{i}=\mathbf{4}$ \\
\hline BSMPDUE $<90$ & $0.208^{* * *}$ & $0.202^{* * *}$ & $0.160^{* * *}$ & $0.102^{* * *}$ & $0.060^{* *}$ \\
BSMPDUE $\geq 90$ & 0.027 & $0.041^{* *}$ & $0.057^{* * *}$ & $0.061^{* * *}$ & $0.071^{* * *}$ \\
BSMNACC & $0.329^{* * *}$ & $0.348^{* * *}$ & $0.338^{* * *}$ & $0.274^{* * *}$ & $0.203^{* * *}$ \\
BSMCHOFF & $0.042^{* *}$ & 0.035 & $0.279^{* * *}$ & $0.194^{* * *}$ & $0.117^{* * *}$ \\
\hline
\end{tabular}

Panel B: SAVGMRSCORE

\begin{tabular}{lccccc} 
& $\boldsymbol{i}=\mathbf{0}$ & $\boldsymbol{i}=\mathbf{1}$ & $\boldsymbol{i}=\mathbf{2}$ & $\boldsymbol{i}=\mathbf{3}$ & \multicolumn{1}{c}{$\boldsymbol{i} \mathbf{4}$} \\
\hline BSM PDUE $<90$ & -0.011 & -0.018 & -0.001 & 0.025 & \multicolumn{1}{c}{$0.054^{*}$} \\
BSMPDUE $\geq 90$ & -0.027 & $-0.039^{*}$ & -0.036 & $-0.047^{*}$ & -0.045 \\
BSM NACC & 0.010 & -0.005 & 0.017 & -0.008 & 0.003 \\
BSMCHOFF & 0.001 & 0.005 & 0.002 & -0.032 & -0.006 \\
\hline
\end{tabular}

Panel C: NHIGHRISK

\begin{tabular}{llllll} 
& $\boldsymbol{i}=\mathbf{0}$ & $\boldsymbol{i}=\mathbf{1}$ & $\boldsymbol{i}=\mathbf{2}$ & $\boldsymbol{i}=\mathbf{3}$ & $\boldsymbol{i}=\mathbf{4}$ \\
\hline BSMPDUE $<90$ & $0.121^{* * *}$ & $0.138^{* * *}$ & $0.135^{* * *}$ & $0.133^{* * *}$ & $0.118^{* * *}$ \\
BSMPDUE $\geq 90$ & 0.014 & 0.013 & 0.024 & 0.042 & 0.034 \\
BSM NACC & $0.111^{* * *}$ & $0.110^{* * *}$ & $0.112^{* * *}$ & $0.092^{* * *}$ & $0.062^{* * *}$ \\
BSMCHOFF & 0.020 & 0.014 & $0.110^{* * *}$ & $0.064^{* * *}$ & $0.052^{* *}$ \\
\hline
\end{tabular}

Panel D: \$HIGHRISK

\begin{tabular}{llllll} 
& $\boldsymbol{i}=\mathbf{0}$ & $\boldsymbol{i}=\mathbf{1}$ & $\boldsymbol{i}=\mathbf{2}$ & $\boldsymbol{i}=\mathbf{3}$ & $\boldsymbol{i}=\mathbf{4}$ \\
\hline BSM PDUE $<90$ & $0.111^{* * *}$ & $0.123^{* * *}$ & $0.125^{* * *}$ & $0.139^{* * *}$ & $0.125^{* * *}$ \\
BSMPDUE $\geq 90$ & 0.005 & 0.004 & 0.017 & 0.039 & 0.029 \\
BSM N ACC & $0.108^{* * *}$ & $0.104^{* * *}$ & $0.119^{* * *}$ & $0.107^{* * *}$ & $0.086^{* * *}$ \\
BSMCHOFF & 0.019 & 0.013 & $0.114^{* * *}$ & $0.071^{* * *}$ & $0.062^{* * *}$ \\
\hline
\end{tabular}

This table presents the univariate correlations between the proposed BHC-level MLRMs and the contemporaneous and subsequent performance of BHCs' on-balance-sheet mortgages, up to four years ahead, for the subsample of securitizing BHCs over the period 1993-2015.***,**, and $*$ represent significance at $1 \%$, $5 \%$, and $10 \%$ levels, respectively, with Bonferroni adjustment. 
Table 4.6: Non-Securitizing BHCs

\begin{tabular}{lccccc}
\hline Panel A: $\boldsymbol{A}$ V $\boldsymbol{G M} \boldsymbol{R} \boldsymbol{C O R E}$ & & & & \\
& $\boldsymbol{i}=\mathbf{0}$ & $\boldsymbol{i}=\mathbf{1}$ & $\boldsymbol{i}=\mathbf{2}$ & $\boldsymbol{i}=\mathbf{3}$ & $\boldsymbol{i}=\mathbf{4}$ \\
\hline BSMPDUE $<90$ & $0.162^{* * *}$ & $0.163^{* * *}$ & $0.137^{* * *}$ & $0.108^{* * *}$ & $0.064^{* * *}$ \\
BSMPDUE $\geq 90$ & $0.037^{* * *}$ & $0.058^{* * *}$ & $0.049^{* * *}$ & $0.026^{* *}$ & 0.018 \\
BSM NACC & $0.242^{* * *}$ & $0.278^{* * *}$ & $0.283^{* * *}$ & $0.242^{* * *}$ & $0.202^{* * *}$ \\
BSMCHOFF & $0.214^{* * *}$ & $0.236^{* * *}$ & $0.221^{* * *}$ & $0.184^{* * *}$ & $0.133^{* * *}$ \\
\hline
\end{tabular}

\section{Panel B: SAVGMRSCORE}

\begin{tabular}{lccccc} 
& $\boldsymbol{i}=\mathbf{0}$ & $\boldsymbol{i}=\mathbf{1}$ & $\boldsymbol{i}=\mathbf{2}$ & $\boldsymbol{i}=\mathbf{3}$ & $\boldsymbol{i}=\mathbf{4}$ \\
\hline BSMPDUE $<90$ & 0.008 & 0.010 & 0.014 & 0.018 & 0.009 \\
BSMPDUE $\geq 90$ & 0.003 & 0.003 & -0.003 & -0.005 & 0.013 \\
BSMNACC & 0.010 & -0.005 & 0.017 & 0.014 & $0.032^{* * *}$ \\
BSMCHOFF & 0.012 & 0.017 & $0.030^{* * *}$ & $0.036^{* * *}$ & $0.024^{*}$ \\
\hline
\end{tabular}

Panel C: NHIGHRISK

\begin{tabular}{lccccc} 
& $\boldsymbol{i}=\mathbf{0}$ & $\boldsymbol{i}=\mathbf{1}$ & $\boldsymbol{i}=\mathbf{2}$ & $\boldsymbol{i}=\mathbf{3}$ & $\boldsymbol{i}=\mathbf{4}$ \\
\hline BSMPDUE $<90$ & $0.123^{* * *}$ & $0.128^{* * *}$ & $0.134^{* * *}$ & $0.130^{* * *}$ & $0.103^{* * *}$ \\
BSMPDUE $\geq 90$ & $0.025^{* * *}$ & $0.049^{* * *}$ & $0.034^{* * *}$ & 0.020 & 0.012 \\
BSM NACC & $0.065^{* * *}$ & $0.086^{* * *}$ & $0.101^{* * *}$ & $0.086^{* * *}$ & $0.083^{* * *}$ \\
BSMCHOFF & $0.061^{* * *}$ & $0.067^{* * *}$ & $0.085^{* * *}$ & $0.085^{* * *}$ & $0.064^{* * *}$ \\
\hline
\end{tabular}

\section{Panel D: \$HIGHRISK}

\begin{tabular}{lccccc} 
& $\boldsymbol{i}=\mathbf{0}$ & $\boldsymbol{i}=\mathbf{1}$ & $\boldsymbol{i}=\mathbf{2}$ & $\boldsymbol{i}=\mathbf{3}$ & $\boldsymbol{i}=\mathbf{4}$ \\
\hline BSMPDUE $<90$ & $0.110^{* * *}$ & $0.112^{* * *}$ & $0.129^{* * *}$ & $0.125^{* * *}$ & $0.110^{* * *}$ \\
BSMPDUE $\geq 90$ & $0.030^{* * *}$ & $0.051^{* * *}$ & $0.039^{* * *}$ & $0.023^{*}$ & 0.016 \\
BSM NACC & $0.065^{* * *}$ & $0.088^{* * *}$ & $0.104^{* * *}$ & $0.093^{* * *}$ & $0.092^{* * *}$ \\
BSMCHOFF & $0.061^{* * *}$ & $0.062^{* * *}$ & $0.090^{* * *}$ & $0.094^{* * *}$ & $0.084^{* * *}$ \\
\hline
\end{tabular}

This table presents the univariate correlations between the proposed BHC-level MLRMs and the contemporaneous and subsequent performance of BHCs' on-balance-sheet mortgages, up to four years ahead, for the subsample of non-securitizing BHCs over the period 1993-2015.***,**, and $*$ represent significance at $1 \%, 5 \%$, and $10 \%$ levels, respectively, with Bonferroni adjustment. 


\section{Chapter 5}

\section{Empirical Analyses}

\subsection{Introduction}

This chapter presents the results of the empirical analyses. Section 5.2 discusses the descriptive statistics of the risk measures (i.e., the dependent variables) for the matched sample. Section 5.3 presents the results of the empirical analyses testing the main effect of transparency on BHCs' lending decisions as hypothesized in H1. Section 5.4 presents the results of the empirical analyses testing the moderating effects of manager-shareholder alignment (H2), regulatory oversight (H3) and market discipline (H4). Section 5.5 presents additional analyses that test the robustness of my findings to alternative assumptions, alternative research design, alternative matching method, and to specific subsamples and sub-periods. Section 5.6 concludes the chapter.

\subsection{Descriptive Statistics}

Table 5.1 presents descriptive statistics for the matched sample of securitizing BHCs (treatment group) and non-securitizing BHCs (control group) for the period 1993-2015. Panel A presents the statistics for the combined sample of securitizing and non-securitizing BHCs. The mean and median values of 9.3 and 9.1, respectively for $A V G M R S C O R E$ indicates that the typical approved mortgage exhibits 9 out of the 24 risk characteristics used to construct the composite risk score MRSCORE. AVGMRSCORE ranges from low, 4.3, to moderate, 15.4, on a scale of 24 . 
Table 5.1: Descriptive Statistics

\begin{tabular}{lcccccccc}
\hline \multicolumn{2}{l}{ Panel A: Whole Sample } & & & & & & & \\
& N & Mean & St. Dev. & Min & P25 & P50 & P75 & Max \\
\hline AVGMRSCORE & 6,477 & 9.285 & 1.292 & 4.333 & 8.388 & 9.150 & 10.092 & 15.385 \\
SAVGM RSCORE & 6,477 & 0.995 & 0.020 & 0.556 & 0.989 & 0.996 & 1.000 & 1.615 \\
NHIGHRISK & 6,477 & 0.386 & 0.168 & 0 & 0.287 & 0.365 & 0.463 & 1 \\
\$HIGHRISK & 6,477 & 0.357 & 0.178 & 0 & 0.248 & 0.323 & 0.431 & 1 \\
\hline
\end{tabular}

Panel B: Securitizing BHCs

\begin{tabular}{lcccccccc} 
& N & Mean & St. Dev. & Min & P25 & P50 & P75 & Max \\
\hline AVGMRSCORE & 3,824 & $9.263^{*}$ & 1.265 & 4.333 & 8.374 & $9.130^{*}$ & 10.052 & 15.013 \\
SAVGM RSCORE & 3,824 & 0.995 & 0.016 & 0.824 & 0.990 & 0.996 & 1.000 & 1.220 \\
NHIGHRISK & 3,824 & 0.386 & 0.157 & 0 & 0.293 & 0.365 & 0.457 & 1 \\
\$HIGH RISK & 3,824 & 0.355 & 0.165 & 0 & 0.256 & 0.322 & 0.424 & 1 \\
\hline
\end{tabular}

Panel C: Non-securitizing BHCs

\begin{tabular}{lcccccccc} 
& N & Mean & St. Dev. & Min & P25 & P50 & P75 & Max \\
\hline AVGMRSCORE & 2,653 & 9.317 & 1.329 & 5 & 8.417 & 9.196 & 10.154 & 15.385 \\
S AVGM RSCORE & 2,653 & 0.995 & 0.025 & 0.556 & 0.989 & 0.996 & 1.001 & 1.615 \\
NHIGHRISK & 2,653 & 0.386 & 0.182 & 0 & 0.271 & 0.365 & 0.472 & 1 \\
\$HIGHRISK & 2,653 & 0.359 & 0.196 & 0 & 0.236 & 0.325 & 0.444 & 1 \\
\hline
\end{tabular}

This table presents the descriptive statistics, across BHC-years, of the residential mortgage lending measures for the matched sample of securitizing and non-securitizing BHCs. The table shows the descriptive statistics for securitizing BHCs, non-securitizing BHCs, and the combined samples. ${ }^{*}$ in panel B indicates a p-value less than $10 \%$ from a t-test comparing the means, or a rank-sum test comparing the medians, of the securitizing and non-securitizing subsamples. All variables are as defined in appendix A.1. 
The mean and median values for SAVGMRSCORE are 0.995 and 0.996 , respectively, suggesting that the risk profile of loans approved by the average BHC is similar to that of the risk profile of the BHCs' application pools. ${ }^{1}$ The inter-quartile range of $S A V G M R S C O R E$ is close to one, however, the tails show that approvals for some BHCyears are substantially less risk than the applicant pool, and for others substantially more.

The mean and median value of 0.386 and 0.365 , respectively for NHIGHRISK show that approximately $38 \%$ of the mortgages approved by the average BHC have a risk score above the MSA median. The minimum value of zero for NHIGHRISK indicates that some BHCs approve only mortgages with MRSCORE below the MSA median, while the maximum value of one indicates that others approve only mortgages with $M R S C O R E$ above the MSA median. The descriptive statistics for $\$ H I G H R I S K$ lead to similar conclusions. Overall, panel A shows that BHCs in the test sample exhibit variations in their lending decisions, which is crucial in testing my hypotheses.

Panels B and C present the statistics separately for securitizing and non-securitizing BHCs, respectively. The two subsamples are comparable with respect to most of the risk measures. The means and medians of SAVGMRSCORE, NHIGHRISK, and $\$ H I G H R I S K$ for the securitizing BHCs are statistically indistinguishable from those for non-securitizing BHCs. Both the mean and median of AVGMRSCORE for nonsecuritizing BHCs are greater than those of securitizing BHCs, suggesting that the nonsecuritizing BHCs originate more risky loans than securitizing BHCs. However, the magnitude of this difference is relatively small, as the standardized mean difference is only $6 \%$ of the standard deviation for the combined sample.

\subsection{The Effect of Transparency on Bank Lending De- cisions}

To test the effect of transparency on bank risk-taking in residential mortgage lending (H1), I estimate the difference-indifferences as the average of

$$
\left(X_{\text {Post }}^{\text {Treat }}-X_{\text {Pre }}^{\text {Treat }}\right)-\left(X_{\text {Post }}^{\text {Control }}-X_{\text {Pre }}^{\text {Control }}\right)
$$

where $X$ is a mortgage lending risk measure around each accounting pronouncement. I then test whether the DiD is significantly negative (positive) around transparency-enhancing (decreasing) events. Table 5.2 presents the results of these tests around each accounting

\footnotetext{
${ }^{1}$ Recall that $S A V G M R S C O R E$ is the average risk score of mortgages approved by a $\mathrm{BHC}$ in a given year divided by the average risk score of all mortgage applications received by the BHC during the year.
} 
pronouncement using the combined sample of public and private BHCs, the public-BHCsonly sample, and the private-BHCs-only sample. I distinguish between public and private BHCs for two reasons. First, the two groups are different in size and complexity, among other things, which may lead to differences in their lending decisions and in how they respond to transparency changes. Second, the accounting pronouncements would affect public BHCs' transparency more than that of private BHCs, because they primarily apply to public BHCs' financial reporting, e.g., annual reports. Both public and private BHCs, however, are affected by parallel changes in regulatory reporting standards that typically mirror GAAP.

Table 5.2 panel A presents the results for the first transparency event, FAS 125. H1 predicts that securitizing BHCs increase risk-taking following FAS 125 relative to nonsecuritzing BHCs (DiD>0), because FAS 125 decreases transparency. For brevity, I will first discuss the results for the combined sample and highlight the differences for the public BHCs and private BHCs sample. Contrary to H1, AVGM RSCORE decreased both for the control and for the treatment groups, and significantly so for the treatment group, resulting in a negative DiD. ${ }^{2} S A V G M R S C O R E$ increased for the control group and decreased for the treatment group, again contrary to H1. Both NHIGHRISK and $\$ H I G H R I S K$ decreased for both the treatment and control groups, with positive but statistically insignificant DiDs. While a positive DiD is consistent with $\mathrm{H} 1$, the lack of statistical significance means the full sample results do not support H1.

The results for the public and private BHCs subsamples lead to similar inferences, except for $\$ H I G H R I S K$ for the public BHCs subsample. When looking at public BHCs only, $\$ H I G H R I S K$ decreased for the control group and increased for the treatment group. Consistent with H1, the DiD is positive and significant at $10 \%$ (one-tailed). Overall, except for $\$ H I G H R I S K$ for public BHCs, I fail to reject the null hypothesis that securitizing BHCs' risk-taking in their mortgage lending decreases or remains the same following FAS 125, relative to risk-taking by non-securitizing BHCs. This result suggests that FAS 125 did not differentially affect securitizing BHCs' lending decisions. It is possible that FAS 125 did not affect transparency, or that any change in transparency triggered by FAS 125 did not affect lending decisions.

Table 5.2 panel B presents the results for FAS 140. H1 predicts that securitizing BHCs decrease risk-taking following FAS 140 more than non-securitizing BHCs $(\mathrm{DiD}<0)$ because FAS 140 enhances transparency. AVGMRSCORE increased significantly both for the treatment and for the control groups, and the DiD is positive but not significant.

${ }^{2}$ I use two-tailed significance for the pre-post differences for a single group (e.g., $\Delta$ Control for $A V G M R S C O R E$ ) because I do not have a directional prediction. 
$S A V G M R S C O R E$ decreased for both the treatment and the control groups, and the DiD is positive, contrary to $\mathrm{H} 1$, with a p-value of less than $10 \%$. NHIGHRISK decreased for the control group and increased for the treatment group, resulting in a positive DiD with a one-tailed p-value of less than 10\%. \$HIGHRISK increased for both the treatment and the control groups, with a positive DiD. Since DiD is positive for all the risk measures, I fail to reject the null hypothesis that risk-taking by securitizing BHCs increases or remains the same subsequent to FAS 140, relative to risk-taking by non-securitizing BHCs. The results are similar for the public and private subsamples. While the DiD for $\$ H I G H R I S K$ for the private BHCs subsample is negative, it is not statistically significant. As with FAS 125, I find no evidence supporting H1 for FAS 140.

Table 5.2 panel $\mathrm{C}$ presents the results for the third transparency event, FIN 46 (R). Similar to FAS 140, H1 predicts a negative DiD because FIN 46 (R) enhances transparency. The DiD has the expected negative sign for all the risk measures for the combined sample and the private BHCs sample, and for two of the risk measures for the public BHCs sample. While some pre-post differences are significant, all the DiDs lack statistical significance. These results suggest that FIN 46(R) did not differentially affect securitizing BHCs' lending decisions relative to that of the control group.

The last panel of table 5.2 presents the results for FAS 166 \& 167. Similar to FAS 140 and FIN 46(R), H1 predicts a negative DiD around FAS $166 \& 167$. AVGMRSCORE decreased significantly both for the treatment and for the control group, and more so for the control group. The DiD is positive with a p-value of less than 10\%. SAVGMRSCORE increased significantly for the treatment group, resulting in a positive DiD with p-value less than $5 \%$. In both cases, the positive DiD is contrary to H1. None of the pre-post differences or DiDs are significant for NHIGHRISK and $\$ H I G H R I S K$ in the combined sample. While the results are largely the same when looking at private BHCs only, I find some evidence that supports H1 from the public BHCs subsample. For the public subsample, both $N H I G H R I S K$ and $\$ H I G H R I S K$ decrease significantly following FAS 166 \& 167 with a negative DiD significant at the $10 \%$ and $5 \%$ levels, respectively.

In summary, I find some evidence that publicly traded BHCs increased their risk-taking following FAS 125 by increasing their credit supply to high-risk borrowers and that they deceased their risk-taking following FAS 166 \& 167 by decreasing their credit supply to high-risk borrowers. However, most of the tests fail to provide evidence supporting H1 that increasing (decreasing) transparency leads to lower (more) risk-taking by securitizing BHCs than non-securitizing BHCs. Another interpretation of these results is that transparency affects risk-taking but the accounting pronouncements do not significantly change transparency or that they change transparency in a manner or direction that differs from my expectation. 
Table 5.2: The Effect of Transparency on Bank Lending Decisions

\section{Panel A: FAS 125 (DiD $>0$ Predicted)}

I. Combined Sample of Public and Private BHCs

\begin{tabular}{|c|c|c|c|c|c|c|c|c|}
\hline & \multirow[b]{2}{*}{ Obs } & \multicolumn{2}{|c|}{ Pre-period } & \multicolumn{2}{|c|}{ Post-period } & \multicolumn{3}{|c|}{ Differences } \\
\hline & & Control & Treat & Control & Treat & $\Delta$ Control & $\Delta$ Treat & DiD \\
\hline$A V G M R S C O R E$ & 70 & 8.632 & 8.938 & 8.291 & 8.43 & $-0.341^{\dagger}$ & $-0.504^{* *}$ & -0.163 \\
\hline$S A V G M R S C O R E$ & 70 & 0.988 & 0.994 & 0.993 & 0.991 & $0.005^{*}$ & -0.003 & $-0.008^{\dagger}$ \\
\hline NHIGHRISK & 70 & 0.362 & 0.411 & 0.335 & 0.389 & -0.027 & -0.022 & 0.005 \\
\hline$\$ H I G H R I S K$ & 70 & 0.329 & 0.361 & 0.306 & 0.347 & -0.023 & -0.014 & 0.009 \\
\hline
\end{tabular}

II. Public BHCs Only

\begin{tabular}{|c|c|c|c|c|c|c|c|c|}
\hline & \multirow[b]{2}{*}{ Obs } & \multicolumn{2}{|c|}{ Pre-period } & \multicolumn{2}{|c|}{ Post-period } & \multicolumn{3}{|c|}{ Differences } \\
\hline & & Control & Treat & Control & Treat & $\Delta$ Control & $\Delta$ Treat & DiD \\
\hline$A V G M R S C O R E$ & 44 & 8.677 & 8.659 & 8.446 & -0.207 & -0.231 & $-0.420^{* *}$ & -0.189 \\
\hline$S A V G M R S C O R E$ & 44 & 0.989 & 0.995 & 0.992 & -0.002 & 0.003 & -0.006 & -0.009 \\
\hline NHIGHRISK & 44 & 0.378 & 0.359 & 0.362 & -0.010 & -0.016 & -0.007 & 0.008 \\
\hline$\$ H I G H R I S K$ & 44 & 0.341 & 0.306 & 0.313 & -0.003 & -0.027 & 0.004 & $0.031^{\dagger}$ \\
\hline
\end{tabular}

III. Private BHCs Only

\begin{tabular}{|c|c|c|c|c|c|c|c|c|}
\hline & \multirow[b]{2}{*}{ Obs } & \multicolumn{2}{|c|}{ Pre-period } & \multicolumn{2}{|c|}{ Post-period } & \multicolumn{3}{|c|}{ Differences } \\
\hline & & Control & Treat & Control & Treat & $\Delta$ Control & $\Delta$ Treat & DiD \\
\hline$A V G M R S C O R E$ & 26 & 8.555 & 9.409 & 8.028 & 0.735 & -0.527 & $-0.647^{\dagger}$ & -0.119 \\
\hline$S A V G M R S C O R E$ & 26 & 0.988 & 0.992 & 0.995 & -0.002 & $0.008^{\dagger}$ & 0.002 & -0.006 \\
\hline NHIGHRISK & 26 & 0.335 & 0.499 & 0.289 & 0.163 & -0.046 & -0.047 & -0.001 \\
\hline$\$ H I G H R I S K$ & 26 & 0.308 & 0.453 & 0.294 & 0.115 & -0.014 & -0.044 & -0.030 \\
\hline
\end{tabular}


- continued from previous page

Panel B: FAS 140 (DiD $<0$ Predicted $)$

I. Combined Sample of Public and Private BHCs

\begin{tabular}{|c|c|c|c|c|c|c|c|c|}
\hline & \multirow[b]{2}{*}{ Obs } & \multicolumn{2}{|c|}{ Pre-period } & \multicolumn{2}{|c|}{ Post-period } & \multicolumn{3}{|c|}{ Differences } \\
\hline & & Control & Treat & Control & Treat & $\Delta$ Control & $\Delta$ Treat & DiD \\
\hline$A V G M R S C O R E$ & 113 & 8.807 & 8.916 & 9.195 & 9.398 & $0.388^{* * *}$ & $0.482^{* * *}$ & 0.094 \\
\hline$S A V G M R S C O R E$ & 113 & 0.996 & 0.994 & 0.989 & 0.993 & $-0.007^{* *}$ & -0.0004 & $0.007^{*}$ \\
\hline NHIGHRISK & 113 & 0.360 & 0.352 & 0.352 & 0.370 & -0.007 & 0.018 & $0.025^{\dagger}$ \\
\hline$\$ H I G H R I S K$ & 113 & 0.335 & 0.324 & 0.337 & 0.336 & 0.001 & 0.012 & 0.011 \\
\hline
\end{tabular}

II. Public BHCs Only

\begin{tabular}{|c|c|c|c|c|c|c|c|c|}
\hline & \multirow[b]{2}{*}{ Obs } & \multicolumn{2}{|c|}{ Pre-period } & \multicolumn{2}{|c|}{ Post-period } & \multicolumn{3}{|c|}{ Differences } \\
\hline & & Control & Treat & Control & Treat & $\Delta$ Control & $\Delta$ Treat & DiD \\
\hline$A V G M R S C O R E$ & 60 & 8.795 & 8.831 & 9.131 & 9.380 & $0.336^{* *}$ & $0.549^{* * *}$ & $0.213^{\dagger}$ \\
\hline$S A V G M R S C O R E$ & 60 & 0.998 & 0.994 & 0.996 & 0.996 & -0.002 & 0.002 & 0.004 \\
\hline NHIGHRISK & 60 & 0.363 & 0.358 & 0.358 & 0.370 & -0.005 & 0.012 & 0.017 \\
\hline$\$ H I G H R I S K$ & 60 & 0.323 & 0.324 & 0.331 & 0.334 & 0.007 & 0.011 & 0.003 \\
\hline
\end{tabular}

III. Private BHCs Only

\begin{tabular}{|c|c|c|c|c|c|c|c|c|}
\hline & \multirow[b]{2}{*}{ Obs } & \multicolumn{2}{|c|}{ Pre-period } & \multicolumn{2}{|c|}{ Post-period } & \multicolumn{3}{|c|}{ Differences } \\
\hline & & Control & Treat & Control & Treat & $\Delta$ Control & $\Delta$ Treat & DiD \\
\hline$A V G M R S C O R E$ & 53 & 8.820 & 9.012 & 9.268 & 9.419 & $0.448^{* *}$ & $0.407^{\dagger}$ & -0.041 \\
\hline$S A V G M R S C O R E$ & 53 & 0.993 & 0.994 & 0.981 & 0.991 & $-0.013^{* * *}$ & -0.003 & $0.010^{\dagger}$ \\
\hline NHIGHRISK & 53 & 0.356 & 0.345 & 0.346 & 0.371 & -0.010 & 0.026 & 0.036 \\
\hline$\$ H I G H R I S K$ & 53 & 0.349 & 0.323 & 0.343 & 0.338 & -0.006 & 0.015 & 0.020 \\
\hline
\end{tabular}

Continued on next page- 
- continued from previous page

Panel C: FIN 46(R) $(\mathrm{DiD}<0$ Predicted $)$

I. Combined Sample of Public and Private BHCs

\begin{tabular}{|c|c|c|c|c|c|c|c|c|}
\hline & \multirow[b]{2}{*}{ Obs } & \multicolumn{2}{|c|}{ Pre-period } & \multicolumn{2}{|c|}{ Post-period } & \multicolumn{3}{|c|}{ Differences } \\
\hline & & Control & Treat & Control & Treat & $\Delta$ Control & $\Delta$ Treat & DiD \\
\hline$A V G M R S C O R E \mathrm{r}$ & 112 & 9.270 & 9.338 & 8.932 & 8.834 & $-0.339^{* *}$ & $-0.504^{* * *}$ & -0.165 \\
\hline$S A V G M R S C O R E$ & 112 & 0.994 & 0.996 & 0.993 & 0.994 & -0.0002 & -0.002 & -0.002 \\
\hline NHIGHRISK & 112 & 0.349 & 0.367 & 0.359 & 0.361 & 0.010 & -0.007 & -0.016 \\
\hline$\$ H I G H R I S K$ & 112 & 0.334 & 0.350 & 0.334 & 0.334 & 0.000 & -0.016 & -0.016 \\
\hline
\end{tabular}

II. Public BHCs Only

\begin{tabular}{|c|c|c|c|c|c|c|c|c|}
\hline & \multirow[b]{2}{*}{ Obs } & \multicolumn{2}{|c|}{ Pre-period } & \multicolumn{2}{|c|}{ Post-period } & \multicolumn{3}{|c|}{ Differences } \\
\hline & & Control & Treat & Control & Treat & $\Delta$ Control & $\Delta$ Treat & DiD \\
\hline$A V G M R S C O R E$ & 38 & 9.229 & 9.217 & 8.813 & 8.756 & $-0.416^{* * *}$ & $-0.461^{* * *}$ & -0.045 \\
\hline$S A V G M R S C O R E$ & 38 & 0.994 & 0.997 & 0.992 & 0.994 & -0.002 & $-0.003^{*}$ & -0.001 \\
\hline NHIGHRISK & 38 & 0.347 & 0.356 & 0.316 & 0.346 & $-0.031^{\dagger}$ & -0.010 & 0.021 \\
\hline$\$ H I G H R I S K$ & 38 & 0.324 & 0.336 & 0.282 & 0.309 & $-0.042^{*}$ & -0.027 & 0.016 \\
\hline
\end{tabular}

III. Private BHCs Only

\begin{tabular}{|c|c|c|c|c|c|c|c|c|}
\hline & \multirow[b]{2}{*}{ Obs } & \multicolumn{2}{|c|}{ Pre-period } & \multicolumn{2}{|c|}{ Post-period } & \multicolumn{3}{|c|}{ Differences } \\
\hline & & Control & Treat & Control & Treat & $\Delta$ Control & $\Delta$ Treat & DiD \\
\hline$A V G M R S C O R E$ & 74 & 9.291 & 9.400 & 8.992 & 8.874 & $-0.2999^{\dagger}$ & $-0.526^{* *}$ & -0.227 \\
\hline$S A V G M R S C O R E$ & 74 & 0.994 & 0.996 & 0.994 & 0.994 & 0.001 & -0.002 & -0.002 \\
\hline NHIGHRISK & 74 & 0.351 & 0.373 & 0.381 & 0.368 & 0.030 & -0.005 & -0.035 \\
\hline$\$ H I G H R I S K$ & 74 & 0.339 & 0.358 & 0.360 & 0.347 & 0.022 & -0.011 & -0.032 \\
\hline
\end{tabular}

Continued on next page- 
- continued from previous page

Panel D: FAS $166 \& 167(\mathrm{DiD}<0$ Predicted $)$

I. Combined Sample of Public and Private BHCs

\begin{tabular}{|c|c|c|c|c|c|c|c|c|}
\hline & \multirow[b]{2}{*}{ Obs } & \multicolumn{2}{|c|}{ Pre-period } & \multicolumn{2}{|c|}{ Post-period } & \multicolumn{3}{|c|}{ Differences } \\
\hline & & Control & Treat & Control & Treat & $\Delta$ Control & $\Delta$ Treat & DiD \\
\hline$A V G M R S C O R E$ & 174 & 10.939 & $10.657^{* * *}$ & 10.528 & 10.430 & $-0.411^{* * *}$ & $-0.227^{* *}$ & $0.185^{*}$ \\
\hline$S A V G M R S C O R E$ & 174 & 0.995 & 0.993 & 0.991 & 0.995 & -0.003 & $0.002^{*}$ & $0.006^{* *}$ \\
\hline NHIGHRISK & 174 & 0.433 & 0.423 & 0.425 & 0.409 & -0.008 & -0.013 & -0.005 \\
\hline$\$ H I G H R I S K$ & 174 & 0.388 & 0.393 & 0.389 & 0.383 & 0.0003 & -0.010 & -0.010 \\
\hline
\end{tabular}

III. Public BHCs Only

\begin{tabular}{|c|c|c|c|c|c|c|c|c|}
\hline & \multirow[b]{2}{*}{ Obs } & \multicolumn{2}{|c|}{ Pre-period } & \multicolumn{2}{|c|}{ Post-period } & \multicolumn{3}{|c|}{ Differences } \\
\hline & & Control & Treat & Control & Treat & $\Delta$ Control & $\Delta$ Treat & DiD \\
\hline$A V G M R S C O R E$ & 61 & 10.900 & 10.580 & 10.519 & 10.372 & $-0.382^{* *}$ & $-0.207^{\dagger}$ & $0.174^{\dagger}$ \\
\hline$S A V G M R S C O R E$ & 61 & 0.993 & 0.993 & 0.995 & 0.994 & 0.001 & 0.001 & 0.000 \\
\hline NHIGHRISK & 61 & 0.454 & 0.406 & 0.447 & 0.370 & -0.007 & $-0.036^{*}$ & $-0.029^{*}$ \\
\hline$\$ H I G H R I S K$ & 61 & 0.399 & 0.367 & 0.403 & 0.328 & 0.004 & $-0.039^{* *}$ & $-0.043^{* *}$ \\
\hline
\end{tabular}

III. Private BHCs Only

\begin{tabular}{|c|c|c|c|c|c|c|c|c|}
\hline & \multirow[b]{2}{*}{ Obs } & \multicolumn{2}{|c|}{ Pre-period } & \multicolumn{2}{|c|}{ Post-period } & \multicolumn{3}{|c|}{ Differences } \\
\hline & & Control & Treat & Control & Treat & $\Delta$ Control & $\Delta$ Treat & DiD \\
\hline$A V G M R S C O R E$ & 113 & 10.960 & 10.698 & 10.533 & 10.461 & $-0.427^{* * *}$ & $-0.237^{\dagger}$ & $0.190^{\dagger}$ \\
\hline$S A V G M R S C O R E$ & 113 & 0.995 & 0.993 & 0.989 & 0.996 & $-0.006^{* *}$ & $0.003^{\dagger}$ & $0.009^{* * *}$ \\
\hline NHIGHRISK & 113 & 0.422 & 0.431 & 0.412 & 0.430 & -0.009 & -0.001 & 0.008 \\
\hline$\$ H I G H R I S K$ & 113 & 0.383 & 0.407 & 0.381 & 0.412 & -0.002 & 0.005 & 0.007 \\
\hline
\end{tabular}

This table presents the results of the DiD tests for $\mathbf{H 1}$ using the BHC-level measures of risk-taking in residential mortgage lending. Obs reflects the number treatment-control pairs with observations in both the pre and post periods. For each risk measure, $\Delta$ Control is the average value in the post-period minus the average value in the pre-period for the control group. Similarly, $\Delta$ Treat is the pre-post difference for the treatment group. DiD is the difference between $\Delta$ Treat and $\Delta$ Control. ${ }^{* * *},{ }^{* *},{ }^{*},{ }^{\dagger}$ represent p-values below $1 \%, 5 \%, 10 \%$, and $20 \%$, respectively, from the mean tests comparing the corresponding values to zero. All variables are as defined in appendix A.1. 


\subsection{Moderators}

The remaining hypotheses examine the moderating effects of corporate governance (H2), regulatory oversight $(\mathbf{H 3})$, and market discipline $(\mathbf{H 4})$. To test each of these hypotheses, I first obtain a proxy for the corresponding BHC characteristics, and partition the sample in to Low and High groups, based on a median split. Similar to the main DiD design, I form the groups in the year immediately prior to each pronouncement. I then compare the difference in lending decisions between BHCs in the Low and High groups before and after each treatment. I refer to this research design as a quasi difference-in-differences (QDiD) design because, unlike a DiD design, the low and high groups are not matched to ensure all other factors are comparable across groups.

$$
Q D i D=\left(X_{\text {Post }}^{\text {Low }}-X_{\text {Pre }}^{\text {Low }}\right)-\left(X_{\text {Post }}^{\text {High }}-X_{\text {Pre }}^{\text {High }}\right)
$$

In each case, the Low group represents the sub-sample that faces more monitoring and discipline from the corresponding stakeholder when transparency increases. Table 5.3 shows the distribution of the moderating variables across the high and low groups. In all the cases, both the mean and the median are significantly different across the two groups. In untabulated analyses, I also test these hypotheses using a triple-differences design that relies on the matched sample of non-securitizing BHCs as controls for each of the Low and High groups. The findings from these triple-differences tests are qualitatively similar to those presented below.

\subsubsection{Corporate Governance}

To test H2, I partition the sample of securitizing BHCs based on the proportion of managerial ownership, using data from Compustat Executive Compensation (ExecuComp) database. The maintained assumption is that high share ownership better aligns managers' incentives with those of current shareholders' than low share ownership. This test faces a challenge because ExecuComp covers only a small portion of public securitizing BHCs in my sample, resulting in a very small sample to test H2. To address the sample size issue, I also test $\mathrm{H} 2$ using a different strategy. I compare the lending decisions of all public securitizing BHCs with those of private securitizing BHCs. I expect that private BHCs have greater manager-shareholder alignment because their ownership is less dispersed, which should improve monitoring, relative to public BHCs' dispersed ownership.

Table 5.4 panel A presents the results for FAS 125. H2 predicts that, because FAS 125 decreases transparency, securitizing BHCs with weak manager-shareholder alignment 
Table 5.3: Descriptive Statistics for Moderating Variables

\begin{tabular}{lcccc}
\hline & N & Mean & Median & St. Dev. \\
Panel A: Whole Sample & & & & \\
\hline MGTOWNERSHIP & 914 & 0.021 & 0.009 & 0.084 \\
TIER1CAPRATIO & 5997 & 0.126 & 0.119 & 0.044 \\
COREDEPRATIO & 6489 & 0.848 & 0.867 & 0.090 \\
\hline
\end{tabular}

Panel B: High Group

\begin{tabular}{lcccc}
\hline MGTOWNERSHIP & 518 & 0.033 & 0.016 & 0.110 \\
TIER1CAPRATIO & 2581 & 0.157 & 0.146 & 0.045 \\
COREDEPRATIO & 3605 & 0.902 & 0.902 & 0.037 \\
\hline
\end{tabular}

Panel C: Low Group

\begin{tabular}{lclll}
\hline MGTOWNERSHIP & 396 & $0.004^{* * *}$ & $0.004^{* * *}$ & 0.002 \\
TIER1CAPRATIO & 3416 & $0.101^{* * *}$ & $0.104^{* * *}$ & 0.022 \\
COREDEPRATIO & 2884 & $0.781^{* * *}$ & $0.800^{* * *}$ & 0.092 \\
\hline
\end{tabular}

This table presents the descriptive statistics for the moderating variables. Panel A presents the statistics for all observations with non-missing value for each variable. Panel B presents the statistics for BHC-year observations in the High groups based the corresponding variables. For example, the MGTOWNERSHIP row in panel B contains descriptive statistics of MGTOWNERSHIP for the High management ownership group, i.e., above-median ownership. Similarly, panel C contains the statistics for the Low groups based on the corresponding variables. ${ }^{* * *},{ }^{* *},{ }^{*}$ in panel $\mathrm{C}$ represent p-values below $1 \%, 5 \%, 10 \%$, respectively, from the mean and median tests of the High versus Low groups. All variables are as defined in appendix A.1 
decrease their risk-taking following FAS 125, while BHCs with strong manager-shareholder alignment should show no change in risk-taking.

The first part of panel A shows that FAS 125 did not affect the low and high share ownership groups differently, in the very small sample with ExecuComp data. The lack of significance may arise from the small sample size. The test sample contains only four BHCs in the high group and only five BHCs in the low group.

The second part of panel A presents the alternative test comparing public and private securitizing BHCs. AVGMRSCORE decreased significantly for both private and public BHCs following FAS 125, and it decreased more for the private BHCs. The $Q D i D$ is positive and not statistically significant. The pre-post differences in NHIGHRISK and $\$ H I G H R I S K$ are not significant, but the corresponding QDiDs are positive with onetailed p-value less than $10 \%$. Since a positive $Q D i D$ is inconsistent with $\mathrm{H} 2$, the alternative tests also fail to reject the null hypothesis that risk-taking by securitizing BHCs with greater manager-shareholder alignment increases or remains the same following FAS 125, relative to securitizing BHCs with lower manager-shareholder alignment.

Table 5.4 panel B presents the results for the second accounting pronouncement, FAS 140. Since I expect FAS 140 increases transparency, H2 predicts that securitizing BHCs with weak manager-shareholder alignment increase their risk-taking, whereas BHCs with strong manager-shareholder alignment do not change their lending decisions. The first part of panel B shows that, contrary to my hypothesis, AVGMRSCORE increased both for the high and for the low managerial ownership groups, and it increased more for the high group, resulting in a negative $Q D i D$. None of the pre-post differences or $Q D i D$ s are significant for the other three risk measures. The results from the alternative test in panel $\mathrm{B}$ are qualitatively similar to those in panel A. In summary, I find no evidence supporting H2 around FAS 140.

Table 5.4 panel C presents the results for FIN 46(R). Similar to FAS 140, H2 predicts greater risk-taking for BHCs with weak manager-shareholder alignment and no change for BHCs with strong manager-shareholder alignment following FIN 46(R). The results presented in panel $\mathrm{C}$ provide no evidence supporting $\mathrm{H} 2$ around FIN 46(R). While some of the $Q D i D$ s in parts I and II are negative, which is consistent with $\mathrm{H} 2$, none of them are statistically significant.

The results for FAS $166 \& 167$ are in table 5.4 panel D. Similar to FAS 140 and FIN 46(R), H2 predicts greater risk-taking for BHCs with weak manager-shareholder alignment and no change for BHCs with strong manager-shareholder alignment following FAS 166 $\& 167$. I find mixed results for FAS $166 \& 167$. In part I of panel $\mathrm{D}$, the $Q D i D$ for AVGMRSCORE is positive with and significant at $10 \%$ (one-tailed), however the result is 
driven by a decrease in $A V G M R S C O R E$ for the high group. None of the other differences in part I of panel A are significant. In part II of panel D, the QDiD for NHIGHRISK and $\$ H I G H R I S K$ is negative with one-tailed p-values of less than $10 \%$ and $5 \%$, respectively. In both cases, the negative $Q D i D$ is driven by a significant decrease for the public BHCs. In summary, with one exception, the results do not support $\mathrm{H} 2$.

Overall, there is little evidence supporting H2, suggesting that the accounting pronouncements did not affect securitizing BHCs with weak manager-shareholder alignment differently than they affected securitizing BHCs with strong alignment. Moreover, in line with the results for $\mathrm{H} 1$, there is little evidence supporting the hypothesized main effect of transparency on BHCs' lending decisions.

Table 5.4: The Moderating Role of Manager-shareholder Alignment

Panel A: FAS $125($ QDiD $<0$ Predicted)

I. Public Securitizing BHCs with High vs. Low Managerial Ownership

\begin{tabular}{|c|c|c|c|c|c|c|c|c|c|}
\hline & \multicolumn{2}{|c|}{ Obs } & \multicolumn{2}{|c|}{ Pre-period } & \multicolumn{2}{|c|}{ Post-period } & \multicolumn{3}{|c|}{ Differences } \\
\hline & High & Low & High & Low & High & Low & $\Delta$ High & $\Delta$ Low & QDiD \\
\hline$A V G M R S C O R E$ & 4 & 5 & 8.909 & 8.880 & 8.585 & 8.284 & -0.325 & -0.596 & -0.271 \\
\hline$S A V G M R S C O R E$ & 4 & 5 & 0.998 & 0.992 & 0.992 & 0.998 & -0.006 & 0.006 & 0.012 \\
\hline NHIGHRISK & 4 & 5 & 0.431 & 0.339 & 0.433 & 0.380 & 0.002 & 0.041 & 0.039 \\
\hline$\$ H I G H R I S K$ & 4 & 5 & 0.385 & 0.313 & 0.387 & 0.347 & 0.002 & 0.034 & 0.032 \\
\hline
\end{tabular}

II. Public securitizing BHCs Vs. Private securitizing BHCs

\begin{tabular}{|c|c|c|c|c|c|c|c|c|c|}
\hline & \multicolumn{2}{|c|}{ Obs } & \multicolumn{2}{|c|}{ Pre-period } & \multicolumn{2}{|c|}{ Post-period } & \multicolumn{3}{|c|}{ Differences } \\
\hline & Private & Public & Private & Public & Private & Public & $\Delta$ Private & $\Delta$ Public & QDiD \\
\hline$A V G M R S C O R E$ & 26 & 44 & 9.409 & 8.659 & 8.763 & 8.239 & $-0.647^{\dagger}$ & $-0.420^{* *}$ & 0.227 \\
\hline$S A V G M R S C O R E$ & 26 & 44 & 0.992 & 0.995 & 0.994 & 0.990 & 0.002 & -0.006 & -0.008 \\
\hline NHIGHRISK & 26 & 44 & 0.499 & 0.359 & 0.451 & 0.351 & -0.047 & -0.007 & $0.040^{\dagger}$ \\
\hline$\$ H I G H R I S K$ & 26 & 44 & 0.453 & 0.306 & 0.409 & 0.310 & -0.044 & 0.004 & $0.047^{\dagger}$ \\
\hline
\end{tabular}

Continued on next page- 
- continued from previous page

Panel B: FAS 140 (QDiD $>0$ Predicted)

I. Public Securitizing BHCs with High vs. Low Managerial Ownership

\begin{tabular}{|c|c|c|c|c|c|c|c|c|c|}
\hline & \multicolumn{2}{|c|}{ Obs } & \multicolumn{2}{|c|}{ Pre-period } & \multicolumn{2}{|c|}{ Post-period } & \multicolumn{3}{|c|}{ Differences } \\
\hline & High & Low & High & Low & High & Low & $\Delta$ High & $\Delta$ Low & QDiD \\
\hline$A V G M R S C O R E$ & 13 & 13 & 8.844 & 8.975 & 9.474 & 9.276 & $0.631^{*}$ & $0.302^{\dagger}$ & $-0.329^{\dagger}$ \\
\hline$S A V G M R S C O R E$ & 13 & 13 & 0.999 & 0.992 & 1.000 & 0.992 & 0.001 & 0.001 & 0.000 \\
\hline NHIGHRISK & 13 & 13 & 0.356 & 0.366 & 0.369 & 0.379 & 0.014 & 0.013 & 0.000 \\
\hline$\$ H I G H R I S K$ & 13 & 13 & 0.316 & 0.323 & 0.324 & 0.333 & 0.008 & 0.010 & 0.002 \\
\hline
\end{tabular}

II. Public securitizing BHCs Vs. Private securitizing BHCs

\begin{tabular}{|c|c|c|c|c|c|c|c|c|c|}
\hline & $\mathrm{Ol}$ & & Pre-p & eriod & Post-p & eriod & & ifferences & \\
\hline & Private & Public & Private & Public & Private & Public & $\Delta$ Private & $\Delta$ Public & QDiD \\
\hline$A V G M R S C O R E$ & 53 & 60 & 9.012 & 8.831 & 9.419 & 9.380 & $0.407^{\dagger}$ & $0.549^{* * *}$ & 0.142 \\
\hline$S A V G M R S C O R E$ & 53 & 60 & 0.994 & 0.994 & 0.991 & 0.996 & -0.003 & 0.002 & 0.005 \\
\hline NHIGHRISK & 53 & 60 & 0.345 & 0.358 & 0.371 & 0.370 & 0.026 & 0.012 & -0.014 \\
\hline$\$ H I G H R I S K$ & 53 & 60 & 0.323 & 0.324 & 0.338 & 0.334 & 0.015 & 0.011 & -0.004 \\
\hline
\end{tabular}

Continued on next page- 
- continued from previous page

\section{Panel C: FIN 46 (R) (QDiD $>0$ Predicted)}

I. Public Securitizing BHCs with High vs. Low Managerial OwnershipCs

\begin{tabular}{|c|c|c|c|c|c|c|c|c|c|}
\hline & \multicolumn{2}{|c|}{ Obs } & \multicolumn{2}{|c|}{ Pre-period } & \multicolumn{2}{|c|}{ Post-period } & \multicolumn{3}{|c|}{ Differences } \\
\hline & High & Low & High & Low & High & Low & $\Delta$ High & $\Delta$ Low & QDiD \\
\hline$A V G M R S C O R E$ & 8 & 7 & 9.324 & 9.205 & 8.971 & 8.697 & -0.353 & $-0.508^{*}$ & -0.156 \\
\hline$S A V G M R S C O R E$ & 8 & 7 & 0.998 & 0.996 & 0.996 & 0.999 & -0.002 & 0.003 & 0.005 \\
\hline NHIGHRISK & 8 & 7 & 0.308 & 0.359 & 0.356 & 0.363 & 0.047 & 0.004 & -0.043 \\
\hline$\$ H I G H R I S K$ & 8 & 7 & 0.293 & 0.338 & 0.305 & 0.321 & 0.012 & -0.017 & -0.029 \\
\hline
\end{tabular}

II. Public securitizing BHCs Vs. Private securitizing BHCs

\begin{tabular}{|c|c|c|c|c|c|c|c|c|c|}
\hline & \multicolumn{2}{|c|}{ Obs } & \multicolumn{2}{|c|}{ Pre-period } & \multicolumn{2}{|c|}{ Post-period } & \multicolumn{3}{|c|}{ Differences } \\
\hline & Private & Public & Private & Public & Private & Public & $\Delta$ Private & $\Delta$ Public & QDiD \\
\hline$A V G M R S C O R E$ & 74 & 38 & 9.400 & 9.217 & 8.874 & 8.756 & $-0.526^{* *}$ & $-0.461^{* * *}$ & 0.065 \\
\hline$S A V G M R S C O R E$ & 74 & 38 & 0.996 & 0.997 & 0.994 & 0.994 & -0.002 & $-0.003^{*}$ & -0.001 \\
\hline NHIGHRISK & 74 & 38 & 0.373 & 0.356 & 0.368 & 0.346 & -0.005 & -0.010 & -0.005 \\
\hline$\$ H I G H R I S K$ & 74 & 38 & 0.358 & 0.336 & 0.347 & 0.309 & -0.011 & -0.027 & -0.016 \\
\hline
\end{tabular}

Continued on next page- 
- continued from previous page

\section{Panel D: FAS $166 \& 167$ (QDiD>0 Predicted)}

\section{Public Securitizing BHCs with High vs. Low Managerial Ownership}

\begin{tabular}{|c|c|c|c|c|c|c|c|c|c|}
\hline & \multicolumn{2}{|c|}{ Obs } & \multicolumn{2}{|c|}{ Pre-period } & \multicolumn{2}{|c|}{ Post-period } & \multicolumn{3}{|c|}{ Differences } \\
\hline & High & Low & High & Low & High & Low & $\Delta$ High & $\Delta$ Low & QDiD \\
\hline$A V G M R S C O R E$ & 14 & 14 & 10.783 & 10.766 & 10.546 & 10.772 & -0.236 & 0.006 & $0.242^{\dagger}$ \\
\hline$S A V G M R S C O R E$ & 14 & 14 & 0.993 & 0.993 & 0.995 & 0.995 & 0.001 & 0.002 & 0.001 \\
\hline NHIGHRISK & 14 & 14 & 0.409 & 0.438 & 0.379 & 0.406 & -0.030 & -0.032 & -0.002 \\
\hline$\$ H I G H R I S K$ & 14 & 14 & 0.358 & 0.382 & 0.335 & 0.343 & -0.023 & -0.039 & -0.016 \\
\hline
\end{tabular}

II. Public securitizing BHCs Vs. Private securitizing BHCs

\begin{tabular}{|c|c|c|c|c|c|c|c|c|c|}
\hline & \multicolumn{2}{|c|}{ Obs } & \multicolumn{2}{|c|}{ Pre-period } & \multicolumn{2}{|c|}{ Post-period } & \multicolumn{3}{|c|}{ Differences } \\
\hline & Private & Public & Private & Public & Private & Public & $\Delta$ Private & $\Delta$ Public & QDiD \\
\hline$A V G M R S C O R E$ & 113 & 61 & 10.698 & 10.580 & 10.461 & 10.372 & $-0.237^{\dagger}$ & $-0.207^{\dagger}$ & 0.030 \\
\hline$S A V G M R S C O R E$ & 113 & 61 & 0.993 & 0.993 & 0.996 & 0.994 & $0.003^{\dagger}$ & 0.001 & -0.001 \\
\hline NHIGHRISK & 113 & 61 & 0.431 & 0.406 & 0.430 & 0.370 & -0.001 & $-0.036^{*}$ & $-0.035^{\dagger}$ \\
\hline$\$ H I G H R I S K$ & 113 & 61 & 0.407 & 0.367 & 0.412 & 0.328 & 0.005 & $-0.039^{* *}$ & $-0.045^{*}$ \\
\hline
\end{tabular}

This table presents the results of the quasi-DiD tests for H2. The High group is composed of securitizing BHCs with above-median managerial ownership, and the Low group is composed of those with belowmedian managerial ownership. Obs in columns (1) and (2) reflects the number observation in the high and low groups with observations in both the pre and post periods, respectively. For each risk measure, $\Delta \mathbf{H i g h}$ is the average value in the post-period minus the average value in the pre-period for the high group. Similarly, $\Delta$ Low is the pre-post difference for the low group. QDiD is the difference between $\Delta$ Low and $\Delta$ High. Similarly, for the private vs public comparisons in part II of each panel, $\Delta$ Private and $\Delta$ Public refer to the pre-post change for private and public securitizing BHCs, respectively. QDiD refers to the difference between $\Delta$ Private and $\Delta$ Public. ${ }^{* * *},{ }^{* *},{ }^{*},{ }^{\dagger}$ represent p-values below $1 \%, 5 \%, 10 \%$, and $20 \%$, respectively, from the mean tests comparing the corresponding values to zero. All variables are as defined in appendix A.1. 


\subsubsection{Regulatory Oversight}

To test H3, I partition the sample of securitizing BHCs into Low and High groups based on their Tier 1 Capital ratio. BHCs with low Tier 1 Capital ratio (i.e., capital-constrained BHCs) are more likely to face strict regulatory oversight than BHCs with high Tier 1 Capital ratio. Transparency would strengthen regulators' ability to monitor capital-constrained BHCs, leading to lower risk-taking by these BHCs.

As shown in table 5.3, the average Tier 1 Capital ratio for the Low group is significantly lower than that of High group. However, the median Tier 1 capital ratio for the Low group is $10 \%$, indicating that most BHCs in this group are sufficiently capitalized. The ideal Low group for this test is the set of BHCs that are close to violating the minimum Tier 1 Capital requirement. The number of such cases in my test periods around the pronouncements is limited, which why I decided to rely on the median split. I acknowledge that this reduces the power of my test, and that I am trading-off lack of power from low number of observations with lack of power from weak contrast between the Low and High groups.

Table 5.5 panel A presents the results for FAS 125. Under the maintained assumption that FAS 125 reduces transparency, H3 predicts that BHCs with low Tier 1 Capital ratio increase their risk-taking more that those with high Tier 1 Capital ratio, following FAS 125. AVGMRSCORE decreased significantly for low group, and the $Q D i D$ is negative with a one-tailed p-value of less than $10 \%$, contrary to the prediction. The results for NHIGHRISK and $\$ H I G H R I S K$ are similar. These results suggest that more capital-constrained securitizing BHCs decreased their risk-taking more than lessconstrained BHCs, contrary to H3.

Table 5.5 panel B contains the results for FAS 140, which I expect increases transparency. H3 predicts that securitizing BHCs in the low group decrease their risk-taking following FAS 140 more than those in the high group. AVGMRSCORE increased significantly for both the high and low Tier 1 Capital ratio groups, contrary to prediction. None of the other pre-post differences or $Q D i D$ s are significant. These results suggest that FAS 140 did not differentially affect BHCs based on their Tier 1 Capital ratio.

The results in table 5.5 panel $\mathrm{C}$ reflect the effects of FIN 46(R) on securitizing BHCs conditional on the levels of their TIer 1 Capital ratio. Similar to FAS 140, H3 predicts that poorly capitalized securitizing BHCs decrease their risk-taking following FAS 125 more than well-capitalized BHCs. Following FIN 46 (R), AVGMRSCORE decreased significantly for both the high and the low groups, but the $Q D i D$ is not significantly different from zero. I find no significant pre-post differences for the other risk measures. However, the $Q D i D \mathrm{~s}$ for NHIGHRISK and $\$ H I G H R I S K$ are positive, contrary to H3, with a one-tailed pvalue of less $10 \%$. These results suggest that securitizing BHCs with low Tier 1 capital 
ratio increased their risk-taking following FIN $46(\mathrm{R})$, which is consistent with Acharya et al. (2013) finding that banks with low Tier 1 leverage ratio used special securitization conduits to avoid consolidation per FIN 46(R).

Table 5.5 panel D presents the results for FAS $166 \&$ 167. Similar to FAS 140 and FIN 46(R), H3 predicts a negative QDiD around FAS 166 \& 167. AVGM RSCORE decreased significantly for well-capitalized BHCs, whereas the pre-post change is not significantly different from zero for the low group. The $Q D i D$ is positive with a one-tailed p-value less than $10 \%$. SAVGMRSCORE did not change significantly for the high group, and it increased significantly for the low group, resulting in a positive $Q D i D$ with a one-tailed p-value less than 10\%. The pre-post differences in NHIGHRISK and \$HIGHRISK are not statistically significant for both the high and low groups. However, the $Q D i D$ is positive in both cases and has a one-tailed p-value less than $10 \%$ for $\$ H I G H R I S K$. In summary, the evidence in panel $\mathrm{D}$ does not support $\mathrm{H} 3$, as all the $Q D i D$ s are positive. 
Table 5.5: The Moderating Role of Regularity Oversight

Panel A: FAS 125 (QDiD $>0$ Predicted)

\begin{tabular}{|c|c|c|c|c|c|c|c|c|c|}
\hline & \multirow[b]{2}{*}{ High } & \multirow[b]{2}{*}{ Low } & \multicolumn{2}{|c|}{ Pre-period } & \multicolumn{2}{|c|}{ Post-period } & \multicolumn{3}{|c|}{ Differences } \\
\hline & & & High & Low & High & Low & $\Delta$ High & $\Delta$ Low & QDiD \\
\hline$A V G M R S C O R E$ & 34 & 36 & 8.808 & 9.060 & 8.489 & 8.381 & -0.319 & $-0.679^{* *}$ & $-0.361^{\dagger}$ \\
\hline$S A V G M R S C O R E$ & 34 & 36 & 0.991 & 0.996 & 0.994 & 0.988 & 0.003 & -0.008 & -0.011 \\
\hline NHIGHRISK & 34 & 36 & 0.420 & 0.402 & 0.424 & 0.355 & 0.004 & $-0.047^{\dagger}$ & $-0.051^{*}$ \\
\hline$\$ H I G H R I S K$ & 34 & 36 & 0.374 & 0.348 & 0.384 & 0.312 & 0.009 & -0.036 & $-0.045^{\dagger}$ \\
\hline
\end{tabular}

Panel B: FAS 140 (QDiD $<0$ Predicted)

\begin{tabular}{|c|c|c|c|c|c|c|c|c|c|}
\hline & \multirow[b]{2}{*}{ High } & \multirow[b]{2}{*}{ Low } & \multicolumn{2}{|c|}{ Pre-period } & \multicolumn{2}{|c|}{ Post-period } & \multicolumn{3}{|c|}{ Differences } \\
\hline & & & High & Low & High & Low & $\Delta$ High & $\Delta$ Low & QDiD \\
\hline$A V G M R S C O R E$ & 56 & 57 & 9.019 & 8.815 & 9.510 & 9.288 & $0.491^{* *}$ & $0.474^{* * *}$ & -0.017 \\
\hline$S A V G M R S C O R E$ & 56 & 57 & 0.994 & 0.994 & 0.992 & 0.995 & -0.002 & 0.001 & 0.003 \\
\hline NHIGHRISK & 56 & 57 & 0.356 & 0.348 & 0.368 & 0.372 & 0.012 & 0.024 & 0.012 \\
\hline$\$ H I G H R I S K$ & 56 & 57 & 0.326 & 0.322 & 0.334 & 0.338 & 0.008 & 0.017 & 0.008 \\
\hline
\end{tabular}

Panel C: FIN 46 (R) (QDiD $<0$ Predicted)

\begin{tabular}{|c|c|c|c|c|c|c|c|c|c|}
\hline & \multirow[b]{2}{*}{ High } & \multirow[b]{2}{*}{ Low } & \multicolumn{2}{|c|}{ Pre-period } & \multicolumn{2}{|c|}{ Post-period } & \multicolumn{3}{|c|}{ Differences } \\
\hline & & & High & Low & High & Low & $\Delta$ High & $\Delta$ Low & QDiD \\
\hline$A V G M R S C O R E$ & 57 & 55 & 9.389 & 9.284 & 8.873 & 8.793 & $-0.516^{* *}$ & $-0.491^{* *}$ & 0.025 \\
\hline$S A V G M R S C O R E$ & 57 & 55 & 0.997 & 0.995 & 0.994 & 0.995 & -0.003 & -0.001 & 0.003 \\
\hline NHIGHRISK & 57 & 55 & 0.386 & 0.348 & 0.355 & 0.367 & -0.031 & 0.018 & $0.049^{\dagger}$ \\
\hline$\$ H I G H R I S K$ & 57 & 55 & 0.371 & 0.328 & 0.333 & 0.335 & -0.039 & 0.007 & $0.046^{\dagger}$ \\
\hline
\end{tabular}

Panel D: FAS $166 \& 167($ QDiD $<0$ Predicted $)$

\begin{tabular}{|c|c|c|c|c|c|c|c|c|c|}
\hline & \multirow[b]{2}{*}{ High } & \multirow[b]{2}{*}{ Low } & \multicolumn{2}{|c|}{ Pre-period } & \multicolumn{2}{|c|}{ Post-period } & \multicolumn{3}{|c|}{ Differences } \\
\hline & & & High & Low & High & Low & $\Delta$ High & $\Delta$ Low & QDiD \\
\hline$A V G M R S C O R E$ & 93 & 81 & 10.687 & 10.622 & 10.352 & 10.519 & $-0.335^{* *}$ & -0.102 & $0.233^{\dagger}$ \\
\hline$S A V G M R S C O R E$ & 93 & 81 & 0.993 & 0.992 & 0.994 & 0.996 & 0.001 & $0.004^{*}$ & $0.003^{\dagger}$ \\
\hline NHIGHRISK & 93 & 81 & 0.420 & 0.425 & 0.397 & 0.423 & -0.023 & -0.002 & 0.021 \\
\hline$\$ H I G H R I S K$ & 93 & 81 & 0.391 & 0.395 & 0.365 & 0.403 & -0.026 & 0.008 & $0.034^{\dagger}$ \\
\hline
\end{tabular}

Continued on next page- 


\section{- continued from previous page}

This table presents the results of the quasi-DiD tests for H3. The High group is composed of securitizing BHCs with above-median Tier 1 Capital ratio, and the Low group is composed of those with below-median Tier 1 Capital ratio. Obs in columns (1) and (2) reflects the number observation in the high and low groups with observations in both the pre and post periods, respectively. For each risk measure, $\Delta \mathbf{H i g h}$ is the average value in the post-period minus the average value in the pre-period for the high group. Sim-

ilarly, $\Delta$ Low is the pre-post difference for the low group. QDiD is the difference between $\Delta$ Low and $\Delta$ High. ${ }^{* * *},{ }^{* *},{ }^{*},{ }^{\dagger}$ represent p-values below $1 \%, 5 \%, 10 \%$, and $20 \%$, respectively, from the mean tests comparing the corresponding values to zero. All variables are as defined in appendix A.1. 


\subsubsection{Market Discipline}

To test H4, I partition the sample of securitizing BHCs into low and high groups based on their core deposit ratios. Core deposits, which include demand deposits, NOW accounts, money market accounts, and time deposits less than $\$ 100,000$ (raised to $\$ 250,000$ in 2008), are primarily insured by the Federal Deposit Insurance Corporation. ${ }^{3}$ Insured depositors have no incentive to monitor, but other capital providers (uninsured depositors and bondholders) have this incentive.

Table 5.6 panel A presents the results for FAS 125. H4 predicts that BHCs with low core deposit ratios (i.e., high uninsured deposits ratio) would increase their risk-taking following FAS 125 more than BHCs with high core deposits, leading to a positive $Q D i D$. Panel A shows that AVGMRSCORE significantly decreased for both the high and the low core deposit ratio groups, and the $Q D i D$ is negative but insignificant. For the other three risk measures, none of the pre-post differences and $Q D i D$ s are significant. In all cases, the $Q D i D$ is negative, contrary to prediction.

$\mathrm{H} 4$ predicts that BHCs with low core deposit ratios decrease their risk-taking following FAS 140 more than those with high ratios, leading to a negative QDID. Table 5.6 panel B presents the results for FAS 140. AVGMRSCORE increased both for the high and for the low groups, but the $Q D i D$ is statistically indistinguishable from zero. Similar to FAS 125, the other three measures do not change significantly around FAS 140. I find no evidence supporting H4 around FAS 140.

Table 5.6 panel C contains the results for FIN 46(R). As for FAS 140, H4 predicts that BHCs in the low group decrease their risk-taking more than BHCs with in the high group. As in the previous two cases, I do not find any evidence supporting H4 around FIN 46(R). While $A V G M R S C O R E$ decreased significantly both for the high and for the low groups, none of the other pre-post differences and $Q D I D$ s are statistically significant.

The results for FAS 166 \& 167, presented in table 5.6 panel D, paint a similar picture. I find no evidence supporting H4. The QDiDs for NHIGHRISK and $\$ H I G H R I S K$ have one-tailed p-values less than $5 \%$ and $10 \%$, respectively. However, both $Q D i D$ s are positive, which is contrary to $\mathrm{H} 4$.

In summary, I find little evidence supporting the hypotheses that manager-shareholder alignment $(\mathrm{H} 2)$, regulatory ratios $(\mathrm{H} 3)$, and market discipline (H4) moderate the effect of transparency on bank lending decisions. These results are not surprising given that, in section 5.3, I find little evidence supporting the main effect. The lack of evidence

\footnotetext{
${ }^{3}$ https://www.fdic.gov/deposit/deposits/ accessed on September 26, 2018.
} 
supporting my hypotheses can be due to the following reasons. First, it is possible that transparency does not affect bank lending decisions as hypothesized. Second, it is possible that the research design lacks power to identify the hypothesized effects. For example, the propensity score matching may not lead to otherwise identical treatment-control pairs. Third, the accounting pronouncements may not affect transparency, at least not in the expected direction, and the transparency implications of the pronouncements may vary across stakeholders. Last, despite the validation tests in chapter 4, the risk measures may not capture the desired underlying construct, namely bank risk-taking in mortgage lending. In the next subsection, I perform additional analyses to address these concerns to the extent possible. 
Table 5.6: The Moderating Role of Market Discipline

Panel A: FAS 125 (QDiD $>0$ Predicted)

\begin{tabular}{|c|c|c|c|c|c|c|c|c|c|}
\hline & \multirow[b]{2}{*}{ High } & \multirow[b]{2}{*}{ Low } & \multicolumn{2}{|c|}{ Pre-period } & \multicolumn{2}{|c|}{ Post-period } & \multicolumn{3}{|c|}{ Differences } \\
\hline & & & High & Low & High & Low & $\Delta$ High & $\Delta$ Low & QDiD \\
\hline$A V G M R S C O R E$ & 35 & 35 & 8.910 & 8.966 & 8.483 & 8.384 & $-0.427^{\dagger}$ & $-0.581^{*}$ & -0.154 \\
\hline$S A V G M R S C O R E$ & 35 & 35 & 0.993 & 0.995 & 0.995 & 0.987 & 0.003 & -0.008 & -0.011 \\
\hline NHIGHRISK & 35 & 35 & 0.422 & 0.399 & 0.407 & 0.370 & -0.016 & -0.029 & -0.013 \\
\hline$\$ H I G H R I S K$ & 35 & 35 & 0.380 & 0.342 & 0.370 & 0.323 & -0.009 & -0.019 & -0.009 \\
\hline
\end{tabular}

Panel B: FAS 140 (QDiD $<0$ Predicted)

\begin{tabular}{|c|c|c|c|c|c|c|c|c|c|}
\hline & \multirow[b]{2}{*}{ High } & & \multicolumn{2}{|c|}{ Pre-period } & \multicolumn{2}{|c|}{ Post-period } & \multicolumn{3}{|c|}{ Differences } \\
\hline & & Low & High & Low & High & Low & $\Delta$ High & $\Delta$ Low & QDiD \\
\hline$A V G M R S C O R E$ & 53 & 60 & 8.889 & 8.940 & 9.323 & 9.464 & $0.435^{* *}$ & $0.524^{* *}$ & 0.089 \\
\hline$S A V G M R S C O R E$ & 53 & 60 & 0.996 & 0.992 & 0.994 & 0.993 & -0.002 & 0.001 & 0.002 \\
\hline NHIGHRISK & 53 & 60 & 0.339 & 0.363 & 0.359 & 0.380 & 0.020 & 0.017 & -0.003 \\
\hline$\$ H I G H R I S K$ & 53 & 60 & 0.306 & 0.339 & 0.330 & 0.342 & 0.023 & 0.003 & -0.020 \\
\hline
\end{tabular}

Panel C: FIN 46 (R) (QDiD $<0$ Predicted)

\begin{tabular}{|c|c|c|c|c|c|c|c|c|c|}
\hline & \multirow[b]{2}{*}{ High } & \multirow[b]{2}{*}{ Low } & \multicolumn{2}{|c|}{ Pre-period } & \multicolumn{2}{|c|}{ Post-period } & \multicolumn{3}{|c|}{ Differences } \\
\hline & & & High & Low & High & Low & $\Delta$ High & $\Delta$ Low & QDiD \\
\hline$A V G M R S C O R E$ & 60 & 52 & 9.223 & 9.471 & 8.802 & 8.870 & $-0.420^{* *}$ & $-0.601^{* * *}$ & -0.180 \\
\hline$S A V G M R S C O R E$ & 60 & 52 & 0.996 & 0.996 & 0.994 & 0.994 & -0.002 & -0.002 & 0.001 \\
\hline NHIGHRISK & 60 & 52 & 0.373 & 0.361 & 0.363 & 0.358 & -0.009 & -0.004 & 0.006 \\
\hline$\$ H I G H R I S K$ & 60 & 52 & 0.359 & 0.340 & 0.337 & 0.331 & -0.023 & -0.009 & 0.014 \\
\hline
\end{tabular}

Panel D: FAS $166 \& 167$ (QDiD $<0$ Predicted)

\begin{tabular}{|c|c|c|c|c|c|c|c|c|c|}
\hline \multirow[b]{3}{*}{$A V G M R S C O R E$} & \multirow{2}{*}{\multicolumn{2}{|c|}{ High Low }} & \multicolumn{2}{|c|}{ Pre-period } & \multicolumn{2}{|c|}{ Post-period } & \multicolumn{3}{|c|}{ Differences } \\
\hline & & & High & Low & High & Low & $\Delta$ High & $\Delta$ Low & QDiD \\
\hline & 91 & 83 & 10.583 & 10.738 & 10.306 & 10.565 & $-0.276^{*}$ & -0.172 & 0.104 \\
\hline$S A V G M R S C O R E$ & 91 & 83 & 0.992 & 0.994 & 0.994 & 0.996 & $0.002^{\dagger}$ & 0.002 & -0.001 \\
\hline NHIGHRISK & 91 & 83 & 0.422 & 0.424 & 0.392 & 0.428 & $-0.030^{\dagger}$ & 0.005 & $0.035^{*}$ \\
\hline$\$ H I G H R I S K$ & 91 & 83 & 0.396 & 0.390 & 0.368 & 0.400 & -0.028 & 0.010 & $0.038^{\dagger}$ \\
\hline
\end{tabular}

Continued on next page- 


\section{- continued from previous page}

This table presents the results of the quasi-DiD tests for H4. The High group is composed of securitizing BHCs with above-median core deposit ratios, and the Low group is composed of those with below-median core deposit ratios. Obs in columns (1) and (2) reflects the number observations in the high and low groups with observations in both the pre and post periods, respectively. For each risk measure, $\Delta$ High is the average value in the post-period minus the average value in the pre-period for the high group. Similarly, $\Delta$ Low is the pre-post difference for the low group. QDiD is the difference between $\Delta$ Low and $\Delta$ High. ${ }^{* * *},{ }^{* *},{ }^{*},{ }^{\dagger}$ represent p-values below $1 \%, 5 \%, 10 \%$, and $20 \%$, respectively, from the mean tests comparing the corresponding values to zero. All variables are as defined in appendix A.1. 


\subsection{Additional Analyses}

In this section, I explore alternatives to some of my research design choices, to see whether the choices affect my results. These alternatives include the length of the test window, the method for matching treatment to control firms, and a statistical correction for overlapping time intervals created by staggered events. I also explore an alternative definition of the composite risk measure $M R S C O R E$ to test if my results are sensitive to excluding individual components of $M R S C O R E$ that do not pass all validity tests in chapter 4.

\subsubsection{Alternative Test Windows}

The main analyses in the previous section uses a two-year test window. The post-event period is the first calendar year an accounting pronouncement is effective, and the preevent year is the year immediately before the effective year. For example, for FAS 125 which was issued in 1996 and became effective in 1997, the two-year window is $[1996,1997]$. This primary test window has two potential weaknesses.

First, the pre-period of this test window is typically the year during which the accounting pronouncement is issued. An implicit assumption in employing this window is that BHCs do not change their lending behavior until the pronouncement is in effect. My ability to identify the effect of transparency on BHCs lending decisions is reduced if banks start changing their behavior during the issue year, i.e., the pre-period. To test the sensitivity of my results to this assumption, I use an alternative two-year test window where the pre-period is the year immediately before the issue year.

Second, another implicit assumption in defining the primary window is that one year is sufficient to capture banks' reaction to the change in securitization accounting. The DiD research design would have low power to identify the hypothesized effects if banks cannot significantly change their lending behavior in a single year. To address this concern, I use a four-year window where the post-period is the first two years for which the pronouncement is effective, and the pre-period is the immediately preceding two years. This four-year window is similar to the primary window in that the issue year is included in the pre period. 
Table 5.7: Alternative Test Windows

\begin{tabular}{|c|c|c|c|c|c|c|c|c|}
\hline & \multicolumn{4}{|c|}{$\begin{array}{c}\text { Panel A: Two-year Window } \\
\text { Excluding Issue-year }\end{array}$} & \multicolumn{4}{|c|}{ Panel B: Four-year Window } \\
\hline & FAS 125 & FAS 140 & FIN $46(\mathrm{R})$ & FAS 166 & FAS 125 & FAS 140 & FIN $46(\mathrm{R})$ & FAS 166 \\
\hline \multicolumn{9}{|c|}{ I. : $\mathrm{DiD}$ for $\mathrm{H} 1(\mathrm{QDiD}<0$ Predicted $)$} \\
\hline Expected Sign & + & - & - & - & + & - & - & - \\
\hline$A V G M R S C O R E$ & $-0.182^{\dagger}$ & 0.137 & 0.021 & 0.119 & $-0.017^{* * *}$ & $0.006^{* * *}$ & $-0.015^{* * *}$ & $0.111^{* * *}$ \\
\hline$S A V G M R S C O R E$ & $-0.009^{* *}$ & 0.000 & -0.003 & $0.005^{* *}$ & $-0.005^{* * *}$ & $0.000^{* * *}$ & $-0.002^{* * *}$ & $0.003^{* * *}$ \\
\hline NHIGHRISK & 0.002 & 0.002 & 0.000 & -0.001 & $0.007^{* * *}$ & $0.014^{* * *}$ & $-0.010^{* * *}$ & $-0.006^{* * *}$ \\
\hline$\$ H I G H R I S K$ & -0.002 & -0.011 & 0.013 & 0.000 & $0.008^{* * *}$ & $0.001^{* * *}$ & $-0.005^{* * *}$ & $-0.005^{* * *}$ \\
\hline \multicolumn{9}{|l|}{ II. QDiD for $\mathrm{H} 2$} \\
\hline Expected Sign & - & + & + & + & - & + & + & + \\
\hline$A V G M R S C O R E$ & -0.031 & 0.051 & -0.149 & -0.155 & $-0.628^{* * *}$ & -0.215 & -0.348 & -0.170 \\
\hline$S A V G M R S C O R E$ & $0.012^{\dagger}$ & -0.003 & 0.006 & -0.003 & $0.007^{* * *}$ & 0.001 & 0.004 & $-0.001^{\dagger}$ \\
\hline NHIGHRISK & 0.038 & -0.010 & -0.039 & -0.010 & -0.041 & $-0.002^{* * *}$ & -0.072 & -0.035 \\
\hline$\$ H I G H R I S K$ & 0.048 & -0.035 & 0.007 & -0.035 & -0.042 & $0.005^{\dagger}$ & -0.054 & -0.048 \\
\hline \multicolumn{9}{|l|}{ III. QDiD for $\mathrm{H3}$} \\
\hline Expected Sign & + & - & - & - & + & - & - & - \\
\hline$A V G M R S C O R E$ & -0.011 & -0.080 & -0.246 & $0.299^{*}$ & $-0.051^{\dagger}$ & $-0.145^{* * *}$ & $0.182^{\dagger}$ & 0.191 \\
\hline$S A V G M R S C O R E$ & 0.001 & $0.008^{*}$ & $-0.007^{\dagger}$ & $0.007^{* *}$ & -0.004 & $0.002^{* * *}$ & $0.003^{\dagger}$ & 0.005 \\
\hline NHIGHRISK & -0.012 & -0.008 & 0.010 & 0.015 & -0.027 & $-0.022^{* * *}$ & $0.053^{* * *}$ & 0.023 \\
\hline$\$ H I G H R I S K$ & -0.018 & 0.000 & 0.018 & 0.018 & $-0.011^{\dagger}$ & $-0.026^{* * *}$ & $0.043^{*}$ & 0.033 \\
\hline \multicolumn{9}{|l|}{ IV. QDiD for $\mathrm{H} 4$} \\
\hline Expected Sign & + & - & - & - & + & - & - & - \\
\hline AVGMRSCORE & -0.166 & -0.058 & -0.187 & 0.206 & $-0.072^{*}$ & 0.040 & -0.048 & 0.076 \\
\hline$S A V G M R S C O R E$ & -0.006 & -0.001 & 0.000 & 0.002 & -0.006 & $0.001^{*}$ & 0.000 & 0.001 \\
\hline NHIGHRISK & 0.020 & 0.013 & 0.028 & 0.025 & 0.008 & -0.005 & $0.017^{\dagger}$ & 0.024 \\
\hline$\$ H I G H R I S K$ & 0.035 & -0.015 & 0.023 & 0.014 & $0.014^{*}$ & -0.027 & $0.021^{*}$ & 0.018 \\
\hline
\end{tabular}


Table 5.7 presents the analyses using the alternative test windows. The results from the two-year window excluding the issue year, presented in panel A, generally provide similar conclusions to those of the main analyses in the previous section. In almost all the cases, I fail to find support for my hypotheses using the alternative two-year test window. The estimated effects are either statistically indistinguishable from zero or in the opposite direction of my prediction, except for one case. Unlike the main results in table 5.2, SAVGMRSCORE decreased significantly (one-tailed p-value of less 10\%) following FIN 46(R), which is consistent with H3.

Table 5.7 panel B presents the results from the analyses using the four-year test window. The signs of the DiD for $\mathrm{H} 1$ are similar to the signs in the main tests presented in table 5.2, however unlike the other test windows, all the DiDs for H1 are significantly different from zero. This suggests that the four-year test window is more powerful than the two-year windows because the longer pre- and post-periods allow sufficient time for the effect of the accounting pronouncements to be observed, or because this window has more observations. However, the signs of the DiDs are consistent with the directional prediction in $\mathrm{H} 1$ only half the time. Consistent with H1: (i) NHIGHRISK and \$HIGHRISK increased significantly following FAS 125, (ii) all risk measures decreased significantly following FIN 46(R), and NHIGHRISK and \$HIGHRISK decreased significantly following FAS 166 $\&$ 167. In all the other cases, the DiDs have the opposite sign to H1's prediction.

The tests of H2, H3, and H4 using the four-year window do not differ substantially from those using the primary test window. I find evidence in support of $\mathrm{H} 2$ only in two of the cases: (i) AVGMRSCORE decreased significantly following FAS 125, and (ii) \$HIGHRISK increased significantly following FAS 140. I find evidence consistent with H3 for AVGMRSCORE, NHIGHRISK, and $\$ H I G H R I S K$ following FAS 140. Only the increase in $\$ H I G H R I S K$ following FAS 125 is consistent with H4. In each of the other cases, the change in the risk measures around the accounting pronouncements is either not significantly different from zero or it is in the opposite direction of the prediction.

\subsubsection{Alternative Propensity Score Model Assumptions}

This subsection assesses the sensitivity of the results to the two main assumptions in the propensity score matching, namely matching with replacement, and the $10 \%$ tolerance. I test the robustness of the results to matching without replacement, and to matching with a narrower $3 \%$ caliper width. I only change one assumption at a time to isolate the effect, if any, of changing of these assumptions. Table 5.8 panel A contains the results from the 
analyses using propensity score matching with a $3 \%$ caliper width but with replacement. ${ }^{4}$ Except for the increase in $A V G M R S C O R E$ following FAS 166 \& 167 with one-tailed p-value of less than $10 \%$, all the changes in the risk measures around the accounting pronouncements are either not significantly different from zero or they are in the opposite direction of the prediction. Panel B presents the results when I perform the propensity score matching without replacement, but using the same $10 \%$ caliper width as the main tests. ${ }^{5}$ All the changes in risk-taking are either not significant or in the opposite direction of my predictions. In summary, changing these assumptions the propensity score matching did not results in different conclusions, when compared to the main test in earlier section 5.3 .

\footnotetext{
${ }^{4}$ Narrowing the caliper width has a negligible effect on the number of observations, perhaps because I match with replacement. The number of observations for FAS 140 decreased to 100, compared to 112 in table 5.2. All the other numbers of observations for the other events remained the same.

${ }^{5}$ The effect of matching without replacement on the number of observations is similar to that of narrowing the caliper as discussed in the previous footnote.
} 
Table 5.8: Alternative Propensity Score Matching Assumptions

\begin{tabular}{|c|c|c|c|c|c|c|c|c|}
\hline & \multicolumn{4}{|c|}{ Panel A: 3\% Caliper Width } & \multicolumn{4}{|c|}{ Panel B: Without Replacement } \\
\hline & FAS 125 & FAS 140 & FIN $46(R)$ & FAS 166 & FAS 125 & FAS 140 & FIN $46(R)$ & FAS 166 \\
\hline I. : DiD for $\mathrm{H} 1$ & & & & & & & & \\
\hline Expected Sign & + & - & - & - & + & - & - & - \\
\hline$A V G M R S C O R E$ & -0.163 & 0.094 & -0.165 & $0.185^{*}$ & -0.0163 & 0.094 & -0.165 & $0.185^{*}$ \\
\hline$S A V G M R S C O R E$ & $-0.008^{\dagger}$ & $0.007^{*}$ & -0.002 & $0.006^{* *}$ & $-0.008^{\dagger}$ & $0.007^{*}$ & -0.002 & $0.008^{* *}$ \\
\hline NHIGHRISK & 0.005 & $0.027^{\dagger}$ & -0.016 & -0.005 & 0.005 & $0.026^{\dagger}$ & -0.016 & -0.005 \\
\hline$\$ H I G H R I S K$ & 0.009 & 0.011 & -0.016 & -0.011 & 0.009 & 0.011 & -0.016 & -0.010 \\
\hline II. QDiD for $\mathrm{H} 2$ & & & & & & & & \\
\hline Expected Sign & - & + & + & + & - & + & + & + \\
\hline$A V G M R S C O R E$ & -0.271 & $-0.602^{* *}$ & -0.156 & $0.242^{\dagger}$ & -0.271 & $-0.329^{\dagger}$ & -0.156 & $0.242^{\dagger}$ \\
\hline$S A V G M R S C O R E$ & 0.012 & -0.001 & 0.005 & 0.001 & 0.012 & -0.0002 & 0.005 & 0.001 \\
\hline NHIGHRISK & 0.039 & -0.038 & -0.043 & -0.002 & 0.039 & -0.0005 & -0.043 & -0.002 \\
\hline$\$ H I G H R I S K$ & 0.032 & -0.019 & -0.029 & -0.016 & 0.032 & 0.002 & -0.029 & -0.016 \\
\hline III. QDiD for H3 & & & & & & & & \\
\hline Expected Sign & + & - & - & - & + & - & - & - \\
\hline$A V G M R S C O R E$ & $-0.361^{\dagger}$ & -0.043 & 0.025 & $0.233^{\dagger}$ & $-0.361^{\dagger}$ & -0.017 & 0.025 & $0.233^{\dagger}$ \\
\hline$S A V G M R S C O R E$ & -0.011 & 0.005 & 0.003 & $0.003^{\dagger}$ & -0.011 & 0.003 & 0.003 & $0.003^{\dagger}$ \\
\hline NHIGHRISK & $-0.051^{*}$ & 0.006 & $0.049^{\dagger}$ & 0.021 & $-0.051^{*}$ & 0.012 & $0.049^{\dagger}$ & 0.021 \\
\hline$\$ H I G H R I S K$ & $-0.045^{\dagger}$ & 0.004 & $0.046^{\dagger}$ & $0.034^{\dagger}$ & $-0.045^{\dagger}$ & 0.008 & $0.046^{\dagger}$ & $0.034^{\dagger}$ \\
\hline $\begin{array}{l}\text { IV. QDiD for H4 } \\
\text { Expected Sign }\end{array}$ & + & - & - & - & + & - & - & - \\
\hline$A V G M R S C O R E$ & -0.154 & 0.041 & -0.180 & 0.104 & -0.154 & 0.089 & -0.180 & 0.104 \\
\hline$S A V G M R S C O R E$ & -0.011 & 0.003 & 0.001 & -0.001 & -0.011 & 0.002 & 0.001 & -0.001 \\
\hline NHIGHRISK & -0.013 & -0.016 & 0.006 & $0.035^{*}$ & -0.013 & -0.003 & 0.006 & $0.035^{*}$ \\
\hline$\$ H I G H R I S K$ & -0.009 & -0.036 & 0.014 & $0.038^{\dagger}$ & -0.009 & -0.020 & 0.014 & $0.038^{\dagger}$ \\
\hline
\end{tabular}

This table presents the results of the analyses using the alternative propensity score model assumptions. The results in panel A are obtained when using a narrower 3\% caliper width instead of the $10 \%$ caliper width in the main analyses. Panel B contains the results obtained when the propensity score matching is performed without replacement. I present only the DiDs for $\mathrm{H} 1$ and the QDiDs for H2, H3, and H4. Refer to tables 5.2 and 5.4 for descriptions of DiD and QDiD, respectively. ${ }^{* *},{ }^{* *},{ }^{*},{ }^{\dagger}$ represent p-values below $1 \%, 5 \%, 10 \%$, and $20 \%$, respectively, from the mean tests comparing the corresponding values to zero. All variables are as defined in appendix A.1. 


\subsubsection{Alternative Definition of Composite Mortgage Risk Score}

The validation of the BHC-level risk measures and their components in chapter 4 shows that the relation between some components of the composite mortgage risk score and BHClevel mortgage outcomes is inconsistent across mortgage outcome measures or contrary to the predicted relation between mortgage lending risk and mortgage outcomes. In this subsection, I test my hypotheses using an alternate definition of the risk measure, which relies only on the components that consistently pass the validation tests. Table 5.9 presents the results using the alternative risk measure. As in the main tests, the change in risktaking is not significantly different from zero in most cases, and it goes in the opposite direction of the prediction when it is significantly different from zero. The overall conclusion remains similar to that of the main analyses. There is no evidence that clearly shows a significant change in risk-taking around the accounting pronouncements.

\subsubsection{Alternative Matching Method}

A growing literature expresses concern regarding the use of propensity score matching (PSM). King \& Nielsen (2016) assess the ability of PSM to reduce bias relative other matching methods. They find that PSM may not reduce bias sufficiently, and that in some cases it can increase bias. The poor performance of PSM can arise from the fact that a match on the propensity score does not translate into a match on all covariates. Pruning observation based on propensity score differences thus can exacerbate bias, by increasing imbalance on important covariates. I follow best practices in selecting covariates with a theoretical foundation, using a wider caliper (10\%) to minimize the effect of data pruning, and confirming bias reduction by comparing the covariates before and after matching. Nevertheless, it may still be the case that PSM results in poor matching that affects my results. To address this concern, this section tests the hypotheses using a form of coarsened exact matching (CEM).

For each pronouncement, I select the three most important covariates in the propensity score model by comparing their t-stats and partial $\mathrm{R}^{2} \mathrm{~s}$, and partition the sample in to quintiles based on each of the selected covariates. I then match each securitizing BHC with a non-securitizing BHC in the same quintile, for each of the three covariates. I perform this matching sequentially based on the importance of the covariates. Similar to the PSM, I perform this matching separately for each pronouncement during the year the pronouncement is issued, and separately for public and private BHCs.

For example, for FAS 125 and public BHCs, I first match each securitizing BHC to a pool of non-securitizing BHCs that are in the same size (i.e., LOGASSETS) quintile. 
Table 5.9: Alternative Definition of Composite Mortgage Risk Score

\begin{tabular}{|c|c|c|c|c|}
\hline & FAS 125 & FAS 140 & FIN 46(R) & FAS 166 \\
\hline $\begin{array}{l}\text { I. : DiD for H1 } \\
\text { Expected Sign }\end{array}$ & + & - & - & - \\
\hline $\begin{array}{l}\text { AVGMRSCORE } \\
\text { SAVGMRSCORE } \\
\text { NHIGHRISK } \\
\$ H I G H R I S K\end{array}$ & $\begin{array}{r}-0.093 \\
-0.007 \\
0.004 \\
0.002\end{array}$ & $\begin{array}{l}0.156^{*} \\
0.009^{* *} \\
0.022 \\
0.007\end{array}$ & $\begin{array}{l}-0.109 \\
-0.004 \\
-0.017 \\
-0.019\end{array}$ & $\begin{array}{l}0.20^{* *} \\
0.008^{* *} \\
0.031^{* *} \\
0.017\end{array}$ \\
\hline $\begin{array}{l}\text { II. QDiD for } \mathrm{H} 2 \\
\text { Expected Sign }\end{array}$ & - & + & + & + \\
\hline $\begin{array}{l}\text { AVGMRSCORE } \\
\text { SAVGMRSCORE } \\
\text { NHIGHRISK } \\
\$ H I G H R I S K\end{array}$ & $\begin{array}{l}0.048 \\
0.009 \\
0.046 \\
0.037\end{array}$ & $\begin{array}{r}-0.233 \\
-0.007 \\
-0.009 \\
0.007\end{array}$ & $\begin{array}{c}-0.055 \\
0.015 \\
-0.060^{\dagger} \\
-0.046\end{array}$ & $\begin{array}{r}0.090 \\
0.001 \\
0.006 \\
-0.015\end{array}$ \\
\hline $\begin{array}{l}\text { III. QDiD for H3 } \\
\text { Expected Sign }\end{array}$ & + & - & - & - \\
\hline $\begin{array}{l}\text { AVGMRSCORE } \\
\text { SAVGMRSCORE } \\
\text { NHIGHRISK } \\
\$ H I G H R I S K \\
\end{array}$ & $\begin{array}{l}-0.224 \\
-0.013 \\
-0.010 \\
-0.007 \\
\end{array}$ & $\begin{array}{r}0.049 \\
0.001 \\
0.003 \\
-0.012 \\
\end{array}$ & $\begin{array}{l}0.022 \\
0.001 \\
0.007 \\
0.019\end{array}$ & $\begin{array}{l}0.153 \\
0.007^{* *} \\
0.037^{*} \\
0.044^{*}\end{array}$ \\
\hline $\begin{array}{l}\text { IV. QDiD for H4 } \\
\text { Expected Sign }\end{array}$ & + & - & - & - \\
\hline $\begin{array}{l}\text { AVGMRSCORE } \\
\text { SAVGMRSCORE } \\
\text { NHIGHRISK } \\
\$ H I G H R I S K\end{array}$ & $\begin{array}{l}-0.185 \\
-0.011 \\
-0.032 \\
-0.031\end{array}$ & $\begin{array}{r}-0.096 \\
0.001 \\
-0.012 \\
-0.016\end{array}$ & $\begin{array}{r}0.022 \\
-0.002 \\
-0.017 \\
0.013\end{array}$ & $\begin{array}{l}0.096 \\
0.002 \\
0.027^{\dagger} \\
0.040^{*}\end{array}$ \\
\hline
\end{tabular}

This table presents the results of the sensitivity analyses when using an alternative definition of composite mortgage risk score (MRSCORE), which relies only on components that consistently pass all validation tests in chapter 4 . Similar to the other sensitivity tests, I present only the DiDs for H1 and the QDiDs for H2, H3, and H4. Refer to tables 5.2 and 5.4 for descriptions of $\mathrm{DiD}$ and $\mathrm{QDiD}$, respectively. ${ }^{* * *},{ }^{* *},{ }^{*},{ }^{\dagger}$ represent p-values below $1 \%, 5 \%, 10 \%$, and $20 \%$, respectively, from the mean tests comparing the corresponding values to zero. All variables are as defined in appendix A.1. 
I then restrict the pool to all non-securitizing BHCs that are in the same $R O A$ quintile, and finally to those in the same $L E V E R A G E$ quintile. If multiple matches remain after the three rounds of quintile matches, I choose the non-securitizing BHC in the pool with the smallest difference in the third matching covariate ( $L E V R A G E$ in the above example) with the treatment BHC. In all the cases, I find at least one matching non-securitizing $\mathrm{BHC}$ after the first and second round of quintile matching. However, in some cases, I find no matches after the third-level quintile matching. In this case, I select the matching BHCs from the pool in the previous step by comparing actual values of the covariate for the third step and choosing the non-securitizing $\mathrm{BHC}$ in the second pool with the smallest difference in the third covariate. In the above example, if there are no matches on LEVERAGE quintiles, I select a control BHC in the pool of matching non-securitizing BHCs based on the first two quintile (LOGASSETS and ROA) that has the closest LEVERAGE value to the treatment BHC.

Table 5.10 presents the results using the alternative matching strategy and the primary two-year test window in panel A, and the alternative matching strategy and the four-year test window in panel B. When using the two-year window, I find little evidence supporting my hypotheses. As in the previous cases in tables 5.2 to 5.6, most of the DiDs or QDiDs are not statistically significant or go in the opposite direction to my prediction. The only exceptions are the positive $\mathrm{DiD}$ in NHIGHRISK around FAS 125, the positive QDiD in $A V G M R S C O R E$ around FAS 166 \& 167, and the negative QDiD in SAVGMRSCORE, all which are significant at $10 \%$ (one-tailed). I find mixed evidence when using the fouryear test window. Consistent with H1, I find significantly positive DIDs around FAS 125 and significantly negative DIDs around FIN 46 for all risk measures. Contrary to H1, I find positive DiDs around FAS 140 and FAS $166 \& 167$. The result for H2 are either insignificant or contrary to the prediction. I find evidence supporting $\mathrm{H} 3$ around FAS 125 and FAS 140 but not around FIN 46 and FAS $166 \& 167$. The results for H4 are almost always insignificant or contrary to my prediction. In general, similar to the other sensitivity tests, changing the matching strategy does not seem to significantly change my conclusions. 
Table 5.10: Alternative Matching Strategy

\begin{tabular}{|c|c|c|c|c|c|c|c|c|}
\hline & \multicolumn{4}{|c|}{ Panel A: Two-year Window } & \multicolumn{4}{|c|}{ Panel B: Four-year Window } \\
\hline & \multicolumn{2}{|c|}{ FAS 125 FAS 140} & \multirow{2}{*}{$\begin{array}{c}\text { FIN } 46 \\
-\end{array}$} & \multirow{2}{*}{$\begin{array}{c}\text { FAS } 166 \\
-\end{array}$} & \multirow{2}{*}{$\begin{array}{c}\text { FAS } 125 \\
+\end{array}$} & \multirow{2}{*}{$\begin{array}{c}\text { FAS } 140 \\
-\end{array}$} & \multirow{2}{*}{$\begin{array}{c}\text { FIN } 46 \\
-\end{array}$} & \multirow{2}{*}{$\begin{array}{c}\text { FAS } 166 \\
-\end{array}$} \\
\hline $\begin{array}{l}\text { I. : DiD for H1 } \\
\text { Expected Sign }\end{array}$ & + & - & & & & & & \\
\hline$A V G M R S C O R E$ & 0.005 & 0.011 & -0.097 & -0.032 & $0.064^{* * *}$ & $0.161^{* * *}$ & $-0.029^{* * *}$ & $0.038^{* * *}$ \\
\hline$S A V G M R S C O R E$ & 0.001 & -0.003 & 0.000 & 0.000 & $0.001^{* * *}$ & $0.0002^{* * *}$ & $-0.002^{* * *}$ & $-0.001^{* * *}$ \\
\hline NHIGHRISK & $0.021^{\dagger}$ & 0.015 & 0.000 & -0.009 & $0.014^{* * *}$ & $0.030^{* * *}$ & $-0.001^{* * *}$ & $0.015^{* * *}$ \\
\hline$\$ H I G H R I S K$ & 0.011 & 0.002 & -0.005 & 0.001 & $0.007^{* * *}$ & $0.010^{* * *}$ & $-0.002^{* * *}$ & $0.017^{* * *}$ \\
\hline \multicolumn{9}{|l|}{ II. : Q-DiD for $\mathrm{H} 2$} \\
\hline Expected Sign & - & + & + & + & - & + & + & + \\
\hline$A V G M R S C O R E$ & 0.303 & -0.199 & -0.072 & $0.224^{\dagger}$ & 0.216 & -0.045 & -0.175 & 0.203 \\
\hline$S A V G M R S C O R E$ & 0.014 & $-0.007^{\dagger}$ & -0.003 & 0.001 & 0.015 & -0.007 & 0.000 & 0.008 \\
\hline NHIGHRISK & 0.055 & -0.038 & $-0.058^{*}$ & 0.002 & $0.044^{* *}$ & $-0.041^{* * *}$ & -0.054 & 0.023 \\
\hline$\$ H I G H R I S K$ & 0.107 & -0.030 & $-0.082^{* *}$ & -0.014 & 0.088 & $-0.028^{* *}$ & $-0.074^{\dagger}$ & 0.007 \\
\hline \multicolumn{9}{|c|}{ III. : Q-DiD for $\mathrm{H3}$} \\
\hline Expected Sign & + & - & - & - & + & - & - & - \\
\hline$A V G M R S C O R E$ & 0.077 & -0.128 & 0.129 & 0.115 & $0.135^{\dagger}$ & $-0.109^{* *}$ & $0.048^{* *}$ & -0.081 \\
\hline$S A V G M R S C O R E$ & $0.004^{\dagger}$ & 0.000 & 0.001 & 0.000 & 0.002 & $0.001^{* * *}$ & $-0.002^{* *}$ & 0.004 \\
\hline NHIGHRISK & -0.009 & 0.004 & $0.051^{* *}$ & 0.024 & $0.003^{\dagger}$ & $-0.014^{*}$ & $0.019^{* * *}$ & 0.026 \\
\hline$\$ H I G H R I S K$ & -0.013 & 0.010 & 0.034 & $0.032^{\dagger}$ & $0.002^{\dagger}$ & $-0.008^{* *}$ & $0.018^{* * *}$ & 0.030 \\
\hline \multicolumn{9}{|l|}{ IV. : Q-DiD for $\mathrm{H} 4$} \\
\hline Expected Sign & + & - & - & - & + & - & - & - \\
\hline$A V G M R S C O R E$ & -0.049 & -0.252 & -0.050 & -0.027 & -0.113 & $-0.100^{*}$ & 0.093 & -0.075 \\
\hline$S A V G M R S C O R E$ & 0.000 & 0.000 & -0.002 & $-0.003^{\dagger}$ & $-0.002^{\dagger}$ & -0.003 & -0.001 & -0.003 \\
\hline NHIGHRISK & -0.012 & 0.002 & $0.034^{\dagger}$ & 0.020 & -0.044 & 0.022 & $0.043^{* *}$ & 0.013 \\
\hline$\$ H I G H R I S K$ & -0.004 & -0.026 & $0.039^{\dagger}$ & 0.018 & -0.038 & 0.012 & $0.055^{* * *}$ & 0.010 \\
\hline
\end{tabular}

This table presents the results obtained when using the alternative matching technique in section 5.5.4. Panel A contains the results when the alternative matching method is used with the primary two-year test window, and panel B presents the results when the alternative matching method is used with the alternative four-year test window. I present only the DiDs for $\mathrm{H} 1$ and the QDiDs for H2, H3, and H4. Refer to tables 5.2 and 5.4 for descriptions of DiD and QDiD, respectively. ${ }^{* *},{ }^{* *},{ }^{*},{ }^{\dagger}$ represent p-values below $1 \%, 5 \%, 10 \%$, and $20 \%$, respectively, from the mean tests comparing the corresponding values to zero. All variables are as defined in appendix A.1. 


\subsubsection{Alternative Research Designs}

FAS 140 (2000) and FIN 46 (R) (2003) are issued close together, so that the post period for FAS 140 overlaps the pre-period for FIN 46 (R). This section adapts Bertrand \& Mullainathan's (2003) implementation of difference-in-differences design for staggered events to address this issue. I employ the following regression model.

$$
R I S K_{i t}=\alpha_{i}+\alpha_{t}+\theta_{j} I_{j t}+\phi S E C I N D_{i t}+\beta_{j}\left(I_{j t} \times S E C I N D_{i t}\right)+\Gamma X_{i t}+\epsilon_{i t}
$$

The subscripts $i, j$, and $t$ index BHCs, accounting pronouncements, and year, respectively. $R I S K_{i t}$ is a BHC-year level mortgage lending risk measure. $I_{j t}$ is an indicator variable that equals one if year $t$ is greater than the issue year of pronouncement $j$. SECIND $D_{i t}$ is an indicator variable that equals one if $\mathrm{BHC} i$ is securitizing in year $t . X_{i t}$ is a vector of control variables, selected from the covariates used in the propensity score model. I do not use regulatory capital variables as controls because of missing data prior to 1996. The coefficient $\beta_{j}$ captures the effect of pronouncement $j$ on BHCs' risk-taking, while controlling for the other pronouncements.

For each event, this research designs compares securitizing BHCs' lending decisions in the years after the event with the lending decision of securitizing BHCs prior to the event, and of non-securitizing BHCs during the 1993-2015 period. For example for FAS 125, it compares the lending decisions of securitizing BHCs in the period 1997-2015 with those of securitizing BHCs in the period 1993-1996, and of non-securitizing BHCs in the period 1993-2015. This feature can allow me to better estimate the effects of events that fall close together. Unlike the main design that is restricted to a narrow window around each event, this research design can use the whole sample period, increasing the number of observation available to estimate the effects if each event. However, using the full sample period or the unmatched sample can lead to endogeneity issues that are mitigated by the main research design by matching treatment and control groups on relevant variable to establish comparable groups, and by narrowing the time period to limit the effects of other potential events.

I estimate the above regression model over the period 1993-2015, both for the unmatched and for the matched samples. As in Bertrand \& Mullainathan (2003), the unmatched sample contains all securitizing and non-securitizing BHCs with non-missing data to estimate the above regression model. I form the matched sample by propensity scorematching each securitizing BHC with a non-securitizing BHC for each year in the 1993-2015 period.

I limit the sensitivity analyses to $\mathrm{H} 1$, because implementing this approach for the other hypotheses requires four three-way interactions for each hypothesis, which makes interpret- 
ing the results a daunting task. Table 5.11 presents the results. While all regressions in this table contain control variables, I present only the estimated coefficients for the treatment indicator, the event indicators, and their interactions. I will limit the discussion to the interaction terms $(\beta \mathrm{s})$, which are comparable to the DiD estimates in the main analyses (table 5.2).

Table 5.11 panels A and B presents the results for the combined sample of public and private BHCs. The results for the matched sample mostly lead to similar conclusions as those from the DiD tests in table 5.2, however there are some differences in terms of the sign and significance of the estimates. The interaction term for FAS 125 is negative for all risk measures and significant for three out of four. Similar to the main tests, these results are contrary to H1. The interaction term for FAS 140 is positive for all measures, which is also contrary to H1's prediction. The negative coefficients for FIN 46, while consistent with $\mathrm{H} 1$, are not statistically significant. In these three cases, my conclusion is similar to those from the main tests: I fail to find evidence in support of H1. Unlike the main tests, I find some evidence supporting H1 around FAS $166 \& 167$. The interaction term for FAS 166 is negative and significant for two risk measures, NHIGHRISK and $\$ H I G H R I S K$, indicating that BHCs reduced their risk-taking following FAS 166 \& 167 by reducing the proportion of high-risk mortgages they approve. I arrive at similar conclusions when using the unmatched sample, except for FIN 46. The interaction term is significantly negative for all risk measures, supporting $\mathrm{H} 1$.

The results for the public BHCs sample are in Table 5.11 panels $\mathrm{C}$ and D. When focusing on the matched sample of Public BHCs only, I find no significant interactions for FAS 125, FAS 140, and FIN 46 while the interaction terms for FAS 166 \& 167 are significant negative for NHIGHRISK and $\$ H I G H R I S K$. These results are comparable to those from the main test in table 5.2. However, I find different results for FAS 125 when using the unmatched sample of public BHCs. The interaction terms for AVGMRSCORE, NHIGHRISK, and $\$ H I G H R I S K$ are positive and significant, supporting $\mathrm{H} 1$.

As presented in panels $\mathrm{E}$ and $\mathrm{F}$, the results for the private BHCs sample also fail to provide robust evidence supporting $\mathrm{H} 1$, except in few cases. For the unmatched sample, I find negative and significant interactions for FAS 125 when using $A V G M R S C O R E$, NHIGHRISK, and \$HIGHRISK, and for FAS 166 \& 167 when using NHIGHRISK and $\$ H I G H R I S K$, all supporting $\mathrm{H} 1$. Only the significantly negative interaction for $A V G M R S C O R E$ for FIN 46 is consistent $\mathrm{H} 1$. In all the other cases, the interaction is either insignificant or opposite to H1's prediction. In summary, the above results show that the alternative research design does not lead to significantly different conclusions about the effect of transparency on bank risk-taking. 
Table 5.11: Alternative Research Design

Panel A: Combined Public \& Private BHCs Sample: Unmatched Sample

\begin{tabular}{lcccc} 
& $A V G M R S C O R E S A V G M R S C O R E$ & $N H I G H R I S K$ & $\$ H I G H R I S K$ \\
\hline SECIND & 0.091 & $0.003^{* *}$ & 0.009 & 0.003 \\
$I_{F A S 125}$ & $(0.265)$ & $(0.026)$ & $(0.424)$ & $(0.815)$ \\
$I_{F A S 125} \times S E C I N D$ & $0.123^{\dagger}$ & 0.0004 & $-0.082^{* * *}$ & $-0.077^{* * *}$ \\
& $(0.140)$ & $(0.827)$ & $(<0.001)$ & $(<0.001)$ \\
$I_{F A S 140}$ & -0.018 & -0.001 & -0.001 & 0.004 \\
$I_{F A S 140} \times S E C I N D$ & $(0.805)$ & $(0.474)$ & $(0.938)$ & $(0.726)$ \\
& $0.555^{* * *}$ & 0.001 & $0.014^{\dagger}$ & $0.022^{* *}$ \\
$I_{F I N 46}$ & $(<0.001)$ & $(0.426)$ & $(0.153)$ & $(0.044)$ \\
$I_{F I N 46} \times S E C I N D$ & 0.024 & 0.0003 & 0.011 & 0.014 \\
$I_{F A S 166}$ & $(0.705)$ & $(0.829)$ & $(0.261)$ & $(0.215)$ \\
& $1.627^{* * *}$ & 0.001 & $0.096^{* * *}$ & $0.093^{* * *}$ \\
$I_{F A S 166} \times S E C I N D$ & $(<0.001)$ & $(0.466)$ & $(<0.001)$ & $(<0.001)$ \\
Constant & $-0.142^{* *}$ & $-0.003^{* * *}$ & $-0.022^{* *}$ & $-0.024^{* *}$ \\
Observations & $(0.016)$ & $(0.002)$ & $(0.031)$ & $(0.029)$ \\
\hline & $-1.782^{* * *}$ & $0.003^{\dagger}$ & 0.003 & $0.021^{*}$ \\
& $(0)$ & $(0.191)$ & $(0.770)$ & $(0.085)$ \\
& -0.059 & $0.002^{* *}$ & $-0.015^{* *}$ & $-0.022^{* * *}$ \\
& $(0.233)$ & $(0.028)$ & $(0.046)$ & $(0.009)$ \\
& $9.388^{* * *}$ & $0.979^{* * *}$ & $0.405^{* * *}$ & $0.475^{* * *}$ \\
& $(<0.0001)$ & $(<0.0001)$ & $(0.002)$ & $(0.001)$ \\
& 23,033 & 23,033 & 23,033 & 23,033 \\
& 0.357 & 0.006 & 0.046 & 0.035 \\
\hline
\end{tabular}

Continued on next page- 
- continued from previous page

Panel B: Combined Public \& Private BHCs Sample: Matched Sample

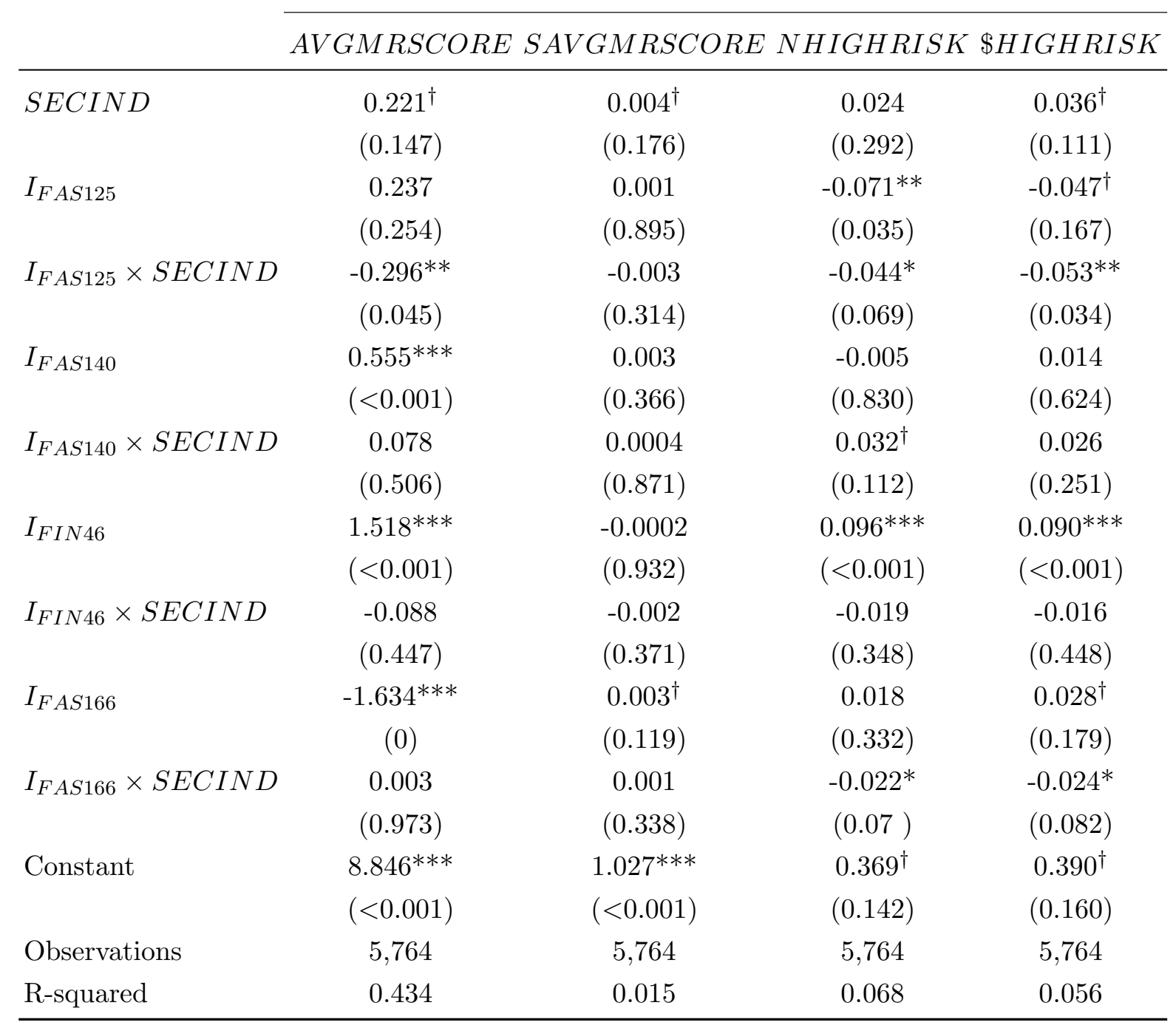

Continued on next page- 
- continued from previous page

Panel C: Public BHCs Sample: Unmatched Sample

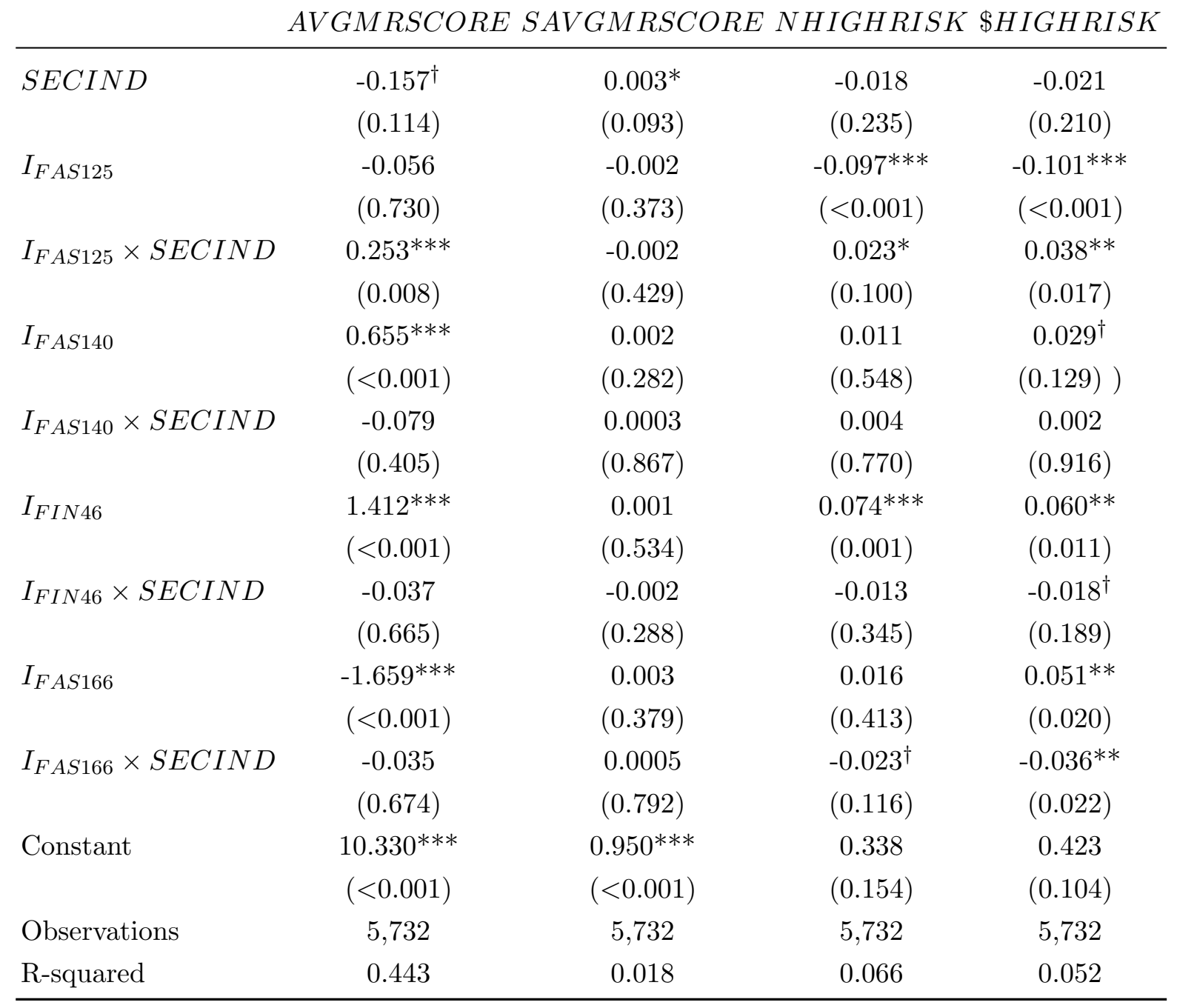

Continued on next page-- 
- continued from previous page

Panel D: Public BHCs Sample: Matched Sample

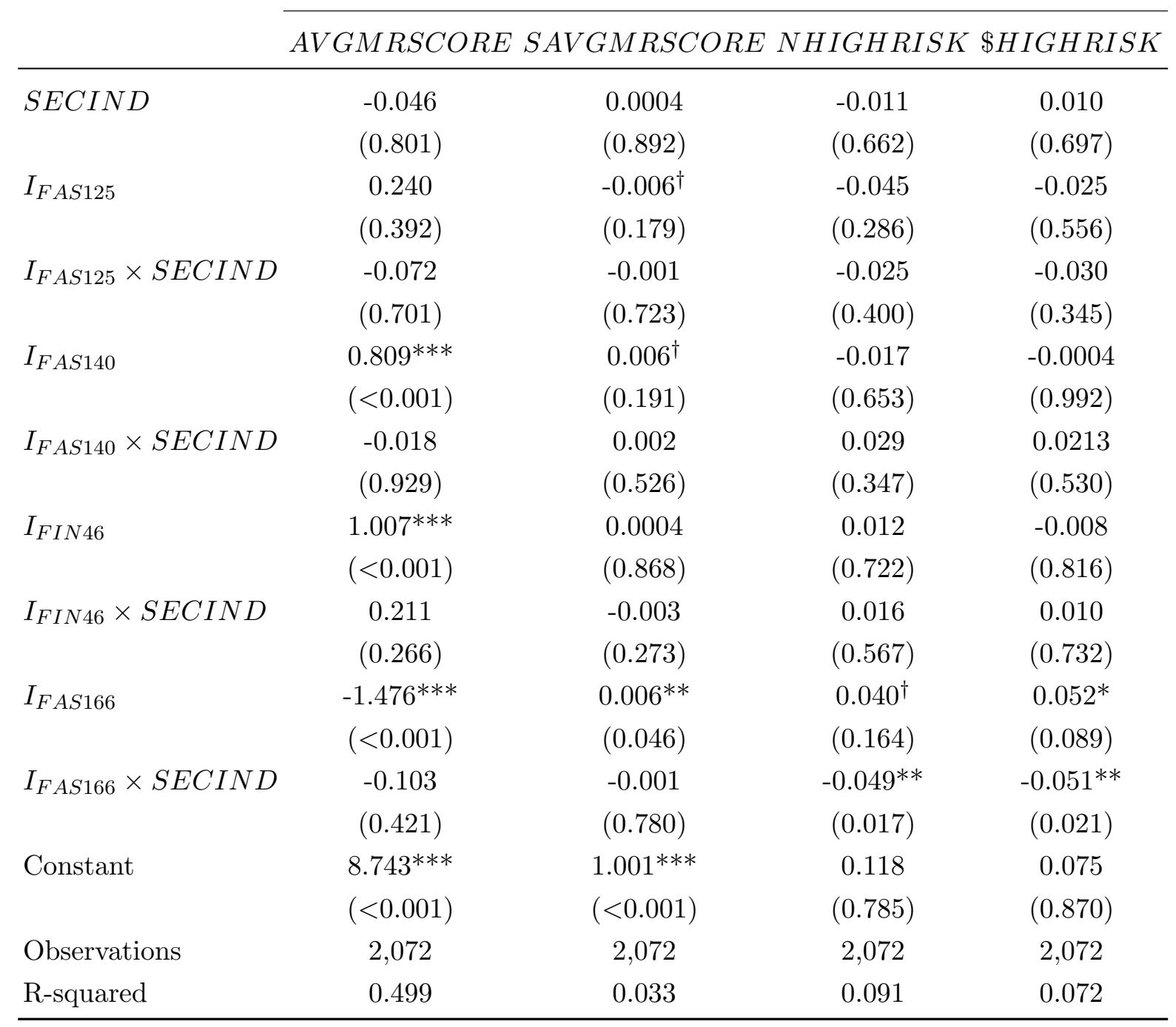

Continued on next page-- 
- continued from previous page

Panel E: Private BHCs Sample: Unmatched Sample

\begin{tabular}{lcccc} 
& $A V G M R S C O R E S A V G M R S C O R E$ & $N H I G H R I S K$ & $\$ H I G H R I S K$ \\
\hline$S E C I N D$ & $0.367^{* *}$ & $0.005^{* *}$ & $0.051^{* *}$ & $0.042^{*}$ \\
$I_{F A S 125}$ & $(0.026)$ & $(0.028)$ & $(0.012)$ & $(0.067)$ \\
$I_{F A S 125} \times S E C I N D$ & $0.198^{*}$ & 0.003 & $-0.070^{* * *}$ & $-0.060^{* * *}$ \\
& $(0.072)$ & $(0.274)$ & $(<0.001)$ & $(0.002)$ \\
$I_{F A S 140}$ & $-0.305^{* *}$ & -0.002 & $-0.050^{* *}$ & $-0.048^{* *}$ \\
$I_{F A S 140} \times S E C I N D$ & $(0.035)$ & $(0.362)$ & $(0.011)$ & $(0.029)$ \\
$I_{F I N 46}$ & $0.508^{* * *}$ & 0.002 & $0.025^{*}$ & $0.027^{*}$ \\
$I_{F I N 46} \times S E C I N D$ & $(<0.001)$ & $(0.373)$ & $(0.065)$ & $(0.057)$ \\
& 0.033 & -0.001 & $0.023^{\dagger}$ & 0.019 \\
$I_{F A S 166}$ & $(0.737)$ & $(0.818)$ & $(0.139)$ & $(0.248)$ \\
$I_{F A S 166} \times S E C I N D$ & $1.639^{* * *}$ & 0.001 & $0.104^{* * *}$ & $0.102^{* * *}$ \\
Constant & $(<0.001)$ & $(0.466)$ & $(<0.001)$ & $(<0.001)$ \\
R-squared & $-0.139^{\dagger}$ & $-0.004^{* *}$ & $-0.024^{\dagger}$ & -0.014 \\
\hline & $(0.131)$ & $(0.017)$ & $(0.132)$ & $(0.406)$ \\
& $-1.838^{* * *}$ & 0.002 & 0.012 & $0.021^{\dagger}$ \\
& $(<0.001)$ & $(0.255)$ & $(0.395)$ & $(0.185)$ \\
& 0.004 & $0.003^{* * *}$ & $-0.018^{*}$ & $-0.021^{*}$ \\
& $(0.958)$ & $(0.005)$ & $(0.079)$ & $(0.069)$ \\
& $9.319^{* * *}$ & $0.983^{* * *}$ & $0.400^{* *}$ & $0.456^{* *}$ \\
& $(<0.001)$ & $(<0.001)$ & $(0.024)$ & $(0.014)$ \\
& 14,639 & 14,639 & 14,639 & 14,639 \\
& 0.336 & 0.007 & 0.052 & 0.041 \\
\hline
\end{tabular}

Continued on next page-- 
- continued from previous page

\begin{tabular}{|c|c|c|c|c|}
\hline \multicolumn{5}{|c|}{ Panel F: Private BHCs Sample: Matched Sample } \\
\hline & $A V G M R S C O R E$ & $S A V G M R S C O R E$ & NHIGHRISK & $\$ H I G H R I S K$ \\
\hline \multirow[t]{2}{*}{$S E C I N D$} & $0.611^{* * *}$ & $0.008^{*}$ & $0.071^{*}$ & $0.070^{*}$ \\
\hline & $(0.010)$ & $(0.077)$ & $(0.080)$ & $(0.08)$ \\
\hline \multirow[t]{2}{*}{$I_{F A S 125}$} & 0.371 & $0.009^{\dagger}$ & $-0.085^{\dagger}$ & -0.069 \\
\hline & $(0.258)$ & $(0.162)$ & $(0.129)$ & $(0.229)$ \\
\hline \multirow[t]{2}{*}{$I_{F A S 125} \times S E C I N D$} & $-0.722^{* * *}$ & $-0.007^{\dagger}$ & $-0.099^{* *}$ & $-0.106^{* *}$ \\
\hline & $(0.002)$ & $(0.146)$ & $(0.014)$ & $(0.012)$ \\
\hline \multirow[t]{2}{*}{$I_{F A S 140}$} & $0.368^{*}$ & 0.001 & 0.004 & 0.020 \\
\hline & $(0.059)$ & $(0.821)$ & $(0.908)$ & $(0.59)$ \\
\hline \multirow[t]{2}{*}{$I_{F A S 140} \times S E C I N D$} & 0.146 & -0.004 & 0.041 & 0.039 \\
\hline & $(0.373)$ & $(0.917)$ & $(0.131)$ & $(0.200)$ \\
\hline \multirow[t]{2}{*}{$I_{F I N 46}$} & $1.672^{* * *}$ & 0.000 & $0.125^{* * *}$ & $0.123^{* * *}$ \\
\hline & $(<0.001)$ & $(0.994)$ & $(<0.001)$ & $(<0.001)$ \\
\hline \multirow[t]{2}{*}{$I_{F I N 46} \times S E C I N D$} & $-0.194^{\dagger}$ & -0.002 & -0.025 & -0.018 \\
\hline & $(0.194)$ & $(0.541)$ & $(0.318)$ & $(0.512)$ \\
\hline \multirow[t]{2}{*}{$I_{F A S 166}$} & $-1.776^{* * *}$ & 0.002 & 0.007 & 0.014 \\
\hline & $(<0.001)$ & $(0.578)$ & $(0.764)$ & $(0.620)$ \\
\hline \multirow[t]{2}{*}{$I_{F A S 166} \times S E C I N D$} & 0.094 & $0.003^{\dagger}$ & -0.007 & -0.007 \\
\hline & $(0.310)$ & $(0.125)$ & $(0.625)$ & $(0.659)$ \\
\hline \multirow[t]{2}{*}{ Constant } & $9.381^{* * *}$ & $1.025^{* * *}$ & 0.465 & $0.489^{\dagger}$ \\
\hline & $(<0.001)$ & $(<0.001)$ & $(0.141)$ & $(0.161)$ \\
\hline Observations & 3,692 & 3,692 & 3,692 & 3,692 \\
\hline R-squared & 0.421 & 0.022 & 0.087 & 0.078 \\
\hline
\end{tabular}

Continued on next page- 


\section{- continued from previous page}

This table contains the results of the analyses using the alternative regression based research design. I estimate the regression $R I S K_{i t}=\alpha_{i}+\alpha_{t}+\theta_{j} I_{j t}+\phi S E C I N D_{i t}+\beta_{j}\left(I_{j t} \times\right.$ $\left.S E C I N D_{i t}\right)+\Gamma X_{i t}+\epsilon_{i t}$ where the subscripts $i, j$, and $t$ index BHCs, accounting pronouncements, and year, respectively. $R I S K_{i t}$ is a BHC-year level mortgage lending risk measure. $I_{j t}$ is an indicator variable that equals one if year $t$ is greater than the issue year of pronouncement $j$. SECIND $D_{i t}$ is an indicator for securitizing BHCs in year $t . X_{i t}$ is a vector of control variables, selected from the covariates used in the propensity score model. I exclude regulatory capital variables from the vector of controls because of missing data prior to 1996 . The coefficient $\beta_{j}$ captures the effect of pronouncement $j$ on BHCs' risk-taking, while controlling for the other pronouncements. I expect $\beta>0$ for FAS 125, and $\beta<0$ for the other pronouncements. p-values in parentheses. ${ }^{* * *},{ }^{* *},{ }^{*},{ }^{\dagger}$ represent p-values below $1 \%, 5 \%, 10 \%$, and $20 \%$, respectively, from the mean tests comparing the corresponding values to zero. All variables are as defined in appendix A.1. 


\subsubsection{Least-transparent Versus Most-transparent Periods}

This section focuses on the least transparent period (pre-FAS 140) and the most transparent period (post-FAS 166 \& 167) to increase the power of my tests. As argued in chapter 2, the effect of FAS 140 and FIN 46 (R) on transparency is not clear. Excluding the years during which these standards were effective enhances the contrast between the low and high transparency periods. I estimate the following regression model using unmatched sample.

$$
R I S K_{i t}=\alpha_{i}+\alpha_{t}+\theta M T_{t}+\phi S E C I N D_{i t}+\beta\left(M T_{t} \times S E C I N D_{i t}\right)+\Gamma X_{i t}+\epsilon_{i t}
$$

As in section 5.5.5, the subscripts $i$ and $t$ index BHCs and year, respectively. $R I S K_{i t}$ is a BHC-year level mortgage lending risk measure. $M T_{t}$ is an indicator variable that equals one for the most transparent period $(t \geq 2010)$, and zero for the least transparent period $(t \leq 2000)$. I omit the period 2000-2010. I also consider an alternate definition of $M T_{t}$ where the least transparent period is the pre-FAS 125 period (1993-1996) instead of the preFAS 140 period (1993-2000). SECIND $D_{i t}$ is an indicator variable that equals one if BHC $i$ is securitizing in year $t$. $X_{i t}$ is a vector of control variables, selected from the covariates used in the propensity score model. $\beta<0$ would indicate that greater transparency leads to lower risk-taking by securitizing BHCs.

Table 5.12 presents the results. The interaction coefficient $\beta$ is significantly negative except for SAVGMRSCORE, indicating that securitizing banks take less risk than nonsecuritizing banks in the most transparent period, relative to the least transparent period. These results support my hypothesis that greater transparency leads to lower risk-taking. I find the strongest support to my hypothesis when comparing pre-FAS 125 and post-FAS $166 \& 167$ periods. This finding is consistent with the argument in chapter 2 that the early securitization accounting standards may not have a clear effect on transparency because some components enhance while others can diminish transparency. This result, however, should be interpreted with caution because of the large gap between the least and most transparent periods, during which many other events including the mortgage crisis have occurred. 
Table 5.12: Least v. Most Transparent Periods

\begin{tabular}{|c|c|c|c|c|c|c|c|c|}
\hline \multirow{3}{*}{$\begin{array}{l}\text { Dep. Var. } \\
\text { Least Transp. Period }\end{array}$} & \multirow{2}{*}{\multicolumn{2}{|c|}{$\begin{array}{c}(1) \\
A V G M R S C O R E\end{array}$}} & \multirow{2}{*}{\multicolumn{2}{|c|}{$\begin{array}{c}(3) \\
S A V G M R S C O R E\end{array}$}} & \multirow{2}{*}{\multicolumn{2}{|c|}{$\begin{array}{l}(5) \\
\text { NHIGHRISK }\end{array}$}} & $(7)$ & (8) \\
\hline & & & & & & & \multicolumn{2}{|c|}{$\$ H I G H R I S K$} \\
\hline & $1993-2000$ & 1993-1996 & 1993-2000 & 1993-1996 & $1993-2000$ & 1993-1996 & $1993-2000$ & 1993-1996 \\
\hline \multirow[t]{2}{*}{$S E C I N D$} & 0.0773 & $0.269^{*}$ & $0.00283^{*}$ & 0.00316 & -0.00429 & $0.0448^{* *}$ & -0.00578 & 0.0361 \\
\hline & $(0.200)$ & $(0.0589)$ & $(0.0974)$ & $(0.447)$ & $(0.656)$ & $(0.0448)$ & $(0.587)$ & $(0.147)$ \\
\hline \multirow[t]{2}{*}{$M T$} & $0.306^{* *}$ & -0.316 & $0.0110^{* *}$ & $0.0134^{*}$ & $0.0844^{* * *}$ & $0.126^{* * *}$ & $0.137^{* * *}$ & $0.210^{* * *}$ \\
\hline & $(0.0492)$ & $(0.244)$ & $(0.0127)$ & $(0.0883)$ & $(0.000703)$ & $(0.00287)$ & $(6.37 \mathrm{e}-07)$ & $(9.08 \mathrm{e}-06)$ \\
\hline \multirow[t]{2}{*}{$M T \times S E C I N D$} & $-0.172^{* *}$ & $-0.311^{* *}$ & -0.00202 & -0.00256 & -0.0138 & $-0.0645^{* * *}$ & $-0.0196^{\dagger}$ & $-0.0606^{* *}$ \\
\hline & $(0.0117)$ & $(0.0361)$ & $(0.295)$ & $(0.553)$ & $(0.205)$ & $(0.00547)$ & $(0.103)$ & $(0.0196)$ \\
\hline \multirow[t]{2}{*}{ Constant } & $10.05^{* * *}$ & $14.37^{* * *}$ & $0.976^{* * *}$ & $0.968^{* * *}$ & 0.387 & $0.675^{*}$ & $0.520^{* *}$ & $1.151^{* * *}$ \\
\hline & $(0)$ & $(5.22 \mathrm{e}-10)$ & & & $(0.105)$ & $(0.0620)$ & $(0.0480)$ & $(0.00439)$ \\
\hline Observations & 9,752 & 9,752 & 9,752 & 9,752 & 9,752 & 9,752 & 9,752 & 9,752 \\
\hline R-squared & 0.402 & 0.402 & 0.009 & 0.009 & 0.063 & 0.063 & 0.054 & 0.054 \\
\hline
\end{tabular}

This table presents the results of the analyses comparing the least-transparent (1993-2000) and most-transparent (2010-2015) periods. I estimate the regression

$$
R I S K_{i t}=\alpha_{i}+\alpha_{t}+\theta M T_{t}+\phi S E C I N D_{i t}+\beta\left(M T_{t} \times S E C I N D_{i t}\right)+\Gamma X_{i t}+\epsilon_{i t}
$$

where $R I S K_{i t}$ is a BHC-year level mortgage lending risk measure for BHC $i$ in year $t$. $M T_{t}$ is an indicator variable that equals one for years in the most transparent period, and zero for years in the least transparent period. The least transparent period is 1993-2010 for odd numbered columns, and 1993-1996 for even numbered columns. The most transparent period is 2010-2015 for all columns. SECIND $D_{i t}$ is an indicator variable that equals one if BHC $i$ is securitizing in year $t$. $X_{i t}$ is a vector of control variables, selected from the covariates used in the propensity score model. All regressions include control variables, and time and firm fixed effects. P-values in parenthesis. ${ }^{* * *},{ }^{* *},{ }^{*},{ }^{\dagger}$ represent p-values below $1 \%, 5 \%, 10 \%$, and $20 \%$, respectively, from the mean tests comparing the corresponding values to zero. All variables are as defined in appendix A.1 


\subsection{Conclusion}

The empirical analyses presented in this chapter provide little evidence supporting my hypotheses. Below, I discuss several possible reasons for the lack of evidence supporting my hypotheses. I plan to explore these further in future work.

First, it is possible that transparency as defined in this thesis does not affect bank lending decisions, or that it affects them differently from my predictions. Transparency refers to the financial reporting transparency of securitization. I hypothesized that transparency affects lending decisions though its effect on bank stakeholders' (shareholders', creditors', and regulators') ability to monitor bank risk-taking. I did not consider how investors in the securitization vehicles may have affected bank lending decisions, because I expect securitization accounting standards to have little effect on their decision to invest in asset-backed securities and the expected returns they demand to do so. I conjecture that securitization investors are more likely to rely on information about the composition of the securitized assets and the structure of the transaction, which are not included in great detail in annual reports or FR Y-9Cs. However, it is conceivable that the securitization investors and their investment and pricing decisions play a primary role in affecting bank lending decisions, resulting in little or no room for the other stakeholders considered in this thesis.

Second, it is possible that the research design lacks power to identify the hypothesized effects. For example, the propensity score matching may not lead to otherwise identical treatment-control pairs. In section 5.5, I performed additional analyses to test the sensitivity of my results to alternative assumptions for the propensity score model, to an alternative matching technique, and to an alternative research design that does not rely on any matching method. The results, while different in some cases, lead to similar conclusions about my hypotheses, suggesting that the lack of results is likely not driven by the specific research design.

Third, the accounting pronouncements may not affect transparency, or not in the direction I expected, and the transparency implications of the pronouncements may vary across stakeholders. For example, contrary to my expectation, if FAS 125 introduced consistency to securitization accounting, the benefits of that consistency may outweigh the negative implications that arise from the financial components approach and QSPEs, resulting in enhanced transparency in the post-FAS 125 period. For FAS 140, the negative effects of the mandatory non-consolidation of QSPEs, which can allow easier off-balance-sheet treatment, may overshadow the positive effects of enhanced transparency. Consistent with this explanation, I find results supporting H1 when I limit my analyses to comparing the least transparent period (pre-FAS 125 or pre-FAS 140) to the most transparent (post-FAS 166 \& 167) period. 
Last, the risk measures may not capture the desired underlying construct of bank risktaking in mortgage lending. In section 5.5, I consider an alternative definition of the risk measure, which excludes components with weak associations with BHC-level mortgage performance measures in the validity tests. The results and conclusions remain similar when using the alternative risk measure. However, I believe that this does not rule out the possibility that the proposed risk measures lack power to identify annual changes in bank lending decisions.

In summary, I find little evidence supporting my hypotheses and I identify several explanations for this apparent lack of results. I believe that further research is needed: (i) to develop better mortgage lending risk measures, (ii) on the effect of the securitization accounting pronouncements on transparency, and (iii) on the mechanisms through which transparency can affect bank lending decision. I find some evidence consistent with (ii). 


\section{Chapter 6}

\section{Large Securitizing BHCs}

\subsection{Introduction}

This chapter examines the lending behavior of the five large securitizing BHCs, hereafter top-five BHCs, that are excluded from the main sample, focusing on potential differences from the BHCs included in the sample. The top-five BHCs are among the largest and most complex BHCs, ranking in the top 20 banks by total assets throughout my sample period 1993-2015. These BHCs also dominate the mortgage securitization market in the United States, with their market share ranging from $40 \%$ in 1998 to $91 \%$ in 2008 . I excluded the top-five securitizing banks from the main sample because they are too different from the other banks to find matching non-securitizing banks within a reasonable tolerance. For instance, I fail to find matching control observations for most of the top-five BHC-years using propensity score matching with a caliper width of $25 \%$, which is considerably wider than the $10 \%$ caliper I use in the main analyses in chapter 5 , and the 1-3\% caliper typically used in the literature. In addition, the large jump in securitization activity in 2001, most of which can be traced to these five banks, coincides with the effective date of FAS 140, and with the new regulatory disclosure requirements. As a result including these BHCs in the test sample may affect my ability to make inference around FAS 140.

I dedicate this chapter to examining these BHCs separately because they have a significant market share in the securitization market and in the banking industry. Moreover, the top-five BHCs are those most likely to benefit from explicit and implicit guarantees from regulators and the government that are afforded to too-big-to-fail banks. These guarantees can increase their appetite for risk-taking, making these banks likely to take advantage of the opacity of securitization to increase their risk-taking in mortgage lending. 
The remainder of this chapter is organized as follows. Section 6.2 presents a background discussion about the top-five BHCs, and a brief review of the literature on too-big-to-fail banks. Section 6.3 contains empirical analyses. Section 6.4 concludes the chapter.

\subsection{Background and Literature}

The main test sample used in previous chapters excludes the top-five securitizing BHCs, namely Bank of America, Citigroup, JPMorgan Chase, Wells Fargo, and Countrywide Financial. Countrywide was one of the largest mortgage lenders in the U.S. until Bank of America acquired it in 2008. Countrywide was a BHC only over the period 2001-2006, prior to which and immediately after, it was a "Domestic Entity Other", an institution type that is not required to file FR-YC. ${ }^{1}$ The top-five BHCs are among the largest and most complex BHCs in terms of total assets. They rank in the top 20 banks by assets throughout my sample period 1993-2015. As of December 31, 2017, JPMorgan Chase, Bank of America, Wells Fargo, and Citigroup were the top four BHCs with total assets of $\$ 2.53$ trillions, $\$ 2.38$ trillions, $\$ 1.95$ trillions, and $\$ 1.84$ trillions, respectively. In comparison, the fifthranked BHC Goldman Sachs has $\$ 0.916$ trillions in total assets, half of the fourth-ranked Citigroup.

Figure 6.1 presents the time series plot of the total outstanding amount of securitized mortgages as reported in FR-Y9C for all BHCs, for the top-five BHCs, and for non-top-five BHCs in my sample. The figure shows that the top-five BHCs as a group dominate the mortgage securitization market, particularly after 2001. While the scale in figure 6.1 makes it difficult to see, the top-five BHCs do not dominate the securitization market prior to 2001 in a similar manner. Their combined outstanding securitized mortgages range from a low $40 \%$ in 1998 to a high $91 \%$ in 2008, as a proportion of total outstanding securitized mortgages for all BHCs in my sample.

\footnotetext{
${ }^{1}$ As defined by the FFIEC, the Domestic Entity Other category contains "domestic institutions that engage in banking activities usually in connection with the business of banking in the United States". https: //www.ffiec.gov/nicpubweb/content/help/institution\%20type\%20description.htm accessed April $16,2018$.
} 


\section{Figure 6.1: Outstanding Securitized Mortgages}

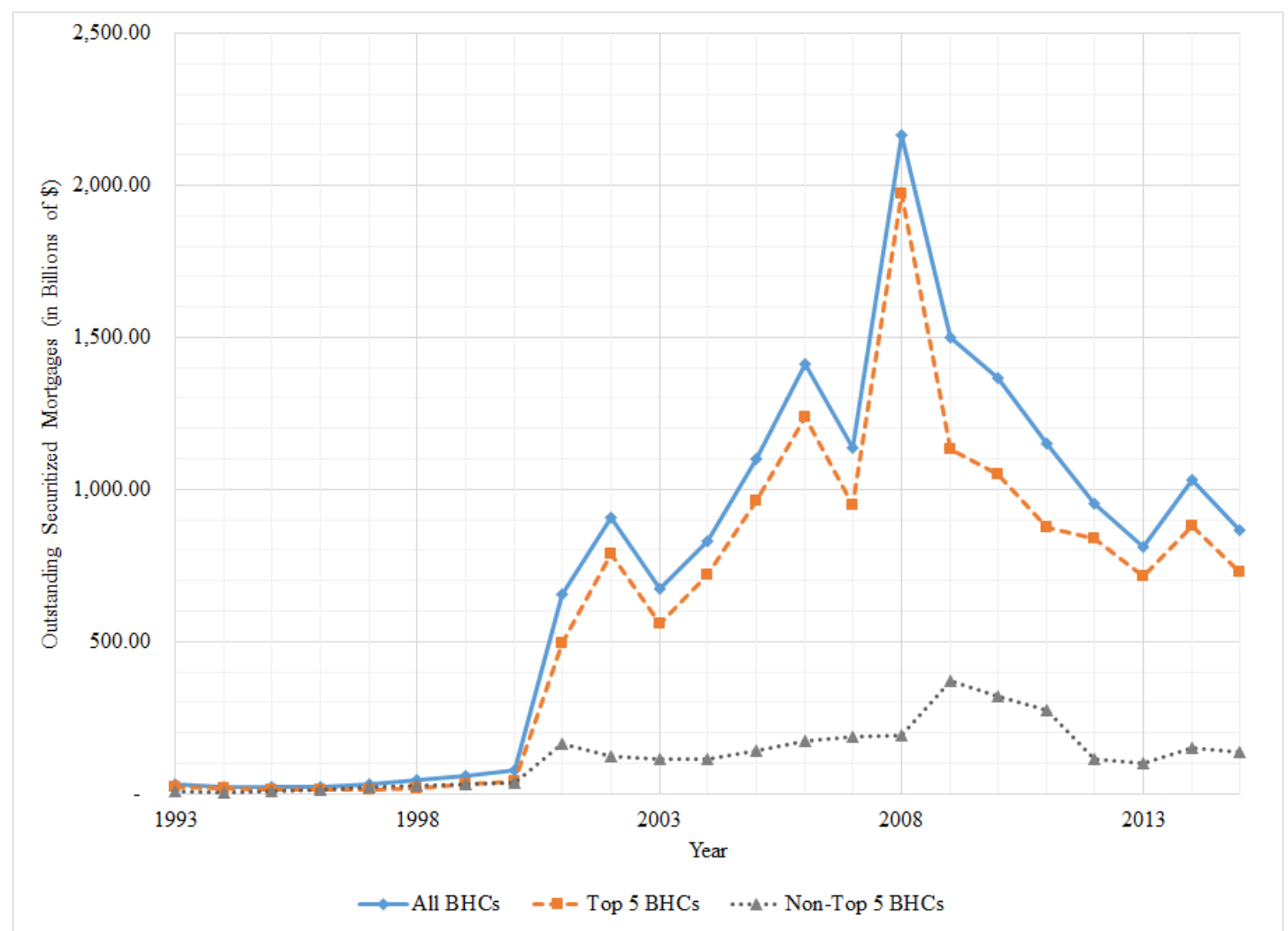

This figure presents a time series plot of total outstanding securitized mortgages over the period 1993-2015 by all BHCs filing FR-Y9C (solid blue line), by the five BHCs excluded from the main sample (dashed orange line), and by BHCs in the main sample (dotted gray line).

These BHCs are also responsible for large jumps in securitization activity in 2001, 2007 and 2008. The total amount of outstanding securitized mortgages jumped significantly in 2001. A large proportion of this jump is due to increases in reported securitization by the top-five BHCs, which are also responsible for the large changes in 2007 and in 2008. The large jump in securitization volume in 2001 mostly happened in quarters 2-4 of 2001, immediately after FAS 140 became effective in the second quarter of 2001 (i.e for securitizations that occurred after March 31, 2001).

It is possible some of the increase in securitization volume was driven by the new reporting regulatory standards that accompanied FAS 140, which may have forced BHCs to report previously undisclosed securitization. However, I manually checked the annual 
reports of the top-five BHCs in 2001, and I find that the jump is mostly driven by new securitization by the top-five BHCs during the last three quarters of 2001. For instance, Securitized mortgages reported on FR Y9C by Bank of America increased by $\$ 60$ billion from 2000 to 2001. Bank of America reports in its 2001 annual report to shareholders that "During the fourth quarter of 2001, $\$ 17.5$ billion of subprime loans were securitized and retained in the available-for-sale securities portfolio" (p. 88), and that it "converted a total of $\$ 52.9$ billion of residential first mortgages into mortgage-backed securities issued through Fannie Mae, Freddie Mac, Ginnie Mae and Bank of America Mortgage Securities" (p.95). In its annual reports, Citi discloses new mortgage securitizations of approximately $\$ 12$ billion and $\$ 24$ billion in 2000 and 2001, respectively. The majority of Citi's securitizations were issued in quarters 2-4 of 2001. Citi's quarterly report for the first quarter of 2001 discloses only $\$ 4$ billion in mortgage securitization. Consistent with a significant increase in new securitizations after FAS 140 became effective, Chernenko, Hanson \& Sunderam (2013) document a sharp rise in new non-prime mortgage securitization in 2001Q4 and thereafter.

Countrywide became a BHC in 2001, adding its stock of mortgage securitizations of $\$ 287$ billions, including $\$ 103$ billions in new securitization, to the FR Y9C database. Countrywide is responsible for the drop in 2007 as it reverted to the category Domestic Entity Other, dropping out of the FR Y-9C database. The large increase in 2008 can also be explained by activities related to the same institution. Bank of America acquired Countrywide in 2008, which led to the re-inclusion of its securitized assets in the FR Y-9C database.

An alternative explanation for this jump in reported securitization is the change in the operating definition of recourse for regulatory reporting. It is possible that securitizing BHCs did not consider credit enhancements as risk retention in the pre-FAS 140 period, resulting in unreported securitizations in the period. This would result in a jump in the post-FAS 140 period, when credit enhancements are explicitly included in the definition of risk retention. In the pre-FAS 140 period, the form Y-9C requires BHCs to report assets sold with recourse, which are defined as assets "transferred with recourse or some other form of risk retention by the bank holding company or a consolidated subsidiary in transactions reported as sales in accordance with generally accepted accounting principles." [emphasis added] (Instructions for Preparation of Consolidated Financial Statements for Bank Holding Companies: Reporting Form FR Y-9C, March 1999, p.HC-F-5) In contrast, in the post-FAS 140 period, the form Y-9C requires BHCs to report "assets sold and securitized with servicing retained or with recourse or other seller-provided credit enhancements." [emphasis added] (Instructions for Preparation of Consolidated Financial Statements for Bank Holding Companies: Reporting Form FR Y-9C, March 2001, p.HC- 
S-2) The instruction also provides a detailed definition of 'recourse or other seller-provided credit enhancements'.

The top-five securitizing BHCs are also among the banks that are considered too-big-tofail (TBTF). Prior literature examines the effect of these guarantees on bank risk-taking. The TBTF practice goes back to at least the 1950s where regulators bailed out large failing U.S. banks (e.g., Hetzel 1991, Prescott, Nurisso et al. 2017), and continues to the present day with the more recent episode involving the bailouts during the financial crisis in the late 2000's (e.g., Bordo 2008). ${ }^{2}$ The expectation that banks will be bailed out reduces creditors' and investors' incentives to monitor banks, dampening market discipline and potentially leading to greater bank risk-taking.

This TBTF problem is similar to the agency problem that arises from deposit insurance, which reduces insured depositors' incentive to monitor bank risk-taking. Merton (1977), Goldberg \& Hudgins (2002), Hovakimian, Kane \& Laeven (2003), and Nier \& Baumann (2006), among others study the effect of deposit insurance on bank risk-taking though its effect on depositors' monitoring incentives. While these agency problems may exist without deposit insurance or even in non-bank firms, deposit insurance exacerbates the inherent moral hazard problem in the banking industry. Merton (1977) provides a theoretical foundation for the above argument that deposit insurance can reduce depositor monitoring and lead to greater bank risk-taking. Hovakimian et al. (2003) argue that deposit insurance leads to risk shifting where insured banks take more risk at the expense of the insuring party, i.e., the Federal Deposit Insurance Corporation (FDIC). Demirgüç-Kunt \& Detragiache (2002), Hovakimian et al. (2003), and Laeven \& Levine (2009) provide empirical evidence that shows deposit insurance leads to greater bank risk-taking.

Similarly, explicit and implicit guarantees afforded to TBTF banks can result in even greater moral hazard problems whereby these banking institutions take greater risk. Dam \& Koetter (2012) examine a sample of German banks over the 1995-2006 period, and they show that higher bailout expectation leads to greater bank risk-taking. Duchin \& Sosyura (2014) examine banks that applied to get assistance from the Troubled Asset Relief Program (TARP), and they find that bailed-out banks increased their risk-taking in the same asset classes that led to the need for the bailout in the first place.

In general, the literature provides both theoretical and empirical support that expectations and realizations of bailouts lead to greater bank risk-taking. As a result, it is

\footnotetext{
${ }^{2}$ A detailed description of the bank bailout during the crisis, through the Troubled Assets Relief Program (TARP), including the list of TARP recipients and the amount they received, is available on the U.S. Treasury Department's website https://www.treasury.gov/initiatives/financial-stability/ TARP-Programs/bank-investment-programs/Pages/default.aspx
} 
reasonable to expect that the top-five $\mathrm{BHC}$ have greater incentive to take more risk than most of the other BHCs in the main sample because they are among the most likely banks to be bailed out. The fact that these five BHCs dominate the mortgage securitization market makes them interesting to explore further. Their response to transparency changes can be different from the other BHCs because they have different risk-taking incentives and because they are large and more complex institutions that may be operating differently than the other BHCs.

\subsection{Analyses of Large BHCs}

This section presents empirical analyses of the lending decisions of the top-five BHCs around the accounting pronouncements, as measured by the risk measures developed in chapter 4, focusing on potential differences from the other BHCs in the main sample. I look for lending behavior by the top-five BHCs that may provide evidence supporting (or contradicting) my hypotheses. I also examine non-top-five BHCs in the top securitization volume decile (top-decile BHCs) because they are more likely to be TBTF than the rest of the securitizing BHCs. This comparison sample allows me to test whether the largest securitizers behave differently around transparency changes than other securitizing BHCs. I form securitization volume deciles annually, based on reported outstanding amount of securitized mortgages as of the December 31 of each year.

\subsubsection{Descriptive Statistics}

Table 6.1 contains descriptive statistics across BHC-year for the top-five securitizing BHCs, for the top-decile securitizing BHCs, non-top decile securitizing BHCs, and nonsecuritizing BHCs. The top-five banks have more assets ( $L N A S S E T S$ ), have more cash $(L N C A S H)$, have more loans $(L N L O A N S)$ on their balance sheet that grow at a higher rate $(L O A N G R)$, securitize more mortgages ( $L N S E C U R I T I Z E D M O R T$ ), service more mortgages (LNSERVICEDMORT), and have more employees (NUMEMPLOYEE), than all the other groups of BHCs, indicating that these BHCs are on average larger and more complex than the other BHC subsamples. The average number of employees for the top-five BHCs is more than three times greater than that of the top-decile banks, an indication of how different the top-five banks are relative to the other banks. They also have higher market valuation $(M V)$ and higher analyst coverage (COVERAGE) than the other BHCs. 
The top-five BHCs have greater loan-to-deposit ratio (LOAN/DEPOSIT) than nontop decile securitizing BHCs and non-securitizing BHCs, indicating that they rely less on deposits to finance their loans. While the mean and median of loan-to-deposit ratio for top-five BHCs are greater than those of the top-decile securitizing BHCs, the differences are not statistically significant. The top-five BHCs have lower loan-to-assets ratio (LOAN/ASSETS), lower deposit-to-assets (DEPOSIT/ASSETS), and lower core deposit ratio (COREDEPRATIO) than the other BHCs, which suggests that they may engage in more non-traditional banking activities. The top-five banks are less capitalized (TIER1CAPRATIO) but they have more liquid assets (LIQRATIO) than the other banks.

All the above observation are consistent with my argument that they are too different from the rest of the BHCs to find suitable matches in the main sample. The BHCs in the top securitization decile, except the top-five, are included in the main sample. While the BHCs in the top decile are larger than other securitizing and non-securitizing BHCs, they are smaller and less complex than the top-five BHCs. Moreover, it is possible to find matching non-securitizing BHCs for the non-top-five banks in the top decile using the propensity score matching. Hence, the top-five banks are uniquely different from the rest, and warrant a separate examination.

Compared to the other BHCs, the top-five BHCs have more provisions (PROVISION) and allowances ( $A L L O W A N C E$ ) for loan losses, have more non-performing loans $(N P L / L O A N S)$, and have more charge-offs (CHARGEOFF) as a proportion of total on-balance-sheet loans. They also have more non-accrual on-balance-sheet mortgages (BSMORTNACC) and have more on-balance-sheet mortgage charge-offs (BSMORTCHOFF). All the mean and median differences between the top-five banks and the other groups for these loan and mortgage outcome measures are statistically significant, except for the difference in BSMORT NACC between the top-five and the top-decile securitizing BHCs. These descriptive statistics indicate that, relative to the BHCs included in the main sample, the top-five BHCs carry riskier loans on their balance sheet. ${ }^{3}$ Riskier mortgages on the balance sheet can arise from risky lending behavior, which I attempt to capture by the four mortgage lending risk measures. However, table 6.1 shows that the means and medians of the mortgage lending risk measures for the top-five BHCs are not statically different from those of the other groups of BHCs, except for NHIGHRISK and \$HIGHRISK.

Overall, table 6.1 shows that the five BHCs that are excluded from the main sample

\footnotetext{
${ }^{3}$ Recall that I consider risk-taking in mortgage lending through both direct mortgage origination and purchase of mortgages originated by third parties. See section 3.2.
} 
are larger, are more complex, and have riskier loans on their balance sheet than the BHCs that were included in the main sample. However, these five BHCs differ significantly in only two attributes of risk-taking in their mortgage lending, when viewed across all years.

Table 6.1: Descriptive Statistics

\begin{tabular}{|c|c|c|c|c|c|c|}
\hline & \multicolumn{3}{|c|}{$\begin{array}{c}\text { Panel A: } \\
\text { Top } 5 \text { Securitizing BHCs }\end{array}$} & \multicolumn{3}{|c|}{$\begin{array}{c}\text { Panel B: } \\
\text { Top Decile Securitizing BHCs }\end{array}$} \\
\hline & $\mathbf{N}$ & Mean & Median & $\mathbf{N}$ & Mean & Median \\
\hline LNASSETS & 97 & 20.331 & 20.463 & 356 & 17.193 & 17.314 \\
\hline$L N C A S H$ & 97 & 17.345 & 17.372 & 356 & 14.034 & 13.936 \\
\hline LNLOANS & 97 & 19.511 & 19.781 & 356 & 16.586 & 16.784 \\
\hline$L O A N G R$ & 96 & 0.190 & 0.057 & 341 & 0.109 & 0.065 \\
\hline LNSECU RITIZEDMORT & 97 & 17.206 & 18.058 & 356 & 14.480 & 14.042 \\
\hline LNMORTSERVICED & 97 & 19.519 & 19.621 & 338 & 16.016 & 16.299 \\
\hline$M V$ & 97 & 18.178 & 18.470 & 307 & 15.411 & 15.622 \\
\hline$B T M$ & 97 & 0.852 & 0.679 & 307 & 0.938 & 0.712 \\
\hline COVERAGE & 74 & 24.878 & 25.500 & 281 & 15.278 & 16.000 \\
\hline NUMEMPLOYEE & 97 & 173,355 & 167,084 & 356 & 18,444 & 9,832 \\
\hline$L O A N / D E P O S I T$ & 97 & 0.931 & 0.900 & 356 & 0.928 & 0.927 \\
\hline$L O A N / A S S E T S$ & 97 & 0.460 & 0.447 & 356 & 0.592 & 0.633 \\
\hline DEPOSIT/ASSETS & 97 & 0.516 & 0.533 & 356 & 0.649 & 0.680 \\
\hline COREDEPRATIO & 97 & 0.654 & 0.741 & 356 & 0.823 & 0.856 \\
\hline LIQRATIO & 97 & 0.388 & 0.407 & 356 & 0.254 & 0.224 \\
\hline TIER1CAPRATIO & 85 & 0.099 & 0.087 & 312 & 0.115 & 0.108 \\
\hline PROVISION & 97 & 0.012 & 0.009 & 356 & 0.008 & 0.005 \\
\hline$A L L O W A N C E$ & 97 & 0.024 & 0.022 & 356 & 0.017 & 0.015 \\
\hline$N P L / L O A N S$ & 97 & 0.032 & 0.021 & 356 & 0.029 & 0.016 \\
\hline CHARGEOFF & 97 & 0.012 & 0.009 & 356 & 0.008 & 0.005 \\
\hline$B S M O R T N A C C$ & 97 & 0.027 & 0.016 & 356 & 0.022 & 0.010 \\
\hline BSMORTCHOFF & 97 & 0.007 & 0.002 & 355 & 0.006 & 0.002 \\
\hline$A V G M R S C O R E$ & 97 & 9.310 & 9.103 & 356 & 9.497 & 9.285 \\
\hline$S A V G M R S C O R E$ & 97 & 0.994 & 0.994 & 356 & 0.996 & 0.995 \\
\hline NHIGHRISK & 97 & 0.365 & 0.355 & 356 & 0.404 & 0.388 \\
\hline$\$ H I G H R I S K$ & 97 & 0.321 & 0.317 & 356 & 0.368 & 0.344 \\
\hline
\end{tabular}


- continued from previous page

\begin{tabular}{|c|c|c|c|c|c|c|}
\hline & \multicolumn{3}{|c|}{$\begin{array}{c}\text { Panel C: } \\
\text { Non-Top Decile Securitizing BHCs }\end{array}$} & \multicolumn{3}{|c|}{$\begin{array}{c}\text { Panel D: } \\
\text { Non-Securitizing BHCs }\end{array}$} \\
\hline & $\mathbf{N}$ & Mean & Median & $\mathbf{N}$ & Mean & Median \\
\hline LNASSETS & 4642 & 14.324 & 13.943 & 19914 & 13.272 & 13.137 \\
\hline$L N C A S H$ & 4642 & 11.076 & 10.798 & 19914 & 10.053 & 9.852 \\
\hline$L N L O A N S$ & 4642 & 13.864 & 13.501 & 19913 & 12.793 & 12.665 \\
\hline$L O A N G R$ & 4505 & 0.118 & 0.080 & 18403 & 0.124 & 0.092 \\
\hline LNSECU RITIZEDMORT & 4101 & 8.828 & 9.118 & & & \\
\hline LNMORTSERVICED & 3561 & 11.701 & 11.910 & 8044 & 10.416 & 10.867 \\
\hline$M V$ & 2170 & 13.109 & 12.965 & 5946 & 11.920 & 11.751 \\
\hline$B T M$ & 2170 & 0.870 & 0.680 & 5946 & 0.888 & 0.689 \\
\hline COVERAGE & 1710 & 7.932 & 5.000 & 3888 & 4.099 & 3.000 \\
\hline NUMEMPLOYEE & 4642 & 2,253 & 326 & 19914 & 391 & 160 \\
\hline$L O A N / D E P O S I T$ & 4641 & 0.845 & 0.846 & 19913 & 0.805 & 0.791 \\
\hline$L O A N / A S S E T S$ & 4642 & 0.646 & 0.660 & 19914 & 0.636 & 0.650 \\
\hline DEPOSIT/ASSETS & 4642 & 0.777 & 0.797 & 19914 & 0.815 & 0.832 \\
\hline COREDEPRATIO & 4641 & 0.850 & 0.868 & 19913 & 0.846 & 0.865 \\
\hline LIQRATIO & 4638 & 0.240 & 0.225 & 19859 & 0.246 & 0.234 \\
\hline TIER1CAPRATIO & 4128 & 0.125 & 0.118 & 17254 & 0.134 & 0.121 \\
\hline PROVISION & 4642 & 0.006 & 0.003 & 19902 & 0.006 & 0.003 \\
\hline$A L L O W A N C E$ & 4642 & 0.016 & 0.014 & 19913 & 0.015 & 0.013 \\
\hline$N P L / L O A N S$ & 4642 & 0.016 & 0.009 & 19882 & 0.015 & 0.008 \\
\hline CHARGEOFF & 4642 & 0.005 & 0.002 & 19901 & 0.006 & 0.002 \\
\hline BSMORTNACC & 4639 & 0.013 & 0.007 & 19831 & 0.011 & 0.004 \\
\hline BSMORTCHOFF & 4631 & 0.004 & 0.001 & 19747 & 0.002 & 0.000 \\
\hline$A V G M R S C O R E$ & 4637 & 9.250 & 9.125 & 19826 & 9.141 & 9.014 \\
\hline$S A V G M R S C O R E$ & 4637 & 0.995 & 0.996 & 19826 & 0.993 & 0.996 \\
\hline NHIGHRISK & 4637 & 0.384 & 0.365 & 19826 & 0.379 & 0.350 \\
\hline$\$ H I G H R I S K$ & 4637 & 0.354 & 0.322 & 19826 & 0.357 & 0.317 \\
\hline
\end{tabular}

This table presents the descriptive statistics, across BHC-years, for the top-five securitizing BHCs and other groups of non-top-five BHCs. Panel A presents the descriptive statistics for the top-five banks. Panel B presents the statistics for securitizing BHCs in the top mortgage securitization decile. BHCs are assigned to mortgage securitization decile annually based on their outstanding amount of securitized mortgages reported for each year. In panel C, I report the statistics for securitizing BHCs that are not in the top decile. Panel D contains the descriptive statistics for non-securitizing BHCs. All variables are as defined in appendix A.1. The means and medians for the top-five banks are statistically different from those of the other groups at least at the $10 \%$ level, except for those cases presented in bold font. 


\subsubsection{Mortgage Lending Around Standard Changes}

While the top-five BHCs, on average over the period 1993-2015, appear similar to the other BHCs in terms of mortgage lending behavior, it is possible that they behave differently within narrow windows around the accounting standards, which is more relevant to my thesis. Figure 6.2 presents time series plots of AVGMRSCORE, SAVGMRSCORE, NHIGHRISK, and $\$ H I G H R I S K$ over the period 1993-2015 for the top-five securitizing BHCs, for non-top-five securitizing BHCs, and non-securitizing BHCs. I first discuss the changes in the risk measures around the years, in which the accounting pronouncements became effective (indicated by the vertical lines). I then discuss the difference between the time series dynamics of the top-five BHCs and that of the other BHCs.

The time series plots of $A V G M R S C O R E$ in Figure 6.2 panel (a) show that $A V G M R S C O R E$ for the top-five banks decreases over the period 1996-1998, however this decline in risk appears to be a continuation of a trend that goes back at least to 1994. Hence, it is less likely that the decrease in $A V G M R S C O R E$ is driven by FAS 125, which was issued in 1996 and became effective in 1997. AVGMRSCORE for the top-five banks increased in the pre-FAS 140 period up to and including the first year in which FAS 140 was effective (1998-2001), it remained stable for the second year of the post-FAS 140 period (2002), and it declined from 2002 to 2005, which spans the pre- and post-FIN 46 periods. These results suggest that the top-five BHCs did not change their lending behavior immediately after FAS 140 became effective, and that FAS 140 may have contributed to halt the increase in risk-taking by these top-five banks. AVGMRSCORE then declines during the post-FIN 46 period (2003-2005), suggesting that the large banks reduced their risk-taking following FIN 46. AVGMRSCORE increases rapidly from 2006-2009, and declined sharply in the following years. While the switch from increasing to decreasing AVGMRSCORE happens in 2009, the issue year of FAS 166 \& 167, it also coincides with the financial crisis, which makes it difficult to attribute this change to either the standards or the economic climate.

The average changes in $A V G M R S C O R E$ around the four accounting pronouncement events for the non-top-five banks are similar to those for the top-five banks described in the previous paragraph, suggesting that the top-five banks did not behave differently in their mortgage lending than the other banks. It is possible that the time series fluctuations in $A V G M R S C O R E$ for all groups of banks are driven by other economic factors such as aggregate mortgage demand, the financial crises, or business cycles.

Similarly, the graphs for SAVGMRSCORE, NHIGHRISK, and \$HIGHRISK in panels (b), (c), and (d), respectively, provide no clear evidence that shows the top-five BHCs behaved differently around the accounting standard changes. SAVGMRSCORE 
Figure 6.2: The time series of mortgage lending risk

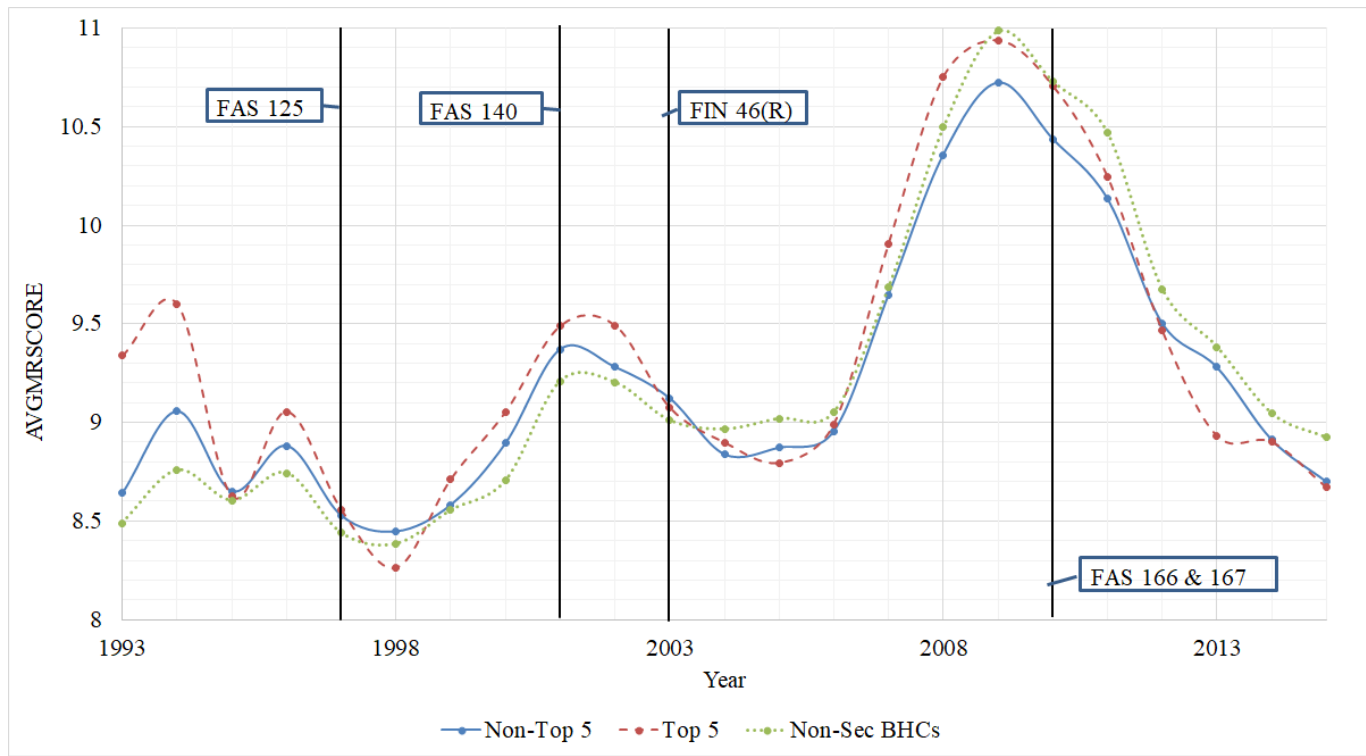

(a) AVGMRSCORE

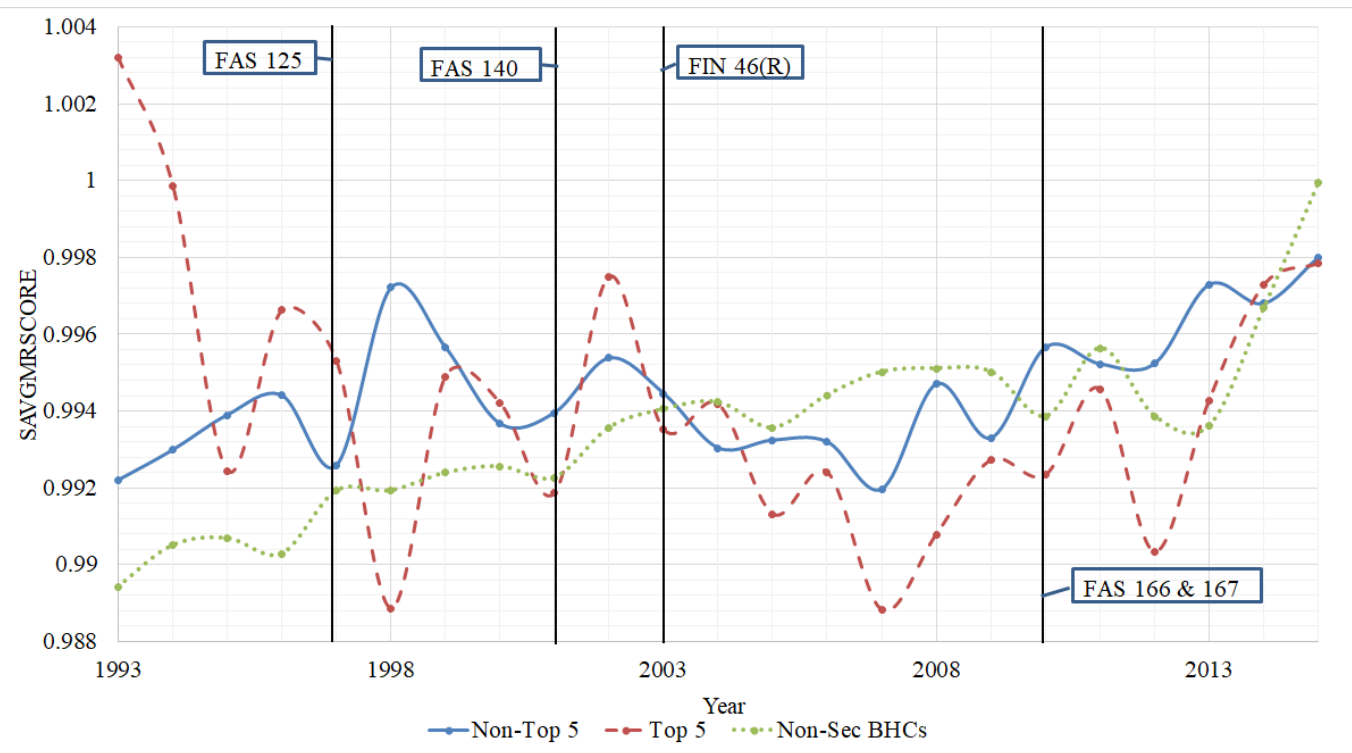

(b) SAVGMRSCORE 


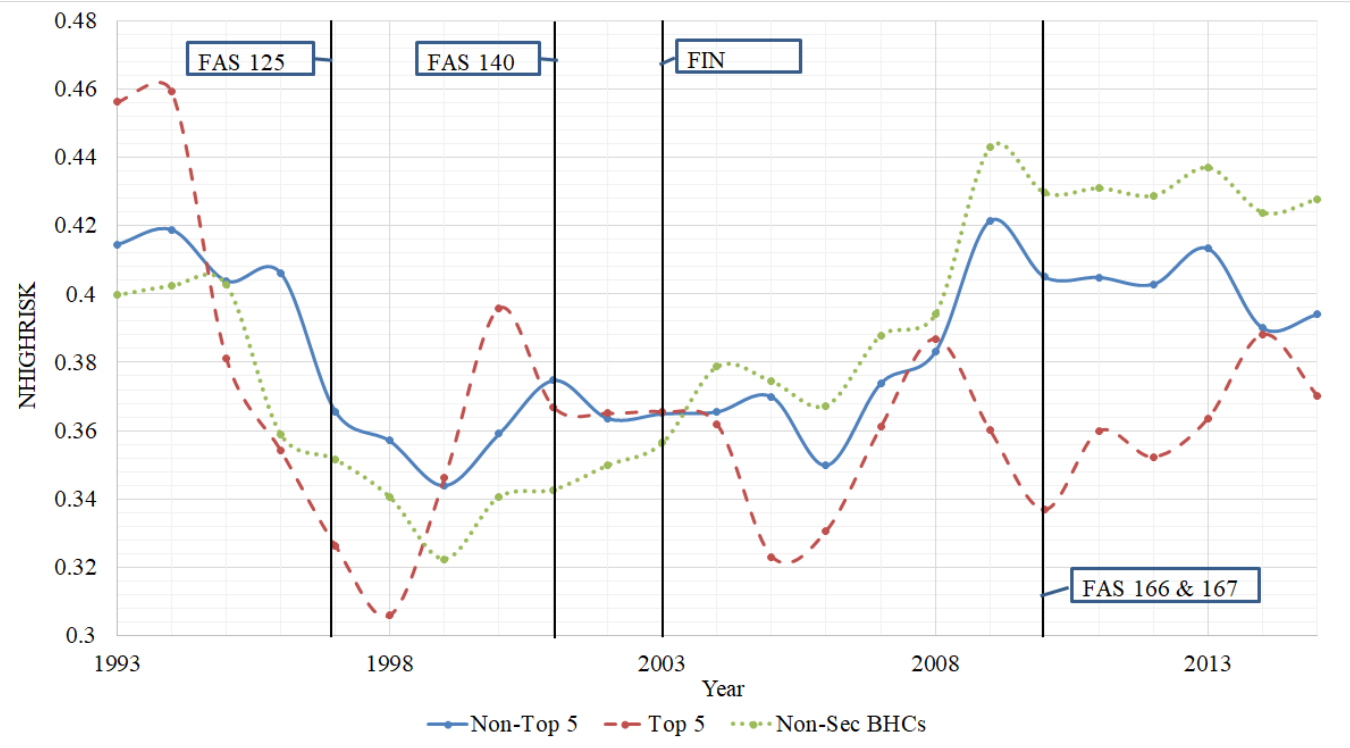

(c) NHIGHRISK

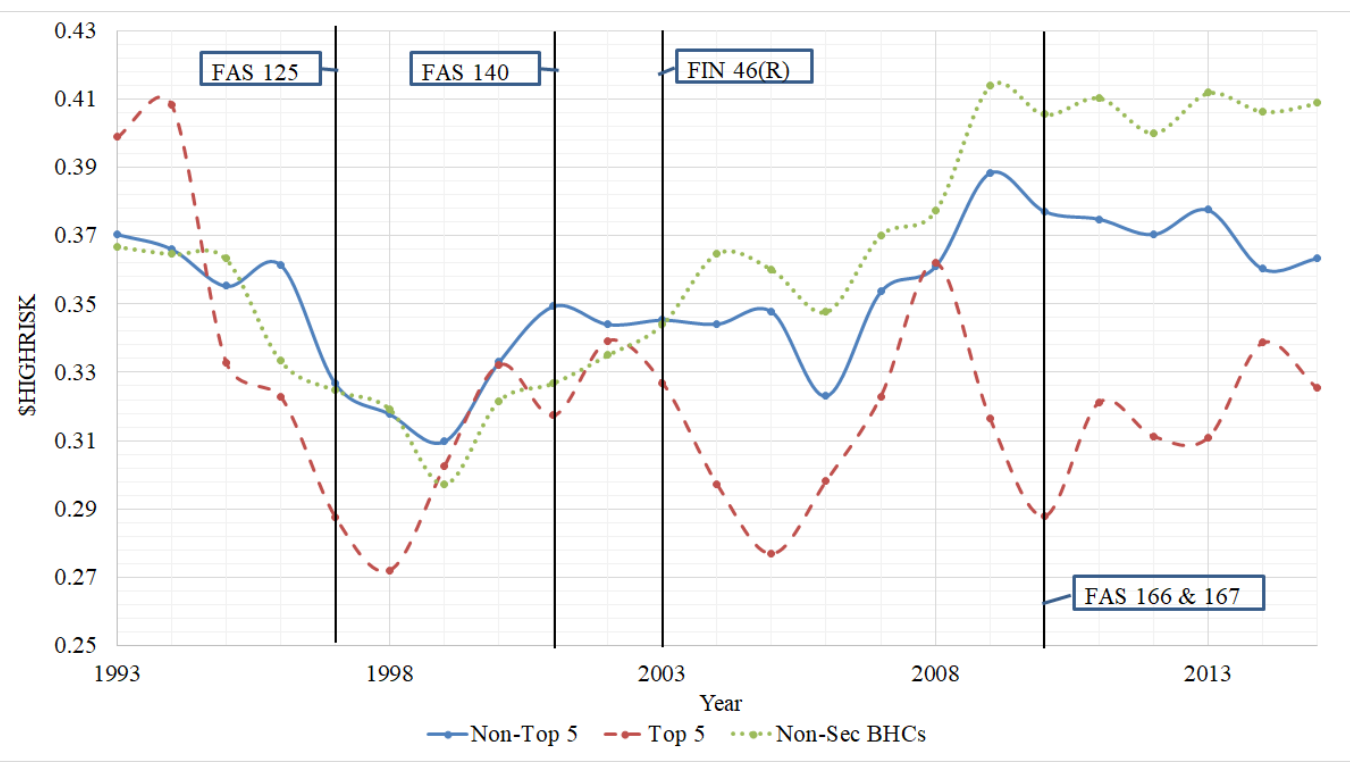

(d) $\$ H I G H R I S K$

This figure presents the time series plots of the average mortgage lending risk measures for three groups of BHCs, namely the top-five securitizing BHCs (dashed red line), non-top-five securitizing BHCs (solid blue line), and non-securitizing BHCs (dotted green line) over the period 1993-2015. Panels (a), (b), (c), and (d) present the graphs for AVGMRSCORE, $S A V G M R S C O R E, N H I G H R I S K$, and $\$ H I G H R I S K$, respectively. 
fluctuates year to year for all groups of banks, much less so for non-securitizing banks, making a reasonable inference about lending behavior around standard changes difficult. NHIGHRISK and $\$ H I G H R I S K$ fluctuate less frequently, but they do not show different risk-taking behavior between the top-five banks and the other banks. Since NHIGHRISK and $\$ H I G H R I S K$ exhibit similar patterns, I discuss only the case for NHIGHRISK.

During the period leading up to and immediately after FAS 125, NHIGHRISK decreased for all groups of BHCs, suggesting FAS 125 did not affect bank risk-taking. For both groups of securitizing BHCs, NHIGHRISK increased over the pre-FAS 140 period starting in 1998 up until 2000/2001, and remained relatively constant over the postFAS 140 period (2001-2005), which also encompasses the pre- and post-FIN 46 period. These observations suggest that securitizing BHCs slowed down their risk-taking following FAS 140, but FIN 46 did not influence their behavior. For the non-securitizing BHCs, NHIGHRISK increased from 1999 to 2004, suggesting that, unlike for securitizing BHCs, neither FAS 140 nor FIN 46 had an impact on the non-securitizing BHCs' lending behavior. NHIGHRISK increased for all groups of BHCs from 2005 to 2008, followed by further increase in 2009 for the non-top-five BHCs but by sharp decline for the top-five BHCs over the same year. The average NHIGHRISK for the top-five BHCs remains below that of the non-top-five BHCs for the entire post-crisis period. This result suggests that the top-five BHCs reduced their risk-taking immediately after the financial crises.

Overall, the graph for NHIGHRISK shows that there are some potential differences in lending behavior between the top-five banks and other banks in the main sample. I use a quasi-DiD design similar to that of the main test for $\mathrm{H} 2$ through $\mathrm{H} 4$ (section 5.4), to test if these potential differences are statistically significant. I find that the differences are mostly insignificant, supporting the original conclusion that the top-five BHCs did not behave differently than the other BHCs. I arrive at similar conclusion using a regression framework similar to the one presented in section 5.5.5.

Table 6.2 presents the results of statistical tests of changes in risk-taking around the accounting pronouncements for the top-five BHCs as well as top decile BHCs and other securitizing BHCs. As in section 5.5, I use a four-year window around each pronouncement with two years in the pre-period and two years in the post-period. For each group of BHCs, I use a t-test to compare the top-five BHCs' average risk-taking before and after each pronouncement. I also use a t-test to assess whether the change in the top-five BHCs' risk-taking around each pronouncement differs from that of the non-top-five securitizing BHCs. The design for this test is similar to that of the tests for $\mathrm{H} 2-\mathrm{H} 4$, and I again refer to the difference between pre-post changes for the top-five and non-top-five BHCs as QDiD.

Panel A shows that none of the risk measures changed significantly around FAS 125 
for the top-five BHCs, compared to a significant decrease in NHIGHRISK for non-topfive securitizing BHCs. The differences between the top-five and non-top-five BHCs, i.e., QDiDs, are not statistically significant. These results suggest that the top-five BHCs did not change their lending decisions in response to FAS 125, and that they did not differ from the non-top-five BHCs in their lending decision around FAS 125.

As shown in panel B, AVGMRSCORE increased significantly around FAS 140 for both groups. SAVGMRSCORE, NHIGHRISK, and $\$ H I G H R I S K$ did not change significantly for the top five BHCs, while $S A V G M R S C O R E$ decreased and $\$ H I G H R I S K$ increased for the non-top-five BHCs. In all the cases, the QDiDs are not significant, indicating that FAS 140 did not affect the top-five BHCs differently than the other BHCs.

Panel C shows that AVGMRSCORE decreased significantly around FIN 46 for both the top-five BHCs and non-top-five BHCs groups, but the differences between the two groups is not significant. For SAVGMRSCORE, NHIGHRISK, and \$HIGHRISK, none of the pre-post changes and QDiDs are significant. Once again, these results show no change in the top-five BHCs' lending decision around FIN 46 and that their behavior was not significantly different from that of non-top-five BHCs. 
Table 6.2: Transparency and Risk-taking by Top-five BHCs

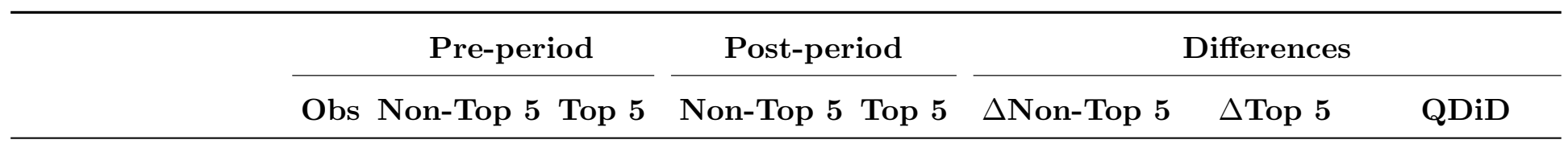

Panel A: FAS 125

\begin{tabular}{llllllrrr}
\hline AVGMRSCORE & 977 & 9.324 & 9.110 & 8.700 & 8.805 & -0.624 & -0.305 & -0.152 \\
SAVGMRSCORE & 615 & 0.993 & 0.996 & 0.993 & 0.996 & 0.000 & 0.000 & -0.0002 \\
NHIGHRISK & 615 & 0.411 & 0.420 & 0.385 & 0.340 & $-0.026^{* *}$ & -0.080 & -0.054 \\
\$HIGHRISK & 615 & 0.361 & 0.371 & 0.344 & 0.305 & -0.017 & -0.066 & -0.048 \\
\hline
\end{tabular}

שv Panel B: FAS 140

\begin{tabular}{lllllllll}
\hline AVGMRSCORE & 977 & 8.516 & 8.487 & 9.156 & 9.271 & $0.64^{* * *}$ & $0.784^{* * *}$ & 0.144 \\
SAVGMRSCORE & 703 & 0.996 & 0.992 & 0.994 & 0.993 & $-0.002^{*}$ & 0.001 & 0.004 \\
NHIGHRISK & 703 & 0.350 & 0.326 & 0.368 & 0.381 & 0.018 & 0.055 & 0.038 \\
\$HIGHRISK & 703 & 0.314 & 0.287 & 0.342 & 0.325 & $0.028^{* *}$ & 0.0380 & 0.009 \\
\hline
\end{tabular}

Panel C: FIN 46(R)

\begin{tabular}{lllllllll}
\hline AVGMRSCORE & 977 & 9.324 & 9.490 & 8.856 & 8.846 & $-0.468^{* * *}$ & $-0.644^{* * *}$ & -0.176 \\
SAVGMRSCORE & 977 & 0.995 & 0.995 & 0.993 & 0.993 & -0.002 & -0.002 & -0.001 \\
NHIGHRISK & 977 & 0.369 & 0.366 & 0.368 & 0.342 & -0.001 & -0.024 & -0.022 \\
\$HIGHRISK & 977 & 0.347 & 0.330 & 0.346 & 0.287 & -0.001 & -0.043 & -0.042 \\
\hline
\end{tabular}


- continued from previous page

Panel D: FAS $166 \& 167$

\begin{tabular}{llllllllc}
\hline AVGMRSCORE & 928 & 10.01 & 10.33 & 10.58 & 10.82 & $0.570^{* * *}$ & $0.490^{* *}$ & -0.069 \\
SAVGMRSCORE & 928 & 0.993 & 0.990 & 0.995 & 0.993 & 0.002 & 0.003 & 0.002 \\
NHIGHRISK & 928 & 0.379 & 0.374 & 0.413 & 0.349 & $0.034^{* * *}$ & -0.025 & $-0.060^{* * *}$ \\
\$HIGHRISK & 928 & 0.357 & 0.343 & 0.383 & 0.302 & $0.026^{* *}$ & -0.041 & $-0.066^{* *}$ \\
\hline
\end{tabular}

This table presents the average changes in risk-taking by the top-five securitizing BHCs excluded from the main sample around the accounting pronouncements. The table also contains the average changes in risk-taking by nontop-five securitizing BHCs, i.e. BHCs in the main sample, for comparison. ${ }^{* * *},{ }^{* *},{ }^{*}$, represent p-values below $1 \%$, $5 \%, 10 \%$, respectively, from the mean tests comparing the corresponding values to zero. All variables are as defined in table 5.1 or appendix A.1. 
Panel D shows that $A V G M R S C O R E$ increased significantly following FAS $166 \& 167$ for both the top-five and non-top-five BHCs, but the QDiD is insignificant, suggesting that there was no significant difference in how top-five and non-top-five securitizing BHCs reacted to FAS 166 \& 167. However, the results for NHIGHRISK and $\$ H I G H R I S K$ suggest otherwise. Both NHIGHRISK and $\$ H I G H R I S K$ increased significantly for non-top-five BHCs but not for the top-five BHCs, resulting in a significantly negative QDiD.

In summary, while there is some evidence that suggests the top-five BHCs increased their risk-taking following FAS 140 and FAS 166 \& 167, and decreased their risk-taking following FIN 46, this evidence is limited to only one of the four risk measures. All the other risk measures show no significant change around the pronouncements for the topfive BHCs. Moreover, in almost all the cases, the top-five BHCs' risk-taking around the pronouncements is not significantly different from that of non-top-five BHCs. The only exceptions of significant QDiDs for NHIGHRISK and \$HIGHRISK around FAS 166 \& 167 arise from significant changes in non-top-five BHCs' lending decision relative to no change by the top-five BHCs.

Table 6.3 presents a similar set of tests for BHCs in the top securitization decile. The results are mostly similar to those in table 6.2 for the top-five securitizing BHCs. As in the case of the top-five BHCs, the evidence overwhelmingly suggests that BHCs in the top securitization decile did not change their lending behavior significantly following the accounting pronouncements. The table provides some evidence that suggests BHCs in the securitization decile 1 to 9 changed their lending behavior following the pronouncements. However, the difference in risk-taking between top-decile and non-top-decile BHCs is not significant in almost all cases.

\subsection{Conclusion}

The evidence presented in this chapter leads to the conclusion that the top-five securitizing BHCs excluded from the main sample do not differ from the BHCs in the main sample in a way that affects my conclusions about the effect of transparency on bank risk-taking. This conclusion is supported by untabulated additional analyses that show no statistically significant difference in the riskiness of new loans between the top-five BHCs and BHCs in my main ample, even after controlling for other relevant factors. However, as shown in figure 6.1, the top-five BHCs increased their securitization activity immediately after FAS 140 became effective. Further research is required to asses whether FAS 140 in fact drives this jump in securitization activity. 
Table 6.3: Transparency and Risk-taking by BHCs in the Top Securitization Decile

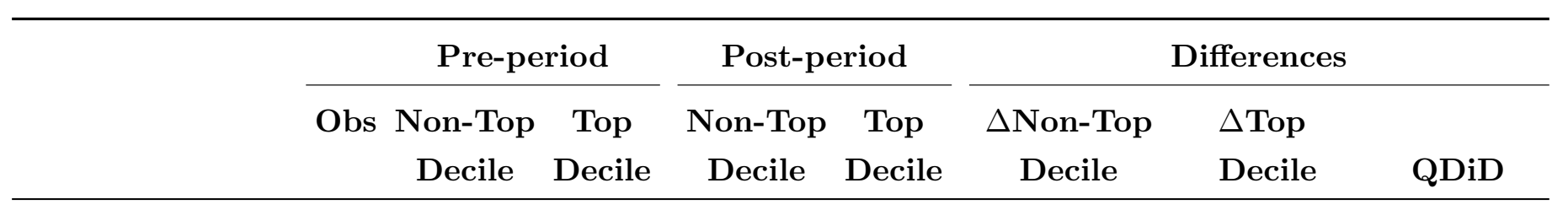

Panel A: FAS 125

\begin{tabular}{lllllccrl}
\hline AVGM RSCORE & 977 & 9.295 & 9.056 & 8.673 & 9.018 & $-0.622^{*}$ & -0.038 & 0.131 \\
SAVGMRSCORE & 615 & 0.993 & 0.994 & 0.993 & 1 & 0.000 & $0.006^{*}$ & $0.006^{* *}$ \\
NHIGHRISK & 615 & 0.409 & 0.438 & 0.381 & 0.420 & $-0.028^{* *}$ & -0.018 & 0.011 \\
\$HIGHRISK & 615 & 0.360 & 0.377 & 0.338 & 0.388 & -0.022 & 0.011 & 0.032 \\
\hline
\end{tabular}

एँ. Panel B: FAS 140

\begin{tabular}{llllllrrr}
\hline AVGMRSCORE & 977 & 8.479 & 8.922 & 9.126 & 9.539 & $0.647^{* * *}$ & $0.617^{* * *}$ & -0.029 \\
SAVGMRSCORE & 703 & 0.996 & 0.997 & 0.994 & 0.995 & $-0.002^{*}$ & -0.002 & 0.001 \\
NHIGHRISK & 703 & 0.344 & 0.411 & 0.363 & 0.425 & 0.019 & 0.014 & -0.005 \\
\$HIGHRISK & 703 & 0.308 & 0.372 & 0.338 & 0.387 & $0.03^{* *}$ & 0.015 & -0.015 \\
\hline
\end{tabular}

Panel C: FIN 46(R)

\begin{tabular}{llllllllr}
\hline AVGMRSCORE & 977 & 9.295 & 9.700 & 8.840 & 9.017 & $-0.455^{* * *}$ & $-0.683^{* * *}$ & -0.228 \\
SAVGMRSCORE & 977 & 0.995 & 0.995 & 0.993 & 0.994 & -0.002 & -0.001 & 0.001 \\
NHIGHRISK & 977 & 0.365 & 0.415 & 0.367 & 0.374 & 0.002 & -0.041 & -0.043 \\
\$HIGHRISK & 977 & 0.343 & 0.386 & 0.345 & 0.341 & 0.002 & -0.045 & -0.048 \\
\hline
\end{tabular}


- continued from previous page

Panel D: FAS 166 \& 167

\begin{tabular}{llllllllr}
\hline AVGMRSCORE & 928 & 9.994 & 10.25 & 10.55 & 10.84 & $0.556^{* * *}$ & $0.59^{* * *}$ & 0.028 \\
SAVGMRSCORE & 928 & 0.993 & 0.993 & 0.994 & 0.994 & 0.001 & 0.001 & 0.001 \\
NHIGHRISK & 928 & 0.379 & 0.376 & 0.415 & 0.385 & $0.036^{* * *}$ & 0.009 & -0.026 \\
\$HIGHRISK & 928 & 0.358 & 0.343 & 0.385 & 0.343 & $0.027^{*}$ & 0.000 & -0.027 \\
\hline
\end{tabular}

This table presents the average changes in risk-taking by the BHCs in the top securitization decile around the accounting pronouncements. For each year, I assign securitizing BHCs into deciles based on their securitization volume, measured by the outstanding amount of securitized mortgages reported in that year. The top-five securitizing BHCs are included in the top decile. The table also contains the average changes in risk-taking by securitizing BHCs in the other deciles for comparison. ${ }^{* * *},{ }^{* *},{ }^{*}$, represent p-values below 1\%, 5\%, 10\%, respectively, from the mean tests comparing the corresponding values to zero. All variables are as defined in table 5.1 or appendix A.1. 



\section{Chapter 7}

\section{Discussion and Conclusion}

This thesis examines whether and how financial reporting transparency affects banks' operating decisions, a question with both academic and practical relevance. As discussed in greater detail in chapter 2, a vast academic literature in accounting, finance, and economics examines transparency and its effects on banks' operating decisions, with particular interest in the role of transparency in promoting sound operating decisions such as avoiding excessive risk-taking. Standard setters and regulators who are responsible for establishing the accounting and reporting standards that shape banks' FRT should benefit from understanding the effects of transparency on bank operating decisions. Bank regulators and supervisors, responsible for ensuring the soundness of reporting institutions, can benefit from understanding the effects of specific accounting standards and transparency on bank operating decisions such as risk-taking in mortgage their lending. Policy makers can benefit from my research question in their effort to ensure a stable financial system.

I explore the research question in a residential mortgage lending and securitization setting, in which prior research (e.g., Keys et al. 2010) documents a relation between securitization and bank risk-taking in mortgage lending without a particular attention to transparency. I hypothesize that the financial reporting transparency for securitization influences this relation because transparency influences external stakeholders' ability to monitor managers' risk-taking behavior. I exploit five FASB securitization accounting pronouncements to identify the effect of transparency on banks' mortgage lending decisions. The pronouncements provide four distinct transparency shocks during my sample period, dividing the period into multiple sub-periods with varying levels of transparency. I construct new measures of bank risk-taking in mortgage lending using publicly available loan-level data from the HMDA database, which I validate using BHC-level on-balancesheet mortgage delinquencies and charge-offs reported on the FR Y-9C form. 
The empirical results do not support my hypotheses, with most of the estimated effects either statistically indistinguishable from zero or in the opposite direction of the prediction. These results, which are robust to multiple sensitivity tests, suggest that transparency as defined in this thesis does not affect bank lending decisions as measured by the proposed risk-taking measures in the predicted directions. This observation is counter-intuitive and it is contrary to FASB's and bank regulators' intention for issuing financial and regulatory reporting standards that require more transparent reporting of securitization activity. FASB states that one of its primary purposes is "to establish and improve financial accounting and reporting standards to provide useful information to investors and other users of financial reports" "and the Federal Reserve Board states that it publicly releases certain regulatory reports "so investors, depositors, and creditors can better assess the financial condition of the reporting banks". ${ }^{2}$ In both cases, greater transparency is presumed to lead to better stakeholder monitoring of bank decision making. The null results in this thesis suggest that transparency changes following new accounting pronouncements did not influence bank lending decisions, which in turn suggests either that banks sound make lending decisions regardless of transparency, or that the pronouncements did not enhance transparency sufficiently for external stakeholders to efficiently monitor banks' lending decisions. In hindsight, we know the first case not to be true at least in the early- to mid-2000s.

I identify the following alternative explanations for the null results. First, the accounting pronouncements may not affect transparency, at least not in the manner assumed in this thesis, because banks may restructure their operations to subvert the new tighter reporting standards (Bens \& Monahan 2008). I find some evidence supporting this explanation. More specifically, I find that securitizing banks take lower risk than non-securitizing banks in the most transparent period compared to the least transparent period. Further research investigating the effect of the pronouncements on the financial reporting transparency of securitizing can address this concern.

Second, the research design may lack power to identify the hypothesized effects in the specific settings considered in this thesis because the setting is too broad or the matching techniques do not provide a good control group. In this case, identifying a narrower setting and/or a better research design might yield results supporting the hypotheses. Another alternative avenue to increase the power of my tests is to identify BHCs that took relatively too much risk in the pre-periods, and compare their lending decisions in the pros-periods with BHCs that took relatively less risk in the pre-periods. However, any power gained from this strategy could be reduced by the decrease in power as a result of focusing on

\footnotetext{
${ }^{1}$ http://www.fasb.org/jsp/FASB/Page/SectionPage\&cid=1176154526495, accessed May 16, 2018.

2 https://www.federalreserve.gov/supervisionreg/topics/reporting.htm, accessed May 16, 2018.
} 
a small proportion of banks from an already small sample. It is also possible that any decrease in a risk-taking following too much risk-taking can be a result of reversion to the mean, and not driven by transparency.

Third, it is possible that identifying securitizing banks using the outstanding balance of securitized mortgages may not correctly identify banks actively securitizing when the mortgages are originated. A textual analysis of BHC annual and quarterly reports to identify new securitization activity in a given year, as in Niu \& Richardson (2006) might improve the identification of securitizing BHCs.

Fourth, the risk measures may not capture the desired underlying construct of bank risk-taking in mortgage lending. Since the measures have demonstrated some level of validity, future research with refined mortgage lending risk measures would need to improve upon the measures used here. For example, the current measures assume that all individual risk characteristics are equally important throughout the sample period. Identifying the relative relevance of these characteristics and implementing a potentially time-varying weighting scheme reflecting their relative importance might improve the performance of the composite measures. I scale dollar-valued characteristics by the corresponding MSAaverages to account for local area socio-economic differences. However, this geographic adjustment may obscure bank risk-taking through more lending in risky neighborhoods. Alternative risk measures without geographic adjustments might also improve the measures.

Last, this thesis focuses on the financial reporting transparency of individual BHCs and its effect on their individual lending decisions. However, the effect of FASB pronouncements and regulatory disclosure requirements can go beyond individual BHCs. Improving the transparency of individual BHCs can enhance the transparency of financial markets. For example, greater securitization transparency by individual BHCs can improve the transparency, and thereby the efficiency, of ABS and stock markets. This can improve investors' ability to understand and price their risk exposure as a result of securitization, and lead to better sharing of the underlying risk among market participants. In this case, enhancing the transparency of individual BHCs may not lead to lower risk-taking if the risk is properly priced and distributed across the economy, reducing any single party's exposure.

This thesis is related to and contributes to the following streams of literature. First, I propose new measures of bank risk-taking in mortgage lending using the publicly available mortgage-level HMDA database together with the Census and other local area socioeconomic databases. Prior literature examining banks' mortgage lending decisions (e.g., Mian \& Sufi 2009, Keys et al. 2010, Agarwal et al. 2012, Jiang et al. 2014b) combines these 
datasets with commercial or proprietary datasets to construct risk measures based on borrowers' FICO scores and ex post delinquency rates. My proposed measures, unlike those in the literature, are entirely ex ante and based on publicly accessible databases. Other studies such as Loutskina \& Strahan (2009), Xie (2016), and Dou et al. (2018) use the HMDA dataset to examine banks' overall mortgage approval rates. While bank mortgage approval rate is an important lending decision, it does not completely capture banks' risk-taking in their mortgage lending. For instance, an increase in approvals of high-quality mortgages can lead to a higher approval rate, without greater risk-taking. My measures are based on the mortgage-level borrower and property characteristics, and they can differentiate between approvals of high- and low-quality mortgages.

Second, this thesis is related to the stream of literature examining the effect of securitization on banks' incentives to screen and monitor borrowers (e.g., Mian \& Sufi 2009, Keys et al. 2010, 2012, Wang \& Xia 2014). I extend this literature by examining the role of transparency for bank risk-taking in mortgage lending. By comparing securitizing banks' lending decision before and after transparency shocks with that of non-securitizing banks during the same periods, I can disentangle the effect of the securitization activity from the effect of transparency. My findings, with the caveats discussed above, suggest that transparency does not affects the extent to which securitization reduces banks' screening and monitoring incentives.

Third, I contribute to prior research that examines the effect of transparency on bank risk-taking. Bushman \& Williams (2012) and Bushman \& Williams (2015) find that banks with greater FRT for loan losses have lower overall bank risk. This thesis adds to this literature by examining transparency and bank risk-taking in a specific operating activity, namely lending decisions. In this respect, my thesis is closely related to Ertan et al. (2017), who find that enhancing loan-level disclosures for securitized loans improves banks' lending standards for those loans in the EU. In contrast to Ertan et al. (2017), I examine FRT as opposed to loan-level disclosure, the US as opposed to the EU, and borrower screening for both securitized and retained loans as opposed to only securitized loans. Unlike Ertan et al. (2017), who show that transparency enhances the quality of loans, I find no evidence that transparency affects banks' risk-taking in their mortgage lending.

Fourth, this study contributes to a growing stream of literature on the real effects of accounting on banks' operating activities. Xie (2016), and Dou et al. (2018) find that fair value accounting and the consolidation of securitization conduits per FAS $166 \& 167$ affect banks' credit supply decisions. I add to this literature by exploring the riskiness of the mortgages that banks originate, a dimension of lending decisions that is not explored in this literature. 
Last, this thesis contributes to the literature examining the effects of pool-level (e.g., Schmidt \& Zhang 2018) or asset-level disclosures (e.g., Neilson et al. 2018) by issuers of SEC-registered ABS on ABS investors' trading behavior and the valuation of ABS by investors and credit rating agencies, respectively. I add to this literature by examining the effects of BHC-level transparency as opposed to ABS-level transparency, and by focusing on bank lending decisions instead of those of ABS market participants.

Moreover, my thesis uses loan-level data for all mortgage originations by a BHC, which is complementary to the pool- or loan-level data for securitization entities used in Ertan et al. (2017), Neilson et al. (2018), and Schmidt \& Zhang (2018). The ABS pool- or loanlevel data account only for a fraction of a the sponsoring BHCs' mortgage originations. I believe future research examining the effects of such asset-level disclosures (e.g., Reg AB II) on bank lending decisions can be fruitful.

My findings and their implications to the literature should be interpreted with caution because of the caveats discussed above. Further research is required to develop better mortgage lending risk measures, to examine the effect of the accounting pronouncements on transparency, and to investigate how transparency affects banks' mortgage lending decisions. 



\section{References}

Acharya, V. \& Ryan, S. G. (2016), 'Banks financial reporting and financial system stability', Journal of Accounting Research 54(2), 277-340.

Acharya, V., Schnabl, P. \& Suarez, G. (2013), 'Securitization without risk transfer', Journal of Financial Economics 107(3), 515-536.

Affinito, M. \& Tagliaferri, E. (2010), 'Why do (or did?) banks securitize their loans? Evidence from Italy', Journal of Financial Stability 6(4), 189-202.

Agarwal, S., Chang, Y. \& Yavas, A. (2012), 'Adverse selection in mortgage securitization', Journal of Financial Economics 105(3), 640-660.

Anacker, K. B. (2015), 'Analyzing census tract foreclosure risk rates in mature and developing suburbs in the United States', Urban Geography 36(8), 1221-1240.

Bank for International Settlements (2012), '82nd annual report 2012'. Accessed: 08-132016. Available from: http://www.bis.org/publ/arpdf/ar2012e.pdf.

Barth, M. E., Ormazabal, G. \& Taylor, D. J. (2012), 'Asset securitizations and credit risk', The Accounting Review 87(2), 423-448.

Barth, M. E. \& Schipper, K. (2008), 'Financial reporting transparency', Journal of Accounting, Auditing \& Finance 23, 173-191.

Beatty, A. \& Liao, S. (2014), 'Financial accounting in the banking industry: A review of the empirical literature', Journal of Accounting 83 Economics 58, 339-383.

Bebchuk, L. \& Spamann, H. (2010), 'Regulating bankers' pay', The George Town Law Journal 98, 247-287. 
Bens, D. A. \& Monahan, S. J. (2008), 'Altering investment decisions to manage financial reporting outcomes: Asset-backed commercial paper conduits and fin 46', Journal of Accounting Research 46(5), 1017-1055.

Berkovec, J. A., Canner, G. B., Gabriel, S. A. \& Hannan, T. H. (1994), 'Race, redlining, and residential mortgage loan performance', The Journal of Real Estate Finance and Economics 9(3), 263-294.

Bertrand, M. \& Mullainathan, S. (2003), 'Enjoying the quiet life? corporate governance and managerial preferences', Journal of political Economy 111(5), 1043-1075.

Bordo, M. D. (2008), An historical perspective on the crisis of 2007-2008, Technical report, National Bureau of Economic Research.

Boyd, J. H. \& Prescott, E. C. (1986), 'Financial intermediary-coalitions', Journal of Economics Theory 38, 211-232.

Bushman, R. M. (2014), 'Thoughts on financial accounting and the banking industry', Journal of Accounting and Economics 58(2-3), 384-395.

Bushman, R. M. \& Williams, C. D. (2012), 'Accounting discretion, loan loss provisioning, and discipline of banks' risk-taking', Journal of Accounting and Economics 54(1), 1-18.

Bushman, R. M. \& Williams, C. D. (2015), 'Delayed expected loss recognition and the risk profile of banks', Journal of Accounting Research 53(3), 511-553.

Campbell, J. Y. \& Cocco, J. F. (2015), 'A model of mortgage default', The Journal of Finance 70(4), 1495-1554.

Campbell, T. S. \& Dietrich, J. K. (1983), 'The determinants of default on insured conventional residential mortgage loans', The Journal of Finance 38(5), 1569-1581.

Canner, G. B., Gabriel, S. A. \& Woolley, J. M. (1991), 'Race, default risk and mortgage lending: A study of the FHA and conventional loan markets', Southern Economic Journal pp. 249-262.

Cardone-Riportella, C., Samaniego-Medina, R. \& Trujillo-Ponce, A. (2010), 'What drives bank securitisation? the Spanish experience', Journal of Banking and Finance 34(11), 2639-2651.

Casu, B., Clare, A., Sarkisyan, A. \& Thomas, S. (2013), 'Securitization and bank performance', Journal of Money, Credit and Banking 45(8), 1617-1658. 
Chan, S., Gedal, M., Been, V. \& Haughwout, A. (2013), 'The role of neighborhood characteristics in mortgage default risk: Evidence from New York City', Journal of Housing Economics 22(2), 100-118.

Chen, W., Liu, C. C. \& Ryan, S. G. (2008), 'Characteristics of securitizations that determine issuers' retention of the risks of the securitized assets', The Accounting Review 83(5), 1181-1215.

Chernenko, S., Hanson, S. \& Sunderam, A. (2013), The rise and fall of securitization. Working paper, The Ohio State University.

Chomsisengphet, S. \& Pennington-Cross, A. (2006), 'The evolution of the subprime mortgage market', Federal Reserve Bank of St. Louis Review 88(1), 31-56.

Christensen, D. M. (2016), 'Corporate accountability reporting and high-profile misconduct', The Accounting Review 91(2), 377-399.

Clauretie, T. M. (1990), 'A note on mortgage risk: Default vs. loss rates', Real Estate Economics 18(2), 202-206.

Cortes, F. \& Thakor, A. (2015), Does securitization increase risk?: A theory of loan securitization, reputation, and credit screening. Working paper, Northeastern University.

Dam, L. \& Koetter, M. (2012), 'Bank bailouts and moral hazard: Evidence from germany', The Review of Financial Studies 25(8), 2343-2380.

Dechow, P. M., Myers, L. A. \& Shakespeare, C. (2010), 'Fair value accounting and gains from asset securitizations: A convenient earnings management tool with compensation side-benefits', Journal of Accounting and Economics 49(1-2), 2-25.

Dechow, P. M. \& Shakespeare, C. (2009), 'Do managers time securitization transactions to obtain accounting benefits?', The Accounting Review 84(1), 99-132.

Demirgüç-Kunt, A. \& Detragiache, E. (2002), 'Does deposit insurance increase banking system stability? an empirical investigation', Journal of monetary economics 49(7), 13731406 .

Demsetz, H. \& Lehn, K. (1985), 'The structure of corporate ownership: Causes and consequences', Journal of political economy 93(6), 1155-1177.

Demyanyk, Y., Koijen, R. S., Van Hemert, O. et al. (2010), Determinants and consequences of mortgage default. Federal Reserve Bank of Cleveland, Working Paper No. 10-19R. 
Deng, Y., Quigley, J. M. \& Order, R. (2000), 'Mortgage terminations, heterogeneity and the exercise of mortgage options', Econometrica 68(2), 275-307.

Diamond, D. W. (1984), 'Financial intermediation and delegated monitoring', Review of Economic Studies 51(3), 393-414.

Dou, Y. (2017), Spillover effects of consolidating securitization entities on small business lending. Working paper, New York University.

Dou, Y., Liu, Y., Richardson, G. \& Vyas, D. (2014), 'The risk-relevance of securitizations during the recent financial crisis', Review of Accounting Studies 19(2), 839-876.

Dou, Y., Ryan, S. G. \& Xie, B. (2018), 'The real effects of fas 166/167 on banks mortgage approval and sale decisions', Journal of Accounting Research 56(3), 843-882.

Duchin, R. \& Sosyura, D. (2014), 'Safer ratios, riskier portfolios: Banks response to government aid', Journal of Financial Economics 113(1), 1-28.

Elul, R. (2016), 'Securitization and mortgage default', Journal of Financial Services Research 49(2-3), 281-309.

Elul, R., Souleles, N. S., Chomsisengphet, S., Glennon, D., Hunt, R. et al. (2010), "What" triggers" mortgage default?', American Economic Review 100(2), 490-94.

Elul, R. et al. (2006), 'Residential mortgage default', Business Review (Q3), 21-30.

Ertan, A., Loumioti, M. \& WITTENBERG-MOERMAN, R. (2017), 'Enhancing loan quality through transparency: Evidence from the european central bank loan level reporting initiative', Journal of Accounting Research 55(4), 877-918.

Fahlenbrach, R. \& Stulz, R. M. (2011), 'Bank CEO incentives and the credit crisis', Journal of Financial Economics 99(1), 11-26.

Financial Accounting Standards Board (1975), 'Statement of Financial Accounting Standards No. 5. Accounting for Contingencies'.

Financial Accounting Standards Board (1985), 'FASB Technical Bulletin No. 85-2. Accounting for Collateralized Mortgage Obligations (CMOs)'.

Financial Accounting Standards Board (1987), 'Statement of Financial Accounting Standards No. 94. Consolidation of All Majority-Owned Subsidiaries'. 
Financial Accounting Standards Board (1996a), 'Emerging Issues Task Force Issue No. 9620. Impact of FASB Statement No. 125 on Consolidation of Special-Purpose Entities'.

Financial Accounting Standards Board (1996b), 'Statement of Financial Accounting Standards No. 125. Accounting for Transfers and Servicing of Financial Assets and Extinguishments of Liabilities'.

Financial Accounting Standards Board (2000), 'Statement of Financial Accounting Standards No. 140. Accounting for Transfers and Servicing of Financial Assets and Extinguishments of Liabilities (a replacement of FASB Statement No. 125)'.

Financial Accounting Standards Board (2003a), 'FASB Interpretation No. 14. Reasonable Estimation of the Amount of a Loss: an interpretation of FASB Statement No. 5'.

Financial Accounting Standards Board (2003b), 'FASB Interpretation No. 46 (revised December 2003). Consolidation of Variable Interest Entities: an interpretation of ARB No. 51 '.

Financial Accounting Standards Board (2009a), 'Statement of Financial Accounting Standards No. 166. Accounting for Transfers of Financial Assets: an amendment of FASB Statement No. 140'.

Financial Accounting Standards Board (2009b), 'Statement of Financial Accounting Standards No. 167. Amendments to FASB Interpretation No. 46(R)'.

Firestone, S., Van Order, R. \& Zorn, P. (2007), 'The performance of low-income and minority mortgages', Real Estate Economics 35(4), 479-504.

Gallemore, J. (2013), Does bank opacity enable regulatory forbearance? Working paper, University of North Carolina.

Ghent, A. C. \& Kudlyak, M. (2011), 'Recourse and residential mortgage default: Evidence from US States', Review of Financial Studies p. hhr055.

Goldberg, L. G. \& Hudgins, S. C. (2002), 'Depositor discipline and changing strategies for regulating thrift institutions', Journal of Financial Economics 63(2), 263-274.

Gorton, G. \& Pennacchi, G. G. (1995), 'Banks and loan sales: Marketing nonmarketable assets', Journal of Monetary Economics 35(3), 389-411. 
Gramlich, E. M. (2004), Subprime mortgage lending: Benefits, costs, and challenges, in 'Remarks by Governor Edward M. Gramlich at the Financial Services Roundtable Annual Housing Policy Meeting, Chicago, Illinois'.

Greenbaum, S. I. \& Thakor, A. V. (1987), 'Bank funding modes. securitization versus deposits', Journal of Banking and Finance 11(3), 379-401.

Hetzel, R. L. (1991), 'Too big to fail: Origins, consequences, and outlook', Economic Review.

Holod, D. \& Peek, J. (2007), 'Asymmetric information and liquidity constraints: a new test', Journal of Banking \& Finance 31(8), 2425-2451.

Hovakimian, A., Kane, E. J. \& Laeven, L. (2003), 'How country and safety-net characteristics affect bank risk-shifting', Journal of financial services research 23(3), 177-204.

Jackson, J. R. \& Kaserman, D. L. (1980), 'Default risk on home mortgage loans: A test of competing hypotheses', Journal of Risk and Insurance pp. 678-690.

Jagtiani, J. \& Lang, W. W. (2011), 'Strategic defaults on first and second lien mortgages during the financial crisis', The Journal of Fixed Income 20(4), 7-23.

Jiang, W., Nelson, A. A. \& Vytlacil, E. (2014a), 'Liar's loan? effects of origination channel and information falsification on mortgage delinquency', Review of Economics and Statistics 96(1), 1-18.

Jiang, W., Nelson, A. A. \& Vytlacil, E. (2014b), 'Securitization and loan performance: Ex ante and ex post relations in the mortgage market', Review of Financial Studies $\mathbf{2 7}(2), 454-483$.

John, K., Litov, L. \& Yeung, B. (2008), 'Corporate governance and risk-taking', The Journal of Finance 63(4), 1679-1728.

Kane, G. D. (1995), 'Accounting for securitized assets', The CPA Journal 65(7), 44.

Kane, G. D. (1997), 'The problem of how to account for asset securitization transactions', Journal of Accounting Education 15(1), 39-51.

Karaoglu, N. E. (2005), Regulatory capital and earnings management in banks: The case of loan sales and securitizations. Working paper, FDIC Center for Financial Research. 
Keys, B. J., Mukherjee, T., Seru, A. \& Vig, V. (2010), 'Did securitization lead to lax screening? Evidence from subprime loans', The Quarterly Journal of Economics 125(1), 307362.

Keys, B. J., Seru, A. \& Vig, V. (2012), Review of Financial Studies 25(7), 2071-2108.

Kiff, J., Jobst, A., Scarlata, J. \& Kisser, M. (2009), 'Restarting securitization markets: Policy proposals and pitfalls', Global Financial Stability Report.

King, G. \& Nielsen, R. (2016), 'Why propensity scores should not be used for matching', Copy at http://j. mp/1sexgVw Download Citation BibTex Tagged XML Download Paper 378.

Krysan, M., Couper, M. P., Farley, R. \& Forman, T. A. (2009), 'Does race matter in neighborhood preferences? results from a video experiment', American Journal of Sociology $\mathbf{1 1 5}(2), 527-559$.

LaCour-Little, M. (2008), 'Mortgage termination risk: A review of the recent literature', Journal of Real Estate Literature 16(3), 297.

Laderman, E. (2001), 'Subprime mortgage lending and the capital markets', The Federal Reserve Bank of San Francisco Economic Letter (2001-38).

Laeven, L. \& Levine, R. (2009), 'Bank governance, regulation and risk taking', Journal of Financial Economics 93(2), 259-275.

Lambrecht, B., Perraudin, W. \& Satchell, S. (1997), 'Time to default in the UK mortgage market', Economic Modelling 14(4), 485-499.

Landsman, W. R., Peasnell, K. V. \& Shakespeare, C. (2008), 'Are asset securitizations sales or loans?', The Accounting Review 83(5), 1251-1272.

Lawrence, A., Minutti-Meza, M. \& Zhang, P. (2011), 'Can big 4 versus non-big 4 differences in audit-quality proxies be attributed to client characteristics?', The Accounting Review 86(1), 259-286.

Leland, H. E. \& Pyle, D. H. (1977), 'Informational asymmetries, financial structure, and financial intermediation', The Journal of Finance 32(2), 371-387.

Leuven, E. \& Sianesi, B. (2003), 'Psmatch2: Stata module to perform full Mahalanobis and propensity score matching, common support graphing, and covariate imbalance testing', http://ideas.repec.org/c/boc/bocode/s432001.html . version 4.0.11. 
Loutskina, E. \& Strahan, P. E. (2009), 'Securitization and the declining impact of bank finance on loan supply: Evidence from mortgage originations', Journal of Finance 64(2), 861-889.

Mattey, J. \& Wallace, N. (2001), 'Housing-price cycles and prepayment rates of US mortgage pools', The Journal of Real Estate Finance and Economics 23(2), 161-184.

Merton, R. C. (1977), 'An analytic derivation of the cost of deposit insurance and loan guarantees an application of modern option pricing theory', Journal of Banking $\&$ F $i$ nance 1(1), 3-11.

Mian, A. \& Sufi, A. (2009), 'The consequences of mortgage credit expansion: Evidence from the U.S. mortgage default crisis', The Quarterly Journal of Economics (November).

Minton, B., Sanders, A., Strahan, P. E. et al. (2004), Securitization by banks and finance companies: Efficient financial contracting or regulatory arbitrage?, Technical report.

Morgan, D. P. (2002), 'Rating banks: Risk and uncertainty in an opaque industry', American Economic Review 92(4), 874-888.

Morton, T. G. (1975), 'A discriminant function analysis of residential mortgage delinquency and foreclosure', Real Estate Economics 3(1), 73-88.

Nadauld, T. D. \& Sherlund, S. M. (2013), 'The impact of securitization on the expansion of subprime credit', Journal of Financial Economics 107(2), 454-476.

Neilson, J. J., Ryan, S. G., Wang, K. P. \& Xie, B. (2018), 'Asset-level transparency and the (e) valuation of asset-backed securities'. Working paper, Penn State University.

Nier, E. \& Baumann, U. (2006), 'Market discipline, disclosure, and moral hazard in banking', Journal of Financial Intermediation 15(3), 332-361.

Niu, F. \& Richardson, G. D. (2006), 'Are securitizations in substance sales or secured borrowings? capital-market evidence', Contemporary Accounting Research 23(4), 11051133.

O'Brien, P. C. (2011), 'Securitisation, transparency, and failure risk', Irish Accounting Review 18(1), 39-50.

Oz, S. (2016), Did FAS 166 and FAS 167 improve the transparency of securitizing banks? Working paper, McGill University. 
Pennacchi, G. G. (1988), 'Loan sales and the cost of bank capital', Journal of Finance 43(2), 375-396.

Plosser, C. I. (2014), Simplicity, transparency, and market discipline in regulatory reform, in 'Speech given at the conference on Enhancing Prudential Standards in Financial Regulations, Federal Reserve Bank of Philadelphia, April', Vol. 8.

Prescott, E. S., Nurisso, G. et al. (2017), 'The 1970s origins of too big to fail', Economic Commentary (October).

Sandor, R. L. \& Sosin, H. B. (1975), 'The determinants of mortgage risk premiums: A case study of the portfolio of a savings and loan association.', Journal of Business 48, 27-38.

Saunders, A., Strock, E. \& Travlos, N. G. (1990), 'Ownership structure, deregulation, and bank risk taking', The Journal of Finance 45(2), 643-654.

Schipper, K. \& Yohn, T. L. (2007), 'Standard-setting issues and academic research related to the accounting for financial asset transfers', Accounting Horizons 21(1), 59-80.

Schmidt, B. \& Zhang, H. (2018), 'Periodic disclosure of asset-backed securities and bond trading'. Working paper, Ohio State University.

Securities Exchange Commission (2005), 'Asset-Backed Securities', Federal Register 70(5), 1506-1632.

Securities Exchange Commission (2014), 'Asset-Backed Securities Disclosure and Registration', Federal Register 79(185), 57184-57346.

Stiglitz, J. E. (2010), 'Lessons from the global financial crisis of 2008', Seoul Journal of Economics 23(3), 321-339.

Stulz, R. (2014), Governance, risk management, and risk-taking in banks. NBER Working Paper.

Uzun, H. \& Webb, E. (2007), 'Securitization and risk: empirical evidence on us banks', The Journal of Risk Finance 8(1), 11-23.

Vandell, K. D. \& Thibodeau, T. (1985), 'Estimation of mortgage defaults using disaggregate loan history data', Real Estate Economics 13(3), 292-316.

Wang, Y. \& Xia, H. (2014), 'Do lenders still monitor when they can securitize loans?', Review of Financial Studies 27(8), 2354-2391. 
Xie, B. (2016), 'Does fair value accounting exacerbate the procyclicality of bank lending?', Journal of Accounting Research 54(1), 235-274. 
APPENDICES 



\section{Appendix A}

\section{Variable Descriptions}

\section{A.1 Mortgage Lending Risk Measures}

\begin{tabular}{|c|c|c|}
\hline Variable & Description & Data Sources \\
\hline \multicolumn{3}{|c|}{ Panel A: Composite Measures } \\
\hline$M R S C O R E$ & $\begin{array}{l}\text { The mortgage-level composite risk score, which is } \\
\text { the sum of all high-risk indicators based on the } \\
\text { individual characteristics described in Panel B } \\
\text { below. }\end{array}$ & $\begin{array}{l}\text { HMDA, HMDA/CRA } \\
\text { Census, BEA Personal } \\
\text { Income, FHFA House } \\
\text { Price Index }\end{array}$ \\
\hline$A V G M R S C O R E$ & $\begin{array}{l}\text { The BHC-year average } M R S C O R E \text { for all } \\
\text { mortgages approved by the BHC during the year } \\
\text { divided by the BHC-year average MRSCORE for } \\
\text { all applications received by the BHC during the } \\
\text { year. }\end{array}$ & Same as above \\
\hline NHIGHRISK & $\begin{array}{l}\text { The number of high-risk approved mortgages } \\
\text { divided by the total number of approved mortgages, } \\
\text { where high-risk mortgages are those with above } \\
\text { MSA-median MRSCORE. }\end{array}$ & Same as above \\
\hline$\$ H I G H R I S K$ & $\begin{array}{l}\text { The total dollar amount of high-risk approved } \\
\text { mortgages divided by the total dollar amount of all } \\
\text { approved mortgages, where high-risk mortgages are } \\
\text { those with above MSA-median MRSCORE. }\end{array}$ & Same as above \\
\hline
\end{tabular}




\section{-continued from previous page}

\begin{tabular}{|c|c|c|}
\hline Variable & Description & Data Sources \\
\hline \multicolumn{3}{|c|}{ Panel B: Individual Borrower Characteristics } \\
\hline I.BLACK & $\begin{array}{l}\text { An indicators variable that equals one if the } \\
\text { borrower is Black, and zero otherwise. }\end{array}$ & HMDA \\
\hline I.HISPANIC & $\begin{array}{l}\text { An indicators variable that equals one if the } \\
\text { borrower is Hispanic, and zero otherwise. }\end{array}$ & HMDA \\
\hline I.NOCOBORR & $\begin{array}{l}\text { An indicators variable that equals one if there is no } \\
\text { co-borrower, and zero otherwise. }\end{array}$ & HMDA \\
\hline INCOME & $\begin{array}{l}\text { The inverse of borrower income divided by local } \\
\text { area median income. }\end{array}$ & $\begin{array}{l}\text { HMDA, HMDA/CRA } \\
\text { Census }\end{array}$ \\
\hline$L T I$ & $\begin{array}{l}\text { The borrower's loan-to-income ratio divided by } \\
\text { local area median loan-to-income ratio, where } \\
\text { loan-to-income ratio is the loan amount divided by } \\
\text { the borrower income. }\end{array}$ & HMDA \\
\hline \multicolumn{3}{|c|}{ Panel C: Individual Loan Characteristics } \\
\hline$L O A N$ & $\begin{array}{l}\text { The dollar amount of the mortgage divided by the } \\
\text { local area median mortgage amount. } \\
\text { The ratio of the loan amount to the estimated local } \\
\text { area median house value. I estimate the local area }\end{array}$ & HMDA \\
\hline$L T M E D V$ & $\begin{array}{l}\text { median house value in a given year by adjusting the } \\
\text { corresponding median house value from }\end{array}$ & $\begin{array}{l}\text { HMDA, HMDA/CRA } \\
\text { Census, FHFA HPI }\end{array}$ \\
\hline I.NOINCOME & $\begin{array}{l}\text { HMDA/CRA census database for changes in } \\
\text { MSA-level house price indexes. } \\
\text { An indicators variable that equals one if there is no } \\
\text { reported borrower income, and zero otherwise. }\end{array}$ & HMDA \\
\hline \multicolumn{3}{|c|}{ Panel D: Individual Property Characteristics } \\
\hline I.OWNOCC & $\begin{array}{l}\text { An indicators variable that equals one if the } \\
\text { property is owner-occupied, and zero otherwise. }\end{array}$ & HMDA \\
\hline \multicolumn{3}{|c|}{ Panel E: Individual Geographic Characteristics } \\
\hline$B L A C K P E R C$ & $\begin{array}{l}\text { The percentage of Black population in the census } \\
\text { tract (county). }\end{array}$ & HMDA/CRA Census \\
\hline EARNPERJOB & $\begin{array}{l}\text { The county average earnings per job divided by the } \\
\text { MSA average earnings per job. }\end{array}$ & BEA Personal Income \\
\hline
\end{tabular}

Continued next page- 


\section{-continued from previous page}

\begin{tabular}{|c|c|c|}
\hline Variable & Description & Data Sources \\
\hline GOVASSIST & $\begin{array}{l}\text { The county per capita government benefits divided } \\
\text { by the MSA per capita government benefits. }\end{array}$ & BEA Personal Income \\
\hline$H I S P A N I C P E R C$ & $\begin{array}{l}\text { The percentage of Hispanic population in the } \\
\text { census tract (county). }\end{array}$ & HMDA/CRA Census \\
\hline I.LIFECYCLE & $\begin{array}{l}\text { An indicator variable for census tracts in central } \\
\text { cities or mature suburbs. I obtain an indicator for } \\
\text { census tracts in central cities from HMDA and I } \\
\text { create an indicator for mature suburbs based on the } \\
\text { median year housing units were built available from } \\
\text { HMDA/CRA Census. }\end{array}$ & $\begin{array}{l}\text { HMDA, HMDA/CRA } \\
\text { Census }\end{array}$ \\
\hline$M E D H H I N C$ & $\begin{array}{l}\text { The census tract median household income divided } \\
\text { by the MSA average of the census tract median } \\
\text { house hold income. }\end{array}$ & HMDA/CRA Census \\
\hline$M E D V A L U E$ & $\begin{array}{l}\text { The logarithm of the estimated census tract median } \\
\text { house value. I estimate the census tract median } \\
\text { house value by adjusting the median value from the } \\
\text { HMDA/CRA database for changes in house price } \\
\text { indexes. }\end{array}$ & $\begin{array}{l}\text { HMDA/CRA Census, } \\
\text { FHFA HPI }\end{array}$ \\
\hline MINORITY & $\begin{array}{l}\text { The percentage of monitory population in the } \\
\text { census tract (county). }\end{array}$ & HMDA/CRA Census \\
\hline NONHOUSWLTH & $\begin{array}{l}\text { The county per capita income from dividends, } \\
\text { interest, and rent divided by the corresponding } \\
\text { MSA value. }\end{array}$ & BEA personal income \\
\hline OWNRATE & $\begin{array}{l}\text { The homeownership rate in the census tract } \\
\text { (county). }\end{array}$ & HMDA/CRA Census \\
\hline UNEMPRATE & $\begin{array}{l}\text { The county unemployment rate from Bureau of } \\
\text { Labor Statistics. }\end{array}$ & $\begin{array}{l}\text { BLS Employment } \\
\text { Database }\end{array}$ \\
\hline$P E R I N C$ & The county per capita personal income. & BEA personal income \\
\hline POVERTY & $\begin{array}{l}\text { The percentage of census tract (county) population } \\
\text { under the poverty line. }\end{array}$ & HMDA/CRA Census \\
\hline$V A C R A T E$ & The census tract (county) home vacancy rate. & HMDA/CRA Census \\
\hline$\triangle H P I i$ & $\begin{array}{l}\text { Change in MSA house price index over the previous } \\
i \text { years, where } i=1,3,5 \text {. }\end{array}$ & FHFA HPI \\
\hline$\triangle U N E M P R A T E$ & The annual change in $U N E M P R A T E$. & $\begin{array}{l}\text { BLS Employment } \\
\text { Database }\end{array}$ \\
\hline
\end{tabular}

This table presents the description of mortgage risk characteristics used to construct the composite mortgage risk measures, grouped into borrower characteristics (Panel A), loan characteristics (Panel B), property characteristics (Panel D). The first column contains the name of the characteristics. The second column provides the definition and the third column contains the name(s) of the data source(s). 


\section{A.2 Loan Portfolio Performance Measures and Other Variables}

\begin{tabular}{|c|c|}
\hline Variable Name & Description \\
\hline \multicolumn{2}{|c|}{ Panel A: Balance Sheet Mortgage Performance Measures } \\
\hline$B S M O R T P D U E<90$ & $\begin{array}{l}\text { The total on-balance-sheet mortgages secured by single family } \\
\text { residential properties in the U.S excluding lines of credit that are } \\
\text { past due } 30 \text { through } 89 \text { days (BHCKC } 236+\text { BHCKC238) divided } \\
\text { by total on-balance-sheet single family residential mortgages } \\
\text { (BHCK5367+BHCK5368). }\end{array}$ \\
\hline$B S M O R T P D U E \geq 90$ & $\begin{array}{l}\text { The total on-balance-sheet mortgages secured by single family } \\
\text { residential properties in the U.S excluding lines of credit that are } \\
\text { past due } 90 \text { days or more and still accruing (BHCKC } 237+ \\
\text { BHCKC } 239 \text { ) divided by total on-balance-sheet single family } \\
\text { residential mortgages (BHCK5367+BHCK5368). }\end{array}$ \\
\hline BSMORTNACC & $\begin{array}{l}\text { The total on-balance-sheet mortgages secured by single family } \\
\text { residential properties in the U.S excluding lines of credit that are } \\
\text { not accruing (BHCKC } 229+\text { BHCKC230) divided by total } \\
\text { on-balance-sheet single family residential mortgages } \\
\text { (BHCK5367+BHCK5368). }\end{array}$ \\
\hline BSMORTCHOFF & $\begin{array}{l}\text { The net charge-off associated with on-balance-sheet mortgages } \\
\text { secured by single family residential properties in the U.S. excluding } \\
\text { lines of credit ((BHCKC234+BHCKC235) - } \\
\text { (BHCKC218+BHCKC218)) divided by total on-balance-sheet single } \\
\text { family residential mortgages (BHCK5367+BHCK5368). }\end{array}$ \\
\hline \multicolumn{2}{|c|}{ Panel B: Regulatory Capital Ratios } \\
\hline TIER1CAPRATIO & The ratio of Tier 1 capital to total risk-weighted assets \\
\hline TIER1LEVRATIO & The ratio of Tier 1 capital to average total assets \\
\hline TOT ALCAPRATIO & The ratio of total capital to total risk-weighted assets \\
\hline
\end{tabular}




\section{Appendix B}

\section{Matching FR Y-9C and HMDA Datasets}

This appendix describes the procedure for matching the BHCs from the FR Y-9C dataset with the mortgage-level data from the HMDA dataset. I first identify subsidiaries and their branch offices of each BHC. To do so, I use the FFIEC's Relationships file, which provides the history of ownership between two financial institutions. Since the relationship file provides only direct ownership history, I trace relationships iteratively until I reach the bottom of the organizational structure. This allows me to map all direct and indirect subsidiaries to the top-tier BHC. I use FFIEC's Attributes files to get more information about the characteristics of these subsidiaries. I identify branch offices for each subsidiary using FFIEC's Branch Attributes file, which provides information about branch offices including the head office identifier.

The next step is to identify which subsidiaries and branches of the BHCs file HMDA reports. The main challenge in doing so is matching the unique identifier codes in the two databases. The HMDA database identifies entities by a combination of Agency Code and Respondent ID. Agency code is a unique code that identifies the regulator to which the entity sends its HMDA filing. Respondent ID is either an identifier code assigned to the entity by its direct regulator, or the entity's federal Tax-ID. The FR Y-9C database identifies entities by the Federal Reserve identification number, RSSD ID.

Beginning 2004, the HMDA Respondent Panel files contain the RSSD IDs for most HMDA reporters. Since no such link between the two databases exists for the pre-2004 period, I use the following strategy to link the HMDA and FR Y-9C databases in this period. Since both RSSD IDs and HMDA IDs are unique and stable overtime, any post- 
2004 match between the two sets of identifiers also applies to the pre-2004 period. Applying the post-2004 match to the pre-2004 period provides RSSD IDs for approximately half of the HMDA filing institutions for the period 1993-2003. This procedure fails to identify the RSSD IDs of for entities that ceased to exist before 2004 because of failures or mergers. For these cases, I manually collect their RSSD IDs from FFIEC's "Institution Search" webpage: https://www.ffiec.gov/nicpubweb/nicweb/SearchForm.aspx. To ensure I get the correct matches, I check if the historical location and type of the institutions are identical in the two datasets. 


\section{Appendix C}

\section{Propensity Score Matching}

To create a matched pair of treatment and control BHCs, I first estimate the logistic regression model in equation C.1. I estimate the model separately for privately held and publicly traded BHCs because private and public BHCs are economically different from each other and because I can improve the performance of the model for public BHCs by including market-based variables.

$$
\begin{aligned}
\operatorname{SECBANK}_{i t}=\alpha_{t} & +\beta_{1 t} \text { FUNDING }_{i t}+\beta_{2 t} \text { REGCAPITAL }_{i t} \\
& +\beta_{3 t} \text { RISKTRANSFER }{ }_{i t}+\beta_{4 t} \text { PERFORMANCE }_{i t} \\
& +\beta_{5 t} \text { OTHERS }
\end{aligned}
$$

The dependent variable $S E C B A N K_{i t}$ is a securitization indicator that takes the value one if $\mathrm{BHC} i$ has outstanding securitized residential mortgages over the threeyear period that ended in year $t$ and zero otherwise. I select the covariates based on prior literature (e.g., Affinito \& Tagliaferri 2010, Cardone-Riportella et al. 2010, Minton et al. 2004, Uzun \& Webb 2007) that examines determinants of securitization. The literature identifies four incentives for engaging in securitization: (i) funding and liquidity $\left(F U N D I N G_{i t}\right)$, (ii) transferring risk and reducing cost of financial distress $\left(R I S K T R A N S F E R_{i t}\right)$, (iii) regulatory capital arbitrage $\left(R E G C A P I T A L_{i t}\right)$, and (iv) enhancing performance (PERFORMANCE $\left.E_{i t}\right)$. OTHERS $S_{i t}$ includes variables such as size, book-to-market, volatility, and analyst following that are used in similar propensity score models in prior work (e.g., Oz 2016). Table C.1 defines each of the covariates used in the propensity score model.

Table C.2 presents the estimation results for the propensity score model. The adjusted pseudo- $\mathrm{R}^{2}$ ranges between $22 \%$ and $34 \%$ for public BHCs and between $7 \%$ and $14 \%$ for 
private BHCs. The pseudo-R2 for the public BHCs is consistent with Oz (2016) who applies propensity score matching in a similar context around FAS $166 \& 167$. However, the pseudo-R2 for the private BHCs is lower, suggesting the propensity score matching may not provide a sufficiently balanced matched sample. As a result, I test the robustness of my results to excluding the private $\mathrm{BHC}$ sample.

I match each securitizing $\mathrm{BHC}$ to the non-securitizing $\mathrm{BHC}$ with the closest propensity score. ${ }^{1}$ I perform a one-to-one matching with replacement, imposing a $10 \%$ caliper. In comparison, most studies in the literature (e.g., Casu et al. 2013, Lawrence et al. 2011, Oz 2016) use a small caliper width (typically less than 5\%), while others (e.g., Christensen 2016) use a caliper width equal to 0.2 times the standard deviation of the logit of propensity scores (approximately 25\% in my setting). A smaller caliper reduces the likelihood of matching a treatment $\mathrm{BHC}$ to a control $\mathrm{BHC}$ with a significantly different propensity score (i.e., bad matches). However, a small caliper can also lead to loss of more observations at the higher end of the propensity score distribution. King \& Nielsen (2016) show that pruning more observations can result in greater biases. I argue that a very small caliper (e.g., $<5 \%$ ) is not ideal for my setting because I have a relatively small number of securitizing BHCs in my treatment group, making my setting more sensitive to data pruning. In untabulated results, I find that there is no improvement in the number of matched pairs or covariate balance when using a $25 \%$ caliper, relative to the $10 \%$ used in this thesis. I also find that the $10 \%$ caliper results in more observations than the $3 \%$ or $5 \%$ calipers. I use matching with replacement to retain as many observations as possible. In section 5.5, I check the robustness of my results to the choices I made here. I reproduce the main findings using 3\% and 5\% calipers, and using matching without replacement. I also reproduce the main results using a coarsened exact matching based on select covariates to ensure that my results are not driven by the propensity score matching.

I present the descriptive statistics before and after matching only for the matching (event) years to assess the success of the matching process in improving the covariate balance between the treatment and control groups immediately before the events. Table C.3 panel A presents the descriptive statistics for the unmatched sample for the matching years (i.e., 1996, 2000, 2002, and 2009). The asterisks in columns (10) and (11) indicate statistically significant differences between the means and medians of the securitizing and non-securitizing subsamples. The securitizing and non-securitizing subsamples have significantly different mean and median for most of the covariates, underscoring the need to perform the matching process to reduce the difference between the treatment and control groups. Securitizing BHCs have lower total deposits and greater loan-to-deposits ratio

\footnotetext{
${ }^{1}$ I use the Stata command psmatch2 developed by Leuven \& Sianesi (2003) to perform the matching.
} 
than non-securitizing BHCs, suggesting that securitizing BHCs rely less on regular deposits to finance their lending activity. Securitizing BHCs have lower interbank ratio and higher leverage, which indicates that they rely more on the interbank lending market and other non-deposit credit markets. The table also shows that securitizing BHCs have lower regulatory capital ratios than non-securitizing $\mathrm{BHCs}$, consistent with regulatory capital management being an incentive for securitization (). The securitizing BHCs also have more provisions and allowances for loan losses as well as more write-offs, indicating that their loans are riskier than those of non-securitizing BHCs. Moreover, Securitizing BHCs are larger, more liquid (stock market), and have greater analyst coverage than non-securitizing BHCs.

Table C.3 panel B presents the descriptive statistics for the matched sample. Comparison of the two panels reveals that the matching procedure has decreased the covariate imbalance between the securitizing and non-securitizing sub-samples. The only significant differences after matching are the mean differences for LOGASSETS and the median differences for $M V$. However, these differences are not economically significant. For example, the mean different for LOGASSETS, which equals 0.21 (or $\$ 256,066$ ), is only a fraction of the standard deviation of $L O G A S S E T S$ (1.323). I also assess the standardized percentage bias, which is the difference between the means of the treatment and control groups as a percentage of the square root of the average of the variances in the treatment and control groups. Figure C.1 presents the distribution of standardized percentage bias across the covariates before and after matching. The standardized percentage bias is the difference between the means of the treatment and control groups as a percentage of the square root of the average of the variances in the treatment and control groups. A value of zero for the standardized percentage bias indicates reflects bias, whereas deviations from zero in either direction reflect bias, and the greater the deviation the greater the bias. The distribution of the standardized percentage bias for the unmatched sample (first part of figure C.1) has long and fat tails with a large deviation from zero, whereas the distribution for the matched sample shows the observations are concentrated close to zero. These findings show that the matching process has significantly reduced the bias. 
Table C.1: Covariates Description

\begin{tabular}{|c|c|c|c|}
\hline Incentive & Variable & Description & $\begin{array}{l}\text { Data } \\
\text { Source }\end{array}$ \\
\hline \multirow{9}{*}{$\begin{array}{l}\text { Funding and } \\
\text { Liquidity }\end{array}$} & COREDEPRATIO & $\begin{array}{l}\text { The ratio of core deposits (i.e., demand deposits, NOW } \\
\text { accounts, money market accounts, and time deposits less } \\
\text { than } \$ 100,000) \text { to total deposits }\end{array}$ & FR Y-9C \\
\hline & DEPOSIT/ASSETS & The ratio total deposits to total assets & FR Y-9C \\
\hline & FUNDINGCOST & $\begin{array}{l}\text { The ratio of interest expense to the sum of total deposits, } \\
\text { total money market funds and other interest-bearing funds }\end{array}$ & FR Y-9C \\
\hline & INTERBANK & $\begin{array}{l}\text { The ratio of lending to other banks to the sum of borrowings } \\
\text { from other banks and lending to other banks }\end{array}$ & FR Y-9C \\
\hline & $L O A N / A S S E T S$ & The ratio of net loans to total assets & FR Y-9C \\
\hline & $L O A N / D E P O S I T$ & $\begin{array}{l}\text { The ratio of net loans to the sum of deposits and other } \\
\text { short-term funds }\end{array}$ & FR Y-9C \\
\hline & $L O A N G R$ & The logarithmic growth in loans & FR Y-9C \\
\hline & $L E V E R A G E$ & The ratio of total liability to average total asset & FR Y-9C \\
\hline & LIQRATIO & $\begin{array}{l}\text { The sum of cash, securities held for sale, trading assets, } \\
\text { federal funds sold, and securities purchased with the intent } \\
\text { to resale divided by total assets }\end{array}$ & FR Y-9C \\
\hline \multirow{3}{*}{$\begin{array}{l}\text { Regulatory } \\
\text { Capital } \\
\text { Management }\end{array}$} & TIER1CAPRATIO & The ratio of Tier 1 capital to total risk-weighted assets & FR Y-9C \\
\hline & TIER1LEVRATIO & The ratio of Tier 1 capital to average total assets & FR Y-9C \\
\hline & TOTALCAPRATIO & The ratio of total capital to total risk-weighted assets & FR Y-9C \\
\hline \multirow{4}{*}{ Risk Transfer } & $A L L O W A N C E$ & The ratio of loan loss allowances to total loans & FR Y-9C \\
\hline & CHARGEOFF & The ratio of net charge-offs to total assets & FR Y-9C \\
\hline & $N P L / L O A N S$ & The ratio of non-performing loans to total loans & FR Y-9C \\
\hline & PROVISION & The ratio of loan loss provisions to total assets & FR Y-9C \\
\hline \multirow{2}{*}{$\begin{array}{l}\text { Performance } \\
\text { Boosting }\end{array}$} & INTINCRATIO & $\begin{array}{l}\text { The ratio of gross interest income to gross outstanding ac- } \\
\text { counts }\end{array}$ & FR Y-9C \\
\hline & $R O A$ & Return on Assets & FR Y-9C \\
\hline & $A V G V O L U M E$ & $\begin{array}{l}\text { The average daily trading volume over the previous calen- } \\
\text { dar year }\end{array}$ & CRSP \\
\hline \multirow{2}{*}{ Others } & $B T M$ & $\begin{array}{l}\text { The ratio of book value of equity to market value of equity } \\
\text { at the preceding December } 31\end{array}$ & $\begin{array}{l}\text { FR Y-9C } \\
\& \text { CRSP }\end{array}$ \\
\hline & $C O V E R A G E$ & $\begin{array}{l}\text { The number of analyst following the } \mathrm{BHC} \text { in the previous } \\
\text { calendar year }\end{array}$ & IBES \\
\hline
\end{tabular}

Continued on next page- 
- continued from previous page

\begin{tabular}{lllc}
\hline Incentive & Variable & Description & Source \\
\hline LOGASSETS & The natural logarithm of total assets & FR Y-9C \\
The natural logarithm of the market value of equity at the & CRSP \\
preceding December 31 & $\begin{array}{l}\text { The standard deviation of daily stock returns over the pre- } \\
\text { vious calendar year }\end{array}$ & CRSP \\
\hline
\end{tabular}


Table C.2: Propensity Score Model

\begin{tabular}{|c|c|c|c|c|c|c|c|c|c|c|c|c|}
\hline & (1) & $(2)$ & (3) & $(4)$ & (5) & (6) & (7) & (8) & (9) & (10) & (11) & $(12)$ \\
\hline & \multicolumn{6}{|c|}{ Panel A: Public BHCs } & \multicolumn{6}{|c|}{ Panel B: Private BHCs } \\
\hline & $\begin{array}{l}1996- \\
2015\end{array}$ & $\begin{array}{c}\text { Match- } \\
\text { ing } \\
\text { Years } \\
\text { (Pooled) }\end{array}$ & $\begin{array}{c}1996 \\
\text { (FAS } \\
125)\end{array}$ & $\begin{array}{c}2000 \\
(\text { FAS } \\
140)\end{array}$ & $\begin{array}{c}2002 \\
(\text { FIN 46) }\end{array}$ & $\begin{array}{c}2009 \\
(\text { FAS } \\
166 \& \\
167)\end{array}$ & $\begin{array}{l}1996- \\
2015\end{array}$ & $\begin{array}{c}\text { Match- } \\
\text { ing } \\
\text { Years } \\
\text { (Pooled) }\end{array}$ & $\begin{array}{c}1996 \\
\text { (FAS } \\
125)\end{array}$ & $\begin{array}{l}2000 \\
(\text { FAS } \\
140)\end{array}$ & $\begin{array}{c}2002 \\
\text { (FIN } 46\end{array}$ & $\begin{array}{c}2009 \\
(\mathrm{FAS} \\
166 \& \\
167)\end{array}$ \\
\hline LOGASSETS & $\begin{array}{c}1.13^{* * *} \\
(7.94)\end{array}$ & $\begin{array}{c}1.25^{* * *} \\
(3.55)\end{array}$ & $\begin{array}{c}0.13 \\
(0.07)\end{array}$ & $\begin{array}{c}2.40^{* *} \\
(2.09)\end{array}$ & $\begin{array}{c}0.86 \\
(0.50)\end{array}$ & $\begin{array}{c}2.59 * * * \\
(3.17)\end{array}$ & $\begin{array}{c}0.60^{* * *} \\
(18.59)\end{array}$ & $\begin{array}{c}0.69^{* * *} \\
(8.33)\end{array}$ & $\begin{array}{c}0.65^{* * *} \\
(2.72)\end{array}$ & $\begin{array}{c}0.77^{* * *} \\
(4.67)\end{array}$ & $\begin{array}{c}0.61^{* * *} \\
(3.92)\end{array}$ & $\begin{array}{c}0.39^{* *} \\
(2.00)\end{array}$ \\
\hline$L I Q R A T I O$ & $\begin{array}{c}-1.77^{* * *} \\
(-3.11)\end{array}$ & $\begin{array}{c}-1.21 \\
(-0.93)\end{array}$ & $\begin{array}{c}1.49 \\
(0.55)\end{array}$ & $\begin{array}{l}-1.53 \\
(-0.45)\end{array}$ & $\begin{array}{l}-5.38^{*} \\
(-1.77)\end{array}$ & $\begin{array}{l}-2.51 \\
(-0.62)\end{array}$ & $\begin{array}{c}0.34 \\
(0.93)\end{array}$ & $\begin{array}{l}1.55^{*} \\
(1.69)\end{array}$ & $\begin{array}{c}3.41 \\
(1.40)\end{array}$ & $\begin{array}{c}2.37 \\
(1.14)\end{array}$ & $\begin{array}{c}0.55 \\
(0.36)\end{array}$ & $\begin{array}{c}1.59 \\
(0.70)\end{array}$ \\
\hline$L O A N G R$ & $\begin{array}{l}0.049 \\
(0.31)\end{array}$ & $\begin{array}{l}-0.013 \\
(-0.03)\end{array}$ & $\begin{array}{c}0.81 \\
(0.84)\end{array}$ & $\begin{array}{c}-0.66 \\
(-0.73)\end{array}$ & $\begin{array}{c}1.32 \\
(1.14)\end{array}$ & $\begin{array}{l}1.48^{*} \\
(1.79)\end{array}$ & $\begin{array}{c}-0.39 * * * \\
(-2.89)\end{array}$ & $\begin{array}{c}-0.78^{* *} \\
(-2.02)\end{array}$ & $\begin{array}{l}0.050 \\
(0.07)\end{array}$ & $\begin{array}{l}-0.28 \\
(-0.32)\end{array}$ & $\begin{array}{c}0.15 \\
(0.34)\end{array}$ & $\begin{array}{c}-1.75^{* *} \\
(-2.04)\end{array}$ \\
\hline LOAN/DEPOSITS & $\begin{array}{c}-0.66^{* * *} \\
(-4.46)\end{array}$ & $\begin{array}{c}0.57 \\
(0.33)\end{array}$ & $\begin{array}{c}5.52 \\
(0.64)\end{array}$ & $\begin{array}{l}-3.38 \\
(-0.47)\end{array}$ & $\begin{array}{c}2.09 \\
(0.52)\end{array}$ & $\begin{array}{l}-1.09 \\
(-0.80)\end{array}$ & $\begin{array}{c}-1.83^{* * *} \\
(-3.14)\end{array}$ & $\begin{array}{l}-0.79 \\
(-0.76)\end{array}$ & $\begin{array}{l}-0.039 \\
(-0.00)\end{array}$ & $\begin{array}{l}0.053 \\
(0.04)\end{array}$ & $\begin{array}{c}3.52 \\
(0.85)\end{array}$ & $\begin{array}{l}-6.75 \\
(-0.76)\end{array}$ \\
\hline$L O A N / A S S E T S$ & $\begin{array}{c}1.41^{* *} \\
(2.31)\end{array}$ & $\begin{array}{c}0.67 \\
(0.23)\end{array}$ & $\begin{array}{l}-1.14 \\
(-0.10)\end{array}$ & $\begin{array}{c}7.61 \\
(0.76)\end{array}$ & $\begin{array}{l}-7.47 \\
(-1.11)\end{array}$ & $\begin{array}{c}0.44 \\
(0.10)\end{array}$ & $\begin{array}{c}2.44^{* * *} \\
(2.95)\end{array}$ & $\begin{array}{c}2.18 \\
(1.29)\end{array}$ & $\begin{array}{c}8.01 \\
(0.45)\end{array}$ & $\begin{array}{c}1.94 \\
(0.68)\end{array}$ & $\begin{array}{l}-8.56 \\
(-1.52)\end{array}$ & $\begin{array}{c}9.46 \\
(0.84)\end{array}$ \\
\hline DEPOSITS/ASSETS & $\begin{array}{c}-3.89^{* * *} \\
(-6.95)\end{array}$ & $\begin{array}{c}-1.84 \\
(-0.66)\end{array}$ & $\begin{array}{c}6.16 \\
(0.61)\end{array}$ & $\begin{array}{l}-7.08 \\
(-0.67)\end{array}$ & $\begin{array}{c}-0.64 \\
(-0.09)\end{array}$ & $\begin{array}{l}-7.06^{*} \\
(-1.88)\end{array}$ & $\begin{array}{c}-5.78^{* * *} \\
(-7.00)\end{array}$ & $\begin{array}{c}-4.98^{* * *} \\
(-3.04)\end{array}$ & $\begin{array}{c}-4.62 \\
(-0.29)\end{array}$ & $\begin{array}{l}-1.76 \\
(-0.60)\end{array}$ & $\begin{array}{c}0.18 \\
(0.04)\end{array}$ & $\begin{array}{l}-11.2 \\
(-1.12)\end{array}$ \\
\hline COREDEPRATIO & $\begin{array}{c}2.23^{* * *} \\
(6.13)\end{array}$ & $\begin{array}{c}2.37^{* * *} \\
(2.72)\end{array}$ & $\begin{array}{c}4.11 \\
(1.53)\end{array}$ & $\begin{array}{c}0.41 \\
(0.20)\end{array}$ & $\begin{array}{c}2.89 \\
(1.30)\end{array}$ & $\begin{array}{l}4.25^{* *} \\
(2.16)\end{array}$ & $\begin{array}{c}1.69^{* * *} \\
(5.58)\end{array}$ & $\begin{array}{l}0.017 \\
(0.02)\end{array}$ & $\begin{array}{l}-3.87 \\
(-1.32)\end{array}$ & $\begin{array}{l}-0.82 \\
(-0.42)\end{array}$ & $\begin{array}{l}-0.69 \\
(-0.45)\end{array}$ & $\begin{array}{c}3.57^{* *} \\
(2.17)\end{array}$ \\
\hline FUNDINGCOST & $\begin{array}{c}6.02 \\
(0.84)\end{array}$ & $\begin{array}{c}17.7 \\
(1.03)\end{array}$ & $\begin{array}{l}93.8^{*} \\
(1.72)\end{array}$ & $\begin{array}{c}1.73 \\
(0.04)\end{array}$ & $\begin{array}{c}38.2 \\
(0.82)\end{array}$ & $\begin{array}{l}-33.9 \\
(-0.69)\end{array}$ & $\begin{array}{c}1.93 \\
(0.41)\end{array}$ & $\begin{array}{l}-10.7 \\
(-0.92)\end{array}$ & $\begin{array}{l}-0.56 \\
(-0.01)\end{array}$ & $\begin{array}{l}-5.96 \\
(-0.22)\end{array}$ & $\begin{array}{l}-18.8 \\
(-0.71)\end{array}$ & $\begin{array}{l}64.7^{* *} \\
(2.27)\end{array}$ \\
\hline INTERBANK & $\begin{array}{c}-2.30 * * * \\
(-3.11)\end{array}$ & $\begin{array}{l}-2.33 \\
(-1.36)\end{array}$ & $\begin{array}{c}-1.94 \\
(-0.46)\end{array}$ & $\begin{array}{l}-4.17 \\
(-1.06)\end{array}$ & $\begin{array}{l}-1.36 \\
(-0.31)\end{array}$ & $\begin{array}{c}3.88 \\
(0.72)\end{array}$ & $\begin{array}{c}0.81 \\
(1.31)\end{array}$ & $\begin{array}{c}1.73 \\
(1.19)\end{array}$ & $\begin{array}{l}-2.34 \\
(-0.49)\end{array}$ & $\begin{array}{c}3.62 \\
(1.19)\end{array}$ & $\begin{array}{c}2.66 \\
(0.99)\end{array}$ & $\begin{array}{l}-3.57 \\
(-0.92)\end{array}$ \\
\hline$L E V E R A G E$ & $\begin{array}{c}5.89^{* *} \\
(2.54)\end{array}$ & $\begin{array}{c}8.22 \\
(1.28)\end{array}$ & $\begin{array}{c}69.0^{* *} \\
(2.03)\end{array}$ & $\begin{array}{l}-2.18 \\
(-0.10)\end{array}$ & $\begin{array}{c}26.0 \\
(1.29)\end{array}$ & $\begin{array}{c}12.4 \\
(1.08)\end{array}$ & $\begin{array}{c}1.61 \\
(0.86)\end{array}$ & $\begin{array}{c}7.61 \\
(1.42)\end{array}$ & $\begin{array}{c}28.8 \\
(1.43)\end{array}$ & $\begin{array}{c}0.17 \\
(0.01)\end{array}$ & $\begin{array}{c}9.32 \\
(0.64)\end{array}$ & $\begin{array}{l}-11.7 \\
(-1.28)\end{array}$ \\
\hline$N P L$ & $\begin{array}{c}5.95^{* *} \\
(2.34)\end{array}$ & $\begin{array}{c}6.95 \\
(1.11)\end{array}$ & $\begin{array}{l}60.7^{*} \\
(1.79)\end{array}$ & $\begin{array}{l}65.4^{*} \\
(1.78)\end{array}$ & $\begin{array}{c}82.4^{* * *} \\
(2.92)\end{array}$ & $\begin{array}{l}-11.2 \\
(-1.34)\end{array}$ & $\begin{array}{l}-1.11 \\
(-0.87)\end{array}$ & $\begin{array}{c}2.80 \\
(0.92)\end{array}$ & $\begin{array}{c}9.28 \\
(0.40)\end{array}$ & $\begin{array}{l}-0.70 \\
(-0.04)\end{array}$ & $\begin{array}{l}-0.011 \\
(-0.00)\end{array}$ & $\begin{array}{l}-2.44 \\
(-0.58)\end{array}$ \\
\hline PROVISION & $\begin{array}{c}-30.7^{* * *} \\
(-3.18)\end{array}$ & $\begin{array}{c}-36.8 \\
(-1.37)\end{array}$ & $\begin{array}{c}-123 \\
(-1.38)\end{array}$ & $\begin{array}{c}58.6 \\
(0.57)\end{array}$ & $\begin{array}{c}-196^{* * *} \\
(-2.74)\end{array}$ & $\begin{array}{l}-50.6 \\
(-1.05)\end{array}$ & $\begin{array}{c}-6.03 \\
(-1.13)\end{array}$ & $\begin{array}{l}-27.1^{*} \\
(-1.71)\end{array}$ & $\begin{array}{c}5.59 \\
(0.09)\end{array}$ & $\begin{array}{l}-83.4 \\
(-1.58)\end{array}$ & $\begin{array}{l}-64.1 \\
(-1.34)\end{array}$ & $\begin{array}{l}-11.1 \\
(-0.49)\end{array}$ \\
\hline$A L L O W A N C E$ & $\begin{array}{c}15.7^{* *} \\
(2.14)\end{array}$ & $\begin{array}{l}8.11 \\
(0.44)\end{array}$ & $\begin{array}{c}-53.1 \\
(-1.20)\end{array}$ & $\begin{array}{l}14.7 \\
(0.25)\end{array}$ & $\begin{array}{l}125^{* *} \\
(2.31)\end{array}$ & $\begin{array}{c}25.5 \\
(0.63)\end{array}$ & $\begin{array}{c}9.76^{* * *} \\
(2.58)\end{array}$ & $\begin{array}{c}13.6 \\
(1.34)\end{array}$ & $\begin{array}{c}37.6 \\
(1.21)\end{array}$ & $\begin{array}{c}31.4 \\
(1.16)\end{array}$ & $\begin{array}{c}15.2 \\
(0.55)\end{array}$ & $\begin{array}{c}15.1 \\
(0.88)\end{array}$ \\
\hline CHARGEOFF & $\begin{array}{c}27.2^{* * *} \\
(2.69)\end{array}$ & $\begin{array}{c}39.9 \\
(1.44)\end{array}$ & $\begin{array}{c}208 \\
(1.62)\end{array}$ & $\begin{array}{c}-101 \\
(-0.80)\end{array}$ & $\begin{array}{c}42.4 \\
(0.58)\end{array}$ & $\begin{array}{c}62.3 \\
(1.42)\end{array}$ & $\begin{array}{c}0.13 \\
(0.02)\end{array}$ & $\begin{array}{c}7.92 \\
(0.54)\end{array}$ & $\begin{array}{c}64.0 \\
(0.96)\end{array}$ & $\begin{array}{c}74.0 \\
(1.09)\end{array}$ & $\begin{array}{c}11.7 \\
(0.26)\end{array}$ & $\begin{array}{l}-14.6 \\
(-0.76)\end{array}$ \\
\hline INTINCRATIO & $\begin{array}{c}4.29 \\
(0.68)\end{array}$ & $\begin{array}{l}-10.1 \\
(-0.65)\end{array}$ & $\begin{array}{l}-12.2 \\
(-0.30)\end{array}$ & $\begin{array}{l}-1.80 \\
(-0.05)\end{array}$ & $\begin{array}{l}17.5 \\
(0.36)\end{array}$ & $\begin{array}{l}15.8 \\
(0.45)\end{array}$ & $\begin{array}{c}-24.4^{* * *} \\
(-5.85)\end{array}$ & $\begin{array}{l}-6.90 \\
(-0.67)\end{array}$ & $\begin{array}{l}-5.46 \\
(-0.14)\end{array}$ & $\begin{array}{c}3.20 \\
(0.18)\end{array}$ & $\begin{array}{c}29.1 \\
(1.25)\end{array}$ & $\begin{array}{l}-15.6 \\
(-0.74)\end{array}$ \\
\hline$R O A$ & $\begin{array}{l}1.07 \\
(0.19)\end{array}$ & $\begin{array}{c}7.10 \\
(0.60)\end{array}$ & $\begin{array}{l}-27.2 \\
(-0.41)\end{array}$ & $\begin{array}{c}42.5 \\
(0.62)\end{array}$ & $\begin{array}{l}-40.5 \\
(-0.52)\end{array}$ & $\begin{array}{l}-5.85 \\
(-0.39)\end{array}$ & $\begin{array}{c}8.59^{* * *} \\
(2.76)\end{array}$ & $\begin{array}{c}8.72 \\
(1.27)\end{array}$ & $\begin{array}{l}116^{*} \\
(1.91)\end{array}$ & $\begin{array}{c}14.8 \\
(0.68)\end{array}$ & $\begin{array}{l}-3.84 \\
(-0.23)\end{array}$ & $\begin{array}{l}23.6^{*} \\
(1.90)\end{array}$ \\
\hline TIER1LEVRATIO & $\begin{array}{c}0.45 \\
(0.13)\end{array}$ & $\begin{array}{c}3.35 \\
(0.36)\end{array}$ & $\begin{array}{l}-0.016 \\
(-0.08)\end{array}$ & $\begin{array}{l}-0.041 \\
(-0.15)\end{array}$ & $\begin{array}{c}0.24 \\
(0.73)\end{array}$ & $\begin{array}{l}-0.47^{*} \\
(-1.79)\end{array}$ & $\begin{array}{c}9.04^{* * *} \\
(3.51)\end{array}$ & $\begin{array}{c}13.8^{* *} \\
(1.98)\end{array}$ & $\begin{array}{c}7.06 \\
(0.37)\end{array}$ & $\begin{array}{c}3.60 \\
(0.21)\end{array}$ & $\begin{array}{l}32.2^{*} \\
(1.78)\end{array}$ & $\begin{array}{c}-0.78 \\
(-0.06)\end{array}$ \\
\hline
\end{tabular}


- continued from previous page

Panel A: Public BHCs

\begin{tabular}{|c|c|c|c|c|c|c|c|c|c|c|c|c|}
\hline & & \\
\hline & $\begin{array}{l}1996- \\
2015\end{array}$ & $\begin{array}{c}\text { Match- } \\
\text { ing } \\
\text { Years } \\
\text { (Pooled) }\end{array}$ & $\begin{array}{c}1996 \\
\text { (FAS } \\
125)\end{array}$ & $\begin{array}{c}2000 \\
\text { (FAS } \\
140)\end{array}$ & $\begin{array}{c}2002 \\
(\text { FIN 46) }\end{array}$ & $\begin{array}{c}2009 \\
(\text { FAS } \\
166 \& \\
167)\end{array}$ & $\begin{array}{l}1996- \\
2015\end{array}$ & $\begin{array}{l}\text { Match- } \\
\text { ing } \\
\text { Years } \\
\text { (Pooled) }\end{array}$ & $\begin{array}{c}1996 \\
\text { (FAS } \\
125)\end{array}$ & $\begin{array}{c}2000 \\
\text { (FAS } \\
140)\end{array}$ & $\begin{array}{c}2002 \\
\text { (FIN } 46\end{array}$ & $\begin{array}{c}2009 \\
(\mathrm{FAS} \\
166 \& \\
167)\end{array}$ \\
\hline TIER1CAPRATIO & $\begin{array}{l}7.76^{*} \\
(1.75)\end{array}$ & $\begin{array}{c}4.29 \\
(0.40)\end{array}$ & $\begin{array}{c}2.05 \\
(0.61)\end{array}$ & $\begin{array}{l}-1.58 \\
(-1.00)\end{array}$ & $\begin{array}{l}-1.30 \\
(-0.58)\end{array}$ & $\begin{array}{c}-0.0072 \\
(-0.03)\end{array}$ & $\begin{array}{c}-12.3^{* * *} \\
(-4.32)\end{array}$ & $\begin{array}{c}-18.4^{* *} \\
(-2.27)\end{array}$ & $\begin{array}{c}30.7 \\
(1.01)\end{array}$ & $\begin{array}{l}-12.1 \\
(-0.54)\end{array}$ & $\begin{array}{l}-17.8 \\
(-0.97)\end{array}$ & $\begin{array}{c}-36.7 * * \\
(-2.55)\end{array}$ \\
\hline TOTCAPRATIO & $\begin{array}{l}-6.81 \\
(-1.61)\end{array}$ & $\begin{array}{l}-3.38 \\
(-0.36)\end{array}$ & $\begin{array}{l}0.052 \\
(0.88)\end{array}$ & $\begin{array}{l}0.070 \\
(1.03)\end{array}$ & $\begin{array}{c}0.11 \\
(1.38)\end{array}$ & $\begin{array}{l}-0.13^{*} \\
(-1.95)\end{array}$ & $\begin{array}{c}3.69 \\
(1.43)\end{array}$ & $\begin{array}{l}11.5 \\
(1.55)\end{array}$ & $\begin{array}{l}-24.2 \\
(-0.82)\end{array}$ & $\begin{array}{c}8.11 \\
(0.39)\end{array}$ & $\begin{array}{l}-0.81 \\
(-0.05)\end{array}$ & $\begin{array}{c}23.5^{* *} \\
(2.02)\end{array}$ \\
\hline$A V G V O L U M E$ & $\begin{array}{c}-0.081^{*} \\
(-1.87)\end{array}$ & $\begin{array}{l}-0.012 \\
(-0.12)\end{array}$ & $\begin{array}{c}0.88 \\
(0.45)\end{array}$ & $\begin{array}{l}-1.71 \\
(-1.55)\end{array}$ & $\begin{array}{l}-0.55 \\
(-0.34)\end{array}$ & $\begin{array}{l}-0.51 \\
(-0.76)\end{array}$ & & & & & & \\
\hline$B T M$ & $\begin{array}{l}0.044 \\
(0.58)\end{array}$ & $\begin{array}{c}0.0033 \\
(0.02)\end{array}$ & $\begin{array}{c}11.0 \\
(0.30)\end{array}$ & $\begin{array}{l}-7.05 \\
(-0.25)\end{array}$ & $\begin{array}{l}-79.4^{*} \\
(-1.76)\end{array}$ & $\begin{array}{l}-3.00 \\
(-0.18)\end{array}$ & & & & & & \\
\hline$C O V E R A G E$ & $\begin{array}{c}-0.0097 \\
(-0.85)\end{array}$ & $\begin{array}{c}0.0097 \\
(0.37)\end{array}$ & $\begin{array}{c}46.0 \\
(1.39)\end{array}$ & $\begin{array}{c}13.9 \\
(0.57)\end{array}$ & $\begin{array}{c}3.20 \\
(0.13)\end{array}$ & $\begin{array}{c}5.38 \\
(0.28)\end{array}$ & & & & & & \\
\hline$M V$ & $\begin{array}{c}-0.26^{* *} \\
(-2.13)\end{array}$ & $\begin{array}{l}-0.43 \\
(-1.41)\end{array}$ & $\begin{array}{l}16.8 \\
(0.65)\end{array}$ & $\begin{array}{c}10.7 \\
(0.39)\end{array}$ & $\begin{array}{l}-4.65 \\
(-0.18)\end{array}$ & $\begin{array}{c}17.9 \\
(0.68)\end{array}$ & & & & & & \\
\hline VOLATILITY & $\begin{array}{c}-10.7^{* *} \\
(-2.57)\end{array}$ & $\begin{array}{l}-16.4^{*} \\
(-1.73)\end{array}$ & $\begin{array}{l}-16.3 \\
(-0.74)\end{array}$ & $\begin{array}{l}-25.0 \\
(-0.95)\end{array}$ & $\begin{array}{c}13.2 \\
(0.58)\end{array}$ & $\begin{array}{l}-13.9 \\
(-0.58)\end{array}$ & & & & & & \\
\hline Constant & $\begin{array}{c}-18.2^{* * *} \\
(-7.20)\end{array}$ & $\begin{array}{c}-22.4^{* * *} * \\
(-3.34)\end{array}$ & $\begin{array}{c}-96.8 * * * \\
(-2.70)\end{array}$ & $\begin{array}{l}-8.23 \\
(-0.35)\end{array}$ & $\begin{array}{l}-33.2^{*} \\
(-1.71)\end{array}$ & $\begin{array}{c}-36.5^{* * *} \\
(-2.81)\end{array}$ & $\begin{array}{c}-6.49^{* * *} \\
(-3.12)\end{array}$ & $\begin{array}{c}-14.9 * * * \\
(-2.60)\end{array}$ & $\begin{array}{l}-38.6 \\
(-1.58)\end{array}$ & $\begin{array}{l}-12.5 \\
(-0.97)\end{array}$ & $\begin{array}{l}-17.4 \\
(-1.07)\end{array}$ & $\begin{array}{c}10.3 \\
(0.77)\end{array}$ \\
\hline Observations & 4,958 & 1,018 & 255 & 260 & 259 & 244 & 13,210 & 2,644 & 504 & 739 & 875 & 526 \\
\hline Pseudo R-squared & 0.18 & 0.22 & 0.34 & 0.28 & 0.32 & 0.22 & 0.096 & 0.094 & 0.14 & 0.070 & 0.078 & 0.12 \\
\hline
\end{tabular}

\section{9}

Panel B: Private BHCs

This table presents the logistic propensity score models estimated over the 1996-2015 period and the matching years, namely 1996 (FAS 125), 2000 (FAS 140), 2002 (FIN 46), and 2009 (FAS 166 \& 167). I start in 1996 instead of 1993 because I cannot observe regulatory capital ratios prior to 1996. Panel A presents the logistic models for public BHCs and Panels B presents the models for private BHCs. In both panels, the dependent variable $S E C B A N K_{t}$ equals one if the BHC has outstanding securitized mortgages in the three-year period ending in year $t$, and zero otherwise. All other variables are as defined in Table C.1. 
Table C.3: Covariate Balance

Panel A: Before Matching

\begin{tabular}{|c|c|c|c|c|c|c|c|c|c|c|c|c|}
\hline & \multicolumn{4}{|c|}{ All BHCs } & \multicolumn{4}{|c|}{ Non-securitizing BHCs } & \multicolumn{4}{|c|}{ Securitizing BHCs } \\
\hline & Obs & Mean & Median & St.Dev. & Obs & Mean & Median & St.Dev. & Obs & Mean & Median & St.Dev. \\
\hline & $(1)$ & $(2)$ & $(3)$ & (4) & $(5)$ & $(6)$ & $(7)$ & $(8)$ & $(9)$ & $(10)$ & (11) & $(12)$ \\
\hline LOGASSETS & 4578 & 13.363 & 13.085 & 1.252 & 3814 & 13.128 & 12.937 & 0.960 & 764 & $14.533^{* * *}$ & $14.068^{* * *}$ & 1.775 \\
\hline LIQRATIO & 4550 & 0.258 & 0.244 & 0.112 & 3789 & 0.258 & 0.246 & 0.112 & 761 & 0.254 & 0.237 & 0.109 \\
\hline$L O A N G R$ & 4231 & 0.119 & 0.089 & 0.225 & 3487 & 0.124 & 0.096 & 0.223 & 744 & $0.093^{* * *}$ & $0.062^{* * *}$ & 0.234 \\
\hline$L O A N / D E P O S I T S$ & 4578 & 0.801 & 0.802 & 0.206 & 3814 & 0.789 & 0.791 & 0.188 & 764 & $0.862^{* * *}$ & $0.855^{* * *}$ & 0.273 \\
\hline DEPOSITS/ASSETS & 4578 & 0.808 & 0.826 & 0.090 & 3814 & 0.817 & 0.834 & 0.080 & 764 & $0.761^{* * *}$ & $0.783^{* * *}$ & 0.115 \\
\hline COREDEPRATIO & 4578 & 0.844 & 0.861 & 0.089 & 3814 & 0.845 & 0.861 & 0.088 & 764 & 0.840 & 0.858 & 0.093 \\
\hline$F U N D I N G C O S T$ & 4578 & 0.029 & 0.029 & 0.010 & 3814 & 0.029 & 0.029 & 0.010 & 764 & $0.028^{* * *}$ & $0.027^{* * *}$ & 0.011 \\
\hline$I N T E R B A N K$ & 4532 & -0.005 & 0.000 & 0.054 & 3773 & -0.001 & 0.000 & 0.052 & 759 & $-0.026 * * *$ & $-0.015^{* * *}$ & 0.061 \\
\hline$L E V E R A G E$ & 4578 & 0.909 & 0.912 & 0.033 & 3814 & 0.909 & 0.912 & 0.033 & 764 & $0.911^{*}$ & $0.914^{* *}$ & 0.029 \\
\hline$N P L$ & 4565 & 0.016 & 0.008 & 0.026 & 3801 & 0.015 & 0.007 & 0.026 & 764 & $0.019 * * *$ & $0.010 * * *$ & 0.026 \\
\hline PROVISION & 4572 & 0.008 & 0.004 & 0.015 & 3808 & 0.007 & 0.003 & 0.016 & 764 & $0.010 * * *$ & $0.005^{* * *}$ & 0.014 \\
\hline$A L L O W A N C E$ & 4578 & 0.016 & 0.014 & 0.010 & 3814 & 0.015 & 0.013 & 0.011 & 764 & $0.017^{* * *}$ & $0.015^{* * *}$ & 0.008 \\
\hline INTINCRATIO & 4523 & 0.067 & 0.067 & 0.014 & 3765 & 0.067 & 0.068 & 0.014 & 758 & $0.064^{* * *}$ & $0.063^{* * *}$ & 0.013 \\
\hline$R O A$ & 4578 & 0.008 & 0.010 & 0.014 & 3814 & 0.008 & 0.010 & 0.013 & 764 & $0.007^{*}$ & 0.010 & 0.017 \\
\hline TIER $1 L E V R A T I O$ & 4555 & 0.088 & 0.085 & 0.031 & 3791 & 0.088 & 0.085 & 0.032 & 764 & $0.085^{* * *}$ & $0.082^{* * *}$ & 0.027 \\
\hline TIER 1 CAPRATIO & 4555 & 0.129 & 0.118 & 0.060 & 3791 & 0.131 & 0.119 & 0.063 & 764 & $0.117^{* * *}$ & $0.112^{* * *}$ & 0.041 \\
\hline TOTCAPRATIO & 4555 & 0.143 & 0.132 & 0.059 & 3791 & 0.145 & 0.133 & 0.063 & 764 & $0.135^{* * *}$ & $0.129^{* * *}$ & 0.038 \\
\hline$A V G V O L U M E$ & 1513 & 9.555 & 9.137 & 2.191 & 1105 & 8.996 & 8.808 & 1.816 & 408 & $11.068^{* * *}$ & $10.83324^{* * *}$ & 2.397 \\
\hline$B T M$ & 1510 & 0.991 & 0.693 & 1.058 & 1102 & 0.990 & 0.717 & 0.920 & 408 & 0.992 & $0.624^{* * *}$ & 1.365 \\
\hline COVERAGE & 1048 & 5.260 & 3.000 & 6.093 & 708 & 3.613 & 2.000 & 3.874 & 340 & $8.688^{* * *}$ & $6.000^{* * *}$ & 8.119 \\
\hline$M V$ & 1510 & 12.059 & 11.729 & 1.779 & 1102 & 11.608 & 11.415 & 1.394 & 408 & $13.277^{* * *}$ & $13.149^{* * *}$ & 2.108 \\
\hline VOLATILITY & 1513 & 0.030 & 0.025 & 0.020 & 1105 & 0.030 & 0.025 & 0.019 & 408 & 0.030 & $0.023^{*}$ & 0.021 \\
\hline
\end{tabular}


Panel B: After Matching

\begin{tabular}{|c|c|c|c|c|c|c|c|c|c|c|c|c|}
\hline & \multicolumn{4}{|c|}{ All BHCs } & \multicolumn{4}{|c|}{ Non-securitizing BHCs } & \multicolumn{4}{|c|}{ Securitizing BHCs } \\
\hline & Obs & Mean & Median & St.Dev. & Obs & Mean & Median & St.Dev. & Obs & Mean & Median & St.Dev. \\
\hline & $(1)$ & $(2)$ & $(3)$ & $(4)$ & $(5)$ & $(6)$ & $(7)$ & $(8)$ & $(9)$ & $(10)$ & $(11)$ & $(12)$ \\
\hline$L O G A S S E T S$ & 994 & 14.063 & 13.791 & 1.323 & 419 & 13.907 & 13.690 & 1.232 & 575 & $14.177^{*}$ & 13.882 & 1.376 \\
\hline$L I Q R A T I O$ & 994 & 0.253 & 0.238 & 0.108 & 419 & 0.253 & 0.243 & 0.113 & 575 & 0.252 & 0.233 & 0.105 \\
\hline$L O A N G R$ & 994 & 0.100 & 0.064 & 0.234 & 419 & 0.103 & 0.066 & 0.222 & 575 & 0.097 & 0.063 & 0.242 \\
\hline$L O A N / D E P O S I T S$ & 994 & 0.832 & 0.838 & 0.169 & 419 & 0.819 & 0.821 & 0.171 & 575 & 0.841 & 0.846 & 0.167 \\
\hline$L O A N / A S S E T S$ & 994 & 0.644 & 0.658 & 0.115 & 419 & 0.642 & 0.654 & 0.119 & 575 & 0.646 & 0.663 & 0.112 \\
\hline DEPOSITS/ASSETS & 994 & 0.783 & 0.802 & 0.091 & 419 & 0.791 & 0.810 & 0.085 & 575 & 0.777 & 0.797 & 0.095 \\
\hline COREDEPRATIO & 994 & 0.839 & 0.857 & 0.090 & 419 & 0.841 & 0.859 & 0.083 & 575 & 0.838 & 0.855 & 0.095 \\
\hline$F U N D I N G C O S T$ & 994 & 0.027 & 0.025 & 0.011 & 419 & 0.027 & 0.026 & 0.011 & 575 & 0.027 & 0.025 & 0.011 \\
\hline$I N T E R B A N K$ & 994 & -0.020 & -0.012 & 0.057 & 419 & -0.017 & -0.012 & 0.055 & 575 & -0.022 & -0.012 & 0.058 \\
\hline$L E V E R A G E$ & 994 & 0.910 & 0.913 & 0.027 & 419 & 0.910 & 0.912 & 0.028 & 575 & 0.911 & 0.914 & 0.026 \\
\hline$N P L$ & 994 & 0.019 & 0.010 & 0.029 & 419 & 0.019 & 0.009 & 0.036 & 575 & 0.018 & 0.011 & 0.023 \\
\hline PROVISION & 994 & 0.009 & 0.004 & 0.012 & 419 & 0.008 & 0.004 & 0.012 & 575 & 0.009 & 0.004 & 0.013 \\
\hline$A L L O W A N C E$ & 994 & 0.016 & 0.014 & 0.008 & 419 & 0.016 & 0.014 & 0.008 & 575 & 0.016 & 0.014 & 0.008 \\
\hline CHARGEOFF & 994 & 0.006 & 0.003 & 0.011 & 419 & 0.006 & 0.003 & 0.011 & 575 & 0.007 & 0.003 & 0.011 \\
\hline INTINCRATIO & 994 & 0.064 & 0.062 & 0.013 & 419 & 0.063 & 0.062 & 0.013 & 575 & 0.064 & 0.062 & 0.013 \\
\hline$R O A$ & 994 & 0.007 & 0.009 & 0.012 & 419 & 0.007 & 0.009 & 0.012 & 575 & 0.007 & 0.009 & 0.012 \\
\hline TIER $1 L E V R A T I O$ & 994 & 0.087 & 0.083 & 0.025 & 419 & 0.087 & 0.083 & 0.027 & 575 & 0.086 & 0.083 & 0.024 \\
\hline TIER $1 C A P R A T I O$ & 994 & 0.122 & 0.115 & 0.041 & 419 & 0.124 & 0.115 & 0.044 & 575 & 0.121 & 0.114 & 0.039 \\
\hline TOTCAPRATIO & 994 & 0.138 & 0.130 & 0.039 & 419 & 0.139 & 0.130 & 0.042 & 575 & 0.137 & 0.130 & 0.036 \\
\hline$A V G V O L U M E$ & 422 & 10.642 & 10.415 & 1.929 & 163 & 10.423 & 10.324 & 1.720 & 259 & 10.779 & 10.506 & 2.041 \\
\hline$B T M$ & 422 & 0.998 & 0.641 & 1.116 & 163 & 0.996 & 0.646 & 1.099 & 259 & 1.000 & 0.635 & 1.129 \\
\hline COVERAGE & 422 & 5.633 & 4.000 & 5.392 & 163 & 5.031 & 4.000 & 4.823 & 259 & 6.012 & 4.000 & 5.698 \\
\hline$M V$ & 422 & 12.870 & 12.845 & 1.582 & 163 & 12.698 & 12.798 & 1.519 & 259 & 12.978 & $12.897^{*}$ & 1.614 \\
\hline VOLATILITY & 422 & 0.029 & 0.025 & 0.016 & 163 & 0.028 & 0.025 & 0.015 & 259 & 0.029 & 0.025 & 0.016 \\
\hline
\end{tabular}

This table presents the descriptive statistics for the covariates used in the propensity score model before (Panel A) and after (Panel B) matching. For these tables, I pool the private and public BHCs for all matching years together. Columns (1)-(4) present the statistics for all BHCs, columns (5)-(8) present the statistics for the non-securitizing subsample, and columns (9)-(12) show the statistics for the securitizing subsample. ${ }^{* * *},{ }^{* *}$, and $*$ in columns (10) and (11) represent two-tailed p-values of $<0.01,<0.05$, and $<0.1$ from mean and Wilcoxon rank-sum test, respectively. In panel B, I used a paired version of both tests. All Variables are as defined in Table C.1. 
Figure C.1: Covariate Balance Before and After Matching

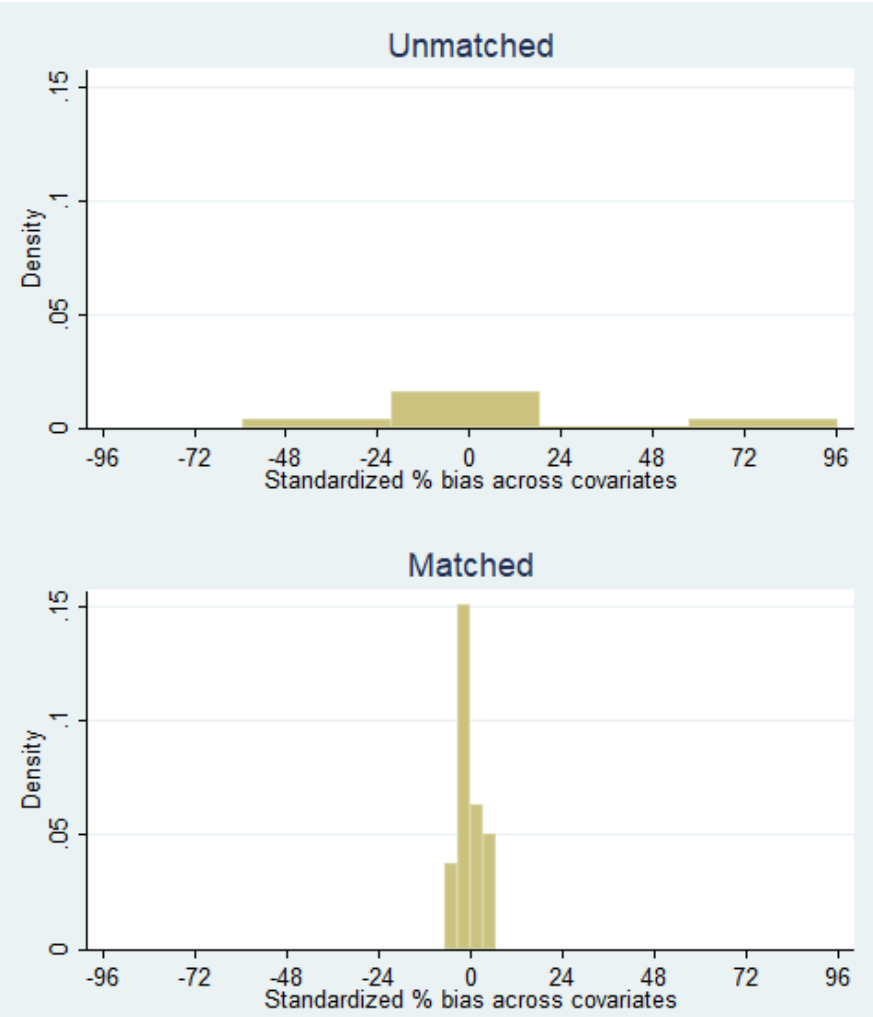

This figure presents the distribution of the standardized percentage bias across the covariates used in the propensity score matching, measured before and after matching. I generated this graph using the Stata command pstest from Leuven \& Sianesi's (2003) package. The standardized percentage bias is the difference between the means of the treatment and control groups as a percentage of the square root of the average of the variances in the treatment and control groups. 


\section{Appendix D}

\section{Determinants of Mortgage Risk: Literature Summary}

The appendix presents the list of risk factors prior research examines as determinants of mortgage termination risk. I group the factors into borrower characteristics (Panel A), loan characteristics (Panel B), property characteristics (Panel D). The first column contains the name of the characteristics. The second column provides the description of how the characteristics is related to mortgage risk. The third column contains a list of papers that examine the relation between the characteristic and mortgage risk. The last column provides the names of variables used in this thesis to capture the characteristics. Section 4.3.2 and Appendix A.1 present the exact definition of these variables. I do not include some of characteristics listed in this table in the development of the proposed mortgage lending risk measures because of lack of data or because they are not observable at origination. 


\section{Summary of Mortgage Risk Factors from Prior Research}

$\begin{array}{llll}\text { Characteristics Description } & \text { Papers } & \text { Variables }\end{array}$

\section{Names}

\section{Panel A: Borrower Characteristics}

Age

Co-borrower

Credit card

utilization

Debt Burden

FICO Scores

Government assistance
Young borrowers are riskier than older borrowers.

Borrowers with no co-borrower are riskier than those with a co-borrower.

Borrowers with high credit card utilizations are riskier than those with low utilization.

Borrowers with high debt burden are riskier than those with low debt burden.

Borrowers with low FICO (credit) scores are riskier than those with high FICO score.

Borrowers receiving government assistant are riskier than borrowers who are not on government assistance.
Morton (1975),

Canner, Gabriel \&

Woolley (1991)

Chan et al. (2013)

I.NOCOBORR

Elul et al. (2010), Jagtiani \& Lang (2011)

Demyanyk et al. (2010), Chan et al. (2013)

Elul et al. (2010), Jagtiani \& Lang (2011), Demyanyk et al. (2010), Chan et al. (2013), Elul (2016)

Canner et al. (1991) GOVASSIST 
Summary Mortgage Risk Factors from Prior Research (continued)

\begin{tabular}{|c|c|c|c|}
\hline Characteristics & Description & Papers & Variables \\
\hline Income & $\begin{array}{l}\text { Low income borrowers are riskier than } \\
\text { medium and high-income borrowers. }\end{array}$ & $\begin{array}{l}\text { Vandell \& Thibodeau } \\
\text { (1985), Lambrecht, } \\
\text { Perraudin \& Satchell } \\
\text { (1997), Demyanyk } \\
\text { et al. (2010) }\end{array}$ & INCOME \\
\hline Income volatility & $\begin{array}{l}\text { Borrowers with more volatile income are } \\
\text { riskier than those with less volatile income. }\end{array}$ & Morton (1975) & \\
\hline $\begin{array}{l}\text { Length of } \\
\text { employment in } \\
\text { current job }\end{array}$ & $\begin{array}{l}\text { Borrowers with short history in their } \\
\text { current job are riskier than those with long } \\
\text { history. }\end{array}$ & $\begin{array}{l}\text { Vandell \& Thibodeau } \\
\text { (1985) }\end{array}$ & \\
\hline Marital status & $\begin{array}{l}\text { Divorced Borrowers are riskier than other } \\
\text { borrowers. }\end{array}$ & $\begin{array}{l}\text { Morton (1975), } \\
\text { Vandell \& Thibodeau } \\
\text { (1985), Lambrecht } \\
\text { et al. (1997), Canner } \\
\text { et al. (1991) }\end{array}$ & \\
\hline $\begin{array}{l}\text { Non- } \\
\text { discretionary } \\
\text { spending }\end{array}$ & $\begin{array}{l}\text { Borrowers with more non-discretionary } \\
\text { spending (e.g., other debt payments and } \\
\text { medical bill) are riskier than those with less } \\
\text { non-discretionary spending. }\end{array}$ & $\begin{array}{l}\text { Vandell \& Thibodeau } \\
\text { (1985) }\end{array}$ & \\
\hline $\begin{array}{l}\text { Non-housing } \\
\text { wealth }\end{array}$ & $\begin{array}{l}\text { Borrowers with less non-housing wealth are } \\
\text { riskier than those with more non-housing } \\
\text { wealth. }\end{array}$ & $\begin{array}{l}\text { Vandell \& Thibodeau } \\
\text { (1985) }\end{array}$ & NONHOUSWLTH \\
\hline $\begin{array}{l}\text { Number of } \\
\text { dependents }\end{array}$ & $\begin{array}{l}\text { Borrower with more dependents are riskier } \\
\text { than those with fewer or no dependents. }\end{array}$ & Morton (1975) & \\
\hline
\end{tabular}

Continued next page- 
Summary Mortgage Risk Factors from Prior Research (continued)

\begin{tabular}{|c|c|c|c|}
\hline Characteristics & Description & Papers & Variables \\
\hline Occupation & $\begin{array}{l}\text { Borrower with more stable occupations such } \\
\text { as professionals and executives are less risky } \\
\text { than borrowers with less stable occupations } \\
\text { such as self-employment and salespersons. }\end{array}$ & $\begin{array}{l}\text { Morton (1975), } \\
\text { Vandell \& Thibodeau } \\
\text { (1985) }\end{array}$ & \\
\hline Race & Minority borrowers are riskier. & $\begin{array}{l}\text { Chan et al. (2013), } \\
\text { Canner et al. (1991) }\end{array}$ & $\begin{array}{l}\text { I.BLACK, } \\
\text { I.HISPANIC }\end{array}$ \\
\hline Second Mortgage & $\begin{array}{l}\text { Borrowers with a second mortgage are } \\
\text { riskier than those with no second mortgage. }\end{array}$ & $\begin{array}{l}\text { Elul et al. (2010), } \\
\text { Chan et al. (2013) }\end{array}$ & \\
\hline \multicolumn{4}{|c|}{ Panel B: Loan Characteristics } \\
\hline Loan amount & Larger loans are riskier than smaller loans. & $\begin{array}{l}\text { Vandell \& Thibodeau } \\
\text { (1985), Elul et al. } \\
\text { (2010), Elul (2016) }\end{array}$ & $L O A N$ \\
\hline $\begin{array}{l}\text { Low } \\
\text { documentation }\end{array}$ & $\begin{array}{l}\text { Low documentation loans such as those } \\
\text { with missing income are riskier than loans } \\
\text { with proper documentation. }\end{array}$ & $\begin{array}{l}\text { Elul et al. (2010) } \\
\text { Chan et al. (2013), } \\
\text { Elul (2016) }\end{array}$ & I.NOINCOME \\
\hline
\end{tabular}

Continued next page- 
Summary Mortgage Risk Factors from Prior Research (continued)

\begin{tabular}{|c|c|c|c|}
\hline Characteristics & Description & Papers & Variables \\
\hline $\begin{array}{l}\text { Loan-to-value } \\
\text { (LTV) }\end{array}$ & $\begin{array}{l}\text { Mortgages with higher LTV are riskier than } \\
\text { those with lower LTV. }\end{array}$ & $\begin{array}{l}\text { Sandor \& Sosin } \\
\text { (1975), Morton } \\
\text { (1975), Campbell \& } \\
\text { Dietrich (1983), Deng } \\
\text { et al. (2000), } \\
\text { Clauretie (1990), Elul } \\
\text { et al. (2010), Jagtiani } \\
\text { \& Lang (2011), } \\
\text { Demyanyk et al. } \\
\text { (2010), Elul (2016), } \\
\text { Jackson \& Kaserman } \\
\text { (1980) }\end{array}$ & $\begin{array}{l}L T M E D V \\
A V G L T P, L T A V G P\end{array}$ \\
\hline Mortgage Age & Mortgages are riskier in the early years. & $\begin{array}{l}\text { Elul et al. (2006), } \\
\text { Elul (2016) }\end{array}$ & \\
\hline Term-to-maturity & Conflicting evidence. & $\begin{array}{l}\text { Morton (1975), } \\
\text { Campbell \& Dietrich } \\
\text { (1983), Jackson \& } \\
\text { Kaserman (1980) }\end{array}$ & \\
\hline
\end{tabular}

\section{Panel C: Property Characteristics}

Age

Mortgages secured by older properties are riskier than those secured by recently built properties.

Vandell \& Thibodeau (1985)
MEDHOUSAGE

Continued next page- 


\section{Summary Mortgage Risk Factors from Prior Research (continued)}

\begin{tabular}{|c|c|c|c|}
\hline Characteristics & Description & Papers & Variables \\
\hline Owner occupancy & $\begin{array}{l}\text { Mortgages secured by owner-occupied } \\
\text { properties are riskier than those secured by } \\
\text { investment properties. }\end{array}$ & Chan et al. (2013) & I.OWNOCCUPIED \\
\hline $\begin{array}{l}\text { Property } \\
\text { condition }\end{array}$ & $\begin{array}{l}\text { Mortgages secured by properties in a good } \\
\text { condition are less risky than those secured } \\
\text { by properties in poor condition. }\end{array}$ & $\begin{array}{l}\text { Sandor \& Sosin } \\
(1975)\end{array}$ & \\
\hline Property value & $\begin{array}{l}\text { Mortgages secured by properties with } \\
\text { greater valuations are less risky than those } \\
\text { secured by properties with lower valuation. }\end{array}$ & $\begin{array}{l}\text { Sandor \& Sosin } \\
\text { (1975), Vandell \& } \\
\text { Thibodeau (1985) }\end{array}$ & $M E D V A L U E$ \\
\hline \multicolumn{4}{|c|}{ Panel D: Geographic Characteristics } \\
\hline $\begin{array}{l}\text { Current and } \\
\text { expected housing } \\
\text { market } \\
\text { conditions }\end{array}$ & $\begin{array}{l}\text { The current and expected housing market } \\
\text { conditions in the local area are negatively } \\
\text { associated with mortgage risk. }\end{array}$ & $\begin{array}{l}\text { Sandor \& Sosin } \\
(1975)\end{array}$ & $\triangle H P I$ \\
\hline $\begin{array}{l}\text { Current and } \\
\text { expected } \\
\text { neighborhood } \\
\text { conditions }\end{array}$ & $\begin{array}{l}\text { The current and expected neighborhood } \\
\text { conditions are negatively associated with } \\
\text { mortgage risk. }\end{array}$ & $\begin{array}{l}\text { Vandell \& Thibodeau } \\
\text { (1985) }\end{array}$ & \\
\hline $\begin{array}{l}\text { Home ownership } \\
\text { rate }\end{array}$ & $\begin{array}{l}\text { Mortgages in neighborhoods with higher } \\
\text { home ownership rate are riskier than those } \\
\text { in neighborhoods with lower home } \\
\text { ownership rate. }\end{array}$ & Anacker (2015) & $O W N R A T E$ \\
\hline
\end{tabular}




\section{Summary Mortgage Risk Factors from Prior Research (continued)}

\begin{tabular}{|c|c|c|c|}
\hline Characteristics & Description & Papers & Variables \\
\hline $\begin{array}{l}\text { Local area } \\
\text { unemployment }\end{array}$ & $\begin{array}{l}\text { Mortgages in areas with high } \\
\text { unemployment are riskier than those in low } \\
\text { unemployment areas. }\end{array}$ & $\begin{array}{l}\text { Vandell \& Thibodeau } \\
\text { (1985), Elul et al. } \\
\text { (2010) }\end{array}$ & $\begin{array}{l}U N E M P R A T E, \\
\triangle U N E M P R A T E\end{array}$ \\
\hline $\begin{array}{l}\text { Median house } \\
\text { value }\end{array}$ & $\begin{array}{l}\text { Mortgages in neighborhoods with low } \\
\text { median house value are riskier than those in } \\
\text { neighborhoods with high median house } \\
\text { value. }\end{array}$ & Anacker (2015) & $M E D V A L U E$ \\
\hline Median house age & $\begin{array}{l}\text { Mortgages in neighborhoods with higher } \\
\text { median house age are riskier than those in } \\
\text { neighborhoods with lower median house age. }\end{array}$ & Anacker (2015) & $M E D H O U S A G E$ \\
\hline Median income & $\begin{array}{l}\text { Mortgages in areas with low median income } \\
\text { are riskier than those in areas with high } \\
\text { median income. }\end{array}$ & Chan et al. (2013) & $\begin{array}{l}\text { MEDBORRINC, } \\
\text { MEDFAMINC, } \\
\text { MEDHHINC }\end{array}$ \\
\hline $\begin{array}{l}\text { Minority } \\
\text { percentage }\end{array}$ & $\begin{array}{l}\text { Mortgages in neighborhoods with higher } \\
\text { minority percentages are riskier that those } \\
\text { with lower minority percentages. }\end{array}$ & $\begin{array}{l}\text { Chan et al. (2013), } \\
\text { Anacker (2015) }\end{array}$ & $\begin{array}{l}\text { MINORITY, } \\
\text { BLACKPERC, } \\
\text { HISPANICPERC }\end{array}$ \\
\hline $\begin{array}{l}\text { Neighborhood } \\
\text { desirability }\end{array}$ & $\begin{array}{l}\text { Mortgages in more desirable neighborhoods } \\
\text { are less risky than those in less desirable } \\
\text { neighborhoods. }\end{array}$ & $\begin{array}{l}\text { Sandor \& Sosin } \\
(1975)\end{array}$ & $\begin{array}{l}\text { POVERTY, } \\
\text { MEDFAMINC, } \\
\text { MEDHHINC, } \\
\text { UNEMPRATE, } \\
\text { MINORITY, } \\
\text { BLACKPERC, } \\
\text { VACRATE }\end{array}$ \\
\hline $\begin{array}{l}\text { Neighborhood } \\
\text { life-cycle }\end{array}$ & $\begin{array}{l}\text { Mortgages in central cities and mature } \\
\text { suburbs are riskier than those in developing } \\
\text { suburbs. }\end{array}$ & Anacker (2015) & I.LIFECYCLE \\
\hline
\end{tabular}


Summary Mortgage Risk Factors from Prior Research (continued)

\begin{tabular}{|c|c|c|c|}
\hline Characteristics & Description & Papers & Variables \\
\hline $\begin{array}{l}\text { Percentage of } \\
\text { vacant units }\end{array}$ & $\begin{array}{l}\text { Mortgages in neighborhoods with higher } \\
\text { percentage of vacant units are riskier than } \\
\text { those in neighborhoods with lower } \\
\text { percentage of vacant units. }\end{array}$ & Anacker (2015) & $V A C R A T E$ \\
\hline
\end{tabular}

$\stackrel{\infty}{\circ}$ 